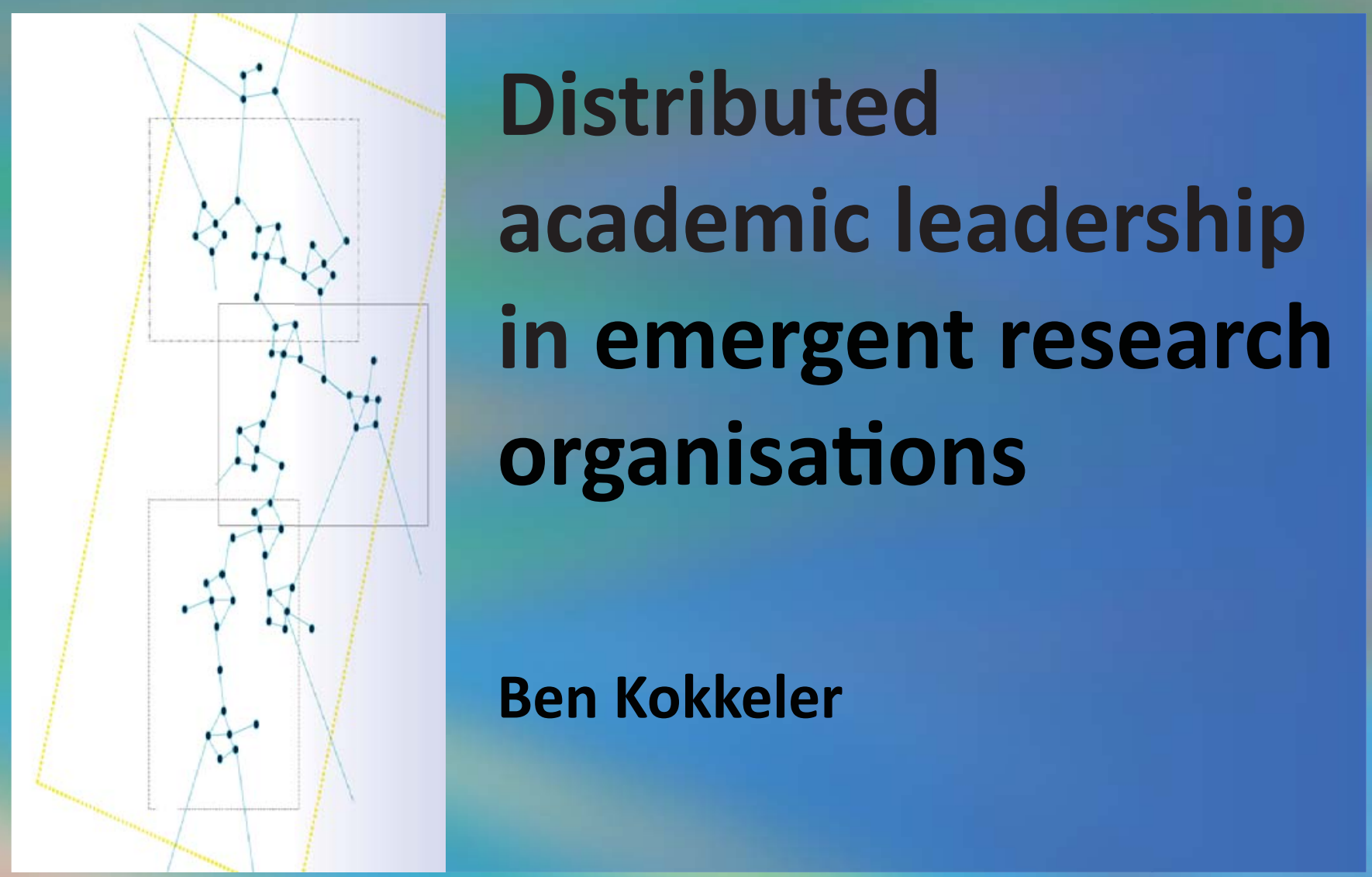




\title{
DISTRIBUTED ACADEMIC LEADERSHIP IN EMERGENT RESEARCH ORGANISATIONS
}

\author{
PROEFSCHRIFT \\ ter verkrijging van \\ de graad van doctor aan de Universiteit Twente, \\ op gezag van de rector magnificus, \\ Prof.dr. H. Brinksma, \\ volgens het besluit van het College voor Promoties \\ in het openbaar te verdedigen \\ op woensdag 29 oktober 2014 om 16.45 uur
}

door

Bernardus Josephus Maria Kokkeler

geboren op 9 mei 1958

te Enschede. 
Dit proefschrift is goedgekeurd door:

Promotor(s): $\quad$ prof.dr. Stefan Kuhlmann, University of Twente prof.dr. Olaf Fisscher, University of Twente

Assistant promotor: prof.dr. Arie Rip, University of Twente 


\title{
Distributed
} academic leadership in emergent research organisations

\author{
Ben Kokkeler
}


Promotion committee:

Chair:

prof.dr. Ton Mouthaan, University of Twente

Secretary:

prof.dr. Ton Mouthaan, University of Twente

Promotor(s):

prof.dr. Stefan Kuhlmann, University of Twente

prof.dr. Olaf Fisscher, University of Twente

Assistant promotor:

prof.dr. Arie Rip, University of Twente

Members:

prof.dr. Bärbel Dorbeck-Jung, University of Twente

prof.dr. Peter Apers, University of Twente

prof.dr. Maria Nedeva, Manchester Business School

prof.dr. Jeroen Huisman, University of Ghent

Cover design:

Romke Schievink (SENNA Multimedia), Anneke, Chris and Henriëtte

Kokkeler, based on an Ebru design and made by Gülbeyhan Baykal

"Co-travelling distributed leaders in colliding transformative worlds"

(Ben Kokkeler)

Lay-out and traffic: Hèla Klaczynski

Printed by Koninklijke Wöhrmann, Zutphen, The Netherlands

ISBN: 978-90-365-3585-4 DOI: 10.3990/1.9789036535854

Alle rechten voorbehouden. Behoudens de door de Auteurswet 1912 gestelde uitzonderingen, mag niets uit deze uitgave worden verveelvoudigd (waaronder begrepen het op slaan in een geautomatiseerd gegevensbestand) of openbaar gemaakt, op welke wijze dan ook, zonder voorafgaande schriftelijke toestemming van de uitgever. De bij toepassing van artikel 16B en 17 Auteurswet 1912 wettelijk verschuldigde vergoedingen wegens fotokopiëren, dienen te worden voldaan aan de Stichting reprorecht, Postbus 882, 1180 AW te Amstelveen. Voor het overnemen van een gedeelte van deze uitgave in bloemlezingen, readers en andere compilatiewerken op grond van artikel 16 auteurswet 1912 dient men zich tevoren tot de uitgever te wenden. Hoewel aan de totstandkoming van deze uitgave de uiterste zorg is besteed, aanvaarden de auteur(s), redacteur(en) en uitgever geen aansprakelijkheid voor eventuele fouten of onvolkomenheden. 


\section{Distributed academic leadership in emergent research organisations}

\section{INDEX}

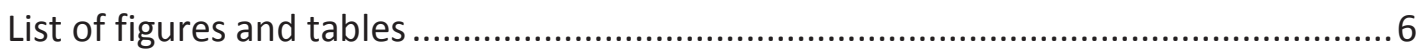

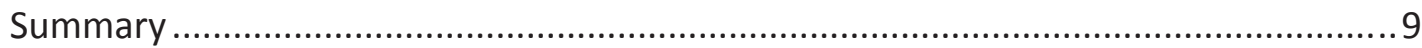

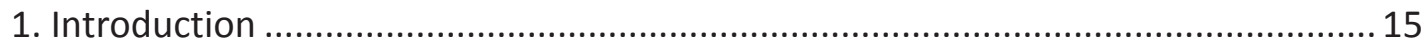

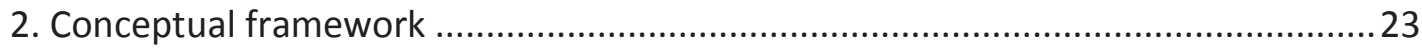

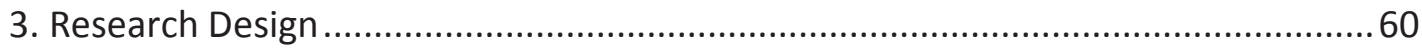

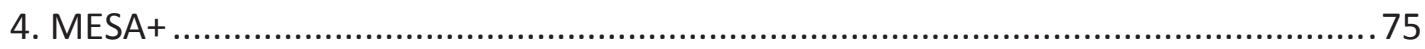

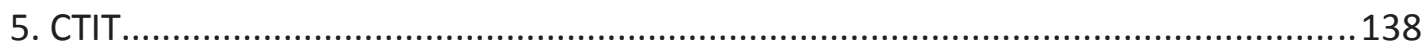

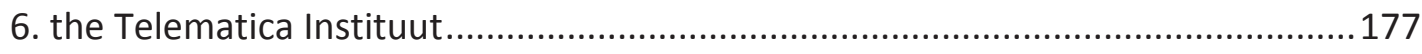

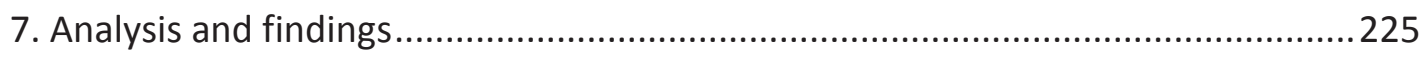

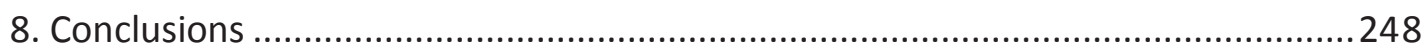

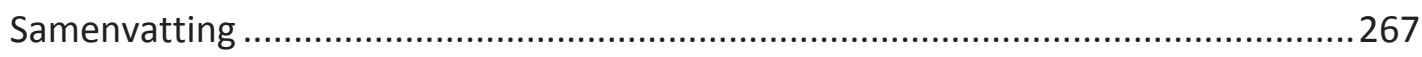

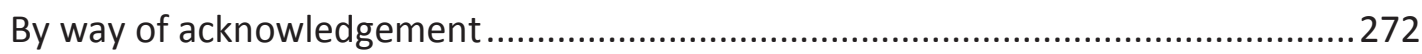

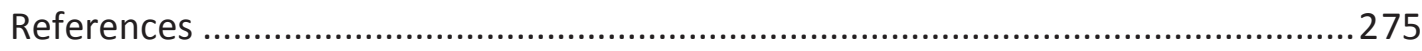




\section{List of figures and tables}

\section{Figures}

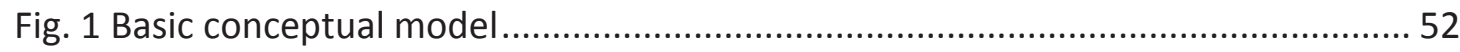

Fig. 1.a Conceptual model arrangements ............................................................... 52

Fig. 1.b Conceptual model learning spaces ................................................................ 53

Fig. 1.c Conceptual model sites of distributed leadership and organisational change .... 53

Fig. 2 Stabilising patterns of distributed leadership interaction .................................... 70

Fig. 3 Leadership key activities layered processes model ............................................. 71

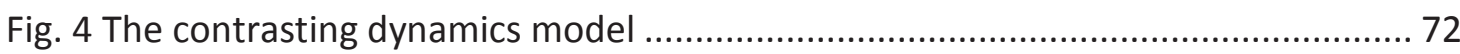

Fig. 5. CTIT's constellation of research and application areas (Annual Report, 2000)... 164

fig. 1a Sites of organisational change and leadership ................................................ 226

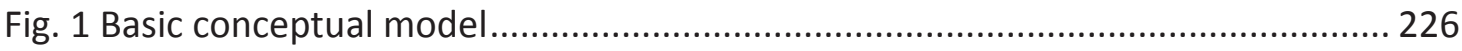

Fig. 1b Conceptual model distributed leadership, Fig. 1.c: Conceptual model spaces .. 227

Fig. 5 Leadership key activities layered processes model........................................ 228 


\section{Tables}

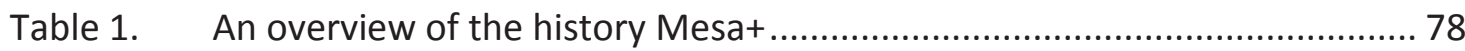

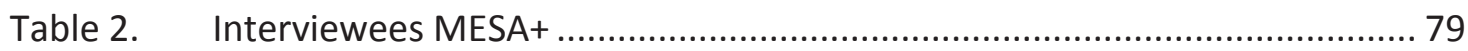

Table 3. Summary of MESA's development over time (according to the conceptual ... model) ................................................................................................. 133

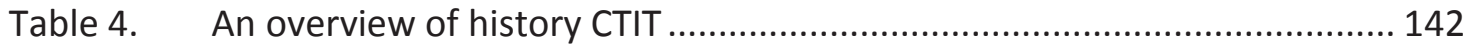

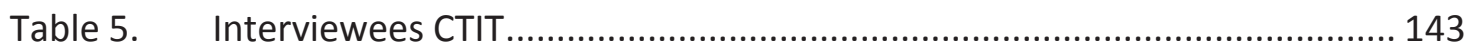

Table 6. Summary of CTIT's development over time (according to the conceptual

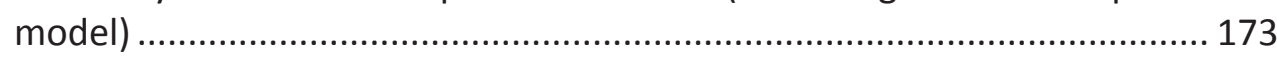

Table 7. An overview of the history of TRC and Telematica Instituut..................... 181

Table 8. Interviewees TRC and Telematica Instituut ........................................... 182

Table 9. Summary of $\mathrm{Tl}^{\prime}$ 's development over time (according to the conceptual

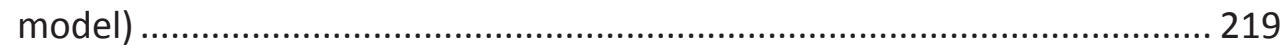

Table 10. Distributed leadership constellations ....................................................... 239

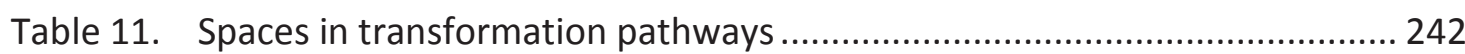




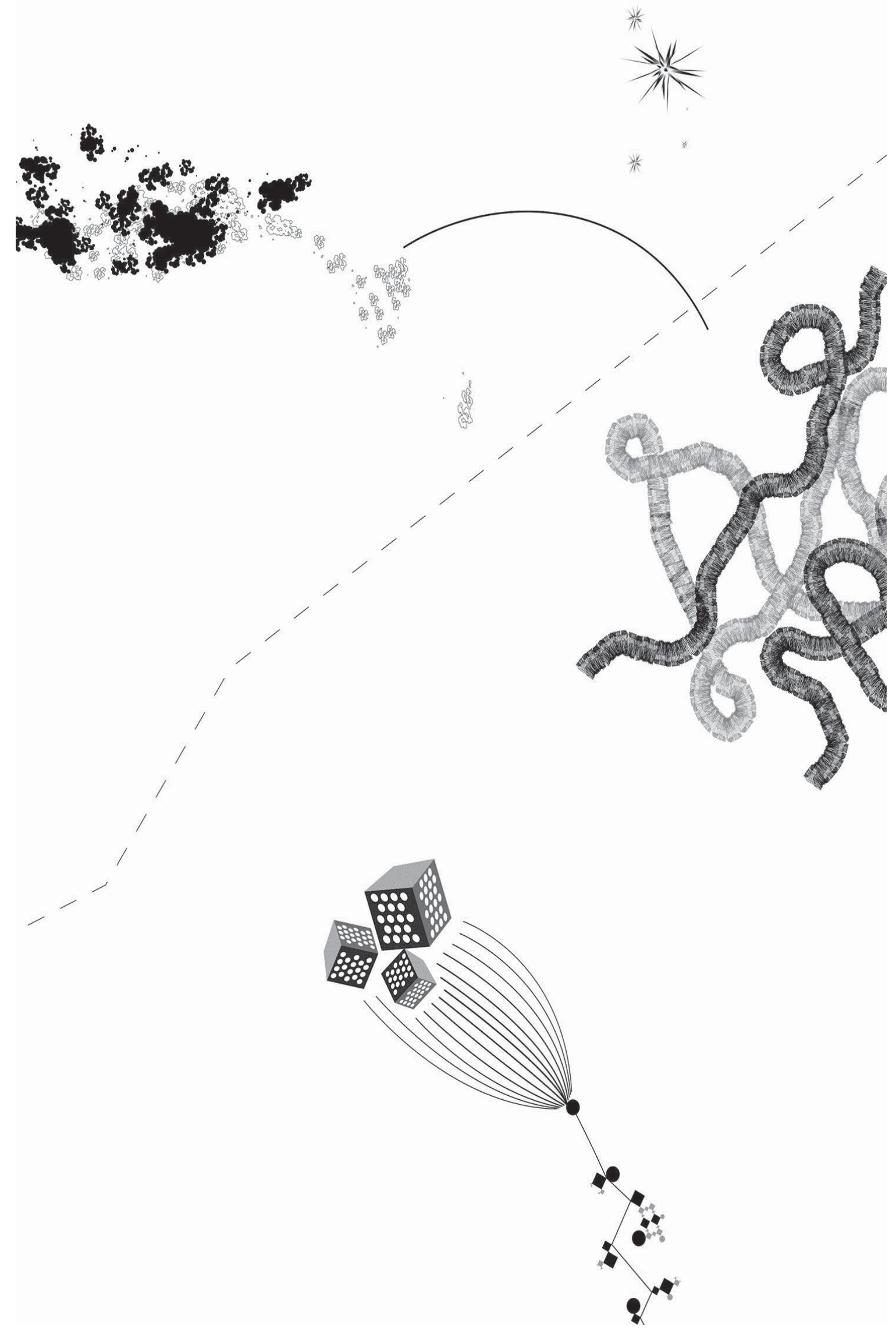




\section{Summary}

Academic leadership, here with respect to scientific research and its organisation, is set in a changing research landscape. In these changes, policy interventions play a role, but just as important are general long-term trends that lead to transformations in the research and innovation landscape. Research organisations such as universities respond proactively through which certain developments such as globalisation are strengthened. Research organisations are themselves in transformation, and go through what I call transformation pathways.

Academic leadership develops in practice and is affected by the overall transformations, while leading academics themselves help to shape transformation paths. Academics work in national and international networks in which increasingly social partners play a role. They consider in which direction to strike out, and actively participate in coalitions and arrangements that themselves evolve in the practice of leadership. Leadership practices and organisational change mutually influence each other.

In this thesis, the distributed nature of leadership practices is central: divided between academics and distributed over time and across professional spaces. Individual characteristics conducive to leadership, however important, are less important for the questions of this thesis than leadership-activity patterns in which several academics play a role and which develop in interaction with organisational change and organisational learning. To be effective, there will be attempts to reduce the complexity of the transformations but without denying them, particularly by including the ambiguities of transformation. This is an entrance point in order to identify important characteristics of distributed leadership-activity patterns.

The complexity of the transformations is visible in the European higher education landscape and universities "in transition" since the sixties, including greater autonomy (in the Dutch higher education system) and differentiation of universities. At the same time, there are transformational developments in scientific fields, particularly in emerging areas such as nanotechnology, IT and open systems, bio-science and biotechnology, which lead to multidisciplinary 'fusion' areas of research and innovation. In tandem, there is a new kind of research organisation, originated inside or outside universities, which combines excellence and

Distributed academic leadership in emergent research organisations Summary 
relevance of research - as it were a new species in the research ecosystem. In this kind of new research organisations formal leadership patterns are insufficient and challenges are addressed by distributed academic leadership. These are sites where evolving distributed academic leadership can be studied.

The University of Twente is a good location for such studies. In the eighties the university became known internationally as an "entrepreneurial" and "innovative" university, in the forefront of the "entrepreneurial universities" in Europe (Clark, 1998). In the period from mideighties and mid-two thousands, a number of initiatives took place both in education, research and innovation, and in the bottom-up development of informal networks of distributed academic leadership. This was not unique to the University of Twente but there it was explicitly thematised, so the University is a good basis for the study of distributed academic leadership in emergent research organisations.

This thesis is a long-term study (fifteen years, about 1990 to 2005) in the recent history of transformations in the research landscape, based on three case studies of emergent research organisations in the fields of nanotechnology, ICT and Open Systems, related to the University of Twente. The case studies are based on interviews with actors, archival research in the research institutes involved and the University of Twente, and personal observations as a participant observer in research organisations in the past thirty years. Besides my immediate tasks as staff in the universities of Twente and Dortmund, in the Telematics Institute and as general secretary of the European Consortium of Innovative Universities (ECIU) I reflected about what happened and tried to understand patterns.

Context and themes are introduced in the first three chapters of the thesis. A conceptual model for organisational change, distributed academic leadership and learning organisations is developed, and further operationalised in the chapter on the research design. The conceptual model has three distinctive features:

- organisational change is approached as a process of "contrasting dynamics";

- the focus is not on competencies of leaders, but on leadership activities that arise in practice, distributed leadership practices;

Distributed academic leadership in emergent research organisations Summary 
- in the long-term pattern analysis of distributed leadership practices organisational learning processes are central.

The collection of empirical data has a focus on informal, entrepreneurial, and ambidextrous leadership constellations in emergent research organisations. Chapters 4, 5 and 6 present the three case studies of research institutes: MESA + Institute for Nanotechnology (originally MESA, focusing on micro systems technology), CTIT, Centre for Telematics and Information Technology, both at the University of Twente, and TI, Telematica Institute, originally TRC, Telematics Research Centre, with a strong relationship with the University of Twente.

Each case chapter begins with the specific context of the case and the details of data collection. Each case is divided into three episodes that present developments in a given period. The history of organisational development and leadership practices is interesting in itself, and provides the prelude to analysis. Distributed leadership arrangements are traced for strategic programming of research, interacting with the development of convergent projects (materialising connecting themes in research projects) and development of new business models (where conditions are developed of work organisation, funding and career that do not comply with what is usual within the university system). The final section of each case chapter briefly outlines how the development of the research institute continued, followed by an initial analysis of the case, preparing for the overall analysis in Chapter 7.

Chapter 7 first presents an overview of the cases based on the key concepts in the conceptual model. This makes clear that there are certain patterns (discussed further in Chapter 8), of which I present the highlights here.

Firstly, there is a new process layer of distributed academic leadership activities in the university organisation: an intermediate level between research institutes, Faculties and the Central Board, stabilising in spaces and arrangements linked to leadership practice, sometimes resulting in temporary formal management positions.

Secondly, it is clear that distributed leadership activities are to some extent orchestrated. This was done explicitly and top down in the Telematics Institute. There is also delegated

Distributed academic leadership in emergent research organisations Summary 
orchestration, from some senior academics, often with a formal management position. This is particularly visible in CTIT. Horizontal, collegiate orchestration is visible in the first phase of CTIT, and MESA +.

Thirdly, there seems to be a pattern in the development of the learning organisation, in which specific distributed leadership practices evolve and institutionalisation occurs. Three phases are visible in the case studies, each covering three to five years.

- A first phase in which entrepreneurial leadership practices are central, where experimenting takes place with new organisational forms and practices. Academic leaders are mandated - limited - freedom, and/or acquire such freedom so as to experiment, as it were in "protected spaces". Constellations of bottom up leadership practices emerge.

- A second phase of stabilisation of change processes: constellations of top-down orchestrated leadership practices play a role in this stabilisation and connections are created, characterised as ambidextrous leadership activities that balance exploration and exploitation through development of new working practices., in which academic leaders can jointly reflect and anticipate (double-loop learning).

- A third phase builds on more or less stabilised practices and arrangements by allowing specific developments to suit new situations and scientific domains, a differentiation process as sociologists would call it.

The three phases are visible in each of the cases. Differences can be characterised as strategic science (MESA +), open innovation (Telematics Institute) and mode-2 knowledge production (CTIT). In the final chapter, I throw the question of whether there is a degree of repetition of these phases, or rather a new pattern in the context of new business models. Tensions between the continued growth and diversification of emergent research organisations and university system in which they function, limit further growth of new models or encourage academic leaders to develop new initiatives.

The co-evolution of arrangements and leadership learning continues, often quite practical and thematic, as in more or less structured communities around the governance of multi-year multi-

Distributed academic leadership in emergent research organisations Summary 
partner research programs, which emerge as alliances and evolve into "Schicksalgemeinschaften".

Apparently, academic leaders succeed in collaboration and realisation of new arrangements, thus creating common futures, while at the same time they must meet high individual performance requirements and expectations. For them, understanding the processes of coevolution of organisational change and distributed leadership practice is important in order to overcome an exclusive focus on immediate and short-term problems.

Distributed academic leadership in emergent research organisations Summary 


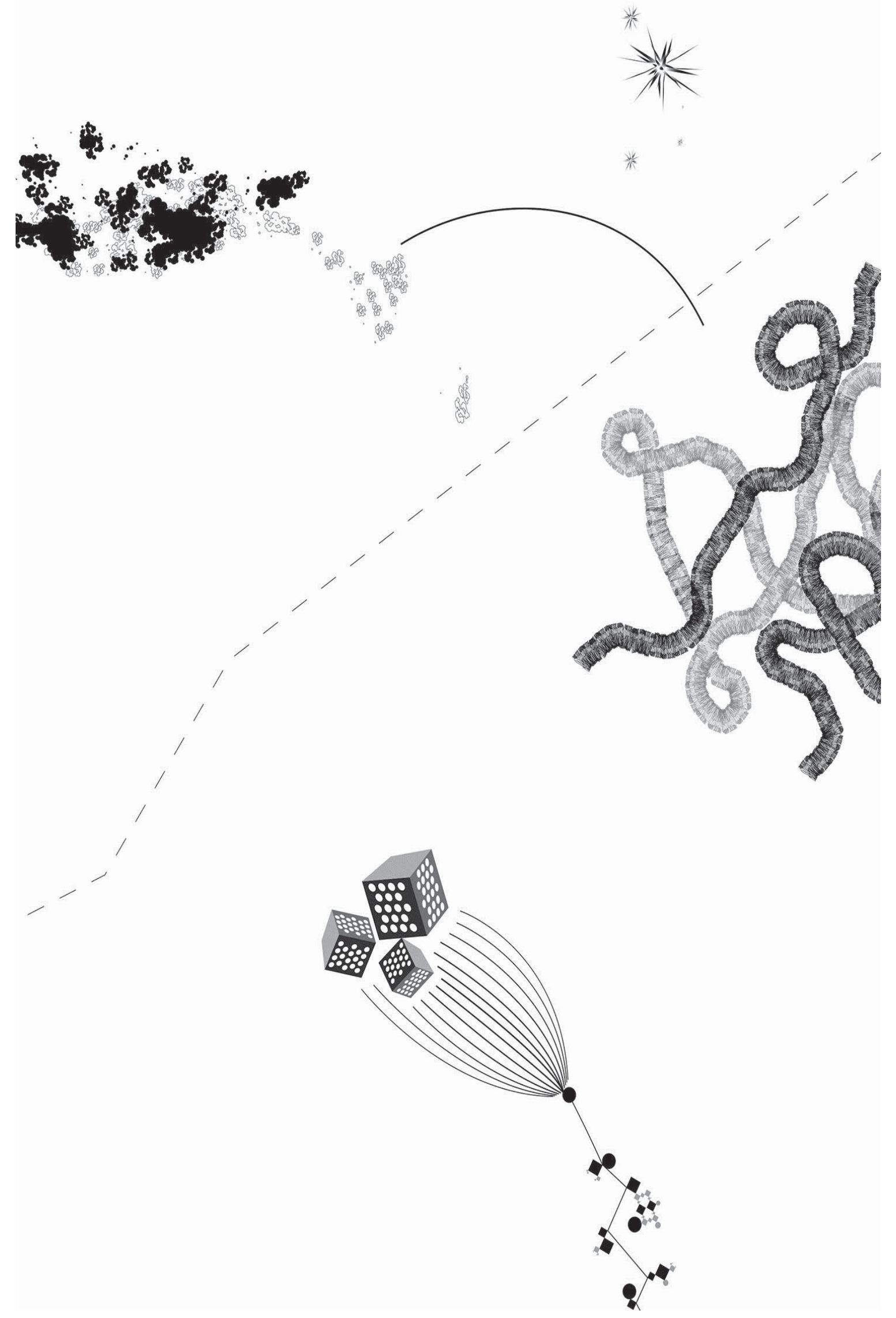




\section{Introduction}

Structural transformations occur, like the internationalisation and increasing cost of scientific research, reflected in strategic agenda setting in policy frameworks. The EU pushes "grand challenges", the Dutch government sets priorities in terms of "top sectors". Academic researchers have to reposition strategically in international networks in which industrial partners can play a role. Teaching has to deal with the consequences of massification and online education in massive open online courses (MOOCs). It is in this world that academic leadership in the organisation and governance of research work takes place and is challenged. The question addressed in this thesis is how academic leadership in research organisations in transformation in a changing world takes place and how one can understand what happens.

Changes in the landscape of science are part of long-term developments, in which specific policy frameworks and interventions play a role, but only a limited role. There are overall transformational pathways of the landscape, as well as transformational pathways of research organisations. Academic leadership practices are shaped by such pathways, as well as shape them. Academics are "knowledgeable agents" (Giddens, 1984).They will consider paths to be taken, and actively participate in forms of leadership that evolve. Leadership practices are actually distributed, dispersed over time and social space (Gronn, 2010; Spillane, Halverson \& Diamond, 2004), and this will actually help addressing the complexities of transformation.

How can lessons be drawn from the ways of working, including muddling through, of academic leaders, in interaction with organisational changes? Empirical study of relevant case studies is necessary, structured by a conceptual framework that can capture the new phenomena in the landscape of science, in research organisations in transformation, and in distributed academic leadership. The first step is to see them as key sites to study distributed leadership in interaction with ongoing changes in research organisations. To study such processes, a case study approach is appropriate (Yin 2003).

In addressing academic leadership, in particular research leadership, in times of transformation, one is confronted with a complex reality, itself full of simplified narratives building on common

Distributed academic leadership in emergent research organisations

1. Introduction 
sense and implicit assumptions. Analysts may need to critically address such narratives. An example is Burton Clark's comment in his key note address at the European Rectors' Conference in Paris in the year 2000 (Clark, 2001): "Finally, I want to stress the growing importance of an entrepreneurial narrative, toward which many participants in this conference can contribute - a convincing story that depicts to university patrons and the general public what progressive universities are like as they combine the new and the old in a revised form of organisation. This narrative is much needed as a counter-narrative, one that challenges both the simplistic understanding of the university as a business, about which we hear so much these days, and the simplistic depiction of universities as passive and helpless instrumentalities whose fate is determined by irresistible external demands." This comment by an internationally reputed scholar on university transformation was made more than a decade ago. It is still valid.

A further point is that most empirical research on academic leadership focuses on academics who are having a leadership position in the formalised structure of a university, say, vice chancellors or deans. "We need to fill in some of the gaps about how leaders actually operate, through observation and ethnographic material" concluded the British Leadership Foundation for Higher Education in its review paper published in December 2012 (Lumby, 2012). Academics conduct leadership roles as a more or less natural part of their work, so attention to informal leadership is important.

This is the setting for my study. As an observing participant in research organisations over the last thirty years, I reflected on what was happening, and attempted to understand patterns, over and above my immediate duties as a staff person in the Universities of Twente and Dortmund, and in the Telematica Institute (I will say more about these experiences in Chapter 3). Now, as an distantiated analyst, I can focus on understanding how academic leaders, in interaction with organisational and landscape changes, not only address immediate concerns, but also contribute to new paths and patterns - which will then shape further development to some extent.

Research organisations in the Dutch research system offer sites to study distributed leadership. In the European higher education landscape at large, universities have been in transition since

Distributed academic leadership in emergent research organisations

1. Introduction 
the 1960s. In the Dutch national system, universities had been allowed a greater autonomy, not only for finance and personnel, but also for quality of education, real estate management, research contracts with industry and interaction with societal partners. Massification of education has had a major impact on university structure and culture, not only in democratisation, the participation of students in councils and campus management, but also in the changing formal and informal management and leadership roles of academics. Transformational developments in the scientific domains, for instance emerging areas as nanotechnology, IT and open systems, bioscience and biotechnology, have led to a range of multidisciplinary 'fusion' areas of research and innovation. In tandem, new types of research organisations, inside or outside universities, emerged which combined excellence and relevance. In a sense, they are a new species in the institutions of the research ecosystem, and could be called generically Centres of Excellence and Relevance (Rip, 2002; 2002).

The University of Twente is an example of a university in transformation, containing research organisations in transformation and interrelated distributed leadership practice. This university was, by the late 1980s, internationally recognised as an "entrepreneurial" and "innovative" university (Schutte\& Van der Sijde, 2000). Burton Clark has highlighted this by presenting the University of Twente as one out of six "entrepreneurial universities" in Europe (Clark, 1998). In a period of about twenty years, between the mid-1980s and 2005, a range of initiatives occurred at the University of Twente in the organisational renewal of education, research and innovation. Academic leadership practice was visible in these initiatives. Seniority and reputation are assets in leadership, in particular for those academics who are prepared to cross boundaries and create spaces for innovation in research organisation, seeking for effective ways to co-operate, without giving up their individual autonomy. The traditional research institutes around a single senior academic (the German model, one could say) were left behind. An interfaculty research institute at the University of Twente would encompass different faculties and research groups. ${ }^{1}$ Also, it would combine (and continuously balance between) excellence and relevance. Several senior

\footnotetext{
${ }^{1}$ In the late 1980 s a change in Dutch Higher Education law allowed University Councils to establish interfaculty research institutes: temporary organisations, based on a five years' research programme and mandate. This change in law created opportunities for academic leaders to shape their own programmes and related organisational processes. These opportunities were seized by academic leaders embarking on new paths of positioning in research networks and partnering with companies.
}

Distributed academic leadership in emergent research organisations

1. Introduction 
academics would be playing leadership roles, some of them having a formal role as manager, for instance as scientific director, or as director of a national research programme. New interactions occurred, and informal networks of distributed academic leadership grew. Such leadership activities were not specific to the University of Twente, or in the Dutch research and higher education system. The new species of research organisation is found worldwide (Arnold, Deuten \& Van Giessel, 2004).

In sketching this picture, I am moving away from traditional views of academic leadership (and from common heroic views of leadership) as an individual performance. It is individual expertise and skills that make the difference. Leadership is accepted from those academics that are high performers, depending on the culture of the institution more or less appreciated as leaders in their own field or in new emerging fields. Academic leadership is then conditional upon a career dedicated to research. Teaching and management are duties, not goals of a career path. Similarly, commercial/entrepreneurial activities are being viewed as important for the relevance of academic work, sometimes giving access to new financial resources, but not a core business. The background conviction is: give an academic the freedom he needs, don't challenge him with duties or distracting activities.

The traditional view also builds on the conviction that individual access to funding, the more the better, is the name of the game. Looking at the importance of an academic's position as researcher in ranking and citation systems, substantial funding would be almost exclusively accessible to individual, high-performing academics. As universities tend to rely increasingly on external funding from research funding agencies, the EU and third parties, creating access to funding is a crucial element of effective leadership. This is reinforced by the tendency of university financial incentive systems to support research groups that are successful in external fund raising.

Thirdly, and partly in contrast with the traditional view just outlined, is the newly emerging conviction that effective research leadership requires strong research management, including sound project and programme development and organisation. It is part of the move to a resultoriented academic work culture and to structures and management power that support it, as in New Public Management (Hood, C., Peters, G., 2004). In addition to reputation, it is now also

Distributed academic leadership in emergent research organisations

1. Introduction 
accountability that counts. One implication is that leadership activities that focus on local cooperation and creation of social networks are additional, and not taken into account in assessing the performance of an academic leader. Individual performance as a research manager counts; sharing power, distribution of roles are a waste of time, unless there is an immediate purpose and outcome.

Scholars have followed these traditional views and underlying assumptions when describing good practice, focusing on individual senior academics who successfully develop a research group, or when studying development of (new) structures and formalised competencies of designated academic managers. While this is valuable, it misses a vital point: the formal structures and formalised positions in it taken up by individuals reflect what a Central Board of the University needs, mainly to steer financial flows. Much more is happening, also bottom-up de facto leadership, including anticipating and addressing changes, up to becoming a bit of a change agent (Weick \& Quinn, 2004). Strategic research programming, increasingly attempted by various actors, does not only require strategic thinking, but also implies new roles and responsibilities and in that sense, articulation of identity as academic leaders. It is this complexity that is opened up by emphasizing distributed academic leadership. This does not do away with the importance of (perhaps heroic) individual leadership, but nuances it, and if it occurs, treats it as a particular constellation of distributed leadership.

The recognition of this complexity, including its increase in times of transformation and attendant attempts to create arrangements to reduce complexity, is particularly important when one does not focus on individual characteristics conducive to leadership, but sees evolving leadership, always linked with organisational change and learning. One could speak of processes of co-evolution of leadership and organisational change, and take such processes as a topic.

Such distributed academic leadership in transformative contexts can be profitably studied in the new species of research institutes emerging from the 1980s onward. Examples are the interfaculty research institutes, a new entity within the structure of a Dutch university, and the

Distributed academic leadership in emergent research organisations

1. Introduction 
so-called "Leading Technological Institutes", a network organisation between universities and private sector partners.

Interfaculty research institutes require academics to develop leadership roles to bridge between disciplines and faculties, and to link up with external partners, which also relates to career opportunities and financial resources, for instance joint multi-annual programmes with industry or with EU grant funding.

These interfaculty research institutes are located at the meso level in the university structure: between the top down steering from the Central Board and the University Council, on the one hand, and the Deans, research groups and external research projects, on the other. Research institutes develop as programmatic bundles of research projects and related work processes led by academics who develop leadership activities as they go along. Such dynamics, and the transformational nature, are also visible in research institutes outside the university system.

Two of the cases in this thesis will be interfaculty research institutes at the University of Twente: the MESA+ institute for nanotechnology and the CTIT institute for ICT. A third casus is the Telematica Instituut, similar to the other two institutes as it was related to the University of Twente and developed in the same time period, but different as it was not part of the university system. All three institutes share a further feature, their inclusion in external programmes and networks, and interest to engage in innovation, often open innovation (Chesbrough, 2003).

The history of these institutes, in their contexts, is interesting to reconstruct in its own right, and the case studies will do that to a certain extent, shedding light on what is happening in the period 1990-2005. But my aim is analytical, to bring out the interaction between distributed leadership practices and organisational change.

Given these overall considerations, it will be clear that the theme of this thesis, distributed academic leadership practices in research organisations in transformation, must be addressed by combining insights from a number of scholarly fields (sociology of science and technology, research management, business administration, public administration, leadership and organisational change), and to some extent, break new ground in how to combine them. Thus, there is not only empirical work to do, but also conceptual work. I could formulate that as a separate research question, about a conceptual framework to understand distributed academic

Distributed academic leadership in emergent research organisations

1. Introduction 
leadership in interaction with changing research organisations in an overall science and innovation landscape in transformation. I will actually address this in the second chapter, when I develop my approach for this study but also outline a conceptual model. This model is broader than what I will focus on in the reconstruction and analysis of the cases.

By then, the cluster of my research questions can be formulated as: what are evolving distributed academic leadership spaces and arrangements in interaction with transformation in research organisations? Can one see patterns, in the Centres of Excellence and Relevance that were studied, and more broadly?

The mapping of what happens is informed by the conceptual model. This allows for some crosscase analysis in Chapter 7. Overall conclusions and further perspectives are presented in the concluding Chapter 8.

Distributed academic leadership in emergent research organisations

1. Introduction 


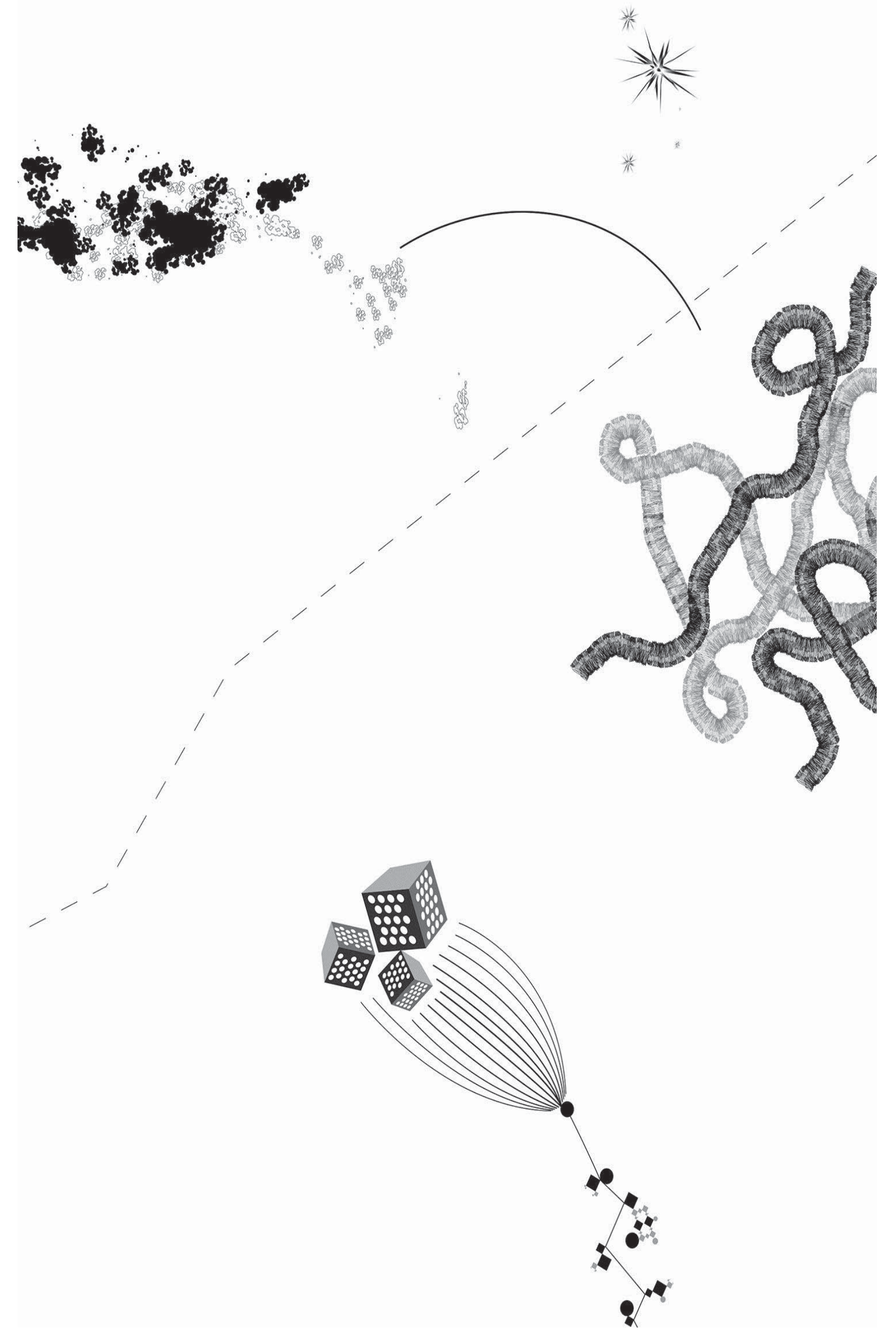




\section{Conceptual framework}

\section{Contents}

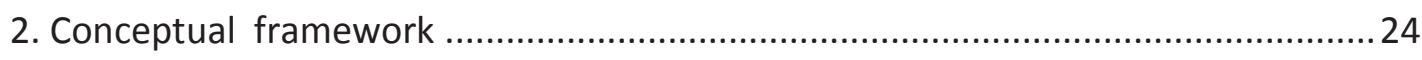

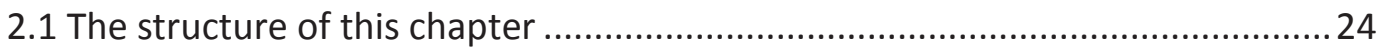

2.2. The changing research and innovation landscape and responses of research organisations

2.2.1 The changing context of HE institutions, as the immediate context of the research organisations studied in this thesis

2.2.2 New species of research organisations ................................................... 30

2.3 Concepts to analyse and understand the processes and patterns ....................34

2.3.1 Varieties of structuration: paths, learning organisations, and spaces ........ 36

2.3.2 Emergent distributed leadership configurations .................................... 42

2.3.3 Contrasting dynamics in distributed leadership configurations.................. 45

2.3.4 Trajectories of spaces and arrangements................................................ 46

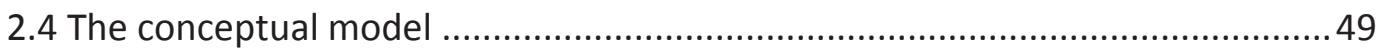

2.4.1 The overall design and interrelations of the conceptual model .................49

2.4.2 Contrasting dynamics in distributed leadership practice .............................54

2.4.3 Stabilising patterns in academic distributed leadership........................... 55

2.4.4 Spaces in emergent research organisations ............................................5

2.4.5 Further use of the conceptual model .................................................5 58

Distributed academic leadership in emergent research organisations

2. Conceptual Framework 


\section{Conceptual framework}

\subsection{The structure of this chapter}

The theme of this thesis concerns academic leadership in interaction with research organisations in transformation. This theme is related to developments in a wider societal context. It will be conceptualised with the help of literature, building on literature in sociology, business administration, public administration, leadership and organisational change. In the literature on leadership, this is theme is often linked to transformations setting challenges for leadership; this then feeds into a heroic view of leadership. What we see in practice, however, are bits and pieces of leadership, distributed over academics, some but not all with formal leadership tasks. And these are part of ongoing transformations, rather than that such transformations are only external challenges. Thus, organisational change is shot through with distributed leadership, and emerging patterns in such leadership may become new arrangements in the organisation. In other words, my theme requires a process approach, which then raises the question of the time perspective necessary to capture the phenomena of interest.

Looking only at the short term, one might miss the point of structuring and destabilizing patterns I will look at mid to long term (five till fifteen years) processes of distributed leadership interactions and related patterns of change, in order to see stabilising patterns, structuration, paths, gelling and lock-ins, loci and inflection points of change ${ }^{2}$.

The choice for study of processes and patterns follows the state of art in research in change management. Pettigrew, Woodman and Cameron, based on an their authoritative overview of literature and appraisal of trends in research, emphasized the need for temporal and situational research of continuous change (Pettigrew et al 2001, p. 704-705). Following their advice, my search for theory and literature ${ }^{3}$ is focused at exploration of "the context, content and process

\footnotetext{
${ }^{2}$ The longer term (fifteen years and more) overall pathways and their dynamics, are not part of my theme, but they will be discussed as a suggestion for further research, in the concluding chapter (Ch. 8).

3 An extensive literature study has been conducted and has been extended and actualised during the ten years of this PhD thesis study. A focus that has been chosen from the start was to concentrate on theory and empirical work that is grounded in studies in Europe. Referring to Pettigrew's appeal to focus on contextual and situational aspects
}

Distributed academic leadership in emergent research organisations 2. Conceptual Framework 
of a change together with their interconnections over time." With a focus on "changing" rather than on "change" my research endeavour is to meet a "dual challenge", once again citing Pettigrew et al: "to attempt to catch reality in flight and to study long term processes in their contexts in order to elevate embeddedness to a principle of method." (Pettigrew et al., 2001, p. 698). The interplay between content, context and process (Pettigrew \& Whipp, 1991) in the evolution of organisational change in research organisations, is briefly introduced here.

First, changes in content of scientific work and evolving new themes are a driving factor for transformations in science and science organisation, be it forces from within the (inter)national science forum, for instance newly emerging scientific fields, or from non-academic partners, for instance companies that embark on R\&D in emerging fields or consumer groups that articulate and lobby for new research themes and the organisation of it.

Second, a continuous changing context is what universities and research groups encounter as of the mid-1980s. The changes in the laws on higher education have given universities an enhanced autonomy and policy frameworks on a European and national level have posed an increasing strategic challenge to university research groups. The interactions with companies have intensified and diversified, for instance co-operation in European research programmes requires inclusion of or even a leading role for multi-partner private firm consortia, causing strong private sector dynamics in terms of time horizons and work processes. Leading research organisations ${ }^{4}$ have become major players in the strategic science (Rip, 2004) and open innovation (Chesbrough, 2003) developments.

Third, change processes and the management and leadership in it have become part of academic practice, as university research organisations are not captured in fixed structures. Continuous surveying changes in the internal (within a university) and external context has become a common activity for managers and academic leaders, sometimes leading to collective reflection and anticipation, in more or less concerted orientations, leadership configurations and emergent research programming (Burnes, 2009).

(Pettigrew et al, 2001), an attempt was made, in order to understand organisational change and leadership issues in an European context, to primarily use of insights that were gathered in this specific context. Studies from the USA and Australia when relevant, were used as well.

${ }^{4}$ In the empirical case studies in this thesis, three examples of leading research organisations will be presented

Distributed academic leadership in emergent research organisations

2. Conceptual Framework 
While a theoretical basis, and literature for studies in leadership and change in scientific organisations, are broadly developed (Dinh et al, 2014), they are still dominated by a focus on individual leadership, behaviour and group dynamics, as indicated in Ch. 1. Empirical work on academic leadership is not well developed, however, and a more elaborated theoretical basis is lacking, particularly for academic leadership in research organisations in transformation. Related to my interest in distributed leadership and change, in my literature study on organisational change, the theme of emergent change and contrasting dynamics in it came forward as topical. Increasingly, organisations, in their interaction with broader transformations in society, embody contrasting processes and dynamics (Pettigrew, 2001; Weick \& Quinn, 2004) or "competing values" (Quinn \& Rohrbauch, 1983). The response of - loosely couples - configurations of leaders is to initiate and create intra-organisational or inter-organisational spaces for explorative, entrepreneurial work that in turn requires that leaders seek for new balances, more or less concerted, between productivity and innovation of organisation (Burgelman, 1983). This joint balancing act in interaction with changing organisations and immediate contexts is captured by the notion of "emergent change" (Burnes, 2009). Emergent change and contrasting dynamics are a central, underlying theme to the concepts of distributed leadership that I will refer to in this Chapter, for instance entrepreneurialism and ambidexterity: on a macro level (the context of the wider research and innovation landscape), the level of the research organisations and the on the level of temporary networks and other configurations of distributed academic leadership.

In this chapter, I will first discuss (in the next Section 2.2) the changing research and innovation landscape and responses of research organisations, this way addressing the changing content and context of research organisations. Then, in Section 2.3, I will discuss concepts to analyse and understand processes and patterns of changing research organisation and leadership in it, the core theme of this thesis. With these interrelated concepts (including informal, entrepreneurial and ambidextrous leadership practices) I operationalize, in Section 2.4, the conceptual framework which is important as such, and informs the empirical case studies.

Distributed academic leadership in emergent research organisations 2. Conceptual Framework 


\subsection{The changing research and innovation landscape and responses of research organisations}

\subsubsection{The changing context of HE institutions, as the immediate context of the research organisations studied in this thesis}

Nationally and internationally, the research and innovation landscape has gone through major changes in the fifteen years between 1990 and 2005, the time period of my empirical studies (Adviesraad voor het Wetenschaps- en Technologiebeleid, 2010), leading to repositioning of universities and companies, and re-inventing of interrelations. The key challenge for universities is to diversify and recombine, into what has been called a 'post-modern university' (Rip, 2011) or a 'porous university' (De Boer et al., 2002). Tensions are visible between the trend towards new public management of universities (Grande et al., 2013) and external pressures and ongoing changes in science and innovation (Smits et al, 2010; Kuhlmann, 1999). For companies, one key challenge is open innovation, and this has implications for their interactions with universities and research institutes.

Meanwhile, structural changes took place in the private sector, leading to repositioning of companies with (university based) research institutes. Major companies started to reorganise their research work and were confronting universities with new demands, be it to focus more on fundamental research in specific areas, or extending research programmes to include research on application and innovation. Coalitions of companies who would otherwise be competitors occurred, together confronting governments, national research organisations and universities with their research priorities (Tidd et al, 2001).

These structural changes are captured by the concept of "Third Generation R\&D" (Roussel, Saad \& Erickson, 1991). Whereas the terms first and second-generation point at firms that show a more or less loosely coupled relation between R\&D policy and strategic management. In second generation $R \& D$, firms try to achieve integral planning and management, but $R \& D$ and business departments still struggle to understand each other, while collaborating in projects, still heading for different time horizons, market and user expectations. Firms in third generation R\&D succeed in creating mutual trust among internal departments, resulting in a portfolio management that balances the different visions and interest.

Distributed academic leadership in emergent research organisations 2. Conceptual Framework 
A development sometimes named "fourth generation R\&D organisation" extends the boundaries of private and public research organisations towards inter-organisational networks. These developments in the research and innovation landscape, labelled as "Open Innovation" led to responses, more or less pro-active, from research groups in firms and universities, resulting in new forms of co-operation and competition between companies. In theoretical perspective, the Open Innovation concept pays little attention to consequences for the organisation of universities and other public knowledge production organisations. Universities are viewed as resources for business, wordings such as "harness" and "harvest" being the key words. Chesbrough observed that companies do no longer invest in central R\&D labs, R\&D becoming increasingly distributed in nature. Furthermore, in this distributed R\&D strategy, universities are being called upon to expand their research, and governments should fund this. Moreover, governments should stimulate knowledge transfer from universities to industry, and universities should allow academic staff to engage in entrepreneurial activities (Chesbrough, 2003 , p. 191). He also defined a set of 'principles' that relate to analytical concepts of cooperation in temporary collectives of (project based) organisations (Section 2.3). In view of its high impact on the changing context of research groups in HE institutions, for instance in IPR and open data, Open Innovation is an example of an emergent change in research organisation.

Due to transformations in the overall science and innovation landscape, different "rule regimes" (Benz, 2007) occur that academics have to deal with while participating in different research and innovation networks. The predominant appearances of these regimes in this period of study are Open Innovation, Mode 2 science and Strategic science.

In their books "Mode 2 of knowledge production" (Gibbons, Limoges, Nowotny, Schwartzman, Scott \& Trow, 1994), and Re-Thinking science; knowledge and the public in an age of uncertainty" (Nowotny, Gibbons \& Scott; 2002), the conclusion is that "closer interaction of science and society signals the emergence of a new kind of science: contextualised, or contextsensitive, science." (р. 4). They approach developments in science organisation as interacting with processes in societal transformation; by presenting the notion of "institutional reflexivity"

\footnotetext{
${ }^{5}$ presented at the time by Chesbrough (2003) in his book. Nowadays, a variety of concepts have been developed, of which in thesis, the general notion of "co-creative learning and crafting" is applied.
}

Distributed academic leadership in emergent research organisations

2. Conceptual Framework 
(p. 43) that addresses the question how knowledgeable agents, for instance academics, deal with ambiguity, with continuous change.

"Strategic science" is presented by Rip (2004) as a mode of knowledge production that is becoming dominant in many fields of science. He characterises "strategic science" as a "regime" of more or less stable rules for doing science, organising it and legitimating it. This regime also includes interactions within the scientific realm and with actors in society. It combines 'excellence' with 'relevance': it incorporates industrial laboratories, and it heads not only for wealth creation but also for quality of life and societal learning. Due to changing contexts and tensions between different regimes traditional modes of collegial governance got under pressure, causing a "reinvention of university collegiality" (Clark, 2001). A transformational process that pushes the limits of the university system, its collegial nature and its bureaucratic procedures. In response to regime changes, new arrangements emerge (Sporn, 2001), often starting out as temporary but adding to open ended pathways towards new configurations in the science and innovation landscape.

Overall transformations in science organisation have been linked with the notion of entrepreneurialism ${ }^{6}$. Etzkowitz (2003) pointed at dynamics in the transformation of research organisation that would result in an overall pathway of research groups developing as "quasifirms". Based on his studies in European universities Clark (1998) has defined five specific features and related transformational pathways of entrepreneurial universities. A strengthened steering core; strong collective leadership to drive strategic decisions forward and support leaders of transformation processes. An expanded developmental periphery and a diversified funding base whereby innovative universities tend to create a rich diversity of interfaces and programmes to deal with the growing and diverse demand of society. A stimulated academic heartland that gradually blends traditional academic values with newer managerial points of view. In interaction with and as a result of the first four features, a campus wide culture of entrepreneurship and change has to be established over time. This framework has been widely cited and applied in research and university management practice, and of course, critically reviewed; related to the core theme of this thesis, some critical reflections can be mentioned.

\footnotetext{
${ }^{6}$ Academic entrepreneurialism is a core concept in this theses. It is briefly being discussed in this section as a phenomenon in the changing context. In the next section it is being introduced in greater detail, in the setting of contrasting dynamics in research organisations. In section 2.3.3 entrepreneurial dynamics are being discussed as a core concept in the empirical study of distributed leadership configurations.
}

Distributed academic leadership in emergent research organisations

2. Conceptual Framework 
The pathways as conceptualised by Clark only indirectly address the internal dynamics of path creation and pathway development; as if pathways would be an empirical result, as they often are, not a conceptual framework to study and recognize the contrasting dynamics that are at work within pathways. Another comment concerns Clark's referral to disciplines and faculties, the model of a university as what Gibbons et al. (1994) call Mode-1 of knowledge production. A second comment is Rip's (2002) observation that Clark, in identifying a periphery interacting with the outside world limits himself to technology transfer and industrial liaison offices, and programmes, which are truly peripheral in the sense that they are centrally organised and not integrated in the life of research groups and departments. More important for actual external interactions is the "semi-periphery of outward-looking, problem-solving research centres"... A fourth comment relates to organisational development and human resource management. Whitchurch (2008) remarks that "organisational positionings are more complex than suggested by Clark, in that professional staff not only operate at the "centre" (in the central 'Administration') and the "periphery" (for instance, in academic departments), but are also creating new locales. As a result, Clark's distinctions between the "strengthened steering core" and the "stimulated academic heartland" may begin to be re-conceptualised." Actually, Leisyte and Enders (2011) have taken this re-conceptualisation a step forward, in their study on entrepreneurial universities and ambidexterity. They see contextual ambidexterity in terms of alignment frictions between universities and their environment reflected in competing values within an entrepreneurial university. While generally agreeing with this approach, I take the notion of alignment frictions one step further, studying contrasting dynamics of ambidexterity in distributed leadership inside research organisations.

\subsubsection{New species of research organisations}

Overall transformations in the science and innovation landscape interrelate with the organisation of research, creating openings for new developments, including the evolution of new species of research organisation which occurred since the 1980s and is now a widespread phenomenon.

The boundaries between the university and the outside world are becoming increasingly porous, and such "porosity" is sought explicitly (De Boer et al., 2002). In the new university setting,

\footnotetext{
${ }^{7}$ Here, Whitchurch uses another notion of periphery than Clark himself does.
}

Distributed academic leadership in emergent research organisations 2. Conceptual Framework 
individual departments, faculties, and research institutes, are relatively independent and can follow own trajectories, emphasizing certain research areas in response to external developments, developing new combinations of research and training, etc. In other words, in the strategically important middle layer in the university, occupied by departments and faculties competing amongst each other for resources and favours from the top, an entrepreneurial element is introduced which increases the flexibility of the institution as a whole. Up to preparing for partial privatization, making deals with other universities, etc. The future (research) university may turn into a conglomerate, rather than the unified organisation envisaged by the proponents of the modern university (Rip, 2011).

Such a university will include, or have alliances with, "Centres of Excellence and Relevance" (abbreviated as CERs) which I already introduced in Chapter 1 as a new species of research organisation.

As Van der Meulen and Rip (1994), and later Rip (2002), have emphasized, a distinguishing feature of a CER is that they are time-limited in terms of core funding (ten, maximum fifteen years). There are often other sponsors, and on that basis, a centre can survive after special funding has stopped. The centres are almost always a good context for PhD training (the USA Engineering Research Centers have the number of PhD students as one performance indicator). They can also offer shorter stretches of on-the-job research training (which may contribute to a PhD), and postdoc training.

Initially, initiatives for Centres of Excellence and Relevance started in the USA, UK and Australia in the 1980s, with core funding from government programmes. The USA Engineering Research Centers, the UK Interdisciplinary Research Centres, and the Australian Collaborative Research Centres all started in the 1980s (Van der Meulen \& Rip, 1994). Such centres also evolved in universities, whether pushed by special funding schemes or emerging in their own right. They were constituted, with contributions from various actors (government agencies, industry, universities). They could be supported by consortia as was the case for instance with the Leading Technological Institutes (LTIS) in the Netherlands from the mid-1990s onwards. LTIs in the Netherlands had links with universities in terms of location and collaboration. For example the Telematica Instituut, close to the campus of the University of Twente, and IMEC, located in Louvain (Belgium), established in 1984 (Van Helleputte \& Reid, 2004).

Distributed academic leadership in emergent research organisations 2. Conceptual Framework 
There is no good overview of CERS in the literature, but the Turpin et al. (2011) Report on Collaborative Research Centres (CRCS) in Australia, covering a time period of more than twenty years, offers general observations on CRCs struggle to balance between embeddedness in the university system and flexibility towards (market) changes. In the early nineties, different organisational foci were visible already: research, corporate and integrated (Liyanaga \& Mitchell, 1993). Turpin et al. (2011) distinguish three types (of CRCs, but the types are generally applicable to CERS): thematic centres, often connected to programmes of national interest (strategic priorities set by government), industrial collaboration centres and business development centres (aiming at new business development).

For my theme, CERs have primarily an impact on participating research groups that can seize opportunities to engage in multi-partner research programmes, and have academics take up informal leadership tasks in project and programme based networks of co-operation. Such tasks vary from anticipating and strategic planning, supervising or managing projects that aim at creation of joint research results, and developing new concepts for external interaction and cooperation. Such tasks are important, but are often not reflected in the formal structures of a university. Spaces within or in addition to formal structures are necessary to let such tasks come into their own.

The CERs are a striking phenomenon, and important for the themes of this study, but they are part of broader changes. In research universities, in the Netherlands and worldwide, the chairs and the departments are the basic units that organise research. At least, that is the picture in structural and governance terms. In material terms, definitely since the 1990s, the picture has become more complex. Budgets that are being supplied by central governments and allocated via university boards or via national science councils, increasingly no longer depend on the decision power of a single chair, but are part of long term projects or programmes. At the same time, diversification of funding sources is the trend (Clark, 1998; Horta, 2008; De Weert, 2007). In EU funding and private sector funding one sees the same trend towards larger projects and programmes. This also changes accountability relations, particularly for academic staff employed on a temporary basis, financed by external projects or programmes. These diversifications are transforming the "face of academic life" (Enders, 2009). What remains is that the dominance of projects and programmes does not lead to strategic portfolios that are

Distributed academic leadership in emergent research organisations 2. Conceptual Framework 
steered from a top strategic management level in the university (although Boards of universities have tried to realize this). The substance of decisions is the responsibility of units and groups at a lower organisational level. (For research institutes, a similar observation holds, even if there is less distance between top management and research performance units.) There may be de facto strategic portfolios of research, as a bottom-up effect of choices of units at a lower level, and these may occasionally take higher level considerations into account. Such strategic competence is an element of academic leadership in the age of Strategic Science.

Strategic action overlaps with entrepreneurial approaches in the broad sense. It is important to keep a broad perspective on entrepreneurialism as being innovative and willing to cross boundaries, to avoid being trapped in a simplistic contrast between commercialisation activities and academic values. An otherwise useful literature study by Rothaermel et al. (2007) suffers from this bias when it says: "university entrepreneurship is currently in the embryonic development stage. Prior to the passage of the Bayh-Dole Act in 1980, the phenomenon was basically non-existent in literature. Moreover, it was not until the late 1990s that the research really took off." (p. 698). There has been a lot of attention, and some analytic study, of Technology Transfer Offices, university spin offs, and science parks (e.g. Clark, 1998, 2001, 2003; Philpott et al., 2011; Fogelberg et al., 2012; Van Looij et al., 2004; IMHE, Shattock, (eds), 2005). One interesting finding is that there is no principle contrast between excellence and commercialisation, or more broadly, valorisation. Van Looij et al. (2004) show that the scientific output of research groups that engage in entrepreneurial activities is not declining, but growing.

Considering the overall changes and the various responses from research organisations, it will be clear that concepts to understand processes and patterns in changing organisations, have to capture the tensions involved in what I have called "contrasting dynamics." In Pettigrew's words, there are dualities: "simultaneously building hierarchies and networks, attempts to centralise strategy and decentralise operations, and moves to create greater performance accountability upwards and greater horizontal integration side-ways." Which takes shape in "the contraction of hierarchies or delayering, decentralisation of strategic and operational vertical networks, investing in IT and redefining organisational boundaries." (Pettigrew et al., 2000, p. 271-272. Similarly, Bolden et al. (2008) observed, in their studies of the UK higher education sector, movements towards "devolution of power" together with a tendency to formation of

Distributed academic leadership in emergent research organisations

2. Conceptual Framework 
"bigger business units". The notion of Centres of Excellence and Relevance is applied to address this evolution of research organisations. Within the evolutionary setting of Centres of Excellence and Relevance, aacademic leaders, more or less concerted, create spaces in multi-party research programmes. These encompassing programmes, showing features of network organisations (Provan, 2007; Nonaka, 1995), have become core elements that structure pathway development of research organisations.

In the present section, I have indicated further dualities in organisational change and distributed leadership, in particular the need to involve more actors (cf. open innovation, in the broad sense I used the term) and cross boundaries, while making sure to perform in one's own right. These phenomena have to be taken in the concepts to be used to understand what is happening, and the eventual conceptual framework.

\subsection{Concepts to analyse and understand the processes and patterns}

For the identification and discussion of important concepts, I will draw on different fields of scholarship of organisational change, change leadership, entrepreneurialism and ambidexterity, as they address aspects of organisational change and distributed agency (including leadership). Taking into account the state of the art in a field, one can see key concepts and ideas behind them that capture the contrasting dynamics in the transformational processes and their partial stabilizations into configurations and arrangements. In terms of Schön (1983), such concepts allow the analyst to "name" what is happening. A clear case is the first of my key concepts, Tushman \& O'Reilly's (1997; 2004) notion of an "ambidextrous organisation", and its extension to the general capacity of "ambidextrous leadership" (Rosing, 2011).

Tushman \& O'Reilly (1997, p. 12) recognized how business organisations could, and often should, operate in two modes at the same time: "Technology cycles and the nature of innovation streams indicate that sustained competitive advantage is built on simultaneously operating in multiple modes: managing incremental, architectural, as well as discontinuous innovation, managing for short-term efficiency and long-term innovation." and "hosting multiple, internally inconsistent architectures, competencies and cultures, with built-in capabilities for efficiency, consistency and reliability on the one hand, and experimentation, improvisation and luck on the other." Their notion of "ambidextrous organisations" has become

Distributed academic leadership in emergent research organisations 
important in business organisation studies, also because it is used for diagnostic purposes. It has been developed further, in particular by Birkinshaw \& Gibson (2004) who contrasted what they called "structural" ambidexterity where structures have to be created and managed to deliver ambidexterity, with the concept of "contextual ambidexterity" that focuses at the organisational cultural aspects, including leadership that stimulates a contextual alignment-oriented work culture. It will be clear that ambidexterity and its organisational-cultural shape is an important concept for analysis and understanding of the phenomena that I study. A core part are the contrasting dynamics of exploration and exploitation within research organisations. ${ }^{8}$

In ambidextrous organisations institutional entrepreneurial dynamics play an important role. There is, by now, a large literature on intrapreneurship (Rothaermel et al., 2007), and an emerging literature on institutional entrepreneurs (cf. special issue edited by Garud et al., 2007). The way Burgelman (1983) phrases his notion of "entrepreneurship from below" is useful in this context. Research organisations as I study them can be seen as sites of "internal corporate venturing" in larger multifaceted organisations settings of universities and companies. Burgelman, in his longitudinal studies, notes that: "strategic choice processes, when exercised in radical innovation, takes the form of experimentation and selection, rather than strategic planning". (p. 242). This "strategy making" rather than "strategic planning" is what typically happens in distributed leadership configurations.

While the literature on academic entrepreneurialism (Etzkowitz, 2003) sometimes draws on this more general analysis, it remains focused on commercialisation issues and the tensions with academic values. As is clear in the quotes from Burgelman, entrepreneurialism is used in the general sense of enterprising or venturing for change. ${ }^{9}$ Evolving research organisations attempt to open up structures, and stretch rules developed under earlier research regimes. The changing overall research and innovation landscape is both an occasion to do so, as well as an incentive, already because of the anticipation on further changes. One aspect of such anticipation how it stimulates creation of spaces for new leadership practices, beyond the immediate self-interest

\footnotetext{
${ }^{8}$ In the previous Section the ambidexterity of larger, inter-organisational joint ventures has been discussed (Ferrary, 2011), without using the term, as it will not be operationalized in this sense in the conceptual framework of this thesis.

${ }^{9}$ A similar broad use of the term occurs when Clark (1998), in his study of innovative/entrepreneurial universities, speaks of a "campus wide culture of entrepreneurship and change" as one feature of such universities.
}

Distributed academic leadership in emergent research organisations

2. Conceptual Framework 
of a research group, on a more strategic level. This is what we will see happening in my case studies.

\subsubsection{Varieties of structuration: paths, learning organisations, and spaces}

Transformational processes will partially stabilize, and such stabilization can take different forms: organisationally as new structures, and developmentally, as pathways. While such phenomena have been discussed in the literature, and the importance of studying processes has been emphasized (cf. Pettigrew) there is no overall conceptualisation, let alone theory. Maybe one should not expect that, given the variety of organisations and contexts. It is possible, though, to take Giddens' concept of 'structuration' as an overall perspective and background reference to specific forms of processes of change and partial stabilization. In his terminology, organisations, including research organisations, are loosely coupled recursive constitutions of structures and knowledgeable agents, including, as in my study, leading academics. Giddens (1984) sees the recursive interactions as sources of continuous change. He defines "structure" not just as a constraint on action, as economists tend to do, but also as enabling. He acknowledges power as access to resources as a driving force for transformation, in his words as the "transformative capacity of all individuals to act either to reinforce or to undercut existing structures." (1984, p. 16)

Giddens himself has paid little attention to developmental aspects and their specific forms, other than in his thinking about macro-level reflexive modernization (Beck, Giddens \& Lash, 1994). There is literature on paths and path dependency, and the notion of 'pathway' is used in historically oriented literature. For analysing and understanding interaction between organisational change and distributed leadership, it is important to mobilize that literature and add further relevant literature about learning organisations and 'spaces' that can open up.

Transformational developments become in particular visible in research organisations that are embedded in or connected to the middle layer of a university system, as I indicated in Chapter 1 and the previous section. Here, I introduce the further notion, that such developments follow paths that emerge and stabilise, particularly if one looks at institutions, here, research organisations. There is literature on path dependency starting with the work of Paul David (1985) and now also path creation (Garud \& Karnøe, 2004; Sydow et al., 2005). The assumption

Distributed academic leadership in emergent research organisations

2. Conceptual Framework 
in this literature is that there will eventually be closure. That may well happen, but the dynamics of such developments are broader: there is the basic sociological phenomenon of structuration (Giddens, 1984; Yates, 1997) and emergent change (Burnes, 2009) evolving over time, and there is recognition of the role of spaces that open up and/or are created intentionally (Rip \& Joly, 2012; Nooteboom, 2008; Whitchurch, 2008). Thus, in view of the theme of this thesis, I will apply a notion of paths at the level of distributed leadership practice and of pathways at the level of evolving research organisations, as I will introduce here. In this overall approach of paths and pathways, actions and interactions can add up to a pattern over time that is followed to a certain extent, a pathway as it were. As the Oxford English Dictionary phrases it, a pathway is "a sequence of changes or events constituting a progression." Recognizing the "progression" is due to the open endedness of pathways a challenge for actors in it and analysts observing it from a distance, a like. Pathways are open-ended and have to be reconstructed taking their open-endedness into account. I have emphasized the structural changes that occur by speaking of a transformation pathway, already in Chapter I. I also mentioned the role of spaces, as opening up in the "progression", as well as spaces within which the "progression" can unfold (as will be explained in the end of this section).

The understanding of transformation pathways and the role of leadership and interrelated spaces are complex and raise complex questions. As transformation pathways are interlinked with changes in the wider science and innovation landscape, it is worthwhile to look at innovation literature, even if my focus is not on trajectories of innovation in context, Transformation pathways occur in innovation, visibly so, and Van de Ven, Polley, Garud \& Venkataraman (1999) have captured this phenomenon by speaking of "innovation journeys", and how gelling of phases in the journey occurs (Rip \& Schot, 2002; Sydow, Schreyögg \& Koch, 2005). Rip \& Schot (2002), Rip (2010) and Rip (2012) have added to this idea by showing how spaces occur in and around the innovation journey (and have used the overall perspective to argue that command-and-control approaches in the management of innovation are most often unproductive. Instead, understanding of ongoing dynamics in the journey is important, which allows their modulation). They look at the timing of strategic management interventions according to the "gelling of phases". This notion of 'gelling' relates to the stabilising of patterns in processes that I conceptualise in this thesis. Regarding 'timing' in innovation processes Burgelman \& Grove introduced in the mid-1990s the notions of "internal selection

Distributed academic leadership in emergent research organisations 2. Conceptual Framework 
environments" and "strategic inflection point" (SIP): a critical period during which major threats as well as new opportunities come about."(1996, p. 18-19).

This way, taking the concept of a transformational pathway as an open ended configuration of paths that are interlinked via spaces that allow distributed leaders to reflect and learn and intervene in course directing, empirically leads to challenges; this implies tracing complex processes (Pettigrew, 1990) and focus on "situations" (Spillane, 2004).

In the context of research organisations, the actual exploration and experimentation of leadership practices takes place in "protected spaces" (Rip, 2003) and "third spaces" (Whitchurch, 2008). Such spaces open up in transformation pathways, and the way they are filled in contributes to further step in the transformation pathways. Thus, transformations of research organisations show a certain sequence, a transformational pathway which shapes further actions and interactions.

The conceptualisation of protected activity spaces and leadership learning spaces in evolving pathways can profit from the insights in innovation journeys. In innovation studies and also in innovation practices it is now generally recognized that innovation starts with experimentation and try-outs in a protected space, in a lab and with dedicated teams working on a project (up to skunk works, as when IBM set apart people, resources and a building to create a personal computer that could compete with Apple's computer, cf. Rip \& Schot 2002). In current studies about innovation in networked and loosely coupled stakeholder groups, Ries \& Blank, while applying the LEAN concept in Silicon Valley, suggested the "pivot" as a concept for "validated learning" in an innovation cycle, as a "structured course correction designed to test a new fundamental hypothesis about the product, strategy, and engine of growth (Blank, 2013).

Translating these insights from innovation studies to the topic of transformation pathways in research organisations, what we see is primarily academics developing their own joint leadership learning spaces in their practices as research project leaders, or as informal leaders of new initiatives; making use of opening spaces or creating them, that allow them to conduct peer to peer 'validated learning' in somewhat protected spaces. Empirical studies on academic leadership learning paths and spaces are scarce, but there is some scientific work that reflects the state of art in literature requires attention here, as it addresses the theme of leadership and organisational change. Whitchurch's (2008) introduced the concept of a "third space" between

Distributed academic leadership in emergent research organisations

2. Conceptual Framework 
professional and academic domains, in which "less bounded forms of professional work alongside academic colleagues, in an expanding institutional community of professionals [emerge]" $(2008 ;$ p. 5).This space is also inhabited by academic staff who undertake projectoriented activities, both short- and long-term. At the same time, cross-boundary professionals are likely to move in and out, actively using the boundaries between third space and professional and academic domains for superordinate purposes." She points out that "third space' is not merely an area of activity, it also relates to development of new roles and even new career perspectives. "In third space, individuals are not only interpreting their roles more actively, but are also undertaking significant 'identity work' in relation to their own career futures." She positions her notion in a broader social development, referring to Taylor's notion of "creative commons"(Taylor, 2008, p. 38). The term "third space" has also been suggested by Nooteboom \& Stam (2008) in an advisory report to the Dutch government on behalf of the Dutch Scientific Council for Government Policy, titled "Micro-foundations for Innovation Policy" (Nooteboom \& Stam, 2008). They advise (on the basis what is happening in practice already) government to promote innovation in third spaces, that "could be virtual or real, in the form of an actual location. By setting interaction apart, in third space, industry can escape from market pressures towards exploitation and academia can protect the autonomy of its fundamental research, while being connected to each other for their mutual benefit." (Nooteboom \& Stam, 2008 , p. 126). Their notion is closer to what Rip has called "protected spaces" for exploratory work and trying out for new product development (Rip \& Schot, 2002), and the protection was protection against interference, legitimized by the open-ended character of research and innovation at an early stage, and the promises that went with them.

These and similar concepts need further empirical study to understand the dynamic nature of spaces for distributed leadership. A theme for further investigation is the paradoxical dynamic of protected and third spaces in transformation pathways. These spaces create opportunities for academics to experiment and learn, but are fully intertwined with the on-going transformational dynamics of science organisation. Even more, they seem to function as hot spots where leadership learning is accelerated and ambidextrous and dual mode steering is being practiced as a way to make internal dynamics and tensions productive (Cameron, 2006; Birkingshaw, 2004).

Distributed academic leadership in emergent research organisations 2. Conceptual Framework 
The tracing and study of these spaces of explorative leadership learning practices requires understanding of learning practices as such in organisational change settings. There is a body of literature on "learning organisations" (Argyris \& Schön, 1996; Senge, 1990) that have been empirically studied in university development (Tabatoni, Davies \& Barblan, 2002). The concept of the "learning organisation" has been introduced by Argyris \& Schön and later on elaborated by Senge in presenting a conceptual framework that defines five "disciplines" that need to be in place in order to establish a learning organisation: personal mastery, tacit mental models, shared vision, team learning, and systems thinking. Tabatoni et al. (2002) underline the usefulness of the learning organisation concept for academics who have to cope with a diffuse environment: "Universities should conceive of themselves as 'learning organisations', not in a conventional pedagogical sense, but in the sense of self-evaluation and on-going monitoring, leading to continuing enhancement of an institution's capacity to respond to, and lead, a turbulent environment. This clearly calls for a university-wide strategic awareness or intelligence which does not destroy or inhibit the creativity of the academic heartland, but enhances its vitality." (2002; p. 12). They speak of strategic management as a process to "prepare people to project themselves into the future (..)". "In organisations considered as learning systems, strategic management becomes the educating process of change agents, the institutional actors."

Concerning learning in an changing context Argyris and Schön pointed as the dissonance between informal and formal realities as a source for learning. The gap between "theory-in-use and espoused theory" as they coined it (Argyris \& Schön, 1978, p. 16-17). Even more, practise based learning it might be a necessity: Boal et al. (2000) state that: "Since it is argued that the environment that surrounds organisations is becoming increasingly hyper-turbulent, we suggest that the essence of strategic leadership is the creation and maintenance of absorptive capacity (to learn) and adaptive capacity (to change) coupled with managerial wisdom (Kairos time)." (p. 516).

Empirical work in the UK led to the concept of the "blended professional" who creates and evolves in the "third space" between academic and professional management domains (Whitchurch, 2008). Based on empirical studies in the UK, USA and Australia, she presented the notion of "blended professionals", an emerging 'species' of professionals who are working in HE. Her stance is that "comparisons with Australia and the United States suggest that such staff

Distributed academic leadership in emergent research organisations 2. Conceptual Framework 
have the potential to make an increasing contribution to the development of institutional capacity and potential in the future." (p. 83). This observation is in accordance with Burton Clarks (2003) remarks on "sustaining change in universities", where he addresses the crucial function of "the bureaucracy of change" in university innovation. Whitchurch reports on trends that employers seek professionals that are able to engage in "rule-making" rather than "rulefollowing" and are "innovative and creative" rather than "bureaucratic". Furthermore she registers that "institutions that are obliged to respond to changes in their environments, are more likely to host professionals who are active in interpreting their roles, and in working across and beyond boundaries." (...) "institutions also require less bounded forms of professional to interpret and contextualise institutional obligations to different constituencies, internal and external, and also to build and develop institutional capacity. (...) While cross-boundary and unbounded professionals actively grow their given roles, a fourth category, blended professionals, represents staff who are increasingly being appointed on the basis of experience that enables them to carry out mixed portfolios, and to contribute to activity that straddles both professional and academic domains." (p. 86-87).

In that perspective of protected spaces interrelated with leadership learning spaces, the vantage point is the common spot on the horizon that a collective of academics share. In horizontal terms, meaning the co-operation in networks. In vertical terms, addressing the different process layers and arenas that academics engage in, locally at the home university, at the middle layer of a university system, or in one of the many programmes and projects on national or international level. And also in time dimensional terms, stabilising patterns and spaces and distributed leadership interventions add up to arrangements that occur. When we speak of protected spaces and third space in relation to distributed leadership activities, work processes and organisation become important, but these are experimented with to realise desired outcomes. Over time, such experiences add up and stabilize, and new ways of working get institutionalized and can be drawn upon. For distributed academic leadership, the idea of spaces is important, because the activities span up a space for interaction and dedicated work that can evolve and stabilize. Spaces can also be created, as when having recognized research institutes

Distributed academic leadership in emergent research organisations 2. Conceptual Framework 
that function as centres for excellence and relevance, to experiment with new kinds of work (e.g. strategic research) and new leadership patterns ${ }^{10}$.

In conclusion, paths of protected spaces and interrelated joint leadership learning spaces can be understood as variations of structuration by distributed leadership practice.

The role of spaces for distributed leadership learning practices deserves further attention, and I will offer some general ideas from literature in Section 2.3.4, before reconstructing transformation pathways in the empirical chapters.

\subsubsection{Emergent distributed leadership configurations}

The occurrence of configurations of distributed leadership in emergent change processes is recognized in literature by authors who have observed academic leadership in longitudinal perspective. Whereas for long academic authority was supreme and decision making was carefully balanced in committees dominated by senior academics, fundamental changes took place in the final decades of the $20^{\text {th }}$ century (Sporn, 2007). Middlehurst (2004) observes "a need for strong strategic capacity, integrated management systems, swift and flexible decision making capabilities and distributed leadership throughout the organisation." Bradshaw et al. (2009) register an integration of tasks that they name "LMG": academic leadership (L), management $(\mathrm{M})$ and governance $(\mathrm{G})$ as interrelated and conjoint dimensions of academic leadership. They interpret these new conjunctions as stimuli for organisational learning.

In the Dutch context strategic planning has become part of academic leadership practices. Different from formalised management activities that are rather visible in the structure of a university, often informal academic leadership activities are as such relatively invisible, for several reasons. First, in terms of labour division, we see that academic leadership practice materialises in part time activities (Reinhardt, 2011); implying that we do not see a specialisation of professional 'leaders' as one might expect in view of the professionalization and full time appointment of deans since the late nineties, but a distributed pattern of academics

\footnotetext{
${ }^{10}$ Such dual roles of spaces can also be seen in science, technology and innovation policy (Rip \& Joly, 2012), and were at work in the early stages of the European Commission's Framework Programmes (for R\&D) (Kohler-Koch \& Edler 1998).
}

Distributed academic leadership in emergent research organisations 2. Conceptual Framework 
that take up leadership activities in research organisation (Ancona, 2007). Second, neither do new committee structures appear as once prescribed by HE law, but occurs a range of research dynamics related working groups, steering groups, programme boards. Thus, in terms of organisational dynamics, these leadership practices follow the pace and direction of the diversified and contextualised programming or research in interaction with multi partner networks. Resulting in ambidextrous leadership activity patterns, as will be discussed later on in this Section.

These emerging, informal and less visible features of academic distributed leadership is in accordance with findings in other sectors of education; the UK National College of School Leadership speaks of these types of leadership as a necessity for transformation and coins its featuring as "the space between the pebbles in the jar" (Jackson, 2003). Necessary as it may be, the informal nature of academic leadership also causes extra challenges for leaders, and sometimes tensions and problems. Based on empirical inquiries among academics Evans (2012) registers an "attention deficit" and concludes that many academics experience "academic citizenship" instead of professional leadership. In response to these deficits spontaneous or crafted constellations of task division occur. Based on empirical studies in Germany, Konradt (2011) observes temporary cycles and patterns in task division in distributed leadership in teams. Such patterns occur also in networks or other temporary configurations of research groups. Other authors propose to look at forms of concertively patterned and reproduced leadership practice, in order to understand varying degrees of structural solidity: spontaneous collaboration, intuitive working relations, and institutionalised practices (Gronn, 2010); or refer to theories on 'distributed cognition' and 'activity theory' in stating: "the sociocultural context is a constitutive element of leadership practice, fundamentally shaping its form. In our distributed view, leadership practice is constituted in the interaction of leaders and their social and material situations." (Spillane, 2001, p. 5).

Regarding innovation leadership in networks, building on the empirical and theoretical work of Hauschildt (2001) on innovation management, Fichter (2009) has developed the concept of "networks and troikas of promotors". Their basic finding, based on empirical work in high tech industry, is that networked constellations interact with a distribution of resources and competencies, especially in early phases of innovation processes where there is a strong need

Distributed academic leadership in emergent research organisations

2. Conceptual Framework 
for mutual motivation and support, embodied in the functions of "promotors"11. Accordingly, regarding leadership in education, Fullan (2005) speaks of "systems thinkers in action" and "intelligent accountability" that stimulate a greater self-review capacity in the context of transparent external accountability.

So, literature points at the necessity to look at change and informal, emerging forms of distributed leadership that reflects functional task divisions and responsibilities that are activity related, no longer solely superimposed by structures that were imposed by HE law (Bennet et al, 2003). Configurations of distributed leadership that of course encompasses informal leadership as well as transactional leadership and management tasks. In recent studies Bryman (2008) and Lumby (2012) stress the necessity to look at informal academic leadership practices, that are often not included in leadership studies, as they conclude. To capture forms of - mostly informal - leadership "from below" the concepts of "distributed leadership" and "emergent leadership" have been introduced and explored in education studies in the US (Spillane et al., 2004) and in the UK (Bolden, Petrov \& Gosling, 2008; Gronn, 2002 \& 2010; Middlehurst, 2004; Leithwood et al, 2004).

In the daily practice of distributed leadership, academics operate in different layers of processes. These leadership activities, although sometimes covered by the same actors, evolve in different process layers. Each layer showing another dynamic: for instance in more formalised layers according to the annual planning and budgeting cycle, in informal layers the dynamics of the activities concerned, a good example is the multi-annual life cycle of a programme or theme.

In conclusion on this part, what we see is a shift from traditional academic, often individual, leadership towards combined, often informal tasks and activities in distributed configurations of academic leadership. Configurations that encompass dissonances in known and new leadership challenges and other contrasting dynamics.

${ }^{11}$ Theoretically Hauschildt and Fichter discern four roles: power, technology, process, and relationship.

Distributed academic leadership in emergent research organisations 


\subsubsection{Contrasting dynamics in distributed leadership configurations}

In the practice of contextualised, academic distributed leadership, keeping a balance, interacting with disruptive developments and diversified resources and competences, anticipating and adapting is a challenge. The balancing activities include agency and structuration, path dependency, and contrasting dynamics. Agency and structuration refers to the duality of transformative organisations and individual and collective entrepreneurial leadership actions. Academics that conduct leadership tasks are acting as knowledgeable agents, they create their own processes and structures. In particular where leadership occurs in ambiguous contexts, leadership practices of academics will result in new, at first temporary structures.

Such leadership tasks are conducted in distributed, loosely coupled or sometimes routinely structured groups of academics, sharing visions, balance competing interest groups and share strategic intelligence. Such practices need not be harmonious, and resources and organisational structures may not be aligned to the intentions of individual leaders.

Transformation and leadership in academic organisation are full of struggles, also between departments and between research institutes and external competitors and partners. In political science, the concept of "arena" has been introduced to capture such dynamics. In governance studies, interrelated arenas have been emphasized (Kuhlmann, 2007; Benz, 2007). Translated back to the practices of leading academics, this implies that they have to live up to different rule regimes in loosely coupled arenas. Dealing with "duality" and "rule regimes" (Kuhlmann, 2007) is a new requirement for leading academics who have to cope with ambiguous situations. Heterogeneous contexts require versatile leaders, or collegiate collectives of leaders (Quinn \& Rohrbaugh, 1983). This overlaps with the notion of ambidextrous leadership and in particular with Birkinshaw's concept of "contextual ambidexterity" (Birkinshaw \& Gibson, 2004), and Rosing's findings on ambidexterity and innovation in organisations (Rosing et al., 2011). One aspect is how collegiate, distributed leadership performs the balancing act between exploration and innovation on the one hand, and effectiveness in producing outputs on the other hand. Contrasting dynamics in the university context are often referred to as the classic tension between exploration and exploitation (Cohen \& March, 1972) or more recently framed as "creativity and implementation" (Rosing, 2011).

Distributed academic leadership in emergent research organisations 
A second concept that addresses contrasting dynamics in research organisations is "academic entrepreneurialism". This concept was introduced in the previous subsection concerning the overall organisational dynamics in interaction with changing contexts. Here, I focus for a while at academic entrepreneurialism in dynamic configurations of distributed leadership.

Academics initiate entrepreneurial initiatives from below and from within existing structures and cultures of research organisations. Similar developments of "internal corporate ventures" (Burgelman et al., 1983) have been studied in industrial companies. In these studies, entrepreneurialism is approached as an interplay between different venturing actors in an organisation, who take up venturing tasks, each in their own right as for instance project leaders, opinion leaders, production managers, marketeers or strategic managers. This view fits in with the practice of academics who increasingly perform and develop project management and business development roles and competencies as part of their academic work (sometimes called soft entrepreneurialism", Philpott, 2011), and managers and administrative staff embark on innovative tasks, being recognised by academics as the "bureaucracy of change" (Clark, 2003). These examples include 'venturing leadership' concerning the development of new organisational approaches in academic work, wherein academics seize the opportunity to go beyond (tacit) protocols and administrative procedure in developing experimental work forms in protected spaces (as introduced in previous sections). In the context of transformation in science areas, the transformative nature of their working contexts triggers academics to develop change agent activities and academic leadership practice of a transformational nature (Weick \& Quinn, 2004). Transformational leadership activities include sense making and working with contrasting values and dynamics.

In conclusion on this part, primarily based on extensive literature on transformational leadership, emergent leadership and internal corporate venturing in private sector settings and based on available literatures on academic entrepreneurialism, in the frame of this thesis I approach academic entrepreneurialism as a balancing act of internal venturing academic leaders, becoming visible in entrepreneurial distributed leadership configurations.

\subsubsection{Trajectories of spaces and arrangements}

Trajectories comprising arrangements of distributed leadership and learning spaces evolve over time, and shifts in interrelated activity patterns can be mapped. This can be seen as an empirical

Distributed academic leadership in emergent research organisations

2. Conceptual Framework 
question, but the concept of arrangements, if assessed in longitudinal perspective, can also be used to indicate a plausible life-cycle of constellations of distributed leadership interaction patterns. At first, academics identify and expose as leading members of a research organisation, still in a fragmented way, each on their own, as leaders of their own projects and groups. Then, around clusters of projects informal networks and social identities grow, visible in themes and programmes. Finally, more structured processes and new organisational entities are established. Patterns now include productivity of programmes and quality control procedures that for academic work rely on peer evaluation as in visitations and refereed journals.

In other words, academic leaders in a distributed configuration, while structuring their working environment in ambiguous contexts, and in balancing contrasting dynamics, create more or less stable trajectories and sometimes paths (Garud \& Karnøe, 2001). A key dynamic is their role as "merchants of hope" (Kets de Vries, 2001): they project promising futures. In particular in fields of science and engineering, this had become an important task for academic leaders (Te Kulve, 2011). In the ambiguous contexts that academic leaders (inter)act in, path dependency materialises in social and professional spaces. Communities of interest (also on the internet), thematic areas in international research networks, and, most prominently in research organisations and its immediate surroundings: in thematic bundles of projects, innovation programmes, and strategic research orientations.

Transformational changes are a challenge for leaders, but also an opportunity. Earlier on in this chapter I spoke of openings in pathways: triggering contexts that those academics who take up pioneering leadership roles, have been looking for. Different from transactional leaders (often managers with a formal position) who primarily have to secure status quo, it could give them freedom to develop their own approach. Bolden et al illustrate this when reporting from their observations: "Despite the complex organisational structures present within universities, many leaders appear to learn how to navigate and utilize the informal path and networks sometimes totally bypassing or undermining the formal structures" (Bolden, 2008, p. 62). These and similar patterns of informal leadership stabilize in different processual layers and sometimes evolve in arrangements, once they add to and informed by specific types of distributed leadership arrangements that enable "boundary work". There is a body of literature in Science \& Technology Studies (STS). Regarding boundary work between the research world and the

Distributed academic leadership in emergent research organisations 2. Conceptual Framework 
governmental domain (Hoppe, 2002, p. 23) defines five conditions of effective boundary arrangements: double participation from and dual accountability to the respective domains ${ }^{12}$; boundary objects that are recognised and usable, for instance planning documents and graphical representations; negotiation, confrontation and mediation ${ }^{13}$ that inform co-production of robust knowledge and power structures ${ }^{14}$. He stresses the crucial importance of "metagovernance and capacity building" to avoid pitfalls of incremental, localised policies.

In longitudinal perspective, three key activities that are connected to dominant patterns in distributed leadership activities appear as sites of distributed leadership in changing research organisations. First, strategic research programming reflects the planning and securing uncertainties in the future, also to create a productive environment for the envisaged development of existing and new academic talent. Second, the reflexive capacity of many individual academics and partners in their innovative external networks lead to joint projects that stabilise in patterns of research project development, of projects that are challenging but also bundling forces based on excellence and relevance (for innovation). Third, the concerted efforts of distributed leadership activity in strategic planning and in joint project development stretch existing rules and regulations, sometime leading to new business model development. Leadership activity patterns in this key area include external relations management and fundraising as well as internal relations management to create openness for new approaches (in hrm and finance) and its embedding in procedures and structures in a research organisation.

These are key activities, sometimes stabilizing patterns of distributed leadership arrangements and spaces that I will present in the empirical cases; it concerns, what Pettigrew called temporal, interconnected trajectories of change (Pettigrew, 1990), and Parandian \& Robinson (2012) then took up in their analysis of stakeholder workshops as "stretches" of interconnection, and Blaschke, Frost \& Hattke (2014) empirically ground as "micro foundations, micro patterns oscillating with macro patterns cycles of change (Hattke et al, 2014).

\footnotetext{
${ }^{12}$ Similarly, Müller-Böling $(1998,2000)$ speaks of "Doppelte Legitimation" of for instance deans

${ }^{13}$ Kellog et al. (2006) present cases of structuring coordination across boundaries in post bureaucratic organisations in what they call "trading zones".

${ }^{14}$ Oborn et al. (2013) conducted research on distributed leadership in policy formation in the UK health sector, drawing at the sociomaterial perspective of Orlikowski, resulting in findings about leadership practices that engage across diverse stakeholders, enabling relations of trust and legitimacy (pp. 254).
}

Distributed academic leadership in emergent research organisations

2. Conceptual Framework 
These key activities do not exhaust everything that is happening in a research organisation in transformation. Halffman \& Hoppe speak of a "twilight zone of hybrid arrangements" in complex transformation processes (Hoppe, 2010). Nevertheless they are important for research organisations, in terms of work and in terms of formal and informal leadership practices. The presentation of the case material in the empirical chapters will be organised in terms of these three key activities as corner stones of episodes with their relative coherent development and, due to the contrasting dynamics that are at work, break and transition to a next episode, this way showing trajectories of change and leadership that encompass several episodes.

\subsection{The conceptual model}

In previous sections concepts from literature, as far as relevant for the theme of this thesis, have been introduced, stemming from a broad spectrum of scholarly fields: organisational change, change leadership, entrepreneurialism and ambidexterity. Also because literature on academic leadership practice was scarce, conceptual and empirical studies based on private sector studies were included as well, focusing on studies on knowledge intensive organisations.

This chapter allows me to put these concepts together, as such and as part of overall processual developments like emerging arrangements and their character. This is too complex to put into a simple model, but it is possible to take the key concepts, ambidexterity, entrepreneurialism and informal, emergent change leadership in an immediate organisational setting of leadership learning spaces and protected activity spaces, and put them together, first to create a conceptual framework for mapping the case studies, and subsequently (in the last chapters), to use it, with the advantage of the empirical findings and analysis, to show how it can be further developed.

\subsubsection{The overall design and interrelations of the conceptual model}

The overall perspective, and in a sense, proto-theory, of the multi-layered processes can be tentatively indicated here, partly building on concepts and understandings discussed in previous sections. Evolution of research organisations creates temporary constellations, more or less protected spaces of experimental leadership that sometimes evolve towards spaces of double loop learning, of joint reflection and anticipation. Protected spaces and sites of joint leadership activities that seem to stimulate leadership learning triggered by external challenges and by

Distributed academic leadership in emergent research organisations

2. Conceptual Framework 
internal contrasting dynamics and tensions. Spaces that offer a certain freedom to experiment, to retreat from the pressures of the market of from internal policy developments, without losing touch with the daily practice of academic work and innovative developments in the organisation of scientific work. In their practices in leadership, distributed leaders shape and follow paths, partially intentionally, connected to development of key activities as for instance joint strategic research programming. They also embark on certain career paths which requires them to plan and take learning steps. And they more or less collectively seize opportunities as these occur. This occurs in interaction with changing research organisations. Taking into account the contexts of research organisations as well, the net effect is a certain overall transformational pathway. There are contingencies involved, but also certain patterns because of their contexts, and because of the characteristics of distributed academic leadership. Thus, there might actually be typical pathways that recur across cases.

Distributed leadership activities in these emergent organisations are triggered by anticipative interventions aimed at temporary common interests, tuning of expectations and exchange of intelligence. These leadership interactions create informal learning spaces. Learning spaces that are connected with specific activity fields, temporarily protected by academic leaders in order to allow for experimenting and learning. Leadership learning sites that are not limited to these activity fields, as academic leaders in transformational settings act in different arenas, at different processual levels, internally and externally.

These organisational change dynamics and interactions in distributed leadership are the building blocks of the conceptual model as presented below (fig. 1).

First, there are the basic processes, the contrasting dynamics as they are analysed in the context of changing organisations interrelated with distributed leadership activities. Their contrasting characteristics, main developments in stabilising processes and the boundary spanning activities that were introduced in previous sections, are summarised in their interrelations in the next subsection (2.4.2).

These dynamics are captured by a set of six concepts that were introduced in previous sections. These interrelated concepts are positioned in the conceptual framework as two pies in dynamic setting (fig. 1, basic conceptual model). One pie represents the domain of distributed leadership, comprising three concepts (fig. 1.a, conceptual model arrangements) that help to understand

Distributed academic leadership in emergent research organisations

2. Conceptual Framework 
and analyse the contrasting dynamics of informal leadership (contrasted by formal, managerial coordination), of explorative entrepreneurialism (in a constant tension with exploitative, commercially oriented enterprising leadership), of contextual ambidextrous leadership (as opposed by formal, structure based ambidextrous task division). Their interrelated working is explained in subsection 2.4.3. The other pie (fig. 1.b, conceptual model learning spaces) represents concepts in the functional domain of leadership learning spaces. In subsection 2.4.4, three concepts that were introduced are described in their interrelated working, also in a tense relation with contrasting concepts: double loop leadership learning spaces (versus single loop learning activity spaces), emergent path development (versus dedicated path creation), open dynamising orientation (versus stabilising orientation).

Second, there are stabilizing patterns that are captured by three core concepts that were stepwise introduced and prepared in previous sections, concepts that help to understand and analyse arrangements and learning spaces of distributed leadership. These core concepts are presented in the conclusive paragraph of subsection 2.3.4, and visualised in the conceptual model as the third pie (fig. 1.c, conceptual model sites of distributed leadership and change).

Distributed academic leadership in emergent research organisations 


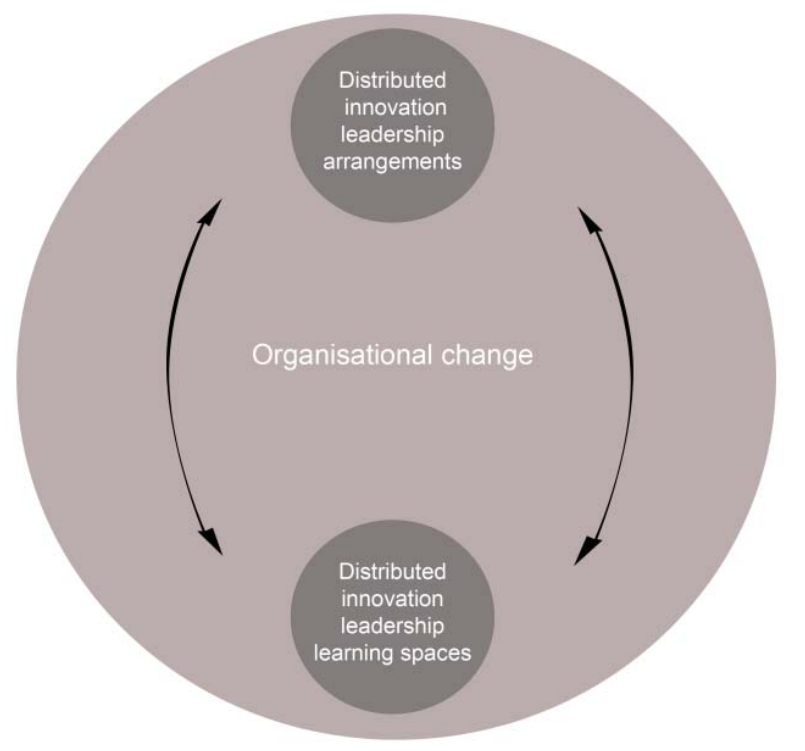

Fig. 1 Basic conceptual model

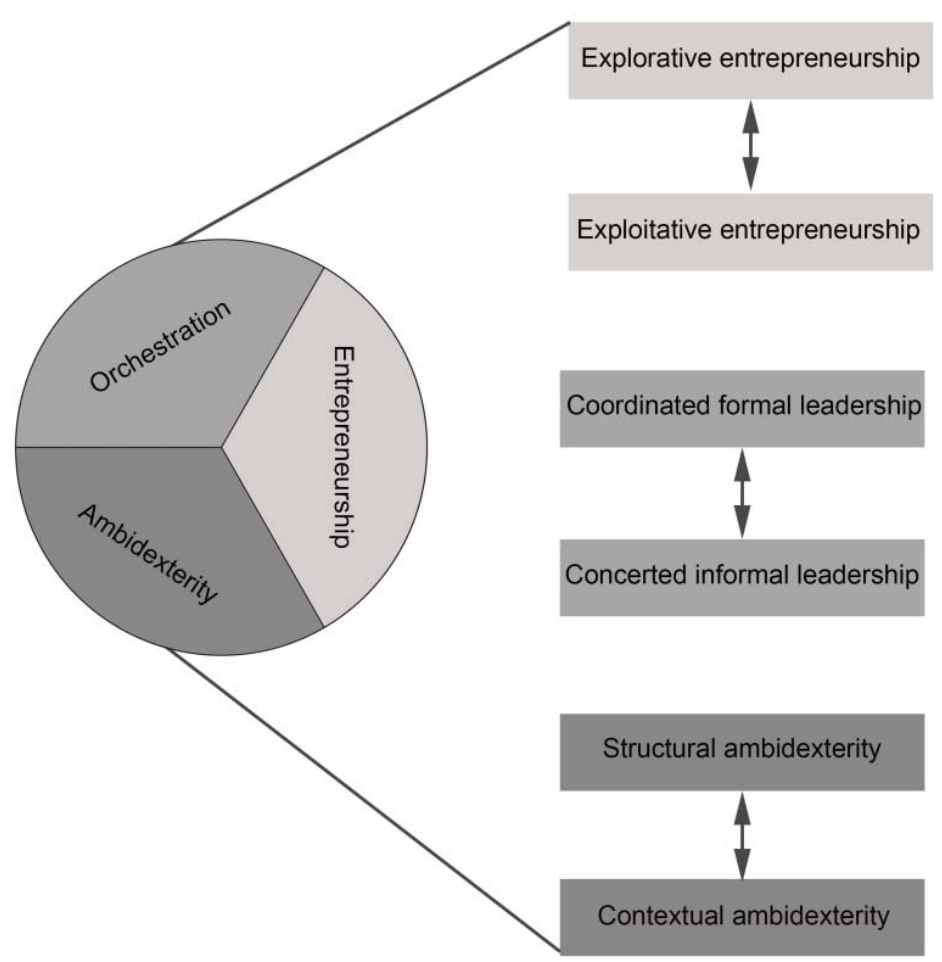

Fig. 1.a Conceptual model arrangements

Distributed academic leadership in emergent research organisations

2. Conceptual Framework 


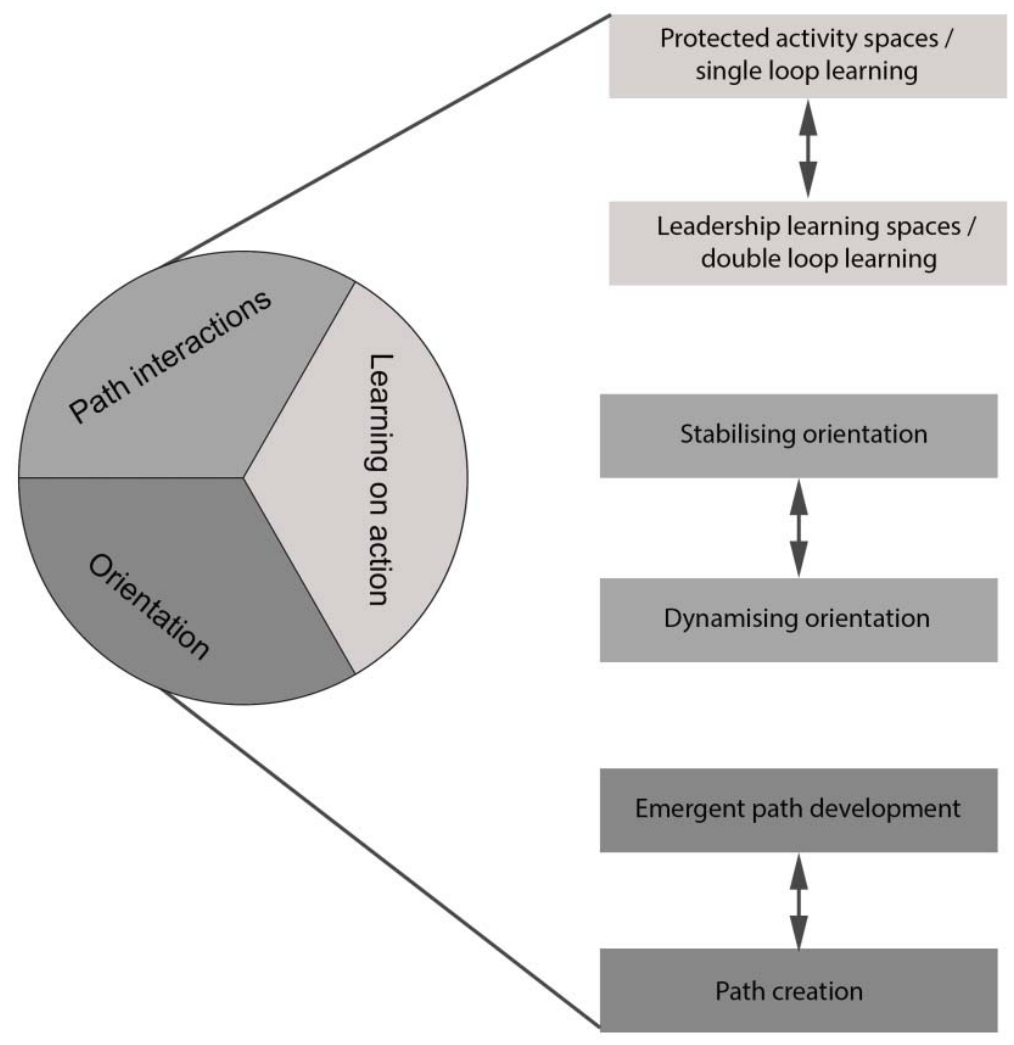

Fig. 1.b Conceptual model learning spaces

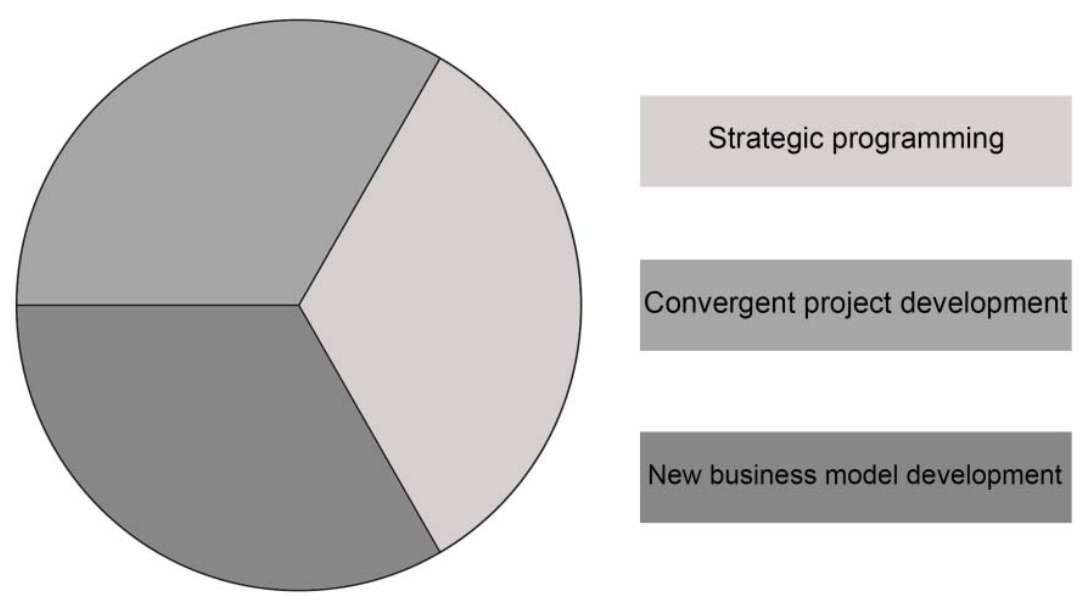

Fig. 1.c Conceptual model sites of distributed leadership and organisational change

Distributed academic leadership in emergent research organisations

2. Conceptual Framework 
It is in this perspective that I will first present the interrelated concepts that address processes of distributed leadership configurations and learning spaces, to be followed by an outline of the overall conceptual model.

\subsubsection{Contrasting dynamics in distributed leadership practice}

Research organisations in transformation feature contrasting dynamics, as becoming visible in for instance the contrasting orientations of exploration and exploitation of scientific knowledge. These and other dynamics are a challenge for distributed leadership and a driving force for boundary work, in order for leadership to direct an organisation and to anticipate or respond to contextual changes that are ambiguous.

In order to understand the contrasting dynamics that are at work in research organisations in transformation, notions and concepts of contrasting dynamics were introduced in previous sections. This allows me to conceptualise, here, interrelations between these concepts.

First, there are the underlying contrasting dynamics in leadership interaction addressed by the concepts of Quinn, Rohrbauch and Cameron, that were introduced in previous sections. Quinn \& Rohrbauch (1983), while focusing on "competing values", focused on analysis of personal skills of individual leaders. Later on, Cameron \& Quinn (2003) developed the competing values approach to suit the analysis of organisational change and leadership at an organisational level. These approaches are supported by visualisations of diagrams, showing in a two-dimensional space contrasting dimensions of internal/external focus and of flexibility/stability. Possible leadership responses are characterized in terms of roles which address different functions in an organisation, like human relations where flexibility is important versus internal processes where stability is important for controlling them.

My adaptation of the competing values model focuses on the leadership activity patterns of a distributed constellation of academic leaders.

Second, there are stabilizing patterns of leadership interactions that show as two main developments in emergent research organisations.

One major development concerns the increasing external orientation of research organisations and challenges for leadership, contrasting with an enhanced focus on quality and productivity

Distributed academic leadership in emergent research organisations

2. Conceptual Framework 
management. Another main development is the increased opening of research organisations and diffusion of boundaries, contrasting with an enhanced management and leadership challenge for long term strategic planning, marketing and management.

These stabilizing patterns interlink with boundary work, in particular leadership boundary work activities, showing as key distributed leadership activities, sometimes occurring as arrangements and spaces; concepts that in their interrelation will be introduced in the next subsections.

In elaborating these two concepts, I refer to Schön (1983) when viewing academics who conduct leadership tasks as "professionals who reflect in action". In developing and conducting leadership tasks, they collectively, often in spontaneous, informal, settings reflect on new and expected situations that they, more or less jointly, have to deal with in terms of leadership interventions. In communication and interactions in distributed leadership configurations, notions crystallize: words that are often quite informal, but tend to have a major impact on the appreciation of situations, challenges and changes to develop joint actions. It is this process that Schön, describes as "naming". In this process of "naming" in distributed leadership configurations, the notions of "arrangements" and "spaces" are articulated by actors and become visible for the eye of the academic analyst, as I will detail in Ch. 3 . In preparing the conceptual framework for the empirical casework, here, I will elaborate the two concepts, keeping in mind that these are concepts that build on literature, but are oriented at the actual process of "naming" in the academic distributed leadership practice ${ }^{15}$.

\subsubsection{Stabilising patterns in academic distributed leadership}

In the previous subsection, the interrelated concepts that help in understanding contrasting dynamics were explained. Here, I introduce the interlinks between the three concepts that address the stabilising patterns in contrasting dynamics in distributed leadership practices. These concepts were chosen in order to address core aspects of dynamics and stabilising patterns in distributed leadership, and to reduce complexity.

First, the concept of "academic entrepreneurialism". Labelled as "explorative entrepreneurial leadership", characterised as "academic leadership activities that balance the contrasting

\footnotetext{
${ }^{15}$ Referring to my own journey as a researcher (as will be detailed in Ch. 3.2), the conceptual model that I offer here reflects the synergy between reflexive experience and literature findings and insights.
}

Distributed academic leadership in emergent research organisations

2. Conceptual Framework 
dynamics of crossing the internal boundaries of the research organisation and external boundaries". As opposed to the concept of "exploitative entrepreneurialism" that is directed as commercialisation of scientific knowledge, creation of practices and structures for knowledge dissemination, science parks etc. Examples of "internal boundaries" are not written common senses, processes, procedures and structures within the hosting university, crossing external boundaries concerns for example submitting multi-disciplinary proposals to disciplinary oriented research funding organisations, arranging pre-competitive projects with competing firms that each co-operate with the same CER on a singular basis.

Second, the concept of "ambidexterity". "Contextual ambidextrous leadership" is characterised as "academic leadership activities focused at changes in organisational culture that balance contrasting dynamics of exploration and exploitation, in alignment with the contextual changes". As opposed to the notion of "structural ambidexterity" that addresses functional divisions and structural relations between contrasting domains of leadership orientation.

Third, the concept of "informal leadership". The concept of "concerted informal distributed leadership" addresses patterns of interrelated activities, based on the logical assumption that academics tend to step forward as leaders driven by dynamics of reputation and interest, acknowledging that it is necessary to initiate or join in temporary coalitions beyond the level of, and sometimes even the immediate interest of, their own research group, in order to reach a joint ambition. The notion is opposed to "formal coordinative leadership" that aims at activities of transaction leadership, in using formalised power and interventions to steer and control for example quality of scientific work.

Together, these concepts constitute a conceptual model to investigate and understand distributed innovation leadership in a setting of contrasting dynamics. Informal leadership is exposed by academics who do not limit themselves to their formal tasks, but seek for new approaches and ways of working. In a concerted way, based on informal interactions, as they see that this is necessary to avoid the pitfall of taking solitary roads that lead to nowhere, to join forces in order to realise (temporary) shared ambitions. In doing so, they go beyond written and tacit rules and procedures, creating 'internal venturing' forms of research organisation that support them to seize opportunities in opening up research programmes and public-private constellations. Balancing the contrasting orientations of exploration and exploitation of the research organisation gets increasingly under pressure once growth in leadership activities

Distributed academic leadership in emergent research organisations

2. Conceptual Framework 
occurs, requiring contextual ambidextrous leadership interventions that re-align internal processes with developments and changes in the immediate internal (university) setting and the wider external context.

\subsubsection{Spaces in emergent research organisations}

The contrasting dynamics and patterns in distributed leadership practice interact with spaces of leadership activity and leadership learning. In order to understand interactions, concepts are required that fit in with the interrelated concepts that were presented to understand contrasting dynamics and patterns in leadership practice. Three concepts were chosen from literature that address the contrasting dynamics in distributed leadership spaces, the choice of these concepts has been introduced in previous sections. To illustrate the contrasting characteristics, each aspect is presented related to its opposite.

First, "double loop leadership learning spaces" " are characterised as "professional spaces allowing for experimental role development and double loop learning, while experimenting with new ways of research organisation, following the dynamics of "protected activity spaces". As opposed to single loop learning within these protected spaces, oriented at improved approaches in specific areas. In practice, where this approach becomes the dominant leadership practice, incremental improvement of processes in order to raise efficiency, leading to successful learning of skills and gathering expertise that can be immediately made effective, often obstructs more radical redesigns and innovations of processes.

Second, "emergent path development" is characterised as "a pattern of boundary work in spaces of distributed leadership interactions between layered processes in a networked research organisation, interlinked with contrasting dynamics in the immediate context of the research organisation". As opposed to path creation, representing dedicated, often formalised alliances of leaders. Where path creation becomes the mainstream distributed leadership practice, for instance to make optimal use of new, capital intensive research apparatus, this may lead to closure and less leadership attention for creating adventurous bonds with for instance initiatives on a strategic level.

Third, a "dynamising orientation" characterised by an open and forward looking orientation of distributed leadership activity spaces, aiming at anticipation in order to seize opening opportunities. As opposed to a stabilising orientation, characterised by inward looking, closed

Distributed academic leadership in emergent research organisations

2. Conceptual Framework 
spaces, aiming a consolidation of knowledge and assets. Clear examples and tedious challenges for academic distributed leadership in this aspect can be found in hrm policy. Where stabilisation and aiming at long term consolidation of knowledge is the mainstream focus of leadership, then an open orientation embodied in international mobility of young researchers, timesharing in temporary research communities and open invitations for temporary open research assignments that would challenge the focus and direction of a research group's orientation, might be frustrated.

These spaces become visible in stabilizing patterns, sometimes in "distributed leadership learning spaces". Conceptually, it is assumed that protected activity spaces interact with boundary spanning leadership activities that in turn, due to the dissonance that occurs while spanning of two or more functional domains of leadership, create leadership learning spaces. Boundary spanning is challenging, as it includes protected spaces that occur at different process layers, for instance operational and tactical. It is extra challenging, as its scope, once a research organisation growths, will comprise internal as well as external protected spaces, for example covering a multi-party consortium.

It is expected that these learning spaces show a dynamic and open orientation, externally interlinked with an overall emergent path development that is driven by dynamics at a larger, contextual scale, and internally driven by double loop learning as a result of the collective reflection of academic leaders triggered by the dissonance between expected and real occurrences of change and leadership.

\subsubsection{Further use of the conceptual model}

While taking into account the risk that a conceptual model simplifies actual complexity of distributed leadership in emergent research organisations, I took the possibility to put the key concepts together in a conceptual framework for mapping the case studies, and finally, to use it, with the advantage of the empirical findings and analysis, to show how it can be further developed, as part of current leadership and organisational change research, also in other areas than higher education.

Distributed academic leadership in emergent research organisations 2. Conceptual Framework 


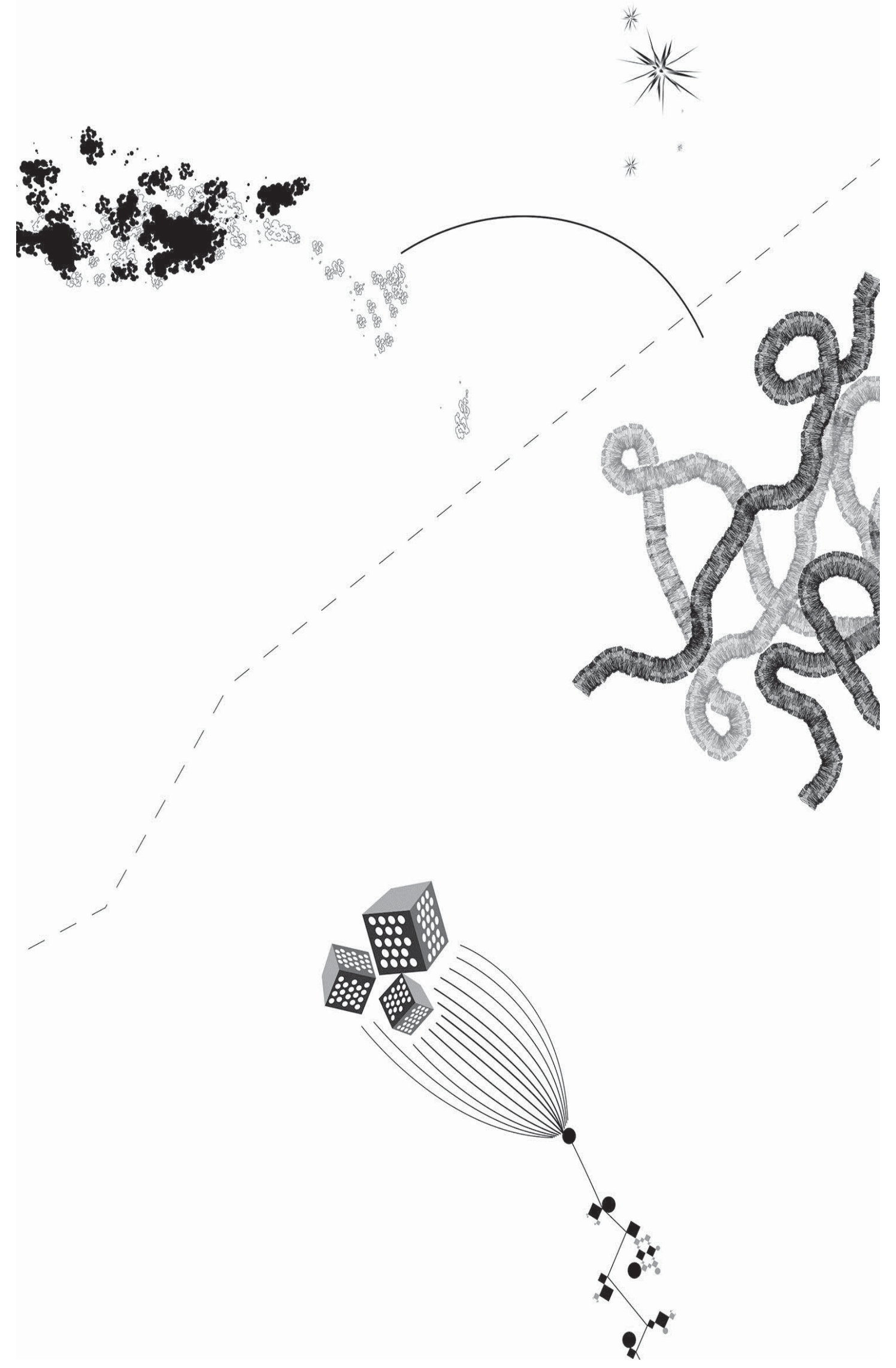




\section{Research Design}

\section{Contents}

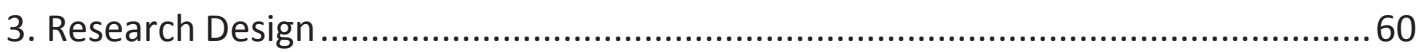

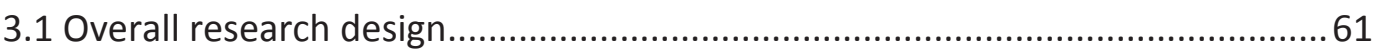

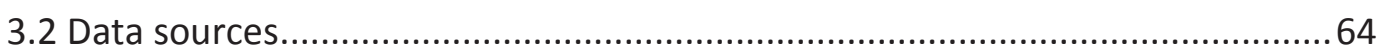

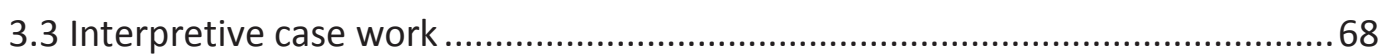

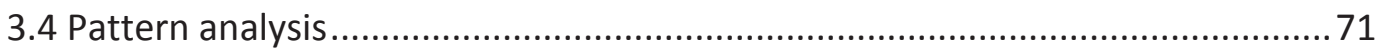

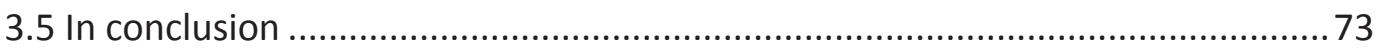

Distributed academic leadership in emergent research organisations 


\subsection{Overall research design}

As indicated in Ch. 1, and developed further in Ch. 2, the key step in addressing my overall question about distributed leadership in interaction with organisational change is to take what I have called 'Centres of Excellence and Relevance' (CER), as sites where one sees distributed leadership in action ${ }^{16}$.

The advantage of this choice is that there is a tradition of studies on bottom-up and distributed leadership in research, and since research organisations have to come to terms with the changing research and innovation landscape (see Ch. 2), one will definitely see responses to change, and can trace some outcomes (like leadership arrangements).

This advantage introduces a disadvantage, however: the choice to take CERs as the site of empirical study may be seen as choosing an extreme case, showing major organisational changes. While this is correct, choosing an extreme case can be a productive research strategy if one can then see interesting interactions and patterns (Pettigrew, 1990, pp. 275-276). This is definitely the case here, as has become clear in Ch. 2. The additional consideration which I noted in Chapter 1 is that research organisations in transformation are an interesting topic anyway, and that not much empirical work has been done on them.

The next step then is to select cases of CERs for in-depth study. I have chosen three cases related to the University of Twente, for which I had privileged access because of my involvement with them in earlier phases of my career. ${ }^{17}$ In Section 3.2 I address the question of creating the necessary distance.

I will briefly describe the three cases, and then conclude by indicating the background approach to tracing processes and outcomes, using Pettigrew's characterizations.

\footnotetext{
16 "Centre of Excellence and Relevance (CER) is, as introduced in Ch. 2, my analyst's term to indicate the new species in the research and innovation landscape; actors in my cases continue to use the term 'institute', but it is not the traditional research institute anymore.

${ }^{17} \mathrm{My}$ involvement as an advisor at a central policy level and in research institutes, gave me insights in the multi-level and longitudinal practices of leadership and governance of a university in transformation. Later on, it allowed direct access to archives of the research institutes and to resource persons - academics who had leadership roles at the time - who were willing to be interviewed during the systematic study of the three cases and their interpretation.
}

Distributed academic leadership in emergent research organisations

3. Research Design 
In the period of study, $1990-2005$, the University of Twente was a university in transformation, internationally acknowledged as an "entrepreneurial university" (cf. Clark 1996). The three research organisations selected are instances of the new species of centres of excellence and relevance, and offer good examples of academic leadership and transformative spaces in interaction with organisational change.

First, MESA, later on merged with CMO (an institute for materials science) and renamed MESA+, working in materials science and nanotechnology. In the early 1990s, MESA was a new start, in the sense that it was the first big research institute to be established at the University of Twente. It could build on existing collaboration among core groups that had built leadership experience with Dutch industry and at the European level. The context of business stakeholders was transparent and relatively stable. MESA's academics exploited the opportunities that the structures of University of Twente offered at the time, but also tried to make a difference.

CTIT and Telematica Instituut (TI) both worked in the domain of ICT. CTIT being a university-wide research organisation, and TI a so-called "Leading Technological Institute", a national research organisation launched at and initially hosted by the University of Twente.

CTIT started on the basis of an interfaculty research group that had already built distributed leadership experience in European projects with industrial partners. CTIT's academic leaders used the opportunity that the University of Twente's research policy framework at the time allowed: in their twinning relation with the national Telematica Instituut and industrial partners, they constructed their own organisational spaces. These spaces were closely linked to an external context of quite diverse business stakeholders.

The third case, the Telematics Research Centre, later the Telematica Instituut, started from scratch. At first, it relied on a dedicated group of companies and knowledge institutions that were instrumental in articulating a framework for joint leadership action. Later, reshaped as a national "Leading Technological Institute", it expanded into a distributed network of a range of diverse companies and knowledge institutions.

A more detailed introduction to each of the cases is presented in chapters 4,5 and 6 , respectively.

Distributed academic leadership in emergent research organisations

3. Research Design 
While case studies are important to capture the complexity, as Yin (2003) has emphasized, ${ }^{18}$ and allow identification of patterns in the processes, which can then be further articulated by comparisons across cases, there is more to say.

The importance of longitudinal, processual and contextual studies has been demonstrated (Pettigrew, 1990). Based on a wide variety of studies, Pettigrew argues that "the overall research challenge is to link the content, contexts, and processes of change over time to explain the differential achievements of change objectives". And he adds that "an approach that offers both multilevel or vertical analysis and processual, or horizontal, analysis is said to be contextualist in character". It is worth quoting Pettigrew (1990) at some length, particularly in relation to his advice on theory and practice of "contextualism" (pp. 268-270).

- “(...) target changes should be studied in the context of changes at other levels of analysis. (..) a source of change is the asymmetries between levels of context, where processes at different levels of analysis are often observed to have their own momentum, rates, pace and trajectory. (...) equally well, an analyst of change has to recognise that activities at some levels of context may be more visible and rapid than at other levels, and thus in the shortterm sources of change may appear unidirectional, while in the longer term a multidirectional pattern may appear."

- “(...) temporal interconnectedness. (...) However, history is to be understood not just as events and chronology; there may be deeper pathways if the analyst searches for structures and underlying logics. But in the search for deeper structures beware of the dangers of determinism. Our approach makes no assumption of predetermined timetables, of ordered and inevitable sequences or stages. Trajectories of change are probabilistic and uncertain because of changing contexts."

- “(...) the role of context and action. (...) processes are both constrained by contexts and shape contexts, either in the direction of preserving or altering them. (...) an attempt is being made to combine these two forms of description and analysis. First of all by conceptualising structure and context not just as a barrier to action but as essentially involved in its production and second by demonstrating how aspects of structure and

\footnotetext{
${ }^{18}$ Yin (2003) offers requirements for the presentation of an "exemplary case study". A high qualitative case study has to be significant, complete, consider alternative perspectives, display sufficient evidence, and be composed in an engaging manner.
}

Distributed academic leadership in emergent research organisations

3. Research Design 
context are mobilized by actors and groups as they seek to obtain outcomes important to them."

- “(...) holistic and multifaceted treatment of change (...). Changes have multiple causes and are to be explained more by loops than lines. (...) the real issue explaining relative competitive performance was (...) by the convergent interactions and interconnected loops among these (...) features, in the firm over time."

- "Time: to what extent have there been development of new roles, new working practices and attitudes?"

These general considerations imply requirements for the three case studies that follow:

- They must be significant, complete, consider alternative perspectives, display sufficient evidence, and be composed in an engaging manner (cf. Yin's (2003) requirements);

- They must cover micro- and meso-levels of organisational development and change, and analyse the interrelations and asymmetry between these levels (as sources of change);

- They must describe a temporal interconnectedness, not as a historical, but as an analytical story, focusing on patterns, evolving structures and pathways.

\subsection{Data sources}

The main sources of data are public documents, archival documents (of the research organisations involved and of the Central Board of the University of Twente), retrospective interviews with leading academics that were (and sometimes still are) participating in the research institutes studied, and my own participant observations during the years 1988 till 2006. Together, they allowed me to reconstruct the histories, and interpret processes with their dynamics and patterns. The historical reconstruction is relatively straightforward. In the next section (3.3), I will discuss the interpretive approach to be taken. In this section, I will discuss the data sources, in particular the status of my participant observations, and in general, the element of reflexive interpretation involved in my construction and use of the data. The latter is important for the understanding of what happened, but has to be done carefully to avoid pitfalls of biased projections. To let the reader see where I stood as a participant observer, and later, as an analyst, I have included an extended autobiographical note. I do more than just noting the

Distributed academic leadership in emergent research organisations

3. Research Design 
positions I held over time, which is usual in academic writing. But it is important also because it indicates that reflexive interpretation was occurring all along.

The in-depth interviews are conducted with more than thirty senior academics who performed leadership roles of scientific director, business manager, programme director, or project leader. They all knew me, or knew of me, from my earlier work in the University of Twente and in the Telematics Institute (see the box about my career, below), so there was reflexive interaction. By the time of the interviews, I could draw on my document study and archival work to anchor the interviewees and make sure we did more than joint reminiscing. Some interviewees were still involved in the work of their research institute, so that the interview occasionally turned into a discussion of present opportunities and challenges.

My own observations as a participant at the time are important as a data source, even if there is the risk of them being individual and subjective recollections. Below, in the Box, I will present my journey through various relevant institutions, to indicate what I could observe and how I participated. Structuring of my observations to ensure validity occurred in a number of ways. There were work documents and reflexive notes that I made at the time, ${ }^{19}$ which provided primary data. I had access to the archives of the research institutes. One of my supervisors (Arie Rip) interviewed me at length about my experiences, thus turning me into a resource person for my own study. In addition, two of my supervisors (Arie Rip and Olaf Fisscher), knowledgeable about the University of Twente, and to some extent about the three research organisations that were studied, regularly interpellated me about my interpretative writing-up of the case studies, partly based on their own observations at the time.

Finally, there were reflexive discussions with academics and staff colleagues. Already earlier, in addition to my regular work (cf. Box), I used opportunities to initiate dialogues with academic colleagues, and wrote these up as reflexive notes. The interviews in the later phase of dedicated data collection turned out to be occasions for reflexive discussion as well.

\footnotetext{
${ }^{19}$ This way of working evolved from my reflexive nature as an academic and professional, but also because most of my assignments that had a dual nature: not only content or result oriented, but also process oriented, for instance as a co-quartermaster of new interfaculty research institutes. In that perspective, I acted as an action researcher afterthe-fact (Boonstra, 2000). The traces of these assignments are work documents in a variety of forms, ranging from policy advises, evaluation reports up to discussion memos.
}

Distributed academic leadership in emergent research organisations

3. Research Design 
The upshot is that I can offer a picture of what happened and how one can interpret the processes and outcomes that is robust, even if the inputs into that picture cannot always detailed.

\section{Box: An autobiographical note:}

In 1988, I entered the academic world as an adviser and policy researcher. By then, I had lived in, and lived with, the system for about ten years, as a student and later on as staff member of a foundation that worked on a daily basis with universities and polytechnics. During those ten years, I had learned to reflect, in the hard way. My steep learning curve was occasioned by the national foundation that conducted project-based technology transfer between knowledge partners in The Netherlands and in developing countries. Development and implementation of "appropriate technologies" was the name of the game in those days. "Appropriate" meant "socially appropriate", supporting those groups in society that were striving for emancipation and democratization. In a twist of fate, I joined the University of Twente. This university had just decided to position itself as the "entrepreneurial university". As an actor in the academic system, I advised and assisted three subsequent rectorates as well as leading academics in research organisations. This position can be interpreted as that of a "bureaucrat of change" (Clark, 2000), as it was a pioneering position, working on new initiatives for strategic research alliances and establishing research organisations on a new, interfaculty, basis. This working context allowed me to actively reflect on my experiences and observations. This was an opportunity to build reflection into my work and use it for meta-reflections to improve policy formation and implementation. Such reflexive action, also in my later work at the University of Dortmund and in the Telematica Instituut, made me an "observing participant" already before I considered writing a PhD thesis on this theme.

\section{$1988-1992$ (University of Twente)}

Exposure to transformation and academic leadership

Policy advisory work, organisational design and implementation of research institutes. Work with leading academics on planning documents (when seconded to research institutes in their nascent phase). Thus, a dual position, advisor to the rectorate as well as to scientific directors, programme leaders and deans.

Distributed academic leadership in emergent research organisations 
$1992-2000$ (University of Twente)

Field work, reflecting, diagnosing

Working with academics on strategy development and new organisational set-ups (research institutes, international co-operation programmes, international study programmes)

$2000-2003$ (University of Dortmund)

Deepening/broadening the reflection, in a Dutch-German context; advising the Rektorat and again also working with academics on strategy development and new organisational set ups (international co-operation programmes, international study programmes, Forschungsbänder) Work visits (interviewing leading academics and managers) to Scotland (Strathclyde), Denmark (Aalborg), Spain (Barcelona) and South Africa (Pretoria)

Preparing the theoretical/interpretative case writing, initial archive work, literature study, when preparing a web survey amongst (Dortmunder) professors about academic leadership that had to be cancelled because of limited response.

\section{$2003-2006$ (University of Twente, Telematica Instituut)}

In parallel, preparing for a cross case analysis, primarily in discussion with supervisor Arie Rip, and also with peers within the Telematica Instituut with an organisation research or knowledge management background.

Continuing the reflection and casework, at the time primarily on the Telematica Instituut.

\section{$2006-2013$ (BMC Management Consulting Group)}

Dedicated data collection and analysis, writing up the cases and checking further points with interviewees and archives. Pursuing reflection in dialogue with supervisors Arie Rip, Olaf Fisscher, at a later stage also Stefan Kuhlmann, and with peers in the field of change management within the BMC Group.

This trajectory was also a learning experience. In interacting with, and often supporting, distributed academic leadership, I was also reflecting on this phenomenon and the role it played in research organisations in transformation. Over the last ten years, I mobilized more and more relevant literature that helped me to get a handle on what I had been observing and reflecting

Distributed academic leadership in emergent research organisations

3. Research Design 
on (cf. Ch. 2). The conceptual model that I offered in Ch. 2.4, thus reflects the synergy between reflexive experience and literature findings and insights.

\subsection{Interpretive case work}

There are two elements in the next step, i.e. the step from data sources to the writing up of the cases. First, there is interpretive reading (in the broad sense) of documents and other texts in their contexts, sensitized by the concepts presented in Ch. 2. For example, the analyst as reader will ask: "do I see distributed leadership here?" or "Is this a case of ambidexterity?"20 I note that not all components of the conceptual model will be taken up systematically. ${ }^{21}$ The conceptual model is too rich to trace all the elements empirically. The interpretative reading is combined with articulation in writing (in the broad sense): writing up (as well as thinking through) what may be seen in the data, and then check for validity (e.g. by cross-checking and triangulation) and for plausibility. Such writing (in the broad sense) is actually one side of the coin of interpretive analysis, the other side being reading (in the broad sense).

The second element is the structuring of the case study texts, what is often called the protocol for the case studies: what has to be included, and which aspects should be highlighted? This has implications for data collection, of course. But often, the data collection produces more material than can be reported. Then, the protocol will guide the selection of what to include in the case study text. The protocol will of course draw on the conceptual model (Ch. 2) - selectively, because as I noted already, the model is too rich to be taken up in all its aspects in the empirical study. A choice was made to keep close to the specifics of research organisations in the age of strategic science, rather than impose general features of distributed leadership to structure the case studies. This choice is further justified by the importance of offering reconstructions of the emergence of Centres of Excellence and Relevance. Key activities of such research organisations (cf. Ch. 2) are actually the sites where distributed leadership activities come into play, and may lead to arrangements that stabilize over time. Thus, there are good reasons to structure the protocol in terms of the three key activities in such research organisations. This will also support longitudinal analysis, because there is now a focus over time: what is happening on these sites

\footnotetext{
${ }^{20}$ This is analysis (and diagnosis) in the form of 'naming' (cf. Schön 1983)

${ }^{21}$ As was explained in Ch. 2, the conceptual model is presented as a result of this thesis research in its own right. In the analysis of the empirical case studies, the core components of leadership arrangements and of the leadership learning spaces were applied.
}

Distributed academic leadership in emergent research organisations

3. Research Design 
(the three key activities), and how does it change from one episode in the development to another.

\section{'Reading' and 'writing'}

The data collected from the retrospective interviews will be taken as an important dataset (while recognizing the risks of bias, which I mitigate by confronting interviewees with recollections from others and with data from archives). The recordings of the interviews are to be listened to at least three times each, and transcripts of key parts have to be made. The key observations will be ordered and systematised around common issues and subsequently compared between different interviewees. The stabilized observations are the building blocks for the three episodes in the development of the research institute (the demarcation of these episodes is indicated below).

The key observations will be collated with my notes from the time that I was participant observer in one or another of the institutes, and with the impressions of one of my supervisors (Arie Rip) from listening to the recordings of the interviews.

The key observations from the interviews will be confronted with data and figures and observations as available in the archival sources. An extensive archive study will be conducted. Because of my previous positions in the research institutes that are studied, I was given access to the public archives of the Central Board, and to the archives of the three institutes. This comprises formal and structured archives of for instance the institute's board meetings, as well as the more informal, only partially structured archives of committees and workgroups. The archival research will thus require document analysis, analysis of strings of notes and letters, search for missing sources, and interpolation when putting the data together in summaries.

Finally, during the writing up of the cases, the interpretations are appraised by the supervisors.

\section{Periodization and pattern recognition}

Processes of interactions, the patterns in them, and emerging and stabilizing arrangements create their own periodization (for example, when certain arrangements continue in a more or less stable manner), in interaction with external events. This can be reconstructed, and as it turned out, the periods coincided roughly with the five year terms of mandate of the scientific

Distributed academic leadership in emergent research organisations 
directors (in the cases of MESA+ and CTIT) and with external interventions (in the case of Telematica Instituuut).

The analysis of patterns in distributed leadership activity over time is focused by considering key activities of research organisations as sites. Three key activities were identified (Ch. 2): first, strategic research programming, second, joint projects that stabilise in patterns of research project development, and third concerted efforts that lead to new business model development. For each of the key activities in each of the episodes in the case studies I will trace how distributed leadership activities occur and may add up to certain patterns, and use the concepts of my conceptual model (see Section 2.4) to identify the actual contrasting dynamics. One could go into more detail about leadership activities. In fact, Bolden et al (2008), building on Spillane's work have offered a useful sketch how this may add up, that I have elaborated (Fig. 2).

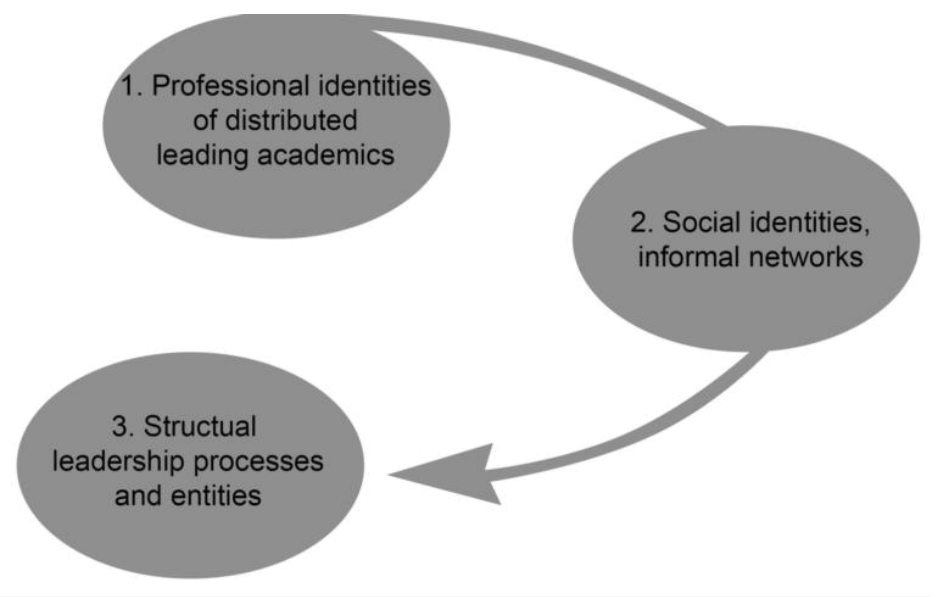

Fig. 2 Stabilising patterns of distributed leadership interaction

Academics as leading members of a research organisation start out on their own, as leaders of their projects and groups, and having occasional interactions in formal settings. Even then, there will already be informal interactions. Then, informal networks and social identities grow, linked to clusters of projects and visible in joint themes and programmes. Eventually, more structured processes and new organisational entities may be established.

While I have occasional data and observations speaking to these processes, I cannot reconstruct them systematically. This sketch does inform my interpretation of what was happening.

The reconstruction of distributed leadership activity is located by a multi-layer process model. The four layered distributed leadership processes of a CER are depicted in Figure 3. Included in

Distributed academic leadership in emergent research organisations

3. Research Design 
the Figure are the key activities of research organisations in the era of Strategic Science which I identified as sites to study distributed academic leadership.

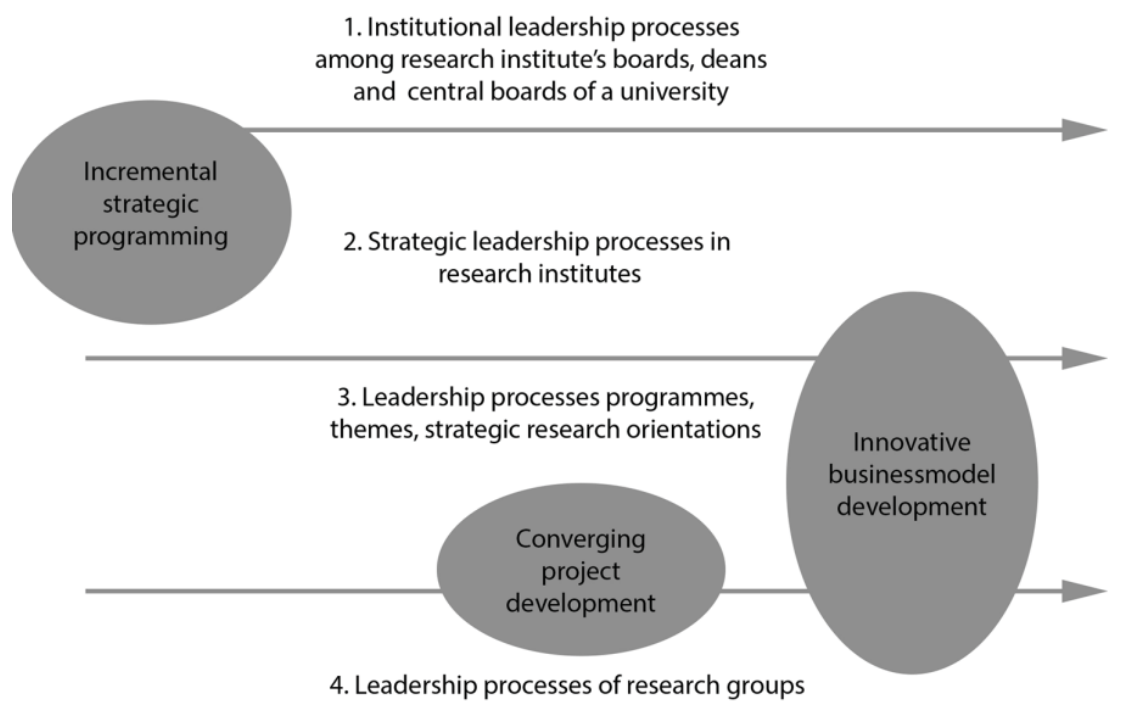

Fig. 3 Leadership key activities layered processes model

Research programming is mainly located in the strategic process layer. Project development takes place on a tactical process layer, and includes more or less effective development of overarching projects that create new alignments among research groups. There is a link with strategy, because project development and research programming are a de facto pattern strategy (Mintzberg, 1994). Of course, sometimes elements of explicit strategy are implemented. The key activity of "business model development" crosses all process layers, combining elements of structure, human resource management, and finance.

\subsection{Pattern analysis}

The further pattern analysis is focused at dominant, sometimes stabilizing, patterns and on contrasting dynamics in these patterns of distributed leadership practice. This pattern analysis is supported by the 'contrasting dynamics in distributed leadership interactions' diagram, as depicted below in fig. 4 .

Distributed academic leadership in emergent research organisations 3. Research Design 


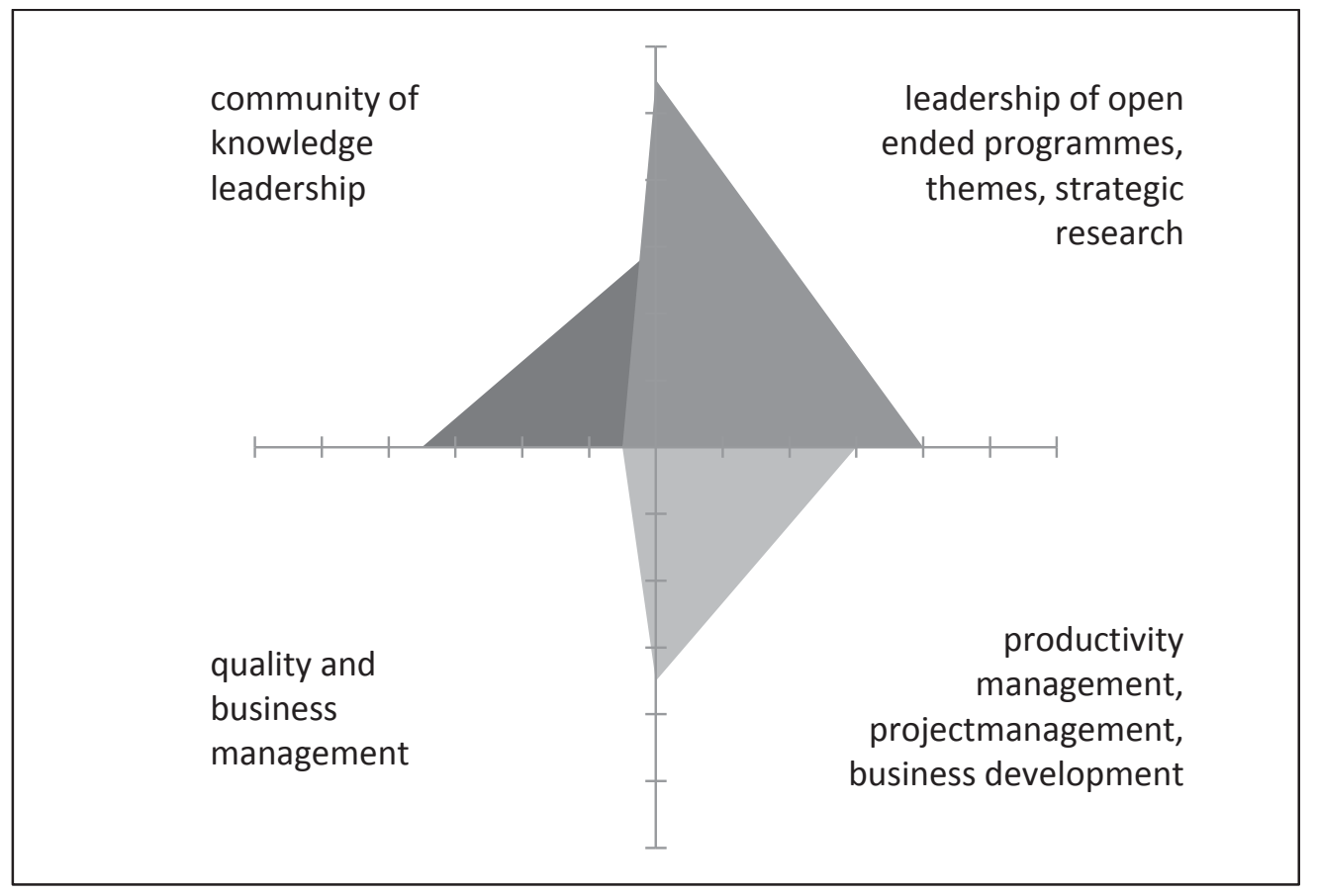

Fig. 4 The contrasting dynamics model

This diagram supports the analyst as a mapping tool, to register dominant patterns and the contrasting dynamics in it. The connected concepts, comprised in the conceptual model (Ch. 2.4), are applied in the pattern analysis. As stated, the conceptual model is richer than could be applied in the empirical cases. Thus, in the concluding section of each case chapter (chapters 4, 5 and 6), I will assess in how far the concepts could be applied, and what their connection brought about in the case analysis. These assessments will be taken together while presenting the conceptual model as a research results in its own right.

Patterns can be mapped on the contrasting dynamics diagram and on the layered distributed leadership process model, resulting in a string of maps that show longitudinal patterns. The background to the concept of longitudinal patterns in key activities of distributed leadership has been introduced (Ch. 2.3.4) as characteristic for research organisations in transformation:

- In research programming, leadership activities occur on the edge of the quadrants, i.e. leadership domains, of knowledge leadership and innovation oriented leadership activities. Reflecting the development of multi-annual and often multi-partner research programmes, in a stepwise, incremental manner, as an emergent research strategy, resulting from interactions with stakeholders in programmatic consortia. Incremental

Distributed academic leadership in emergent research organisations 3. Research Design 
strategic programming arrangements reflect the need to plan and secure the future also for the envisaged development of existing and new talent.

- In research project development, leadership activities appear on the edge of effectiveness driven leadership activities (e.g. research project management) and control driven quality management procedures which for academic work rely on peer evaluation as in visitations and refereed journals. Converging project development is a concerted leadership activity on the edge of human relations and innovation of projects that are challenging but also bundling forces based on excellence and relevance (for innovation).

- In business model development: as an outcome and driving factor of the dynamic interaction in both sites as previously described, becoming visible in stabilizing patterns of leadership activities in financial, human resource management and overall governance approaches. Innovative business model development in turn translates the impact of innovative work to enhanced productivity of the research organisation. Leadership activity patterns include external relations management and fundraising as well as internal relations management to create openness for new approaches and its embedding in procedures and structures in a research organisation.

These three do not cover all types of stabilizing patterns, but are a heuristic entrance point into structuring and presenting the case study material, and allow me to recognize longitudinal patterns that sometimes stabilize in trajectories of distributed leadership arrangements and spaces.

\subsection{In conclusion}

In the presentation of the cases in Chapters 4, 5 and 6, the three sites of distributed leadership practices will be used as sub-headings for the reconstruction of relevant actions and interactions and the patterns in them. The various interactions between the layers are visible in the reconstruction, but will not be thematised separately.

The emphasis, is on telling the story of distributed leadership and patterns in them, recognizing the complexities and contingencies, rather than always putting the elements of the analytical model upfront. In Chapters 7 and 8, however, this will be done, offering analysis in their terms and presenting findings based on this analysis.

Distributed academic leadership in emergent research organisations 3. Research Design 


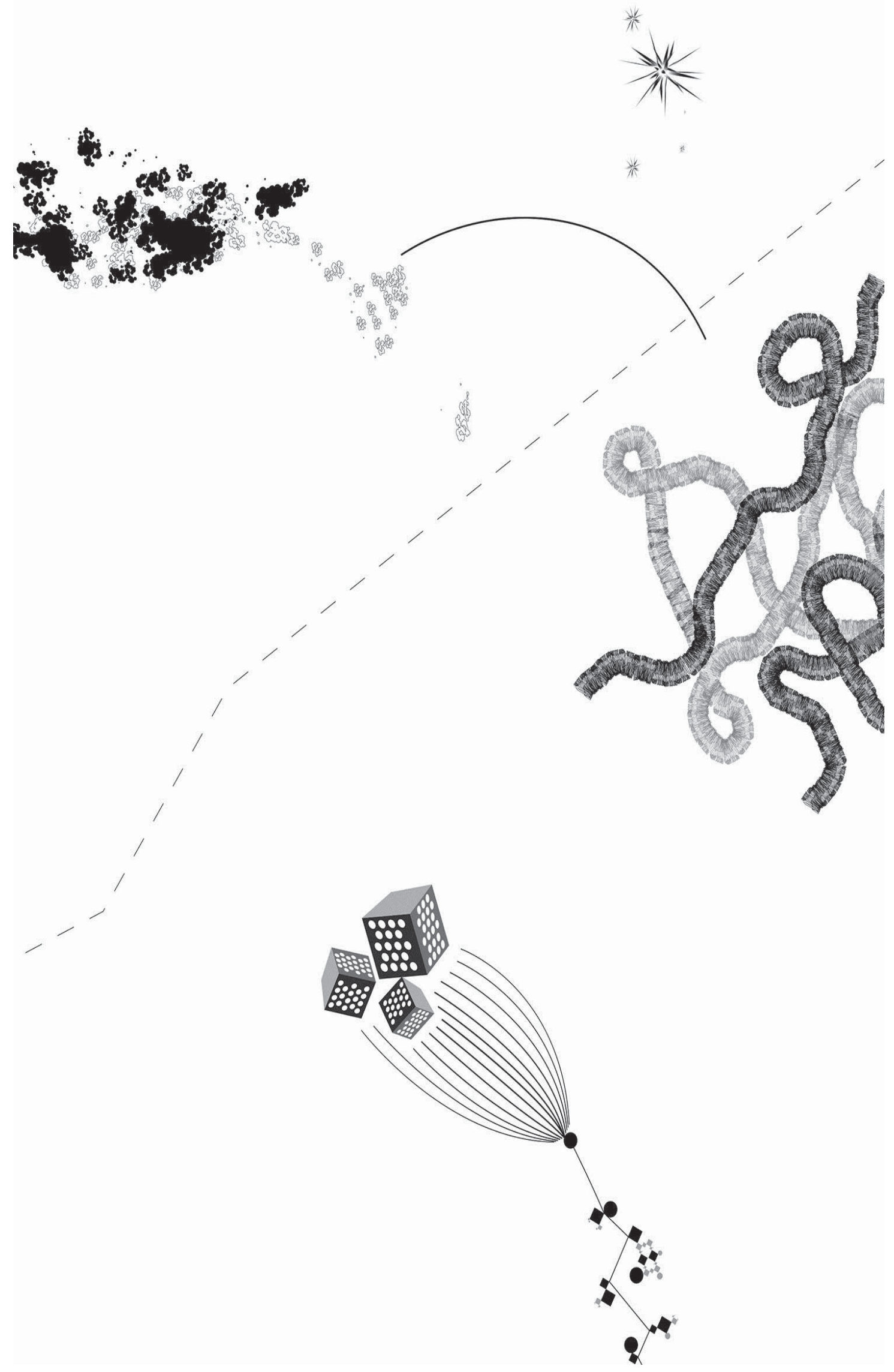




\section{MESA+}

\section{Contents}

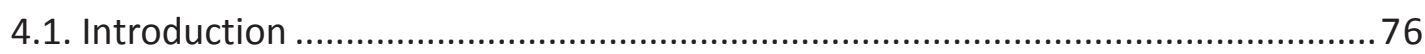

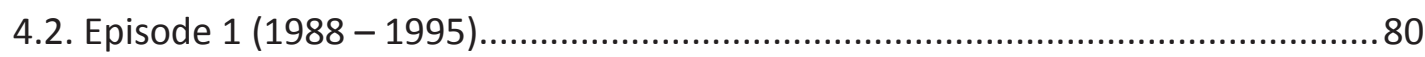

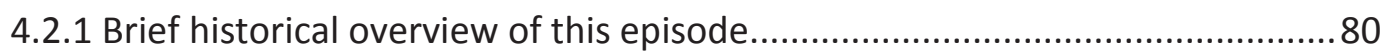

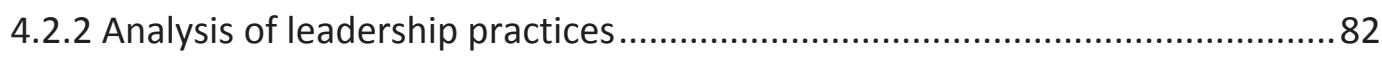

4.2.2.1 Development and execution of a coherent research programme...............82

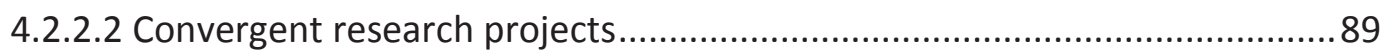

4.2.2.3 A business model for a joint research lab................................................92

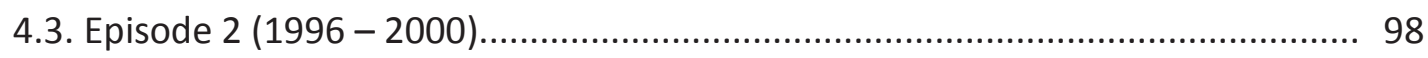

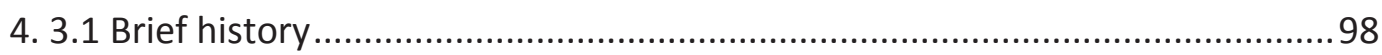

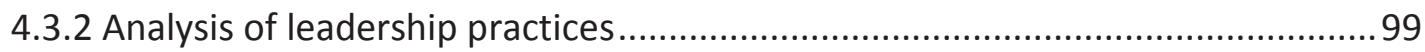

4.3.2.1 Contextual developments urge for rethinking of research programmes

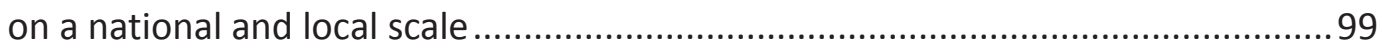

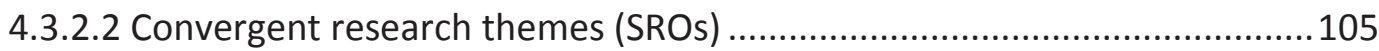

4.3.2.3 The development of a new business model ............................................. 109

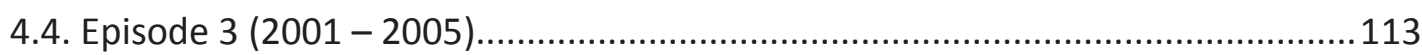

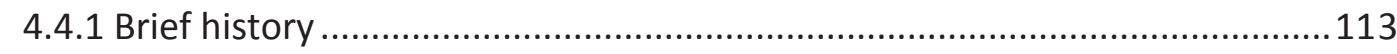

4.4.2 Analysis of research leadership practices ...............................................115

4.4.2.1 Programmes on a national and international scale..................................115

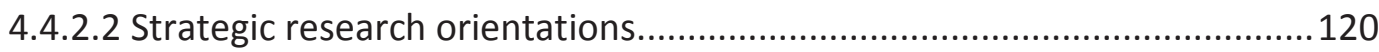

4.4.2.3 Development of a business model for a CER ............................................124

Distributed academic leadership in emergent research organisations 


\subsection{Introduction}

This case study introduces a site of emerging technology research and transformation of research organisation: the MESA+ research institute on nanotechnologies, and its predecessors MESA (microelectronics) and CMO (materials science).

It concerns a story of academic entrepreneurship, an illustrative example of a centre of excellence and relevance. As first of its kind at the time, it had a strong impact on the organisation of research in its home university, the University of Twente. It has generic relevance as well, considering its pathway, as a particular type of institute, .

The leading academics who joined forces in MESA shared a common motive: to create a critical mass and diversity that was felt necessary to be able to embark on emerging new research areas, by bridging between groups and sharing apparatus. Use was made of the freedom that existing structures allowed, innovative challenges were addressed: "there was plenty of space at the bottom", as MESA's founding scientific director liked to say, using the slogan for nanotechnology (originating with Feynman's 1959 dinner talk) for another purpose. Appealing labels were used like micro systems technology, micro systems engineering, sensors, materials, technologies and systems for the information society, and later nanotechnology as an umbrella term.

The search for new ways of working started as a joint initiative of three faculties, Electrical Engineering, Applied Physics and Chemical Engineering. It included, almost by definition, overcoming or balancing between different interests and perspectives, with the Central Board of the University as "concerned bystander" intervening from time to time for strategic reasons. MESA was embedded in the context not just of these faculties but also an increasing number of other research institutes competing for the same local and national research and innovation funds. MESA's leaders seized opportunities of a national policy landscape that was favouring "mass and concentration" and high tech developments, and played an active role in national agenda building, taking into account the international landscape of academic peers, multinational firms and later also possible citizen concerns regarding societal impacts of nanotechnology applications.

Distributed academic leadership in emergent research organisations 
This case study describes MESA's development over a period of seventeen years. MESA, as well as CTIT, the case to be presented in Chapter 5 , were enabled and constrained by the rules of the University and its legal context. MESA did not start from scratch; it could build on previous developments including the planning of a joint clean room facility, implying a concern about longitudinal financial arrangements around the clean room. MESA's academic leaders were also confronted with the legacy of differences between research clusters in micro-systems and in materials science.

\section{The structure of the chapter}

The presentation follows the underlying structure of analysis where the history is divided into episodes. Each episode covers a chronological sequence of events. The focus is on the struggles and achievements of some twenty academics who interacted and found practical ways to meet the opportunities and challenges of a new organisation in a more or less ambiguous context. Most of these academics did not hold formal management positions in the Faculties concerned, but did conduct leadership roles in a loosely coupled network within the institute as well as connected national programmes.

Within each episode, three key activities are taken up for further discussion: strategic programming, project development, and business model development. Under the key activity of "strategic programming" events are presented that show how distributed leadership activities evolved, more or less successfully, in the constitution and promotion of a strategic research programme. The key activity of "project development" concerns distributed leadership activities at a tactical level, showing examples of more or less effective development of overarching projects that created new alignments among MESA research groups. The key activity of "business models" presents leadership activities about organisational arrangements, human resource management, and finance, to address the new challenges.

Distributed academic leadership in emergent research organisations 


\section{An overview of the history}

Episode 1, 1988-1995

\begin{tabular}{|l|l|}
\hline 1988 & Preparations for a joint research lab and institute start \\
\hline 1990 & Official start of MESA \\
\hline 1992 & Business plan developed \\
\hline 1994 & $\begin{array}{l}\text { Accreditation as Research School (Royal Academy of } \\
\text { Sciences) }\end{array}$ \\
\hline 1995 & Final year of the first five year's mandate term \\
\hline
\end{tabular}

Episode 2 1996-2000

\begin{tabular}{|l|l|}
\hline 1996 & Start of the first strategic research orientation (SRO) \\
\hline 1998 & $\begin{array}{l}\text { Changes in leadership: the scientific director retires, hands } \\
\text { over to his successor. In addition, a technical commercial } \\
\text { manager is being appointed. }\end{array}$ \\
\hline 1999 & $\begin{array}{l}\text { In a transitional year, MESA and CMO fuse into MESA+ that is } \\
\text { being acknowledged by the Central Board as a strategic } \\
\text { spearhead institute of the University of Twente. }\end{array}$ \\
\hline 2000 & MESA+ structures its programme as five SROs. \\
\hline
\end{tabular}

Episode 3, 2001-2005

\begin{tabular}{|l|l|}
\hline 2001 & $\begin{array}{l}\text { MESA+ investigates opportunities for new forms of research } \\
\text { funding, including participation of specialised investors. } \\
\text { MESA+ starts to position itself as a leading institute in } \\
\text { national research and innovation programmes. }\end{array}$ \\
\hline 2003 & $\begin{array}{l}\text { MESA+ has become a lead partner in national (NanoNed) and } \\
\text { European (Frontiers) programmes. }\end{array}$ \\
\hline 2004 & $\begin{array}{l}\text { Third five year mandate term ends. The next five year } \\
\text { mandate is agreed upon, but UT's strategic funding support } \\
\text { for spearhead institutes gets under pressure. }\end{array}$ \\
\hline 2005 & $\begin{array}{l}\text { MESA+ fully geared to national programmes. } \\
\text { MESA+ belongs to the top-3 performing among the five } \\
\text { spearhead institutes at UT. }\end{array}$ \\
\hline
\end{tabular}

Table 1. An overview of the history Mesa+

Distributed academic leadership in emergent research organisations

4. Mesa+ 


\section{Sources}

Data sources for the reconstruction and analysis of MESA's development are threefold. The author of this thesis was an observing participant in parts of the life cycle of MESA and MESA+. Secondly, in 2006, seven key actors were interviewed and invited to reflect on specific events and on patterns of leadership activities. Thirdly, publicly available documents as well as archives of MESA and the Central Board of the university were researched.

\section{Interviewees}

\begin{tabular}{|l|l|l|l|l|}
\hline & Name & Episode & Position at the time & Date interview \\
\hline 1 & Kees Eijkel & $1,2,3$ & $\begin{array}{l}\text { Central lab manager, } \\
\text { Technical commercial } \\
\text { manager institute }\end{array}$ & September 2006 \\
\hline 2 & Horst Rogalla & 2,3 & $\begin{array}{l}\text { Scientific director CMO } \\
\text { institute, research } \\
\text { group leader }\end{array}$ & September 2006 \\
\hline 3 & Dave Blank & 2,3 & $\begin{array}{l}\text { Programme director, } \\
\text { later on scientific } \\
\text { director }\end{array}$ & September 2006 \\
\hline 4 & Jose Effing & $1,2,3$ & controller institute & September 2006 \\
\hline 5 & Julius Vancso & $1,2,3$ & Research group leader & September 2006 \\
\hline 6 & David Reinhoudt & $1,2,3$ & $\begin{array}{l}\text { Research group leader, } \\
\text { scientific director }\end{array}$ & May 2006 \\
\hline 7 & Wilfried van de Wiel & 2,3 & SRO leader & September 2006 \\
\hline 8 & Jan Fluitman & 1 & Scientific director & 1991 - 1993 \\
\hline 9 & Theo Popma & 1 & $\begin{array}{l}\text { Chair interfaculty group } \\
\text { TDM, later on rector } \\
\text { magnificus }\end{array}$ & 1994 - 1996 \\
\hline
\end{tabular}

Table 2. Interviewees MESA+

\section{Specific publications and documents}

Duncker. E. (1998). Multidisciplinary Research at the University of Twente. The Challenges of Heterogeneous Cooperation. Enschede: Twente University Press.

Reinhoudt, D. (2007). Moleculaire engineering, synthese en analyse. Boekje bij het Afscheidscollege (13 september 2007). Enschede: University of Twente.

Rip. A. Unpublished notes on the history of MESA+ and the pre-history of the NanoNed programme.

Distributed academic leadership in emergent research organisations 4. Mesa+ 


\subsection{Episode 1 (1988 - 1995)}

\subsubsection{Brief historical overview of this episode}

There had been cooperative movements in UT, like working groups in research between three science and engineering faculties: Applied Fysics, Electrical Engineering and Chemical Engineering. Building on these movements in 1988, the board of the faculty of Electrical Engineering, supported by the Central Board of the University of Twente initiated a strategic study in order to define the programmatic highlights and to assess the feasibility for the organisational set up of a new research institute. New in the sense that the institute would bridge research areas of three faculties, and would embed the development of a new joint research lab. The institute was not starting from scratch. It had been preceeded by a loosely coupled interfaculty "working group on sensors \& actuators" that had been in existence as of the moment (1982) that Dutch HE law enabled such interfaculty groups. Different considerations were combined in the assignment that the board of EE issued for the investigation. It addressed the necessity to structure the future of the working group S\&A now that the Dutch HE law allowed for establishing research institutes. Another point of concern was the joint exploitation of a new research lab ('clean room') for the S\&A Group. A third concern were external funding opportunities. The chances for funding from national funds were decreasing, as the so-called "Strijdplan Micro-Electronica" expired in 1989 and would not be succeeded by a new financial scheme.

The interfaculty investigation committee was chaired by a former member of the Central Board of the University, responsible for research policy, reflecting the strategic nature and importance for the University as a whole.

After ample consultation, mainly addressing strategic considerations, it was decided in 1989 by the faculties concerned and agreed by the Central Board that the institute would start with a focus in electrical engineering, in co-operation with applied fysics and chemical engineering. A professor from the faculty Electrical Engineering was invited to write the programme and select the envisaged programme leaders. Thus, in 1990 Jan Fluitman became the envisaged founding scientific director of the institute. He proposed the name MESA; the acronym for microelectronics, sensors \& actuators, but also consciously chosen as a metaphorical name. According

Distributed academic leadership in emergent research organisations 4. Mesa+ 
to his vision, 'mesa' as a transformational landscape phenomenon or 'mensa' (table in Latin) as a meeting place for people, signalled what an interfaculty institute should stand for.

Professor Fluitman was advised by a working party with representatives from the three faculties and the Central Board (represented by the chairman of the previous investigation committee who was now appointed as member of the advisory group).

In 1990 the MESA institute was officially launched. The first official board meeting took place on December 21st.

In organisational terms, MESA went through a phase of swift growth phase and had to pass a lot of hurdles, as it was a new organisational set-up in the University of Twente that did not fit in with standing procedures. By the year 1994, MESA entered a phase of organisational maturity in the sense that management and steering procedures were in place and more importantly, that MESA started to become accepted inside and externally as an entity (for submitting research proposals to funders), and that a community of researchers started to emerge.

Whereas the initiative in 1988 to develop MESA was influenced by the necessity to join forces to enable the development of new multidisciplinary research areas and to jointly exploit a research lab, by the year 1995 it became clear that MESA in its initial set-up had reached its limits. At the same moment, structural changes took place in the Dutch industrial research landscape, Dutch R\&D firms with an international business scope started to negotiate a joint repositioning: together, supported by the Ministry of Economic Affairs (being responsible for innovation policy) they proposed a "bulk contract" to the three Technical Universities. This arrangement was negotiated with the boards of governors, due to its strategic nature: in exchange for multiannual stability of industrial funding for their PhDs, the Technical Universities accepted the responsibility for financing of research infrastructure and housing ${ }^{22}$.

These and other structural changes influenced movements of bundling and upscaling of research organisation, by the mid-nineties research groups in and around MESA started to join forces, creating new openings for MESA to widen its scope in materials science. The committee that prepared the founding of MESA, as well as leading academics in the years thereafter did not

\footnotetext{
${ }^{22}$ Referring to similar movements in the USA that Chesbrough described in his book on Open Innovation in 2000, these developments can be seen as the advent of open innovation in the Dutch industrial R\&D landscape.
}

Distributed academic leadership in emergent research organisations 
succeed in convincing envisaged partners from materials science, rooted in the Faculties of applied physics and mechanical engineering, to fully join forces, beyond some individual projects. These Faculties preferred the development of an institute on their own. Soon after the official start of the MESA institute, the institute for materials science (CMO) was started, in 1992. It would take until 1996 before the first programmatic co-operation got shape, concerning "nanostructures".

This co-operation foreshadows a new episode in MESA's life, leading to a full merger between the institutes MESA and CMO in 1999, merging into a new institute called MESA+, research institute for materials, technologies and systems for the information society. This merger also included a broadened focus, embarking on a range of commercialisation activities and moving towards programmatic alignments with partners on a national and international scale.

\subsubsection{Analysis of leadership practices}

\subsubsection{Development and execution of a coherent research programme}

The establishment of a coherent and attractive research programme was the main concern and "binding factor" of the group of senior academics that lead MESA in those years. At the start of the institute, a formal document had been agreed upon by the deans and Councils of the three faculties concerned, and later on ratified by the Central Board and the Council of the University. This "instituutsplan" was carved in stone regarding the overall procedures and mandates of the institute's management: it was in that sense a risk management pact between the founding parties, accountability and minimising financial risks for the Faculties was the main thrust of this document and of the preparing negotiations. Based on this plan, it was up to the leading academics in MESA to fill the institute with life, to draw up a coherent research plan that would spark new joint research areas and at the same time leave enough space for individual initiatives.

Getting things on paper, negotiated, connected to financial long term commitments, was one thing. An adventure on its own, as there was no previous experience with it in the faculties concerned. How to find the right balance between an attractive, adventurous research programme on the one hand and a trustworthy, feasible planning of its realisation on the other hand that would secure a sound return on investment?

Distributed academic leadership in emergent research organisations 4. Mesa+ 
Negotiations about the research programme were tough. The founding director and bystanders had to play on different chessboards at the same time. Faculty deans were dealing with a new issue - long-term financial commitments for a joint, interfaculty effort. Moreover this was an effort of which they had no control, that was up to the research groups involved. Professors and chairs of departments involved were ambivalent: keen to co-operate, among other reasons to secure access to the new research facility; but reluctant to take strategic decisions, for this they were seeking back-up from their own deans. Faculty boards and councils were the more balancing and sometime conservative forces: they were pressed by the labour unions to make sure that the career perspective of academic workers would not be hampered. Not without reason, it was feared that research institutes would only invite those academics who showed a strong track record or high potential in research, leaving those academics that were not high ranked in research to do the "dirty work" of teaching.

In the midst of these negotiations, the scientific director stated" in 1992: "it seems as if a research institute is meant to change the research landscape of the university by closing down groups and establishing others. That is not feasible: nevertheless, an institute can energise a more rigorous quality management that stimulates selection of high potential groups." In this opinion he builds on the perspective that he, as founding director, sketched at the start of the institute: "the position of theme leader does not exist in a formal sense. It is proposed to maintain the present hierarchy and meanwhile take the tension for granted that might occur due to the fact that an (mono-disciplinary) academic chairholdership differs from a (multidisciplinary) theme leadership. Or even better: to exploit this tension as a creative source." ${ }^{24} \mathrm{He}$ voiced these and other opinions showing an entrepreneurial attitude, representing a group of about ten leading academics who were looking for and promoting coalitions.

These movements meant a change in culture and vision on research organisation. These opinions were not embraced by academics who were holding management positions, who had to plan and control the allocation of (fixed, or even shrinking) money streams from Dutch government or who had to take multi-annual responsibility for personnel and housing affairs. In particular the board of the Faculty of Applied Physics was outspoken, they persistently voiced concerns with other Faculty boards that responsibilities were not properly assigned between the scientific director of MESA and the deans, and that the sharing of responsibilities would result in

\footnotetext{
${ }^{23}$ Ondernemingsplan 1993-1995, citation translated by the author of this thesis

24 ontwerp-instituutsplan 20 juni 1989, citation translated by the author of this thesis
}

Distributed academic leadership in emergent research organisations 
a matrix organisation. In their opinion, this set-up would result in a continuous row of minor conflicts between Faculties and research institute, distracting the focus of the scientific director from strategic management of the research institute.

Due to these and similar negotiations, MESA's leading academics were for a longer time involved in strategic negotiations of an interfaculty scale that they had not dealt with before. These strategic planning activities resulted in agreements, understandings, plans and contracts. Whereas in academic life academics could work in a relative freedom once agreements with funders were achieved, in this context of change and development of new organisational setups, immediate action was required to fill agreements with life and, in doing so, create visibility and common ground to take further steps.

Thus, getting things done in interaction with research group leaders that were once agreed on paper with deans, required further efforts. MESA developed an innovative way to create a lively institute community. There had been many small-scale 'board room' discussions taking place in order to get the formal agreements settled. Now, materialisation of a joint research programme was embedded in a range of broad, open, informal meetings. In the years 1994 and 1995, MESA effectively mobilised a substantial number of young researchers and brought them together in productive setting. It is clear from Duncker's observations ${ }^{25}$ that the MESA lab made important contributions to internal co-ordination. Also in unplanned ways: for instance, Duncker notes that - in particular young - researchers who were waiting for their time slot to use a specific apparatus, were de facto acting as a market place for exchanging ideas. Coordination was also promoted by leading academics in a planned way, as the MESA management promoted that the lab - the line up of apparatus - was structured as functional to the themes in the MESA research programme instead of following the structure of departmental facility and work places.

Multidisciplinary and thematic approaches were also promoted by organising, as of 1993, regular research workshops of a substantial size and multidisciplinary nature, culminating in an annual internal MESA research day. Workshops at these research days included all scientific and technical staff. The thematic organisation and preparation got high priority among MESA's academic leaders, resulting in lively and well-attended sessions of sometimes 300 researchers at

\footnotetext{
${ }^{25}$ Dr. Elke Duncker conducted observational fieldwork at the MESA lab in the years 1994-1995 for her PhD thesis "Multidisciplinary Research at the University of Twente". Duncker, 1998.
}

Distributed academic leadership in emergent research organisations 4. Mesa+ 
a time ${ }^{26}$. The MESA research days became a vested forum of meeting and orientation, the group overarching thematic approach stabilized, and as of 1995, workshops at these MESA research gatherings were conducted by post docs and PhDs.

The research programme that was drawn up in these initial years of MESA's life, was of an ambitious nature. Taking future developments in science and industry into account, it aimed at a different functional design of research topics than developed so far by the participating departments and research groups. It took the founding director two years to get it written, negotiated and agreed, more or less supported by a loosely organised group of about ten senior academics from different Faculties. It was without precedent at UT that such a community of interest walked this path, so parties were keen to join deliberations and have a say. In doing so, the founding director and the about ten senior academics that supported his undertaking had to develop new practices. They had to talk to the deans, the boards, the councils, the financial directors of the three Faculties concerned, and furthermore to the Central Board of the University, several supporting staff groups (research policy, finance, building) and to members of the University Council. Each of these "chess boards" had their own codes of conduct and procedures, but MESA's founding academics managed to get support from different stakeholders in an often unplanned, improvising way.

First of all, the Central Board of the University acknowledged the strategic importance of this initiative for the university as a whole. They had high expectations of the vision that was brought forward by MESA's promoting academic leaders, of its strategic impact in terms of international positioning. In addition, they were well aware that establishing an interfaculty research institute was a sensitive balancing act that required new ways of co-operation and negotiation between deans and Central Board. In that perspective, the Board was keen to draw lessons from MESA's initiative for the formation process of other interfaculty research institutes. As a result, the Central Board acted as a supporting stakeholder for MESA's organisational development. Specific policy measures and were developed, aimed at creating experimental space in policy and administrative regulations for development of research institutes. Financial incentives were established in the University's budget allocation system. In addition, the Central Board performed leadership interventions, as a collective and individually. From time to time

\footnotetext{
${ }^{26}$ Duncker reports that already at the second meeting more than 60 poster presentations were submitted.
}

Distributed academic leadership in emergent research organisations 
individual members of the Central Board acted as invitee for deliberations between deans and senior academics from MESA, in that sense, creating common ground for exploration. The Board member who was responsible for finance and housing (Frits Schutte) had a particular role. As financial perspectives (a higher return on research investment, a sharing of risks) and housing (the joint decision between Faculties and Board to invest in a clean room facility) were core aspects of research institute formation, in particular in the case of MESA, this Central Board member was hosting and orchestrating a range of meetings concerning MESA's organisation.

As a collective, while combining different responsibilities for strategy, financial affairs, housing, and research policy, the Board addressed governance issues of research institute development in the University Council (in a range of meetings in the years 1991 till 1994). On the one hand in order to develop a policy framework for strategic planning of research institutes. On the other hand to create an understanding in the Council that strategic planning of research organisations asked to rethink positions of governing bodies and senior academics, leaving as much space as possible to senior academics to create new multidisciplinary formations.

Second, at Central Board level, two (advisory) bodies were an important stakeholder with respect to MESA's formation, the Council of Deans ("College van Decanen") and the thematic advisory committee on research affairs ("Centrale Commissie Research"). Especially in the latter, many discussions took place on the formation of research institutes and its implications for the overall research strategy and organisation. The CCR developed via these deliberations as an informal expert body, conducting boundary work between different decision making bodies of the University. The CCR consisted of senior academics that were consulting on a strategic level, combined with their position as associate dean for research in their Faculty. This forum acted as an important stakeholder for the research institutes and for the Council of Deans and the Central Board.

A third stakeholder was the board of the MESA research institute. An important stakeholder for MESA's leading academics; they were the board and were holding decision power for MESA's annual research programme and budget. More importantly, they were the forum that consisted primarily of senior leaders from other research institutes and from industry. This body was a leadership group in itself, signalling and from time to time expressing through interventions towards the deans and the Central Board that MESA as a research institute was independent

Distributed academic leadership in emergent research organisations 4. Mesa+ 
from the founding Faculties. The first board of this kind at the University was installed at the start of MESA ${ }^{27}$.

The Central Board of the University decided in 1990 that research institutes should have a board with a predominantly external orientation. Dutch HE law created the possibility to install a board that would govern an interfaculty research institute, acting with a mandate from the constituing Faculty boards in a timeframe of five years. Within this mandate, Board members balanced between their role as supervisory board, monitoring the progress in the framework of the mandate, and their prime task to advise the scientific director (and his executive board, if in place) and to promote the productive development of an institute. The Board of the University gave deliberately an entrepreneurial interpretation to this opening in the Dutch HE law. In consultation with the deans, they decided to favour board members from outside the University of Twente, that would be proposed by the constituting faculties, representing the trust these faculties had in their steering competencies. Given the strategic ambitions, candidates would be senior academics from either universities or industrial research groups. In the case of MESA, a Board was invited with senior academics from primarily the technical universities of Eindhoven and Delft. Chairman of the first Board was prof. Veltman, former vice chancellor of the TUD ${ }^{28}$. The Board of MESA acted primarily as the immediate advisory group for the senior academics of MESA concerning strategic and organisational matters. But they did not restrict their role to policy advices, they also took an active stance as they took part in deliberations with deans of the constituting faculties and with the Central Board. At the time, it was felt by MESA's leading academics and by the Central Board, that the MESA board played a productive role. The Board strengthened the governing identity and, as they were external experts, used their supervising mandate to assist MESA's leading academics to focus on the strategic and tactical development of the research programme and organisation, avoiding that MESA's leading academics would lose focus due to the daily nitty gritty small scale but acute problems that they had to deal with in order to get new ways of working settled.

\footnotetext{
${ }^{27}$ For each interfaculty research interfaculty research institute that was established, in consultation with the deans a balance was sought for between external representation in the Board of an institute and the trust relationship between the deans of the founding Faculties and respective Board members. Implying that each research institute's Boards developed its own positioning.

${ }^{28} \mathrm{~A}$ few years later, Veltman became chairman of the Central Board of the UT.
}

Distributed academic leadership in emergent research organisations 4. Mesa+ 
A fourth stakeholder were the central administrative managers, staff and policy advisors. These were seconded to MESA as organisational experts in order to assist and advise in the institutes' organisational development. Key player in this episode was the Secretary to the Central Board ${ }^{29}$. Within the scope of his main task to secure a stable and accountable management system for the University, he had an accountability relationship with the administrators of the Faculties. Now that a scientific director was given a mandate for a five years term in research programming, he was looking for ways to give an administrative mandate accordingly, in order to enable the scientific director to engage in hrm and financial affairs. This was not an easy issue: the solutions should fit the law on Higher Education, rules and regulations of the Ministry, and, more importantly should strike a balance between the responsibility of the founding Faculties and the scientific director.

Congruent to the approach of the Central Board, he did not restrict himself to defining rules and procedures, he also consulted and advised the administrative managers of the Faculties, creating an informal reflexive peer to peer learning environment for those managers who stood in the frontline of clashes between entrepreneurial academics and boards and deans of Faculties. Several plenary practice based learning meetings were organised in those years, that were attended by managers of Faculties, as well as managers and advisors on personnel, financial and housing affairs. These informal meetings created common ground for these stakeholders and gave them space to approach initiatives by leading academics for new research organisations in a rather open and entrepreneurial way.

As a result, MESA was the first test case for the UT concerning the practice of academic leadership of an interfaculty research institute. Whereby core governing and leadership functions were conducted by the university's Central Board and Registrar, MESA's leading academics and scientific director, and the deans and managers of the faculties concerned.

The development of the core governing and leadership position in MESA, that of the scientific director, got intertwined with the realisation of the scientific programme. In 1994 the board of the faculty Electrical Engineering decided to establish a new chair in Micro-Systems, to be fulfilled by the MESA director. Signalling that this would be the core area of the research

\footnotetext{
${ }^{29}$ In this episode, in the years 1990 - 1995, Dutch universities had a two tier steering system, where in the rector and the deans were responsible for policy, and the secretary and the managers of the faculties for planning \& control. As of 1998 the board and the deans got integral responsibilities for policy and management.
}

Distributed academic leadership in emergent research organisations 
institute. Much to the regret of the scientific director, they also decided that the MESA board would have to find funding for the new chair, and the financial risks were allocated to the department that the new chair would belong to (the TDM research group).

The resulting research programme $1992-1996$ that was effective in the years 1993 - 1996, had a hybrid structure. On the one hand, it reflected the on-going research agendas of the nine departments concerned, defined as broader themes. On the other hand, it aimed at creating superstructures by defining a selected set of "orientations". The "orientations" were mainly funded by the so called "first" and "second" money streams ${ }^{30}$, that is the target funding from the Central Board of the University $\left(\mathrm{OSF}^{31}\right)$ and the Dutch Research Council. The third "orientation" was agreed at the start of the second episode, in 1996 (nanostructures, in collaboration with UT research organisation CMO, materials science). This way, MESA's leading academics developed a new way of incremental research programming, gradually anticipating on new opportunities that they created jointly by defining and profiling thematic areas and promoting these accordingly at UT's Central Board and the Dutch Research Council, in particular at the branch for technological innovation (the so called STW foundation). This leadership practice worked in the sense that a common framework emerged at MESA and among the stakeholders, that allowed access to new funding regimes, without hampering informal coalitions of professors and associate professors to dream up new themes and promote them. The effectiveness for MESA organisational change path materialised because of the productive interaction between strategic programming and the development of boundary spanning projects, as will explained in the next subsection.

\subsubsection{Convergent research projects}

At the time that MESA got shape, research groups, in particular in the engineering faculties that founded MESA, were used to develop and execute "projects", often in collaboration with an external industrial partner. Most projects were conducted by a PhD student within a research department, related to a single industrial partner. In contrast, MESA's leading academics, in

\footnotetext{
${ }^{30}$ At the time, research funding in the Dutch HE systems was structured along three so called "streams": first, governmental funding; second, research council grants; and third, EU and private sector funding.

${ }^{31}$ OSF is the Dutch acronym for OnderzoekStimuleringsFonds, Research Strategy Fund (translation by the author of this thesis). UT researchers could submit bids for an annual funding scheme, the University Council granted of $2 \mathrm{M}$ guilders per project, following the ranking of an independent advisory panel consisting of external experts. see p. 89 of this thesis.
}

Distributed academic leadership in emergent research organisations 4. Mesa+ 
their strategic drive for new themes, developed a new kind of research projects for co-operation between departments to create new approaches on a methodological or domain level. In shaping this kind of projects MESA's leading academics showed creativity and entrepreneurial ways forward to cross boundaries of their departments and take joint responsibility for a project, more in particular for joint guidance of young researchers. With this project development, MESA materialised a coherent set of "orientations" that had been defined in the multi-annual research programme. Thus, the founding director was consciously seeking for leadership and governing measures that would be effective and sustainable. He was quite aware that a project based, result oriented planning \& control approach would simply not work. The approach, besides being scientifically challenging and adventurous, had to be inviting for entrepreneurial academics from a processual point of view: it should allow for flexibility of cooperation among individual researchers and with external industrial partners, not being hampered by the necessity of departmental agreements or long term commitments. He carefully chose for a human resource centred policy, building an overall strategic intelligence of personnel dynamics in the departments concerned, from a quantitative perspective (workload, coupling between delivery cycles of research projects) and a qualitative perspective (career paths). In doing so, he was not primarily aiming at creation of decision (management) structures but at promoting the development of leadership and new work structures.

Against this backdrop, MESA's leading academics succeeded to define and acquire funding for multidisciplinary programmes along the thematic areas, each programme included two to three research groups, research funding came from several branches of the Dutch Research Council, the EU, and the UT Council. A substantial grant of 1 million guilders was acquired from the Dutch Research Council (in 1993). Besides the substantial the size of the grant was the main impact the acknowledgement as a top-level environment for training of PhD's, part of the national policy scheme for excellence in academic training ${ }^{32}$.

Further success from a strategic research management perspective was the Tempus project with partners in Central and Eastern Europe. As recruiting high potential young researchers was becoming an issue, MESA's leading academics were well aware that partnering with reputed

\footnotetext{
${ }^{32}$ A dedicated policy scheme, at the time initiated by the Ministry of Education to promote "top onderzoekscholen" (excellent research training centres, translation author of this thesis).
}

Distributed academic leadership in emergent research organisations 4. Mesa+ 
universities abroad was a priority. At the time, MESA's leading academics had strong links with researchers in Central Europe and expected an influx from high potentials from this region.

To promote the strategic development of MESA's research programme, a substantial research grant of 2 million guilders was given by the Central Board of the University. The grant was financed by the so-called OSF-programme, a new strategic research policy instrument for the Board of the University. Grant were given, at least in a formal sense, by the Board and the Council of UT. They fixed each year the criteria and allocated subsidies to research programme proposals as appraised by an independent committee. In practice, it was a prestigious and competitive funding scheme, appreciated among researchers at UT. The OSF owed its status due to the procedure and the independent committee. The set up was inspired by the project appraisal procedures of the Dutch STW Foundation, the research council for technology. The committee was chaired by the director of STW, Cees le Pair, comprising furthermore R\&D directors of leading technological firms and of non-university research institutes. The reputation of this committee at the time among UT's academics was that they were effectively identifying adventurous proposals with a strategic focus. Besides the formal selection, resulting in a ranking of proposals, whereby only one proposal got the jackpot of 2 million, the committee gave feedback to each of the programmes. This feedback was appreciated by submittees in order to be more successful in raising external funding perspectives.

The OSF programme mTAS funded came at the right moment and was of a useful nature: it allowed MESA to explore converging research projects. The amount and in particular the strategic signaling of this grant was highly valued by MESA's leading academics: the saw this grant as important seed money to convert their strategic vision into projects that were adventurous, in the sense that new themes and ways of co-operation could be explored. An impulse that came at the right moment in this episode of MESA's live wherein other research funders still had to be convinced about MESA's approach, that is, about the added value of joint research projects between groups on new themes ${ }^{33}$.

The overall combined impact of these kind of grants and subsidies, comprising a total sum of 3.5 million guilders, was substantial in its support for MESA's leading academics who were keen to

\footnotetext{
${ }^{33}$ MESA kept acting as a promotor of this Central Board's strategic research initiative, by submitting proposals in the years thereafter, among others to stimulate co-operation with groups in social sciences on themes as policy formation and technology forecasting.
}

Distributed academic leadership in emergent research organisations 4. Mesa+ 
materialize MESA's research programme in thematic areas and projects that would have a converging working on ongoing research projects.

\subsubsection{A business model for a joint research lab}

MESA's overall mission in this stage of research organisation development was to develop a business model that would give the groups that joint forces a higher return on their time investment. As there was no previous experience in this University (and elsewhere in the Dutch university system) with these entrepreneurial activities, MESA's leading academics took the opportunity to develop their own way forward. Different from a structured approach in industry, there were no formalised investment procedures or evaluation criteria. So, MESA's leading academics' practice showed a dual focus in this period, reflecting their entrepreneurial search for new ways of working, beyond internal rules and regulations and scouting new external opportunities for funding.

Internally, the business case was the establishment and joint exploitation of a new clean room lab for the two groups that were the pillars under the MESA initiative: sensors \& actuators and micro-systems. As the envisaged thematic cooperation would have a high impact on the way of working of this groups, mirrored by substantial and long-term financial commitments for the highly specialised clean room lab, a lot of time and energy was spent in these years on internal negotiations. This internal struggle could have led to MESA's early death, similar to other situations where internal hurdles could not be overcome in due time, hampering or even damaging development of productive external relationship, but this was not the case. MESA's leaders succeeded to keep an external focus as well right from the start of the preparatory investigations in 1989. MESA's leading academics who had taken the initiative forward after the official initiation by the Faculties and Central Board in 1989, were convinced that endogenous developments in their fields of research required multidisciplinary co-operation and availability of state of art research lab facilities that could meet requirements of EU funding and international research partners.

The founding director, supported by Central Board's policy staff, tried to address both foci. Each focus was managed by a separate group of experts. In 1989 the head of the former sensors \& actuators lab was appointed to manage the building process, from the customer side, of the

Distributed academic leadership in emergent research organisations 4. Mesa+ 
new research lab, jointly with the building \& construction central staff of the University. Interviewees tell that this group was fully focused on internal affairs. The head of the building process, later on appointed head of the MESA lab, who would become commercial director of MESA as of 1999, recalls that he was not directly involved in negotiations or other external leadership issues regarding the establishment of the MESA institute. This was the business of the senior academics that co-operated with the founding director, and with the member of the Central Board who was responsible for the real estate policy of the University. This Board member happened to be also responsible for financial policy; in that quality, he had a key role in the negotiations around the financial model for the new institute ${ }^{34}$. The negotiations attracted a lot of attention from deans, professors from other Faculties and from the University Council, as this was the first time that the University developed a joint exploitation model. So far in the Dutch university system, either research facilities were positioned in between universities and jointly exploited, or the board of the university took the final responsibility, acting as the owner of the research facility that was labelled as of strategic importance for the university. The Central Board of the University of Twente however, jointly with the deans concerned and the founding director, explored a new way resulting in three-layer financial model. The Faculties would become the owners of the research lab in the sense of long term financial responsibility, the Central Board would guarantee the basic financing of the lab for a period of time, and in addition would guarantee a dynamic middle layer contribution to the lab, being a ratio of the contribution from the Faculties (the upper layer in the model). Moreover, the scientific director got an annual budget that had to be allocated for the development of new joint research projects.

While establishing this business model for the MESA lab, the Central Board stimulated joint leadership of MESA's leading academics, a productive development of MESA and its lab required a joint effort, in particular in the development of its joint external focus, materialising in joint externally funded projects. Despite pressures from research groups and Faculties on MESA to

\footnotetext{
${ }^{34}$ Whereas in international literature on HE governance and management primarily presidents or (depending on the system) vice chancellors are featured, in the Dutch HE system the role of the 'third member' has to be taken into account as well. In the case of UT, this 'third' board member has been in office for more than ten years, being an influential promotor and author on the concept of the entrepreneurial universities. The financial allocation model that was initiated in the late eighties by board member Boudewijn Nieuwenhuijse, was in the years there after development and improved by this governor (incl the OSF). The then current strategic negotiations with TNO about founding of related, application oriented, TNO-institute attached to core research areas of the university, were coordinated by him. Similarly, as of the mid-nineties, he became the promotor and later on governor of UT's spin off programme.
}

Distributed academic leadership in emergent research organisations 
finance the overall management costs ${ }^{35}$ from the Board's grant, the leading academics gave priority to financial impulses for converging projects in order to materialise a thematic research organisation.

The search for a new business model was not without problems. While the Faculties, MESA's academic leaders and the Central Board were trying to develop a sustainable model, the financial context in those years was still geared to the traditional organisation where Faculties had access to "first money stream" of governmental funding that was allocated to departments along disciplinary structured lines. A financing source that was predictable, it did not show much variability. Another important source that Faculties had access to, was the "second money stream", allocated by the Dutch Research Council, NWO, that was also structured along disciplinary lines. Even the at the time growing "third money stream", grants and contracts from Ministries, industry, and the EU, was not favouring multidisciplinary research and development of joint research lab facilities. An illustrative example (that I addressed briefly in the introduction to this case), is the intervention by the major five Dutch industries with big R\&D labs, that were negotiating with the technical universities about packages of research trainees, de facto an outsourcing of research capacity (including lab facilities). In 1993, these negotiations resulted in an agreement between the main industries and the three technical universities. The industries succeeded to negotiate conditions and prices that were not welcomed by MESA's leaders. They saw that there was no longer liberty to negotiate with these firms on a project-by-project basis, about funding of thematic projects and related costing of housing and lab facilities.

The search for an appropriate business model got furthermore under pressure, as the financial situation at the University at the time was developing not too positive either. In 1992, the MESA board concluded that "steering an institute by allocating financial means happened to become a trivial act" once they got confronted with the bride's gift of the founding faculties. Once after the actual start of MESA in late 1990, in 1991 the budgetary conditions had been detailed, it became clear that the exploitation of the joint clean room facility, the MESA lab, showed an annual debt of 790.000 guilders. The founding Faculties saw this as a temporary problem and expected MESA to see this as a challenge that could be solved by attraction more external

\footnotetext{
${ }^{35}$ Overall management costs would include at the time the salaries of the scientific director, and MESA's financial support staff.
}

Distributed academic leadership in emergent research organisations 
research funding. Unfortunately, due to changes in the University allocation system, the deficit further increased up to 900.000 guilders. This deficit and its 'virtual' increase due to systematic changes, caused a lot of turmoil in the University press and around MESA.

In this problematic financial context MESA's leading academics response was entrepreneurial in the sense that they kept looking for opportunities beyond their common practices. A leadership approach that was already hinted three years before when in 1989 the envisaged scientific director stated: "while embarking on a journey in unknown area, it is wise to create conditions that assure that one is open to encounter new knowledge. The research institute has to create those conditions. This cannot be controlled in a programme, it is a way of working." ${ }^{\prime 36}$

This entrepreneurial response and the anticipative stance of MESA's leaders combined with the financial mandate of the scientific director, caused concerns among the Faculty boards. They were concerned that MESA's leaders in their search for openings and new areas would cause long term risks that would have to be solved in due time by the founding Faculties. As it was the first time that Faculties got engaged in joint exploitation of a research facility, it was difficult for them to deal with the appraisal of uncertainties and risks. Two Faculties, Applied Physics and Electrical Engineering, had strong concerns and stressed repeatedly that proper financial planning procedures should be applied. The third Faculty, Chemical Engineering, opposed once the Central Board considered to give a financial mandate to the scientific director of the institute.

As a result of the different arenas, negotiations with faculties, with the Central Board, and externally with different funders, MESA's leading academics had to spend a lot of time on communication, management of expectations, and accountability in order to live up to expectations. In 1992, the scientific director, on his personal initiative, wrote "a year-after evaluation note" to the Central Board, the founding Faculties and his own board. He voiced concerns about the time and efforts that MESA's leaders had to spend on organisational matters. He confirmed his conviction that MESA was on the right track, and, as MESA was following a steep organisational learning that others could benefit from, he asked for support in solving organisational matters, in particular in drafting a "business plan". The Central Board

\footnotetext{
${ }^{36}$ Ontwerp-instituutsplan MESA, 20 juni 1989 (translation by the author of this thesis).
}

Distributed academic leadership in emergent research organisations 
decided to second a staff member to support him in writing a business plan and to draw up an efficient accountability system.

Meanwhile, performance expectations were rising among the founding Faculties, as becomes clear from the formal correspondence between the scientific director and the Faculty of Electrical Engineering, in their role as administering Faculty. This Faculty expected MESA to acquire a higher rate of externally funded projects than the Faculty itself could have realised, based on the investments that had been made in the clean room lab. The discrepancy of expectations worried MESA's board: if the Faculty of Electrical Engineering continued pushing MESA to find additional income, than this might cause the expectation among the other two Faculties that solving exploitation deficits of the clean room was the main concern of MESA, and they might lose interest in further cooperation.

The deliberations between MESA and the Faculties were further hampered by different modes of financial analysis. MESA's board and leading academics were working towards a programmatic mode of planning and control that would be activity based. The Faculties had to follow a cost based, university wide, accounting system. In the initial years, time and again this led to misunderstandings.

New concerns for MESA were raised once Dutch universities had to move towards a full cost system of accounting. At the University of Twente, this led from time to time to fierce debates, as this system made transparent which part of the overall overhead (housing, management etc.) was allocated to teaching or research. Those who were in favour of education, were reluctant to create incentives to stimulate strategic research interventions that would sponsor new research organisations. The Faculties in humanities and social sciences were reluctant to accept that the Faculties of Engineering would receive a higher incentive due to the higher cost of teaching and research infrastructures. Their argument was furthermore, that student numbers in their fields were growing and that new study programmes required basic research funding. Engineering faculties were put under pressure by this new budget allocation approach: they counted fewer students and were primarily successful in research. Once again, MESA's academic leaders were challenged to meet expectations about financial returns.

MESA's leaders strategic choice was to turn expectations and related tensions into productive arrangements: understanding among MESA's leaders and with the Faculties concerned about

Distributed academic leadership in emergent research organisations

4. Mesa+ 
multi-annual programmes as building blocks for a new business model. Programmes that would allow them to develop and orchestrate an increasing number of projects funded by the Dutch Research Council and the EU. This approach and the understanding was a clear sign of strategic leadership and entrepreneurialism that allowed the scientific director to present a business plan that focussed at creation of new and fuses areas, not on a raise in earned additional income as a prime target. In this business plan, the scientific director presented a typology of projects, comprising five types of projects ${ }^{37}$ :

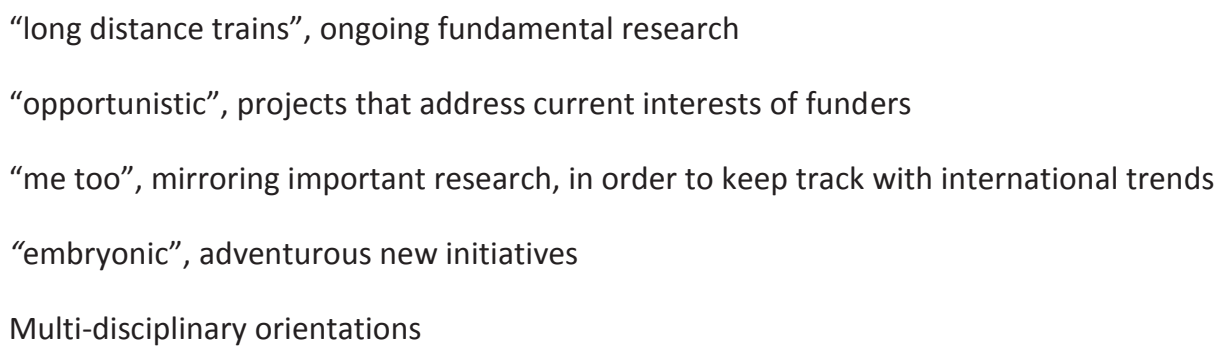

This typology had been drawn up by the direction in consultations with the research group and research theme leaders and MESA's board. It reflects the meta-governance framework that MESA's leading academics were deploying, the balancing act in converting and bundling research projects towards a programmatic approach that would allow for anticipative strategic planning among MESA's distributed academic leaders. The understanding among MESA's academic leaders was achieved, that MESA's added value was to be found in a strategic choice, that is, to focus on the last two types of projects: adventurous new initiatives and multidisciplinary orientations. Their ambition was, that at least 50\% of MESA's turnover should be covered by this type of explorative and boundary spanning projects.

Once these stabilizing leadership arrangements of strategic research programming and business planning reached a broader understanding among MESA's academic leaders, and were more or less accepted by the founding Faculties, MESA's could as of 1994 focus on business development and project development, using the acknowledgement and financial support of the Central Board (as explained in previous subsections) to materialize new research orientations and realize new entries to acquire external funding.

\footnotetext{
${ }^{37}$ The five "labels" are quoted from the Ondernemingsplan 1993, (translation by the author of this thesis)
}

Distributed academic leadership in emergent research organisations 
It was the first time that academic leaders joint forces in an interfaculty research organisation at UT, not only committing to a multi-annual research programme, but also to a business plan and related business model. Meanwhile, similar movements of change in research organisation materialised at the University, as of 1994 the interfaculty research organisation CTIT got off the ground, comprising research groups of seven Faculties.

\subsection{Episode $2(1996-2000)$}

\section{3.1 Brief history}

In this episode, MESA enters a new phase of development. After about two years of stabilizing patterns in leadership and organisational change, once again a period of accelerating changes evolved, which required that MESA, that is, its leading academics and stakeholders like the Board of the University to reflect on its status, positioning and functioning.

In this context of external challenges and changes, a major undertaking for MESA was the positioning towards other research institutes. Research strategy and related new opportunities for major funding became increasingly an issue for university board rooms, and MESA's leading academics were urged as well to come to decisions about partnerships and directions that had no precedence. The merger with the CMO research institute at the University of Twente had a path changing impact on MESA, its research programme and its scale of operations. Also in this episode, MESA's academic leaders, with as most visible spokesman the formal directors of the institute, got a leading role in promoting and negotiating national and international consortia and programmes, that would become operational as 2000 in among others the NanoNed consortium. In interaction with the merger with the $\mathrm{CMO}$ institute, the incoming scientific director as of 1999, played an important role in the re-orientations and negotiations. As part of his taking office, he developed a renewed research programme that included changing directions and external collaborations. This will become clear in section 4.3.2.1, where I will present the overall changes and its outcomes.

Administratively, this period saw the "battle of schools and institutes". This was closely related to the policies pushed by the new Board of the University and its rector-cum-president.

In 1997 a new member of the Central Board came into office, Frans van Vught, in his quality as rector responsible for education, research and internationalisation. In a former position he was scientific director of a interfaculty research institute at the University of Twente (CHEPS, Centre

Distributed academic leadership in emergent research organisations 4. Mesa+ 
for Higher Education Policy Studies) and a well-known expert in the field of higher education policy. In his preparation for his start in office, he made clear that he saw it as his mission to strengthen the international profile and position of the university. His ideas about necessary changes in UT's strategy and organisation addressed all aspects of the organisation. He was convinced, based on his own research insights and those of researchers in his network like Burton Clark, that pathways towards an entrepreneurial university required a strong strategic management that would address all activity fields of a university. He was in favour of research institutes as embodiment of organisational innovation and as a route towards an entrepreneurial academic climate.

At the time, the context went through further changes. MESA was no longer the only interfaculty research institute. In this episode 1996 - 2001, some $80 \%$ of all UT research capacity got organised in interfaculty research institutes. In formal terms, MESA itself entered its second phase. Research institutes got their mandate from the faculty boards concerned and the Central Board of the university for a period of five years; MESA got a renewed mandate for a period of five years.

The national and international science and innovation landscape changed gradually towards multidisciplinary fields and international conglomerates of research groups. In Dutch governmental policy "focus and mass" increasingly became a dominant feature and policy expectations around new forms of knowledge production and innovation were growing (as organised in public-private consortia, for example materialised in the policy scheme for Leading Technological Institutes).

\subsubsection{Analysis of leadership practices}

\subsubsection{Contextual developments urge for rethinking of research programmes on a national and} local scale

As MESA entered the final stage of its first five-year research programme, MESA's academic leaders became aware that new impulses were needed to sustain the growth that was envisaged and to continue an innovative climate that would stimulate and embed new and adventurous areas. They aimed at broadening of the research programme in order to continue boundary spanning and innovative activities across research groups and to improve the exploitation of the lab facilities. The academic leaders were aware that this local basis, in

Distributed academic leadership in emergent research organisations 4. Mesa+ 
particular the necessity to broaden this basis, was a condition in order to be able to embark on new national and international programmes.

At the same time, the research institute $\mathrm{CMO}$, next to MESA, founded by the same three Faculties, entered a phase of reorientation.

CMO, officially started in 1993, had taken off productively. The main targets in terms of facility sharing were met and the institute delivered the kind of support that research groups expected for smooth co-operation and external positioning. The road taken had not been without troubles and setbacks. The national competition for funding from the Dutch Research Council was severe, and $\mathrm{CMO}$ had not become leading partner in the Dutch research school for materials science. A business unit for materials science applications research ${ }^{38}$ went bankrupt, an event that legally had no impact for $\mathrm{CMO}$, as it was organised as an autonomous not-forprofit foundation, but that got a lot of negative attention, signalling that materials research was not matching the interest of companies. More importantly, leading academics from CMO, MESA and the Central Board were convinced that it was timely to join forces, they saw that closer cooperation between CMO and MESA was a unique opportunity to organise capital intensive facilities and related activities on a larger, more efficient, scale.

The recognition of this opportunity was grounded in forecasts of prospective developments in the research fields of both institutes. On a research group level the willingness to co-operate was growing, visible in MESA's decision in 1996 to open a third "orientation" called "nanostructures" jointly with CMO.

An opening for change in overall academic leadership occurred as the scientific management positions at both research institutes came in a phase of re-contracting, once the regular five years' term of appointment ended. The scientific directors that were in office could continue for a next term, but also had the opportunity to hand this position over to another professor. Both directors took this opportunity, each based on their own, different, considerations decided to resign. MESA's director was the first to signal that he considered stopping during his second term. He had served as the driving force of the preparation period 1989-1992 as founding director and as the scientific director since 1992. He was invited to stay in office as from 1995 of, agreeing that his mandate would end not later than 1999. At CMO, basically the same situation

\footnotetext{
${ }^{38}$ Stichting Geavanceerde Materialen (SGM)
}

Distributed academic leadership in emergent research organisations 4. Mesa+ 
occurred: the professor who had been the founding director held the position of scientific director for the first term of five years, signalled that he considered not to continue for a second term.

Changes in the Dutch research landscape urged academic leaders with MESA and CMO to consider opportunities for joining of forces. In 1996, the Dutch government opened a new programme for strategic research institutes, so called LTI's, Leading Technological Institutes: consortia led by industrial partners joined by universities, TNO and other research organisations. Micro systems and nanotechnology were on the list of areas that the government saw as eligible for LTI. However, no LTI's in these areas materialised. According to information that MESA's academic leaders gathered in their professional network, this setback was caused by the leading industrial partners concerned that gave no priority to these fields of research and innovation in their lobbying work for the LTI priority list.

At the local level, UT's Central Board was aiming at quick responses to the swiftly changing research landscape, as of 1995 the policy scheme of "schools and institutes" was developed, aiming for a situation in which directors of interfaculty research institutes would get integral responsibility and decision power for research policy and budget allocation. However, materialisation of this new policy took longer than intended and communicated by the Central Board. In its negotiations with the deans and the university council, only stepwise progress was achieved. Parallel to this process, the Central Board kept signalling to the scientific directors of the interfaculty research institutes, that theirs would be integral steering power in due time. By 1998, MESA's academic leaders got frustrated about the lack of progress.

The breakthrough towards strategic co-operation between MESA and CMO was caused by a change in the national research policy landscape, the introduction of a new national strategic research policy scheme, the so-called "Dieptestrategie". The actual introduction of this scheme, that is, the allocation of major multi-annual research funding to a selected set of strategic initiatives, did not acknowledge the strategic importance of the alliance that MESA had been working on, a strategic alliance with the Technical University of Delft. A strategic endeavour that MESA's academic leaders had embarked on right from the start of the new research organisation in 1990. While getting MESA off the ground, MESA's academic leaders had been

Distributed academic leadership in emergent research organisations 4. Mesa+ 
advocating that MESA's research profile and its clean room facility were an important asset for the Dutch research and innovation landscape in the European market for research funding. The main competitors for the same research funds were research groups in Delft. Despite this competition, talks about some form of strategic partnership had been taken up from time to time. These talks entered a phase of materialisation during this episode of MESA's development. For more than two years (1996-1997), delegations of academic leaders and board members of MESA and the DIMES research institute in Delft had investigated in a constructive way the feasibility of research co-operation and joint exploitation of capital intensive research labs. The envisaged organisation got the ambitious working title "National Research Centre", a set up that included transfer of responsibilities to a joint scientific board and directorate. After ample deliberations in 1997 a joint proposal was submitted for the newly established national research programme "Dieptestrategie". With this strategic investment programme, the Dutch government intended to support a selective number of "peaks" in the research landscape.

However, the joint proposal from Delft and Twente was not acknowledged as of national strategic importance by the national government, no strategic funds were allocated to this joint initiative. The impact of this set back was enormous. It was decided between Delft and Twente to set the negotiations for further co-operation on hold. National research policy organisations, like STW, expressed in public their annoyance of this negative decision of the Dutch government and were looking for other ways to stimulate co-operation in this field of research.

These responses from national stakeholders could have led to a continuation of the alliances talks with Delft. However, at the University of Twente, the Central Board came to the strategic decision that in order to be successful in the national and international competition for research funding via strategic alliances, a further joining of forces within the University was a necessary first step. The Central Board immediately responded with a "local" investment programme, reflecting the same aims as the national "Dieptestrategie" programme, aiming at the formation of "Topinstituten". They could act quickly, as this programme had already been prepared in 1997 as a policy instrument to stimulate research alliances. The timeliness and quick response suited MESA's academic leaders in their search for alternatives in alliance formation.

These events at national and University level sparked talks between academic leaders of research institutes. In January 1998, the scientific director of CMO approached MESA to

Distributed academic leadership in emergent research organisations 4. Mesa+ 
investigate co-operation or even fusion of the research institutes. In June 1998, the scientific directors of MESA and CMO informed their research groups leaders, the boards of the faculties and the Central Board in a joint letter. In fact a letter of intent that paid due respect to the historical dimensions, mentioning a "wish that had been around for years", to the difference between both institutes in term of lifecycle and culture, but also the necessity and actuality of an organisational merger. The letter referred to the swiftly changing national and international research landscape, resulting in strategic research funding via research schools and leading technological institutes. In the consultation of the leading academics in MESA, a range of, primarily positive, reactions were registered. Expectations were that a merger would improve the development of a joint lab and its personnel infrastructure. It was openly discussed, that $\mathrm{CMO}$ and MESA were in different stages and directions of organisational development. Concerns were shared that the merger would take too much attention, to the cost of the pace of further development of the MESA programme. The scientific directors called for mutual trust understanding in order to deal with these differences, concentrated in issues like the name of the new institute, the question which faculty should become the prime responsibility (as Electrical Engineering was for MESA and Applied Physics for $\mathrm{CMO}$ ), and above all: the profile of the new scientific director. Opinions differed, varying from preferences for a senior academic who would devote himself to the overall leadership of the institute instead of managing his own research group, a foreign senior academic, up to a senior who should have strong network relations in Dutch government and industry.

The two scientific directors, in close co-operation with UT's Central Board, dealt with this opportunity and related negotiations ${ }^{39}$. The Central Board formed a taskforce of the two scientific directors, seconded by prof. Reinhoudt and the technical director of CMO as advisors. This taskforce made good progress and was able to create an understanding in the founding Faculties and in the University Council, jointly with the Central Board, that this alliance was an opportunity of strategic importance for the University as a whole.

\footnotetext{
${ }^{39}$ This joint leadership initiative signalled a change in leadership relations between senior academics in the boards of the two research organisations and the academic leaders of the organisations. These seniors in the board had played important leadership roles during previous events. In particular the MESA board expressed their concern that they were not consulted by the Central Board neither given a central role in this important situation. After the merger had been concluded, a new board for the merged organisation was invited.
}

Distributed academic leadership in emergent research organisations 
In this process of merging, the two scientific directors, prof. Jan Fluitman and prof. Horst Rogalla, signalled to make space for a successor that would lead the merged organisation. In January 1999, David Reinhoudt was appointed. Being a chair holder at the founding Faculty of Chemical Engineering, in previous years he had been one of the bridging academic leaders in MESA, promoting an approach of strategic programming by stimulating high potentials to focus on "orientation" areas on the edge of research lines in the programme of the institute.

He was not in MESA's initial core areas of electrical engineering and applied physics, but in the area of chemistry, particularly supramolecular chemistry. His research group belonged to a Faculty that had achieved a strong research reputation internationally and with industrial partners. He had been a frontrunner in European co-operation; at the time he investigated the feasibility of creating a chain of European research labs, in that context aiming at a European research lab status for a joint venture of several research groups in his Faculty. As of 1993, he had taken actively part in foresight studies on a national level on the new area of "nano science" (Reinhoudt, 2007).

For the strategic positioning and multi-annual research it was important, that Reinhoudt took an entrepreneurial leadership approach right from the start, acting as a bridging boundary spanner between competing forces within the University and for that purpose crossing boundaries and management structures of the University. In his role as advisor to the merger between $\mathrm{CMO}$ and MESA, he actively engaged in negotiations at all levels, within MESA, with CMO, the deans and the Central Board. In the MESA management team meeting of December 1998, the last meeting that was led by the then retiring scientific director Fluitman, he informed about his negotiations with the Central Board that were almost finalised. In his opinion the merger was past the point of no return, five research groups from $\mathrm{CMO}$ would join, the name of the merged institute would be MESA+. He stated that he was in a process of negotiation with the Central Board about a multi-annual budget, a budget that would be allocated to MESA+s, once the merger would have been formally concluded.

The merger had no precedence in the University of Twente. Not as to scale, but also not as to leadership arrangements. Before being formally appointed, Reinhoudt as envisaged scientific director negotiated a multi-annual strategic financial scheme with the Central Board that he would be accountable for, reporting directly to the Central Board, no longer to the deans of the

Distributed academic leadership in emergent research organisations 4. Mesa+ 
three Faculties that formally constituted MESA+. MESA+ new scientific director was the first at the University to achieve this overall accountability, and to support him, in June 1999 a new position was created in MESAt: a "technical and commercial director" was appointed with a direct administrative mandate from the Central Board of the University. The management team of MESA+ that in MESA consisted of the scientific director and invited research group leaders was broadened and converted into a consultative body, named Advisory Board: a monthly meeting of twenty five academics, comprising all research group leaders and programme directors of strategic research orientations.

The overall governance structure of MESA+ was restructured in 1999 into two steering bodies. A completely new board was formed, consisting of leaders from industry and from capital investment groups that specialised in innovative technology. In addition, an international scientific board was established.

As had been the case in the first episode of its live, the organisational development of MESA+ and its negotiations with the deans and the Central Board was a catalyst for creation of new policy and arrangements: the "topinstituten" policy scheme, the notion of strategic research orientations, the multi-annual agreement between MESAt's research leaders and the Central Board. As a leadership arrangement, the process of merger negotiations between MESA's en CMO's leaders had no precedence in the University, and had a clear structuring impact. A few months later, in 2000, after four years of negotiations, the Central Board agreed with the deans on the "kanteling" of responsibilities from deans to directors of interfaculty research organisations.

\subsubsection{Convergent research themes (SROs)}

In the second episode MESA's academic leaders focused increasingly on boundary spanning research themes. Building on the "orientations" and strategic research projects that had been developed in the previous episode, an understanding about "strategic research orientations (SROs)" materialized.

In spring 1998, the then scientific director (prof. Fluitman) had shared his assessment of thematic orientations within MESA and with the Central Board.

Distributed academic leadership in emergent research organisations 
The now appointed scientific director coordinated the process of decision-making, he promoted an ambitious set of SROs. In this process, deliberations and negotiations took place with different groups within MESA+ and with the Central Board of the University.

In the final phase of the second episode, as of 1999, MESA+ fully embarked on the development of SROs. Building on the thematic areas that were developed as from the start of MESA in 1990, MESA's academic leaders were inspired by the promising results of the first "orientations", started in the years 1994 and 1996. After an intensive consultative row of meetings, they decided to invest in five SROs: CHEMNET: lead by Albert van den Berg; Nanolink: Juergen Brugger; Terahertz: Gerrit Gerritsma; Advanced photonic structures: Kobus Kuipers; Interface materials science: Dave Blank.

This strategic leadership arrangement was, as an event of strategic importance, acknowledged by MESA's board: despite their interim-status in the transitional period, they took their position, deliberating with the scientific director in several meetings. Departing from a positive stance, as they saw that these themes would have a boundary spanning impact that was important for a successful merger of MESA and CMO. They also saw the importance of timing: in their opinion, strategic decisions could not be postponed till a new board was in place. The impact of their stance was that MESA's academic leaders were given the opportunity to make a full start with MESA+ as of the year 2000, with a strategically important set of thematic projects. They shared concerns as well about timing and organisational dynamics. A new board still had to be invited, discussions hinted towards a board of primarily industrial and commercial experts, the new board should have enough space to guide the institute in new directions. These new directions and even the governance style of new board members, coming from a private sector environment, might fringe with the intended open ended character of SROs.

Another concern related to the dynamics of a merger, comprising a broad span of control of different research groups. The Board had information that many research group leaders were simply waiting what would happen, first looking to the MESA board and the scientific director, resulting in an organisational climate that would not be favourable for a productive start of SROs. They were in particular concerned that the intended boundary spanning and the innovative impact would not materialise.

Distributed academic leadership in emergent research organisations 
Finally, after ample considerations, the Board decided in favour of the proposed five SROs. Their strategic appraisal was that the proposed SROs were adventurous and in terms of innovative impact competitive to innovation projects that STW would promote, implying that MESA's SROs would rank high in the Dutch research and innovation landscape.

MESA's research group leaders that gathered in the consultative so-called "advisory council" were in a similar situation as the Board, in a period of transition. Besides deliberations on the research profile of the SROs, much attention was paid to the role and position of the coordinators of the SROs, later on called "programme directors". Arguments varied and were contrasting. The function of programme director should be fulfilled as if they were newly arriving colleagues, developing academic leadership in order to stimulate research groups to diminish their autonomy in favour of a thematic programme, a SRO. Strong research leadership arrangements would be crucial, administrative co-operation agreements were seen as necessary but not the effective drivers for new and adventurous research directions. On the other hand it was stated that SROs should be organisational spaces that would allow research groups to get familiar and find out in practice which co-operation works effectively. These deliberations in MESA's Advisory Board covered a row of meetings, from spring to autumn. In these meetings MESA's board took a consultative role: presenting a plea for an open minded approach of SROs, to avoid too much institutionalisation, to give maximum space to programme directors in order to allow for new research topics.

The envisaged SRO programme directors were not taking leadership roles in formal bodies like the Advisory Board. In an informal sense they were backed by the scientific director, as their names were already presented in the Advisory Board while formation of SROs and selection of programme directors was still not fully agreed upon. In practice, as they were the writers of the SRO proposals, they organised a leadership learning space.

The establishment of SROs as a new research leadership arrangements was a case of organisational change. For the research groups and their leaders, it implied giving away a certain amount of leadership, steering power and mandate. In some cases, the new SROs could build on the previous thematic research orientations that had been active as of 1994 and 1995. In other cases, chair holders explicitly decide to step aside, to give a runner up, not being a professor

Distributed academic leadership in emergent research organisations 4. Mesa+ 
appointed, the chance and support to develop a promising research area, building on existing networks, expertise and infrastructure.

The Central Board of the University had an active role as a supporter of the newly constituted merged MESA+. They gave firm policy support, communicating in the University Council, among the deans and towards external stakeholders that MESA+ was of high strategic importance for the University.

They agreed with MESA+ on a financial support scheme for a five years period that was by size and character new to the University. The size was substantial, a total commitment of 32,5 million guilders. The character of the agreement was that MESA+ and the Central Board mutually committed themselves to focus on the development of the agreed multi-annual research programme. To that end, the grant was conditionally linked to the research programme, ensuring the commitment of MESAt's academic leaders. The Central Board signaled, that they would focus as well on this agreed programme, they would no longer accept individual applications from research groups that co-operated within MESA+. Not an easy agreement to stick to, taken in consideration that MESA+ covered some $40 \%$ of UT's research capacity $^{40}$. MESA's academic leaders saw this agreement as an important instrument for the development of research projects that materialized the strategic research programme.

In translating the strategic research programme into strategic orientations and projects, the new scientific director played an orchestrating and binding role. In a years' time (1999) he effectively managed negotiations with the different stakeholders within and outside MESA+ (research group leaders, deans, the Central Board, individual chair holders, envisaged programme directors, the Dutch Research Council). He basically followed a stepwise approach: given the five year financial guarantee that had been granted by the Central Board on the condition of an agreed five year research programme, he discussed and agreed with the MESA+ interim board (the former MESA board) on strategic orientations; parallel he consulted and negotiated with the research groups which SROs to define, and how to resource these.

Consulting and negotiating in more or less formal fora resulted in visible leadership of the new scientific director and academics who supported this approach, and the envisaged programme

\footnotetext{
${ }^{40}$ Annual plan 2001, MESA board. MESA+ contributes $40 \%$ of UT's research output, using $21 \%$ of the basic research funding. MESA+ receives $50 \%$ of the Dutch Research Council's grants to research groups at the UT.
}

Distributed academic leadership in emergent research organisations 
directors. The director acted as a promotor for the programme directors, not allowing others to intervene in their way of working. He made clear in the Advisory Board (the collective of research group leaders) that he would listen carefully and would follow advice wherever possible, but appointing the programme directors and assessing their performance was his responsibility. In the negotiations with the deans he countered concerns of the deans that research governance and leadership would rely solely with the scientific director.

The resulting five SROs that were agreed upon in January 2000 had a balanced constitution, based on a process of intensive negotiations, carefully assembled within a broad scope of appealing, adventurous perspectives that MESA+'s academic leaders were invited to reflect on. As from 2000 onwards, this process was partially formalised. The SROs were institutionalised in the sense that their coordinators got a formal position as programme director, directly reporting to the scientific director. Previously, SRO leaders had been reporting on a task basis to the director, formally belonging to a research group, for their career development being depended on the respective deans. Now, they got management responsibilities and admin staff support, in order to facilitate the researchers and make sure that MESA+ would lower the admin burden for research groups of project and programme management of externally funded projects.

This step in institutionalisation was not taken without ample consideration: concerns among the deans led to an intervention by the Central Board that wanted to have programme directors appointed by the deans, following a proposal from the scientific director. MESA+ countered this intervention. The programme directors would from then of be appointed by MESA+, holding an associate professor position under supervision of the dean of the administering faculty.

In the strategic plan that was developed in the year 1999, MESA+ headed for a 70\% coverage of SROs over its research force. By then, 375 researchers were active in MESA+ of which $43 \%$ were working in projects that were funded by NWO/STW, EU and industry.

\subsubsection{The development of a new business model}

Now that the policy climate at the University of Twente was becoming more favourable for research institutes, also the competition in acquiring multi-annual funding from University resources and external funds was rising: five research institutes were now competing. On a national and international scale, coalitions were created and funders were shifting their focus

Distributed academic leadership in emergent research organisations 4. Mesa+ 
gradually towards multi-annual programmes. In this context a more mature business model for MESA+ gradually evolved. According to the organisational change of MESA+ towards an evolving centre for excellence and relevance, this process was not without tensions. The duality of the research institute was becoming more apparent, as the areas of funding were widening: not only in size, but also in diversity. With this diversifying spectrum of funders, MESAt's academic leaders were challenged.

This leadership challenge had an internal and external dimension. Notwithstanding the competition within the University of Twente and its far reaching impact for institutes as MESA+, the reality was by now that a substantial part of MESA+'s finances came from external funders. The dynamics of these external programmes and projects was increasingly becoming predominant for MESA+'s leadership: most of the research leadership's time had to be spend on proposal writing and acquiring projects, as well as on timely execution. This was not a trivial task. A range of, often interrelated, complicating aspects were at stake. Due to the dynamics of the research areas that MESA+ covered, all projects were directly related to the availability and quality of lab facilities and technical staff. In practice, besides the operational management challenge, for MESAt's academic leaders this caused tactical problems and even risks. More than once MESAt's leaders had to consider to temporise or even stop execution of already funded projects for development of its lab facilities, as projects that should exploit these labs were simply lagging behind, implying that subsidy conditions could not be met and already received funds would have to be paid back. For instance in the year 1998 MESA+ was not able to spend the funding as supplied by the Central Board, simply because PhDs could not be recruited in time. In response to problem of a low availability of PhD candidates MESAt's leaders gave full priority to recruit PhD candidates for externally funded projects.

This is an example of the internal focus of organisational development that academic leaders had to devote time to. Meanwhile different and even contrasting dynamics with an external focus anticipating towards new opportunities challenged MESAt's academic leaders. The dichotomy between the leadership arena's at the University level, the research institute level and external arena's got under pressure. While MESAt's academic leaders were fully focussed on external relations and organisation change towards a new business model, they also had to

Distributed academic leadership in emergent research organisations 4. Mesa+ 
participate in the negotiations and powerplay that evolved between the Central Board, the University Council, the deans and the collective of research institute directors about the overall funding model of the University.

The Central Board's on-going struggle with the envisaged new university allocation model ("Kanteling") and MESA+'s need for long term stability and commitment as a basis for acquiring external funding came to a breakthrough in 1999. In negotiations between UT's Central Board and the directors of the research institutes MESA and CMO, a financial arrangement was drafted in its size and nature new to the University of Twente.

The Central Board committed itself to a financial package of 31.250 million guilders in total, the accumulated sum over a time period of 5 years, 2000 till 2004. This package comprised all specific grants that would have been given to MESA and CMO on an annual basis. In addition, about 10 million, 2 million per year, was granted to MESA+ for new investments.

In December 1998, the envisaged new scientific director of the merged institute MESA+ added this arrangement to his letter of appointment. During the year 1999, he used this arrangement as a triggering means of negotiation with the faculties concerned: the bottom line was that the Central Board had agreed upon a condition sine quo pro: either MESA and CMO would join forces in a merged institute headed by the new scientific director, or the Board would retract the commitment.

In terms of financial size and duration of commitment, this was a new arrangement for the University of Twente. The impact on the autonomy for MESA+'s leaders to govern its research programme in a relatively autonomous way and to embark on multi-annual arrangements with external funders, it allowed for a new business model for a research institute that headed for the international market of research funding.

Internally, in the University of Twente, the "32 million deal" was perceived as a successful intervention of a research institute in order to enforce autonomy, the envisaged result of the "kantelingsoperatie" that the Central Board was favouring, but that the deans were opposing to.

For MESAt's business model development as a centre of excellence and relevance, the deliberation and negotiation processes that evolved around the formation of the merger institute and the "32 million deal" had a structurating impact on the alignment of the institute with its immediate context in local and national programmes.

Distributed academic leadership in emergent research organisations 4. Mesa+ 
In the local context, the merger and the five-year planning of human resources and financial means caused a lot of deliberation and negotiations. Already in the year 1998, once the scientific directors of the research institutes MESA and CMO had jointly proclaimed the merger, discussions among academic leaders sharpened in terms of choices that had to be made in terms of strategic research focus. Some research groups were committed to five years plans of more than one research institute, for instance to $\mathrm{CMO}$ and the neighbouring research institute for biomedical engineering. Now that the merger was planned, an issue was whether research groups should fully commit to one research institute. It resulted in an agreement, that this would not be a requirement for a research group, but for an individual researcher. Later on, in 1999, while the new scientific director was finalising discussions on human resourcing of the five year research programme, similar discussions occurred, resulting in the understanding that each group should participate in at least one SRO; once a group would participate in two or more SROs, each individual researcher should commit himself to fully one SRO.

Another struggle with the University procedures concerned the organisational positioning of the (yet to be appointed) SRO leaders, the so called programme directors (PDs). Due to interventions by the deans, SRO leaders were appointed by and had to report to the scientific director, but for their overall career development they were accountable to the dean. The position combined promoting scientific excellence with relevance. A SRO leader got his own administrative staff, in order to support him and the SRO members in project development and (financial) administration: as it were, business development units, aligned to the codes of conduct of research funders and private sector partners, in the heart of a research institute.

Central in this enhanced focus on strategic research co-operation with external partners became the new position of the "technical commercial director" (TCD), that was created in 1999. So far, before the merger, each institute had a full time administrative manager. The new scientific director proposed to the academic leaders and the MESA+ board to allocate this manpower capacity differently, adding admin staff to the SRO directors, and shifting the focus of the position of administrative manager towards a more commercial and public relations focus. This new form of leadership did not cause too much discussion, mainly because the proposed candidate was already a trusted member of the previous MESA institute, with an academic background and being one of the main players in the development of the MESA+ lab facilities. Proposed by the scientific director, he was appointed by the Central Board of the University. The

Distributed academic leadership in emergent research organisations 4. Mesa+ 
TCD got a direct mandate from the Board for financial and personnel affairs. Once appointed, the TCD immediately started to develop an enhanced strategic focus in close collaboration with the scientific director and other academic leaders.

In 2000 the uptake to a higher level of commercialisation became visible. A certain focus on commercialisation had been part of senior academic's deliberations since the start of the MESA institute. Resulting in the execution of a "business plan" as of 1994, followed by discussions as of 1996 about standardisation of working procedures in the lab, as an uptake to prototyping and commercialisation in a dedicated business unit. Now, in 1999, the uptake to commercialisation and acquiring investors for research funding was created.

\subsection{Episode 3 (2001 - 2005)}

\subsubsection{Brief history}

The third episode of this case study covers the years 2001 till 2005. The just merged institute MESA+ came into full operation, swiftly expanding its programming towards national programmes, connected to research projects and to further business model development, geared to the dynamics of national and internal programmes. In 2001, MESA+ employed 400 staff, had a turnover of 55 million guilders of which $50 \%$ was externally funded.

Favourable for MESAt's expansion were the very high expectations around nano science and nano technologies. A political landmark was that US president Bill Clinton promoted this theme in his speech at Caltech in 2000, proclaiming the "National Nano Initiative" in the US. These expectations favoured openings in the Dutch innovation policy and new chances for MESA+. Chances that were anticipated and lobbied for by MESA+'s academic leaders, knowing that innovation policy and priority setting in it were highly dependent on international development. At the same time, another promising area, ICT research and innovation, suffered from setbacks due to the international economic events known as the "bursting of the internet bubble". Competition in research funding was enhancing as the budgets at national level were not growing, in fact decreasing: at the time, costs of personnel and research infrastructure were rising and the student influx in engineering and sciences was decreasing, basic research funding in these areas got under extra pressure.

Distributed academic leadership in emergent research organisations 
While anticipating on the national perspective of growth MESAt's academic leaders were facing tensions within the UT university system that MESA+ was part of. In negotiations about the funding system, basic research funding became a strategic issue in the negotiations between MESAt's academic leaders and the Central Board. At the University of Twente, new study programmes that were effective in attracting students required basic research funding that only could be found by taking it away from other existing studies with lower student numbers.

As regards the organisation of research, UT went through very turbulent times. The Central Board of the University and in particular the President were in favour of a strategic positioning of research institutes, that is to say: that research institutes would get more autonomy from the Faculties and be directly accountable to the Central Board. Throughout this episode, MESAt's academic leaders had to deal with a range of negotiations and interventions of the Central Board and the deans. A policy initiative that already started in 1996, aimed at autonomous budget responsibility for research institutes, went through rough times now.

A more flexible way of research funding was initiated and negotiated by the Central Board, aimed at an enhanced steering and anticipating capacity within the UT research institutes. The academic leaders of these institutes were invited to coordinate their efforts to materialise the strategic priorities of the University, and to jointly anticipate on trends in research priority setting and funding at European and national level.

Coordination and strengthening of the strategic steering capacity of Faculties, research institutes and the central governing bodies was also taken up. Learning from European partner universities that were aiming at a similar entrepreneurial organisational culture ${ }^{41}$, the Board decided to create a University Management Team, consisting of deans and scientific directors, a process that took a couple of years to work productively.

In this turbulent setting, not only academic leaders with a management position, the scientific director and the technical commercial director, but also other leaders were actively involved in a lot of discussions on research governance and funding in the University of Twente.

As MESA+ grew swiftly, MESA+'s academic leaders were often out of office, because a lot of networking, programme building and public relations had to be done. In a way, the playing field for leadership activities shifted from the UT campus towards national and international arena's.

\footnotetext{
${ }^{41}$ At the time, UT's Central Board organised benchmark studies and study tours with deans to the universities in the UK and Scandinavia that were their partners in the European Consortium of Innovative Universities (ECIU) that fort his purpose (strategy development and organisational learning) had been co-founded by the UT in 1996.
}

Distributed academic leadership in emergent research organisations 
This turbulence was also apparent in the heart of MESAt's processes, the way that research groups organised their actual research work. This was in particular for those academic leaders who were research group leaders the truly inspirational challenge, beyond the clear results in terms of extra research funding and access to research infrastructure. The world of on-going miniaturisation in electrical engineering came together with the worlds of molecular assembly in physics and chemistry: in a new, common, MESA+ clean room and facilities research lab; the conceptualisation of this lab, its alignment with different strategic research priorities on a local, national and international level, its governance, was an important challenge for MESA+'s academic leaders at the time.

\subsubsection{Analysis of research leadership practices}

\subsubsection{Programmes on a national and international scale}

At the start of this episode, the MESA+ research institute had gone through a transition period. A period of about two years of merger activities, a lot of deliberations and negotiations, planning and programming, forming new governing bodies and creating a lively and productive organisation.

As of 2001 MESA+'s academic leaders focused their activities, as agreed in annual plans, 2001 being the first year. These annual plans were a periodical optimisation of the actual opportunities against the backdrop of the five-year research plan that had been agreed with the constituting Faculties and the Central Board of the University.

This five-year plan was not seen by MESA+'s academic leaders as a limitating structure, but as an agreed basis and an financial opportunity for development of joint activities. In order to gain results at a programme level that couldn't be achieved by a research group on its own. The orientation towards national and international co-operation and competition fuelled the discussions among MESAt's academic leaders. The annual plan 2001 embodied a flavour of entrepreneurship and strategic drive. The style and wording of the document was ambitious, acknowledging that it would take another two years to get the organisational structure full grown: "MESA+ is the initiator, stage manager and spokesman for the Dutch Nanotech programme in the framework of the national innovation investment scheme ICES-KIS". And concerning international positioning, it was stated: "We aim to benchmark with the league of

Distributed academic leadership in emergent research organisations 
ETH, Cambridge, MIT, and Berkeley." These ambitions were shared and discussed among MESAt's Board and academic leaders and board, leadership interventions were taken as well. In spring 2001, MESA+'s Board, while reviewing the situation once they had been for one year in office, came to the conclusion that MESAt's strategy development and its alignment with developments within the University of Twente needed more attention. Strategy development should occur at a higher pace; it was decided to meet for the time being on a monthly basis, instead of on a half-year basis. This intervention, the strategic repositioning of MESA+s Board, became an issue. In spring 2001, the deans who took part in MESA+'s Board ${ }^{42}$ claimed that it was their responsibility to cater for the long term research strategy, because, as they saw it, research institutes were aiming at mid-term targets. This stance reflected the formal situation, wherein research institutes got a five years mandate from constituting Faculties. It also reflected a mode-1 perspective that in the long run developments in scientific disciplines were the real and lasting results, not the mid-term programmatic multidisciplinary approaches. The contrast with the long term ambition of the scientific director, the TCD and the external Board members, took a range of meetings to overcome differences in opinion and resulted in a productive debate throughout spring. An important outcome was an understanding that was new for the University of Twente: MESAt's academic leaders would be allowed and would pro-actively take a role in the long term research strategy of the co-operating Faculties.

It was agreed that MESA+ should take a pro-active stance in initiating new chairs as a means of influencing and adding to UT's research strategy. SROs were seen as a proper instrument to create new and promising research lines that would create the scientific, human resource and financial basis for a research group. Its effectiveness was underpinned by the recent appointment of two SRO programme directors as professors, funded by and organised within the MESA+ research programme. The time was right to develop this role, as MESA+s Board saw it, as the Central Board of the University was developing plans to constitute a new governing body: a merger of the board of deans and the - so far informal - committee of scientific directors of research institutes, into the "University Management Team".

In early 2002 it became clear that MESA+ had reached the limits of the five-year plan that had been agreed in 1999. The then planned results were achieved in two years' time: the SROs were

\footnotetext{
${ }^{42}$ as of 2000, two of the Board members were deans of the Faculties that had constituted MESA+. The Central Board of UT had imposed that the new board of MESA+ should comprise a delegation of the deans of the founding Faculties.
}

Distributed academic leadership in emergent research organisations 
up and running, the financial basis for the five years' plan was fully geared and matched to external funding from national and international programmes.

In the following years 2003 and 2004, leadership actions were primarily taken by the scientific director, the TCD, the SRO programme directors and some twenty senior academics. They met on a monthly basis in the Advisory Board. It was this forum that made MESA+ research policy in practice, in acting in a concerted way in diverse arenas, that is in negotiations in the University and in several national and international networks. The Board played an active role in two areas: primarily in MESA+'s valorisation and commercialisation strategy development.

The distributed features of MESAt's leadership practices were stretched in this phase, in time and space perspective. As the attention of the SRO programme directors, scientific director and TCD was mainly focussed at the development of national and international programme consortia, they were often in meetings "in The Hague" (the location of Dutch ministries) and "Brussels" (the EU). One indication of distributed leadership was that there were periods of months that no plenary meetings of the Board or Advisory Board took place. The Board for instance didn't meet for eleven months from late 2003 till late 2004.

The members of the Advisory Board were informed about and many of them were engaged in the development of the Nanoned consortium ${ }^{43}$. The negotiations and creation of the programme consortium took from 2001 till 2004. MESAt's academic positioned the MESA SROs as "flagships" in the envisaged Nanoned programme. This milestone was reached in about a years' time, in 2001. MESAt's academic leader made use of the experience that had been gathered in 1999 while organising SROs in the framework of the MESA+ five year research plan. The elaboration of the flagships was not just a matter of scientific creativity, planning and programming. A leadership learning space materialised while academic leaders had to act on and balance interests between different arenas on a level and pace that they had never encountered before.

The contrasting dynamics of excellence and relevance became apparent in this process. The Ministry of Economic Affairs had appointed a senior innovation investment consultant to support the formation of the programme, this intervention caused concerns among MESAt's academic leaders who, different from the scientific director and the TCD, were worried that the

\footnotetext{
${ }^{43}$ Nanoned was at the time a leading Dutch research consortium that comprised some 400 researchers from seven universities and industrial research groups from TNO and Philips.
}

Distributed academic leadership in emergent research organisations 
resulting focus would be too much directed towards commercialisation. Concerns that sharpened due initiatives taken by MESAt's board and TCD. Throughout 2001, the Advisory Board was discussing proposals for a "commercial vehicle" connected to MESA+, called "TwANTS" (Twente Advanced Nano Tech Systems BV). The proposals that the Board and TCD presented caused fundamental discussions in the Advisory Boards. The Board and TCD saw this initiative as vital for MESAt's mid-term positioning and funding base, once the basic funding from the University of Twente would expire. The scientific director and TCD positioned TWANTS as an instrument for transformation, to embark on a new level of activities, meanwhile making the contrasting dynamics of excellence and relevance productive. They carefully presented TwANTS as a preferred partner for commercialisation, that would allow MESA+ to develop research activities that were not possible due to lack of financial support from government, research councils or industrial partners. They argued that TwANTS would boost MESA+'s academic research, different from commercial private sector partners that would just drag commercial high potential ideas out of MESAt's research groups by offering financial returns, without acting as a strategic partner that would be willing to invest in advance and to take risks. The discussions forced the academic leaders to further develop leadership, to engage in strategic decision making in collectives, to overcome contrasting dynamics that were intrinsic to MESAt's constitution. In the same period it occurred that strategic decisions had to be taken as to the focus on national programmes. Research groups within MESA+ were participating in different national programmes. The main focus was the Nanoned initiative, that was leading in. Some research groups were participating in initiatives that happened to become competitors for the same national innovation grant scheme. The Biomade initiative was led by Groningen and the MicroNed led by Delft. Initially the micro initiative would be part of the nano initiative. The strategic considerations and immediate administrative implications caused debates between MESA+s academic leaders that tested the cohesion of the distributed leadership relations. In spring 2003, the Nanoned initiative had reached an understanding among the university partners about the joint investment scheme including the budget allocations to the different research labs. Just before the official deadline of the national funding scheme it became clear however, that research groups had signed up to both the Nanoned and the Microned initiative, resulting in conflicting commitments, implying that due to governmental administrative

Distributed academic leadership in emergent research organisations 
regulations the proposals could not be accepted. A situation that was handled by the Nanoned Board in a 24 hour crash operation.

In 2004 MESAt's academic leaders were confronted with strategic challenges due to interventions by the Central Board and the deans concerning research organisation and funding. Two developments coincided that urged MESA+s academic leaders to participate in many negotiations, within MESA+, with the deans, between research groups, and with the Central Board. It regarded developments in the national system of research funding, resulting in a decreasing budget for universities, and the struggle within the University of Twente to achieve a governance and power balance between "schools and institutes". In response to these developments, in order to secure a stable base for MESA+'s national and international position, in 2004 the scientific director initiated a set of coupled studies. Aiming at international positioning, assignments were given to a British consulting group and to the University of Leiden. The consulting group produced a benchmark that positioned MESA+ in the world wide research and innovation landscape, belonging to the top three of European laboratories in the area of nanotechnology. The Leiden University's research institute CWTS (Centre for Science and Technology Studies) was invited to conduct a citation study that proved MESA+'s reputation.

These strategic initiatives to strengthen MESA+'s position in international research, innovation and valorisation activities were highly appreciated by the Ministry of Economic Affairs, the main stakeholder in the national innovation programme that supported the NanoNed programme. This strategy towards innovation and valorisation could build on MESA+'s experience with commercial start-ups and technology transfer. In (1996) an interfacing unit was created to support technology transfer to high tech firms, including a system for timesharing of MESA+'s lab.

In 2004, MESA+ succeeded to get a prominent role in the EU sponsored Network of Excellence Frontiers (coordinated by Cambridge, UK). MESAt's scientific director presented this as a milestone in MESA's strategy development. "Frontiers is the final phase in the route MESA+, Nanoned, Frontiers. Frontiers is a step that MESA+ has to take in order to play an active role in the development of a European policy for research and innovation." ${ }^{4}$

At the same time, at the basis of MESA+, a sound growth was established. In 2005 three research groups from physics and chemical engineering joined the institute. All in all a complex

\footnotetext{
${ }^{44}$ The actual development of the Frontier NoE is not described here, but saw some problems, despite the initial reputational impact for MESA+.
}

Distributed academic leadership in emergent research organisations 
challenge for MESA+'s leading academics to keep up proper leadership, balancing between an increased growth in size and excellence and a growing network of industrial research partners and valorisation activities reflecting the relevance of MESAt's work.

\subsubsection{Strategic research orientations}

In 1999 the five-year research plan was negotiated and finalised. Based on the agreements reached, the Central Board had allocated a five-year budget. The five-year plan was structured according to strategic themes, named "strategic research orientations". Now that the strategic planning had resulted in a plan, funding, and high expectations, MESA+'s academic leaders were challenged to develop the themes, to converge on-going projects and new projects in coherent themes. MESA+ was a merger of two former research institutes; a particular challenge was therefore to bridge different cultures and approaches. After the budget had been allocated, SRO programme directors were appointed.

Once the SRO programme directors were appointed, during the year 2000 convergent themes were elaborated upon in content and in organisational terms. In the annual plan 2001 an explicit profile of SROs was presented, the central target being that $70 \%$ of the institute's research capacity would be organised in SROs. The SRO was positioned as instrumental for organisational development and development of new approaches: an SRO had to combine "high quality research of at least 5 groups within the institute into a truly multidisciplinary programme" and "the organisational innovative character should be an impulse for discussions on organisation of scientific research". The expectations were high, calling for "an organisational culture that should be lively, catering for scientific curiosity as well as an entrepreneurial attitude among researchers, (...) organised in flexible structures that allow for swift adaptations on a realistic and substantial scale." Of course there were doubts and struggles as well, one of them being that programme directors had to stand primarily for their own course and were basically competing among themselves. Still, strategic planning and getting SROs of the ground was not merely a matter of policy talk and lip service to the Central Board and national innovation policy stakeholders. Academic leaders that were participating at the time tell that the programme directors, jointly with the scientific director, the TCD and some professors formed a well aligned team.

Distributed academic leadership in emergent research organisations 
The thematic approach and research programme development along SROs was also applied while evaluating research progress. In late 2001 MESA+ as a graduate research school had to conduct a self-evaluation, in preparation to the periodical five years' evaluation for accreditation supervised by a Committee of the Dutch Royal Academy of Sciences. This evaluation was focused at the quality of a research institute as a training environment for young researchers, a so-called "research school". Predecessors MESA and CMO had been accredited as research schools.

MESA+ used this opportunity to report in detail on the development of the SROs, the selfevaluation was structured along the SROs. The report stated frankly that it took time for the programme directors to become effective as research leaders. Besides the daily contacts between researchers, the periodical meetings on a monthly basis were for quite some time primarily used to present and to get acquainted. After a while, common ground and trust were created to serve more open discussions on new approaches and orientations.

In particular regarding human resource matters, their academic leadership was tested. In view of the general problems in recruiting PhDs in science and engineering areas, it took a while until all vacancies were fulfilled, which was threatening a swift and productive start of the SROs. As a result, for quite some time the leadership focus was on resourcing and recruitment.

Leadership was also tested in finding new ways of budget allocation; the aim was to raise productivity, overcoming that usual problem that temporary vacancies would cause an underuse of available budgets. To achieve this, programme directors had to trust each other, in order to be willing to optimise budget allocation above the level of their own SRO. As of 2001 programme directors and their staff focused on performance measurement and related interventions. Supported by the scientific director, the five SRO directors jointly created a performance-oriented way of working. Quarterly progress reporting was directly linked to intermediate changes in budget allocations. Underused or non-used budget allocations were reallocated between SROs by the scientific director.

Gradually, the research groups accepted the thematic approach. The SROs served as a structurating principle for the annual forum of MESA+ researchers. The programme directors got responsibility to organise this forum and lead tracks and workshops.

Distributed academic leadership in emergent research organisations 
In early 2001, leadership was challenged due to successes in winning major grants and the urge to deliver in short notice. MESA+ won ten out of thirteen awarded projects that were granted by STW in the Masterplan Nanotechnology. This grant came at the same moment that MESA+ got a 3,5 million guilders grant from STW for investments in research infrastructure. This substantial impulse was of course welcomed by MESAt's leading academics, but also caused major concerns. MESA+s academic leaders saw that these grants were an impulse for the development of strategic research projects, that way strengthening MESA+'s autonomy from the University of Twente. This growth in leadership and steering capacity did not synchronise with the pace of change within the UT-system, more in particular with the Central Board's interventions to give enhanced steering power to research institutes. MESAt's academic leaders were concerned that they would not be able to deliver new labs and research activities to STW, because of the slow pace of materialisation of agreed projects. The MESA lab and its investments, including investment grants from STW, was still not managed by MESA+ but by the Faculty of Electrical Engineering. The "kanteling", giving scientific directors a far-reaching financial mandate, was not yet in place. The large number of vacancies for young researchers, even for professors, took too long to fulfil. Good people were hard to find, but MESA+ was worried that Faculties gave not enough priority to recruitment. These challenges were met, MESA+ succeeded to deliver, the granted projects got off the ground.

In 2002, the overall feeling among MESA+'s academic leaders was optimistic about the thematic approach and funded research projects that were achieved. Nevertheless, the actual academic leadership practice of SROs got blurred. Two programme directors got another position in MESAt's programme, as they were appointed as full professors. One programme director was invited to a chair in Switzerland. Another programme director suddenly died. It was reason to review the SRO approach. The MESA+ Board discussed a policy paper as prepared by the TCD and scientific director: three kinds of SROs were distinguished: converging and thematic, elaborating areas of common interest, and adventurous programmes. The Board supported the initiative to reconsider, but challenged MESA+'s academic leaders to come up with more adventurous approaches. In their opinion, in order for MESA+ to become a top research institute that "moves the frontier of research", they advised to promote a mind-set that would favour exploration of new areas, instead of focussing on continuity based on common interests.

Distributed academic leadership in emergent research organisations 4. Mesa+ 
The academic leaders recognized this appeal; the SRO approach was continued vacant positions for programme directors were filled in.

In 2003 MESAt's SRO approach got adopted and adapted within the University of Twente system. The Central Board decided to fundamentally change the budget allocation model for basic research funding: no longer would a major part of budgets be allocated based on the size of the academic teaching workload or on indicators connected to quality. The main allocation would be based on five-year research programmes as developed and managed by research institutes. The Central Board named these five-year programmes "SROs". But, distinctive from the SROs that MESA+ had developed, these SROs were an instrument of UT's research policy. Not the bottom up collegiate academic leadership was decisive for the pre-selection and final choice of proposals. It became a big challenge for the University Management Team to get to an agreement on the procedure and later on, to a choice of winning proposals. MESA+ started off as usual, inviting six professors to write proposals. Then, influenced by the discussions in the UMT, MESAt's management team considered to pre-select three proposals: one per Faculty that participated in MESA+. In the end, MESA+ submitted six proposals. The result of the competition for UT SROs was beyond expectation for MESA+: five proposals were awarded to MESA+, in addition research groups in MESA+ participated in two other awarded programmes. This number of SROs gave a clear impulse to leadership development and learning in the scope of strategic programming and connected project execution.

At the end of this episode, in 2005, MESAt's academic leaders once again reconsidered the converging themes and SRO approach. In their meetings they shared their concerns about the influence of the Central Board on MESAt's research policy. In hindsight, reflecting on the procedure that the Central Board had stipulated in order to make strategic choices, they would have preferred a procedure that would have challenged MESAt's leaders to make choices. These concerns were also fuelled by the fact that the influence of Faculties on basic research funding was still predominant, in spite of negotiations that had been going on for years between the Central Board and the deans. The scientific director responded to these concerns by actively engaging the academic leaders in continued deliberations throughout the year 2005 to identify new converging thematic areas, not being invited by external funders, but inspired by curiosity

Distributed academic leadership in emergent research organisations 4. Mesa+ 
and relevance as they saw it. These deliberations resulted in a range of different future directions for MESA+.

Parallel to and in interaction with these thematic re-orientation focused at MESAt's basic funding, a re-orientation on external funding opportunities took place as well. The dynamics of and openings to national and international programmes that MESA+ had geared up to, offered a range of opportunities for thematic programme and project development with a high strategic impact. The Central Board was pushing MESA+ to submit a bid for the development of a "Leading Technological Institute", a new innovation policy scheme initiated by Dutch industry and the Ministry of Economic Affairs. It concerned a joint venture with the universities of Nijmegen, Wageningen and Groningen, named "Nano4Vitality Food \& Health"45.

By 2005, the end of this episode in this case study, MESA+ was situated in a spectrum of programmes and projects; in the UT system, within MESA+ and between MESA+ and external partners. Implying that MESA+'s leading academics were steering at different levels of research organisation; the scale of operations created new challenges concerning cohesion of research programming and avoiding the risk of lock in because of dependence on specific programmatic consortia.

\subsubsection{Development of a business model for a CER}

In this episode the business model of the research institute reached a size, complexity and related leadership issues that challenged the boundaries of a university system.

MESA+ headed for a size of operations that geared up with programmes on a national and international scale. These initiatives were consciously planned and responded to, as well as were enabled by the bigger picture developments in organisation and funding of fields of research. Developments that immediately influenced the direction of development of MESA+'s business model.

\footnotetext{
${ }^{45} \mathrm{MESA}+$ was at the time involved in a range of European programmes and initiatives at national level. An example with a high political profile was the growing alliance as negotiated between Central Boards and deans of the three Technical Universities. At the time the Ministry of Economic Affairs' considered to boost this strategic alliance by allocating a 50 million grant, to be allocated jointly and in mutual agreement between the three Technical Universities for a set of strategic orientations.
}

Distributed academic leadership in emergent research organisations 4. Mesa+ 
An Achilles heel to MESA+'s steady growth and flexibility of operations was its ability to recruit excellent PhDs. This was a major problem for all science and engineering research groups in Dutch universities. For an institute of the size and complexity of MESA+ it was a challenge, sometimes even a risk, and a steady burden. As in all professional organisations, recruiting, selecting and most of all adopting new personnel is a core activity that requires attention from senior staff. In MESAt's case, the same senior academics that had to develop new projects, supervise and scrutinise quality, and, in particular in the frame of MESA+s mission as a centre for excellence and relevance, catered for innovative projects that required extra attention in terms of development and execution.

The development of an autonomous recruitment strategy was a first example that MESA+ business model stretched the boundaries of the University's system. In 2001, it took MESA+ on average more than nine months to appoint a new PhD candidate, whereas $75 \%$ of the $\mathrm{PhDs}$ were coming from abroad. Enough reason for an institute of MESA+'s size to develop its own recruitment policy: to go abroad and promote itself in international programmes, in order to get access to promising PhD candidates, no longer relying on UT's reputation or international marketing support.

A second example was MESAt's orientation on co-operation with industrial partners, sponsored by national innovation schemes. Diversification of research funding was an overarching development that already materialised in the late nineties but attracted full attention of MESA+'s Board and academic leaders now. A new leadership activity field for MESA+ was deliberately created: valorisation and new forms of research funding. Based on their expertise and expert networks, concerted leadership activities of the Board, the scientific director and TCD were decisive for the productive development of this new field.

The profile of the Board of the merged MESA+ institute was quite different from the boards of the preceding MESA and CMO institutes. No longer a predominantly scientific profile, but a business profile. Two of the Board members were CEOs of investment and innovation groups. A new management position was created, that of the Technical Commercial Director. In comparison to previous technical directors, the TCD was no longer primarily responsible for the operational management and the research lab management. His task was also to develop a business and valorisation strategy.

Distributed academic leadership in emergent research organisations 4. Mesa+ 
The focus of MESAt's business model shifted primarily to private sector partners, STW and the Ministry of Economic Affairs. Based on the lead position that MESA+ achieved in the national Nanoned consortium, MESAt's scientific director, in his role as scientific director of Nanoned, participated in advisory groups with immediate access to the Minister of Economic Affairs.

In addition to the programme based funding from national innovation programmes, MESA+ worked throughout on the development of a commercial entity in parallel to the research institute: a legally and financially autonomous entity, but via a contract fully connected to MESA+. The name of this entity was TwANTS, Twente Advanced Nano Technology Systems. After two years of preparation and negotiations, in the year 2002 MESA+ got the OK from the Central Board to start TwANTS.

MESA+ got full mandate from the deans and the Central Board for the integral governance and further development of the research laboratories. This was an important milestone for MESA+ business model development, as so far MESA and CMO had been struggling with the budget allocation system of the university and the participating faculties in particular. MESA+ started preparations for a completely new lab facility, a "smart lab" at it was agreed in 2003, supporting growth of MESA+'s research and valorisation activities, but without expanding the running costs for MESA+. A cost development that could not be controlled in the academic leaders' opinion a threat for MESA+'s long-term business model development. The creation of a new centralised lab was of course an issue of negotiations with the deans, who were keen to keep facilities close to and accessible for their Faculties. In this negotiation process, MESA+'s position in consortia like Nanoned was taken into account. MESA+'s scientific director, speaking on behalf of Nanoned, clearly stated that a unilocation at the MESA+ lab was a conditio sine qua non for Nanoned to allow MESA+ to hold the core position in the consortium.

This new area of valorisation was developed consciously, as MESA+'s felt that the envisaged growth of the institute could no longer rely on public research funding in the Dutch context. In a way, MESAt's Board and academic leaders were rather sceptical about the developments in the Dutch research landscape. In that perspective, they saw that the planned growth of the institute required an enhanced alliance strategy with industrial and other commercial partners, be it in EU research and innovation programmes or, even more radically, in co-operation with specialised investment groups that were aiming for high tech innovations. In 2004 MESA+ organised an international benchmark study that was assigned to a British consulting group,

Distributed academic leadership in emergent research organisations 4. Mesa+ 
confirming that towards investors and other parties that MESA+ belonged to the top three of European laboratories.

The same time that MESA+ had stretched the boundaries of the UT-system that it once fully aligned with, shifting the focus of its business model to national and international programmes, including the development of a valorisation unit, the university system struck back.

Already in the year 2001, two years after the five years programmatic funding deal of 32.5 million had been settled between the Central Board and MESA+, MESA+'s academic leaders were told that at the end of that five years' term, as of the year 2004, they would have to compete with other research institutes for a new five years grant. No guarantee was given, no preferred position whatsoever. The Central Board was determined to change the UT funding model in a fundamental way, turning towards full programme based basic funding of research. They saw no risk for MESA+, expecting that, based on its excellence and performance, MESA+ would win a renewed grant as of 2004. In addition, their consideration was also based on their strategic aim, that governance of basic research strategy would no longer be an exclusive power of the deans, but would be given to the scientific directors. A strategic initiative, named "kanteling": negotiations had been going on for years, time and again MESA+'s Board and academic leaders were assured by the Central Board that the "kanteling" would succeed, the external focus of their business model development would in due time be formalised with a strong and clear governance mandate.

However, in 2005 the "kanteling" was cancelled by the Central Board, as of the year 2006 the deans would set strategic research priorities.

MESAt's board and academic leaders were brought in an extremely difficult situation that put their business model under pressure. The major turnover in research funding and related research strategy development was being governed in national programme consortia. The deans of the co-operating Faculties governed the funding for MESAt's basic research.

MESAt's academic leaders felt unsettled with this situation. In the years 2004 and 2005 many meetings of the Advisory Board were devoted to this internal situation, at the cost of focus on external programme related strategic issues. The basic feeling was that the UT-system of research funding was no longer a pillar in MESA+'s business model that they could rely on. In late 2004, MESAt's financial annual plan 2005 was not accepted by the Central Board. According

Distributed academic leadership in emergent research organisations 4. Mesa+ 
to the UT research budget allocation model, MESA+ would go bankrupt, as they had to take a budget cut of more than $20 \%$ and accept a raise in housing costs. A major event that caused cynicism among MESAt's academic leaders. This situation was financially repaired by the Central Board in a few months' time, but harm was done. To MESA+ it was clear that the UT financial system did not support a further growth of MESA+. Although the Faculties that participated in MESA+ had been supportive, they had not been able to avoid this situation, also because other Faculties felt that MESA+ had enjoyed its fair share of strategic research funds and had ample opportunity to achieve more external funding; now it was time to favour other strategic research areas as well. MESAt's Advisory Board concluded that this new situation was a direct threat for MESA+'s organisational stability and further development, in particular for achieving the status of acknowledged leading technological institute in the Dutch research landscape. A fear that became true: without consulting MESA+, the deans of the Faculties of engineering of the three Technical Universities agreed in late 2004, that the time was not right for a TTI on nanotechnology.

In this situation of stress and tension between MESA+'s business model and the UT system, MESAt's academic leaders decided unanimously that all projects including all PhD projects should be fully aligned towards the Nanoned research programme. MESA+ decided for a fully external focus in its further business model development. The clash was complete. In late 2005 the vice chancellors of the three Technical Universities, having consulted the deans but not the scientific directors, agreed on a joint package of "centres of excellence" with the Ministry of Economic Affairs.

\subsection{Concluding observations}

And this is where my story of MESA+ ends, a story of more than fifteen years of academic leadership practice and organisational change. My story ends here, but MESA+ lived on, continued to expand its activities on a national and international level. The national Nanolab programme became one of the main strategic spaces and funding sources for MESAt's research programme. A high point was the establishment of the clean room research facility that ranks among the world top facilities, festively opened by the then Crown-Prince Willem Alexander in 2010. This facility is co-financed by the Nanolab programme. This top rank lab and MESAt's position in the Nanolab programme allows MESA+ to act as acknowledged node in international programmes and networks. MESA+ continued its strategic pathway, its approach of developing

Distributed academic leadership in emergent research organisations 
research projects in conjunction with industrial and other societal partners. The scope of application and fundamental research widened and intensified in the area of health technologies. The development of the policy context favoured a further growth of MESA+. 'Nano' has become a vested theme in national research and innovation programmes. The Dutch government has focused its research innovation policy as of 2009 in nine so called 'top sectors'. MESA+ holds a leading position in the top sector High Tech Science and Materials and MESA's scientific director (Dave Blank) is member of the so called 'Top Team'. Whereas the external context had openings and opportunities that were seized by MESA+'s academic leaders, in the internal context of the University of Twente and the immediate context of the Twente region, other dynamics were influencing MESAt's development. The 'battle of the schools and institutes' continued and came to a 'marriage of convenience' for some time. A balance of interest was realised, albeit a balance that was under continuous pressure, as national research budgets were shrinking and student numbers in science and engineering programmes, the prime financing source for the faculties involved, were under pressure as well. The overall strategic debates in the University continued. In 2013 the Central Board issued a new strategic policy, aiming at a sharpened international profile as a research university, focusing on science and engineering, 'nano' being one of the strategic spear head areas.

The case study describes a period of changes that required MESA, that is, its academic leaders as well as stakeholders like the Board of MESA (comprising experts from industry and innovation investment groups) and the Central Board of the University, to reflect on its status and functioning. MESA started in 1988 and was formally launched in 1990, led by the first scientific director, Jan Fluitman. A major undertaking was the merger with the CMO research institute (materials science), finalised in 1999, a merger process that Fluitman and the director of CMO, Horst Rogalla, had leading roles in, a key role taken by David Reinhoudt, who, in the finalising phase of the merger, was appointed as scientific director of the merged institute: MESA+, the Research Institute for Nanotechnology. These prominent leaders who also held a formal management positions, were acting amidst a growing network of research group leaders, professors and other senior researchers who performed leadership tasks in the development and execution of new overarching research themes, strategic research orientations and alliances with industrial partners in national and international programmes. Several of the academic leaders developed leadership activities in international research as well as in innovation and

Distributed academic leadership in emergent research organisations 4. Mesa+ 
valorisation programmes with industry; the as of 1999 appointed technical commercial director, Cees Eijkel, had a key role in these leadership activities.

There were struggles in the University of Twente, as MESA was one of the first research organisations that geared up to national and international research programmes, and developed leadership and strategy that struck on the limits of the then university system. Administratively, the period saw the 'battle of schools and institutes' ${ }^{46}$. A greater (financial) autonomy for research institutes was closely related to the policies pushed by the Central Board, in particular once the then rector, Frans van Vught, became also the president of the University in his second term as rector. In these negotiations the chairmen of the Central Board, in this period subsequently Ben Veltman and Arie van der Hek, had a key role as it concerned the overall governance of the University. The Board member who was responsible for finance and estate, Frits Schutte, played a key role as he had been negotiating, as of 1988, the budget allocation models that were aimed at strategic co-operation in research.

In the external context, there were struggles as well, that were primarily challenges in terms of competition for research funding, as MESA operated in a rather stable national context of competing research groups and industrial partners, as well as favouring government policy schemes. Schemes that saw setbacks as well, that asked a lot from MESA's academic leaders, in particular in the early years when multidisciplinary projects were not mainstream at the Dutch Research Foundation ${ }^{47}$. An event that had major impact on MESA, was the disapproval of the strategic alliance with TU Delft's research institute for the so-called national strategic investment programme 'Dieptestrategie'. In this struggles with existing structures and interests, anticipating and sometimes creating openings in (inter)national programmes, MESA's leaders could develop new ways of working. Negotiations with other similar centres in the Netherlands continued, renewed efforts to work towards joint submissions were successful; as of 2000

\footnotetext{
${ }^{46}$ This nickname, mainly hinting at a sportive battle, became common language in the University in the mid-nineties, addressing the struggles and negotiations between the Central Board, deans and research institutes about decision power and budgets. Till then, budget power was the sole competence of the Board and the deans. Gradually, institutes required and materialised (through contract research and EU projects) a greater autonomy. The 'battle' went on for more than nine years, till 2005 once the deans got, that is, kept overall strategic decision power. By then, the dean's office had evolved as well: different from the mid-nineties, deans were fulltime, professional administrators, former Central Board members or invited from industry.

${ }^{47}$ Of which the then, in 1994, first appointed 'orientation leader', Albert van den Berg, gave a lively witness report when he was interviewed in 2014, upon being appointed as scientific director of the University's biomedical institute (Mira).
}

Distributed academic leadership in emergent research organisations 4. Mesa+ 
MESA+ could profit from its participation in the national-level R\&D consortium NanoNed of which David Reinhoudt became the scientific director and active promotor. There was a growing number of stakeholders; starting off with some firms and European partners, later on cooperating with a wider spectrum of companies, including high-tech (start-up) SMEs, in a wide range of application areas. These events had implications for MESA's research programme; not just in terms of re-formulation, but in terms of changing directions, collaborations and ways of working. It challenged MESA's leadership and gave ample ground for reflection and learning. This will become clear in the next subsections, where I will present the overall changes and their outcomes.

\section{Overall changes in MESA's organisation}

MESA's organisation grew considerably in terms of scope and size in the fifteen years that this case study covers. It started off as a loosely couple interfaculty conglomerate of research groups, in organisational terms important growth kernels were the interfaculty research group TDM and the clean room facility that urged several research groups to work on sound exploitation and share the running costs. Gradually, as of the mid-nineties, the conglomerate becomes a community of researchers, rather autonomous from the founding Faculties in terms of research programming and research project development. Once MESA merged with CMO, autonomy in terms of identity and in material terms enhanced; a growing number of EU- and industrial projects challenged MESA+'s leaders to focus at relations with partners in external networks and programmes. As the number of projects and partners grew and MESA+ became a preferred partner in innovation programmes, MESA+ changed from a rather autonomous community within UT towards an open CER community in national and international programmes. At the end of this story, in 2006, MESA+ had a coherent autonomous identity, as a node in national and international networks and programmes.

Interactions between MESA's academic leaders and decision led to a rich and varied number of informal gatherings and platforms, while the scope of formal management positions within MESA and at the Faculties and Central Board changed as well. In the initial years, MESA's leaders gathered primarily on an informal basis, often in project- and programme connected groups; formal decision making was limited to the scientific director and the Board of the MESA research institute. Management decisions concerned the financial and human resource affairs that were

Distributed academic leadership in emergent research organisations 
imposed by the University's annual planning and control cycle. Distributed leadership concerned joint anticipation on new funding programmes and other openings in the changing context. As of the mid-nineties the deliberations grow in number, in number and variety of participants. What we see is a growing middle layer of distributed leadership, in between formal management/leadership positions (in MESA's management team) and at strategic and operational (research group) level. Distributed leadership that is mainly connected to strategic themes and orientations in MESA's research programmes, and to external, inter-organisational, research programmes. As of 2000 , we see higher forms of distributed leadership; whereas till then MESA's academic leaders were rowing more or less in the same direction, as of 2000, they wanted to be flagships in national and international consortia.

Within the overall organisational development of the University of Twente, MESA was a driving force and benchmark, being praised and envied by research groups and Faculties outside MESA. MESA+ won the battle between schools and institutes in terms of growth and change dynamics. Meanwhile, the governance structure and culture of the University was changing as well, driven by the policy interventions of the Central Board that largely reflected the international trend towards New Public Management competencies: Faculties were merged, deans were appointed in full time positions, a University Management Team comprising the Central Board, deans and scientific directors was responsible for the University's strategy. In this overall change process MESA+ stretched the boundaries of the University system and, in a general policy intervention that took place in 2005, lost its strategic budget autonomy, an authority that was given to the deans.

Here, we see a specific development path that has generic value for this new species of research organisations, Centres of Excellence and Relevance, as will be clarified in the following subsections.

Distributed academic leadership in emergent research organisations 


\begin{tabular}{|c|c|c|c|}
\hline & Episode 1 & Episode 2 & Episode 3 \\
\hline $\begin{array}{l}\text { Distributed leadership } \\
\text { constellations }\end{array}$ & Emergent, bottom up & Top down orchestrated & $\begin{array}{l}\text { Orchestrated } \\
\text { differentiated } \\
\text { constellations }\end{array}$ \\
\hline Spaces & $\begin{array}{l}\text { Emerging leadership } \\
\text { learning space around } \\
\text { one protected activity } \\
\text { space, fusing existing } \\
\text { areas }\end{array}$ & $\begin{array}{l}\text { Leadership learning } \\
\text { space around an } \\
\text { orchestrated set of } \\
\text { protected activity } \\
\text { spaces } \\
\text { Protected activity } \\
\text { spaces comprising new } \\
\text { areas }\end{array}$ & $\begin{array}{l}\text { an inter-organisational } \\
\text { leadership learning } \\
\text { space, comprising } \\
\text { loosely coupled } \\
\text { protected activity } \\
\text { spaces. } \\
\text { Protected spaces } \\
\text { comprise fusing existing } \\
\text { areas }\end{array}$ \\
\hline $\begin{array}{l}\text { Sites of change and } \\
\text { leadership }\end{array}$ & $\begin{array}{l}\text { Primarily strategic } \\
\text { programming, selective } \\
\text { converging projects and } \\
\text { some business model } \\
\text { development. }\end{array}$ & $\begin{array}{l}\text { Primarily strategic } \\
\text { programming, in } \\
\text { interaction with } \\
\text { converging projects and } \\
\text { innovative business } \\
\text { model development. }\end{array}$ & $\begin{array}{l}\text { Prime focus on strategic } \\
\text { programming and } \\
\text { innovative business } \\
\text { model development. }\end{array}$ \\
\hline
\end{tabular}

Table 3. Summary of MESA's development over time (according to the conceptual model)

\section{Stabilising distributed leadership activities and arrangements}

Leadership in MESA's initial years was mainly connected to formal positions at research groups. Gradually, overarching leadership activities developed, mainly in developing and leading themes that covered research projects of several groups. Stabilising patters of leadership were informal, whereas academics developed leadership beyond their management positions or across domains of research groups. It was a period of explorative entrepreneurial leadership, resulting in new ways of working like the development of themes and later on strategic orientations. MESA's academic leaders were the first in the University of Twente who succeeded in developing a joint multi-annual programme, and to anchor major joint research projects in it. MESA was the first of a kind, an interfaculty research organisation that went deliberately beyond boundaries of research groups and of Faculties. Thus, it felt the need to articulate what it was doing and should do, and developed a business plan, specifying the organisational and financial goals. It was a deliberate attempt to develop joint vision on organisation of research. In the second episode academic leaders were challenged by the growing number and scale of research projects, showing an enhanced number of informal positions, often connected to projected, themes and orientations, that were no longer restricted to formal management 
positions. The main leadership challenge as of 1998 was to merge two separate research institutes (CMO and MESA) into one organisation, and to make it into an inviting and productive environment for co-operation among academics. The informal understanding, in a way arrangement, of incremental strategic programming at MESA, seeking for boundary spanning between different research groups and projects, continued, but became more directive when the tandem of a new scientific director and technical commercial director were appointed in 1999. In the new leadership constellation, the leadership tandem jointly with some twenty research group leaders and SRO leaders, a range of ambidextrous and entrepreneurial leadership activities evolved. Stabilising patterns were contextual ambidextrous, meaning that several academic leaders combined explorative and exploitative activities; an example was the appointed SRO leaders that had to make the tension between excellence and relevance productive. An exception was the movements towards specialisation and connected structural ambidexterity, most prominent in the valorisation activities that were pushed by the technical commercial director and by the new MESA+ board that included experts from business and specialised high tech investors.

The third episode shows a wide variety and high number of leadership activities. Due to the many national and international projects and connected meetings outside the University, distributed leadership got stretched to the limits: in the years 2003 and 2004, some twenty five academic leaders were active in MESA+, but there were few plenary meetings. In their work, there was a strong orientation towards the national NanoNed R\&D programme and the MESA+ SROs. So, it was not just a matter of geographical dislocation, also the prime focus shifted to external relations and dynamics of external programmes. Nevertheless, debates within the University of Twente about research policy and funding models required attention and joint deliberation, which resulted in discussions among MESAt's leaders, as well as among MESA+'s external board members, about strategy and new ambitions. Several initiatives were developed to attract new funders and investors and a range of high-tech start up got off the ground.

Stabilising patterns of leadership occurred as understandings and arrangements between MESA's academic leaders that showed as trajectories during MESA's development. In the course of the third episode, leadership activity patterns had grown in number and changed considerably compared to MESA's start. Whereas MESA started off with some ten leaders and a few themes, fifteen years later we see some thirty leaders and a concerted pattern of informal

Distributed academic leadership in emergent research organisations 4. Mesa+ 
leadership activities in national and international programmes, covering boundary spanning distributed leadership patterns between strategic and operational leadership activities. MESA and later on MESA+ showed continuity in distributed leadership arrangements over time, visible as a trajectory across episodes. These arrangements are briefly analysed separately, here. In the first episode, which covered eight years, two arrangements appeared that were loosely coupled. Strategic programming, creating visibility and reputation for an emerging field of micro-systems research, came first. Particular themes were selected carefully, in intensive consultation with research leaders and in evaluating the feasibility by "trying by doing". Development of convergent projects stabilised, resulting in an understanding, an arrangements among MESA's academic leaders about themes and later, on joint orientations.

In the second episode more intensive connections between strategic programming and project development occurred once MESA received a five-year so-called spearhead grant from the Central Board of the University. This and other opportunities for funding required full attention from MESA's academic leaders: not only its development, but in particular its execution, including finding enough excellent PhDs. Despite this attention for operational matters, MESA's leaders kept developing the strategy as well. The connection between strategy and project execution materialised in the sense that the grant was used to attract and co-finance externally funded projects. By the year 2002, a balance had been reached between programming and project execution; the UT grant had been spent within three years' time. Keeping this balance going did put a lot of pressure on MESA+'s academic leaders. Strategic programming continued to be an important leadership pattern while there was attention to national programmes and business model development. Meanwhile, there was intensive exploration of an innovative business model that would open relations with industry and mobilise new resources, no longer just grants and contracts, but also capital investments. The eventual business model was less innovative than aimed for, because of changes in the governance system of the University of Twente that were decided by the Central Board in 2005.

\section{Stabilising leadership learning spaces}

The way that MESA's academic leaders reflected and anticipated to challenges and the openings that they created, resulted in a range of spaces. Often connected to project and programmes, occurring as more or less protected spaces wherein new ways of working and leadership could

Distributed academic leadership in emergent research organisations 
be explored to find a balance between the search for academic excellence and the challenge to deliver results that were relevant for industrial partners. In that sense, what we see here are not just single loop learning spaces, wherein leaders manage optimal results, but in fact double loop learning spaces, wherein leadership was challenged and new ways forward had to be found.

Some learning spaces were deliberately organised, in that sense creating a path for MESA's development. In the plans and meetings at the time when MESA started, academic leaders used phrases like "spaces for experimentation and learning" that had to be created to "explore unknown territory". MESA's leaders saw that the lay-out of physical spaces could stimulate cooperation, even inspire new, unexpected initiatives. Therefore, they linked physical spaces to specific themes that were attractive for several research groups, themes that were intended to fuse, in the end, several research topics that were carried forward by separate groups. Other examples are spaces that were started to serve exploration of new joint areas, "orientations". In the third episode such strategic orientation spaces became a preferred approach for MESA+'s academic leaders to organise multi-annual programmes as linked to themes in national programmes like NanoNed, and international consortia like the EU sponsored Network of Excellence, Frontiers. Other spaces evolved connected to the pattern of evolving protected spaces. In the first episode, the learning environment included about ten academic leaders connected to a few themes and orientations. Reflection and leadership learning concentrated around the development of a business plan, an unusual joint effort for academic leaders at the time. The learning environment expanded in later years, and became further distributed. Academic leaders were taking on new roles, and were jointly reflecting and learning in the development and execution of multi-annual research projects and in the development of strategic research orientations. By the end of the third episode, learning spaces extended to leadership activities in national and international programmes, and in the domain of start-ups and valorisation, which were expanding at the time.

Distributed academic leadership in emergent research organisations 


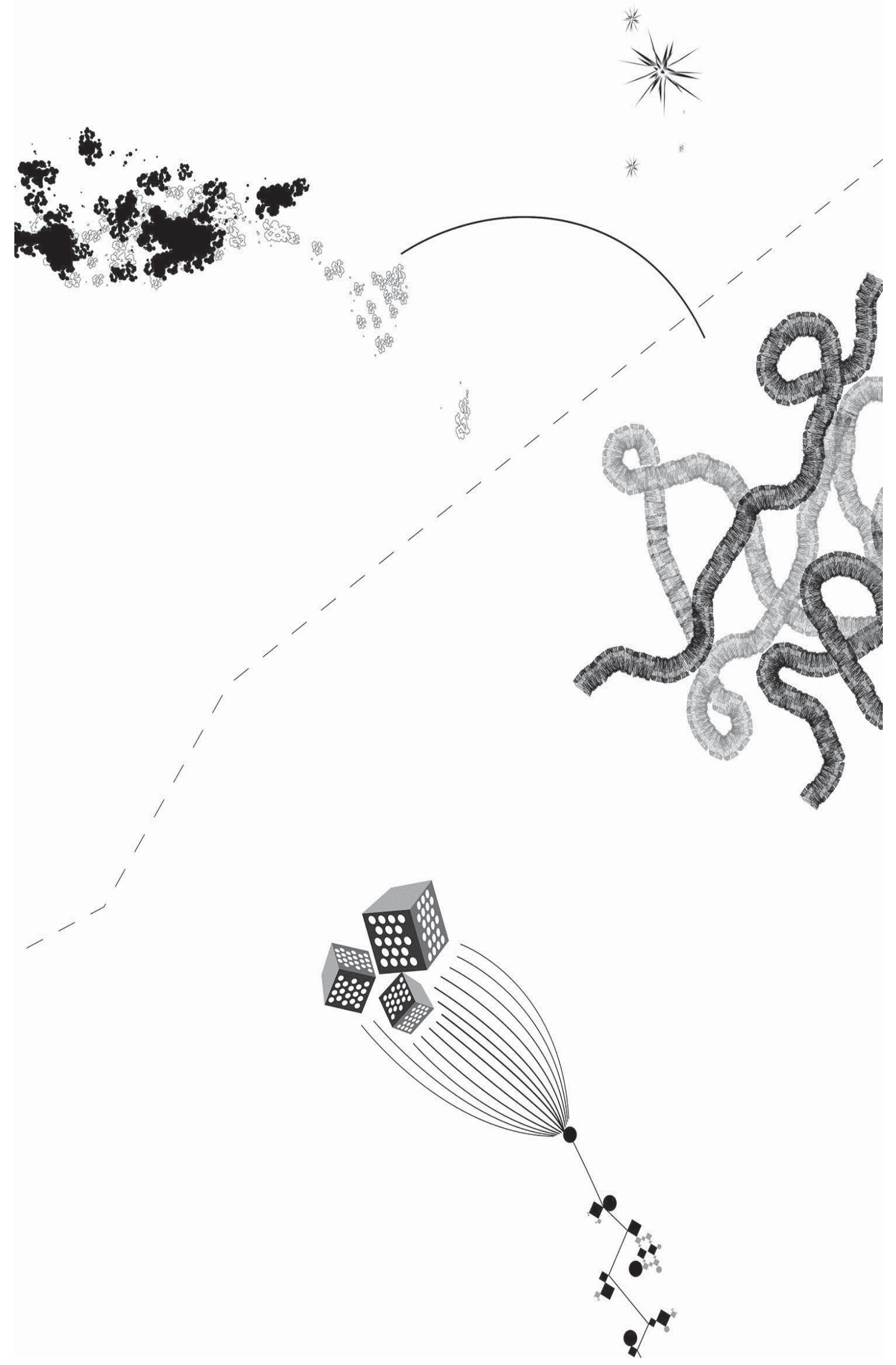




\section{CTIT}

\section{Contents}

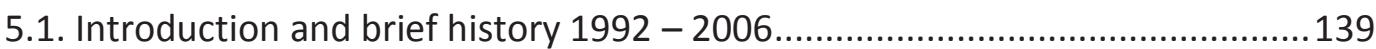

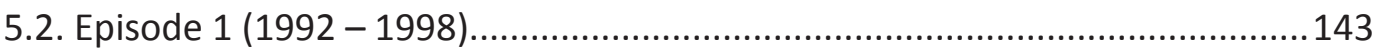

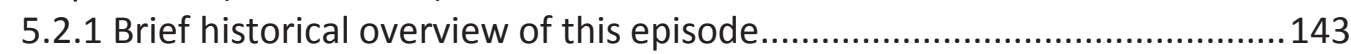

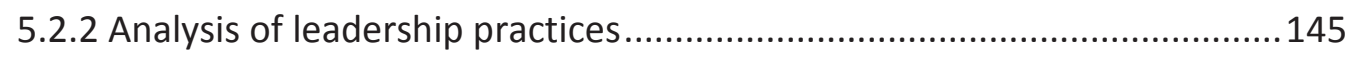

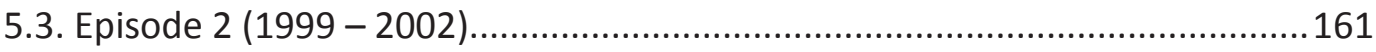

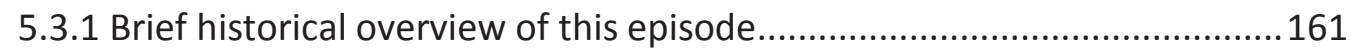

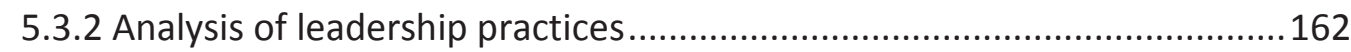

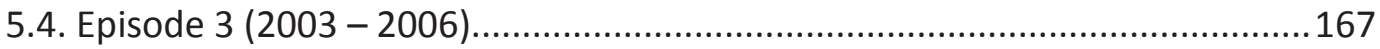

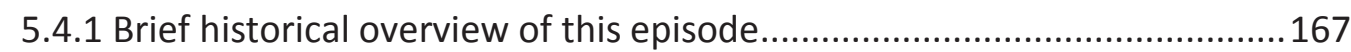

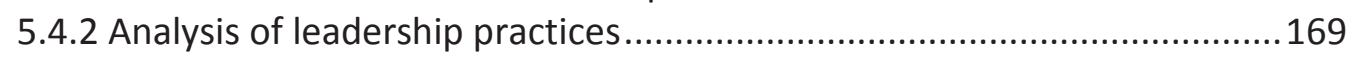

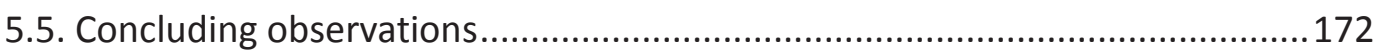

Distributed academic leadership in emergent research organisations

5. CTIT 


\subsection{Introduction and brief history $1992-2006$}

This case study concerns a research institute based at the University of Twente, CTIT. At the start in 1992 it was the abbreviation of Centre of Telematics and Information Technology, nowadays the acronym is just the name of the organisation. It comprised research and academics of research groups from seven Faculties. To understand the genesis of CTIT we have to look at the situation in the early nineties.

First, the world of telecommunication and ICT was on the move. Research groups of the then Faculties of Electrical Engineering and of Informatics, were leading partners in many multipartner projects, often sponsored by the EU. All this had been the incentive to set up an interfaculty group, TIOS (Tele-Informatics and Open Systems). Second, in 1992, the Dutch government decided to invest in a new national research centre on telecommunication and ICT, the Telematics Research Centre. It was an initiative jointly with three big telecom and IT companies. Coalitions of universities and regions were invited to submit proposals. The University of Twente was the driving force in one such regional initiative. There was heavy competition from other universities and regions. To prepare the bid required concerted action between the different levels of the universities and representatives of the local governments. Within the University of Twente, the Central Board, the Deans of the Faculties concerned, and the leading professors from the departments concerned, were involved. It was considered to be a strategic challenge for the University of Twente. One cornerstone of the bid was UT's commitment to establish, complementary to the bid itself, a university-wide programme-based research institute, aligned in terms of research programming with the national centre. In early1994, about two years after the proposal from Twente for the national centre was awarded, seven Faculties formally joined forces in the UT-wide research institute called CTIT, the Centre for Telematics and Information Technology.

The research programming involved was new for the University of Twente. New forms of distributed leadership were at stake. In the area of telecommunication and ICT, there was an interest in multi-disciplinary long-term planning. . Indicative is how mission statements of industries at the time were addressing the necessity of multi-disciplinary approaches, even approaches that would bridge between engineering and social sciences and humanities disciplines.

Distributed academic leadership in emergent research organisations 5. CTIT 
The transformative process of the inception of CTIT continued in CTIT's further development. Co-operation between groups in the different scientific fields took some years to become productive on a substantial level, that is, being more than an occasional shared PhD project. The strategic nature of CTIT's mission frequently led to situations in which the involvement of the Central Board and links with the strategy development of the University had a major impact on the process of research programming and the direction of the research institute.

Clearly, the case of CTIT is a good site to study the main research question of this thesis: What are evolving distributed academic leadership arrangements in research organisations in transformation?

This case study describes CTIT's development over a time frame of thirteen years. The story offers an illustrative example of a centre of excellence and relevance located in a Dutch university, rooted in disciplines varying from mathematics, informatics, electrical engineering to educational science. It had far-reaching impact on the organisation of research in its home university, the University of Twente, and, considering its pathway, it has generic relevance as a particular type of institute.

While CTIT formally started from scratch, it could build on the experience of the interfaculty research group TIOS and participation by senior academics from TIOS. CTIT's academic leaders constructed their own organisational space in the University of Twente, exploiting the opportunities offered by the University's research policy framework which allowed interfaculty groups, and by the twinning relation with the national Telematics Research Centre as well as links with industrial partners. There were close links to a variety of business stakeholders, having different modes of articulation. The external context was not very stable, as becomes clear in the episodes.

\section{The structure of the chapter}

The presentation follows the underlying structure of analysis (see chapter 3, Research Design), where the history is divided into episodes. The description is based on the understanding of patterns in distributed leadership activities. The focus is on the struggles and achievements of some twenty academics who jointly found practical ways to meet, anticipate and create the opportunities and challenges of a new organisation in a more or less ambiguous context. There was learning involved in the leadership activities that emerged, sometimes as a complement to

Distributed academic leadership in emergent research organisations

5. CTIT 
formal management positions in the CTIT or in Faculties concerned, and generally in leadership activities connected to themes in the CTIT's research programme, or in programmes and projects that CTIT developed at a national level.

While the first episode has a natural closure in the first five-year mandate of CTIT running to an end in 1998, it was necessary to start the episode two years before the formal start of CTIT, in 1992. The first episode is there with the most extensive part of the case study, due to its duration and in view of the many important things that happened that had longer term implications for CTIT's organisational development and leadership. The second episode starts with the entrance of a new scientific director, business manager and board and, who will build on what was prepared already but push for changes. The second episode ends once strategic changes have been pushed and the new scientific director (the third since the start of CTIT), enters office, a professor that had been the Dean of Informatics and was willing to leave UT's Central Boards as responsible for research policy, and CTIT becomes integrated in the research policy of the cooperating Faculties. The third episode continues after the second five-year mandate ended and the third mandate is agreed upon, until when the business model of CTIT had stabilised. Within each episode, three key leadership and organisational change activities are taken up for further discussion in the final subsection and in Ch. 7 (Analysis).

Distributed academic leadership in emergent research organisations 


\section{An overview of the history}

Episode 1, 1992-1998

\begin{tabular}{|l|l|}
\hline 1992 & Unofficial start of CTIT \\
\hline 1994 & Official start of CTIT \\
\hline 1996 & CTIT acknowledged as UT's first "spearhead institute" \\
\hline 1998 & Final year of the first five year's mandate term \\
\hline
\end{tabular}

Episode 2 1999-2002

\begin{tabular}{|l|l|}
\hline 1999 & $\begin{array}{l}\text { Transitional year towards the second five year's mandate } \\
\text { term. Organisational and scientific evaluation. Deliberations } \\
\text { about the subsequent five year programme come to a } \\
\text { standstill. }\end{array}$ \\
\hline 2000 & $\begin{array}{l}\text { Changes in leadership: new chairman of the CTIT board, } \\
\text { scientific director and manager. With the broadening of the } \\
\text { programme, new senior academics join. }\end{array}$ \\
\hline 2001 & $\begin{array}{l}\text { With the framework of the second five year programme as } \\
\text { agreed in 2000, all research is being structured according to } \\
\text { five SROs. }\end{array}$ \\
\hline $\begin{array}{l}\text { CTIT gets increasingly engaged in national programmes. } \\
\text { Scientific director's position taken over by former Central } \\
\text { Board member, also being the former Dean of Faculty of } \\
\text { Informatics. }\end{array}$ \\
\hline
\end{tabular}

Episode 3, 2003-2006

\begin{tabular}{|l|l|}
\hline 2003 & $\begin{array}{l}\text { CTIT focuses on strategic planning via five SROs, spaces for } \\
\text { converging themes. CTIT starts to position itself as a network } \\
\text { institute in national programmes. }\end{array}$ \\
\hline 2004 & $\begin{array}{l}\text { Second five year mandate term ends. The next five year } \\
\text { mandate is agreed upon. }\end{array}$ \\
\hline 2006 & $\begin{array}{l}\text { CTIT fully geared to national programmes, NIRICT and others. } \\
\text { CTIT is one of the top-three performing institutes of the five } \\
\text { spearhead institutes at UT }\end{array}$ \\
\hline
\end{tabular}

Table 4. An overview of history CTIT

\section{Sources}

Data sources for the reconstruction and analysis of CTIT's development are threefold. The author of this thesis was an observing participant in different parts of the life of CTIT; this included access to internal, often informal documents of CTIT. Second, in2006 and 2012, twelve key actors were interviewed and invited to reflect on specific events and on patterns of leadership activities at the time. Third, publicly available documents about CTIT were collected and analysed.

Distributed academic leadership in emergent research organisations 5. CTIT 


\begin{tabular}{|c|c|c|c|c|}
\hline & Name & Episode & $\begin{array}{l}\text { Position at the } \\
\text { time }\end{array}$ & Date interview \\
\hline 1 & $\begin{array}{l}\text { Jeroen van de } \\
\text { Lagemaat }\end{array}$ & 1 , partially 2 & Manager institute & September 2006 \\
\hline 2 & Wilma Hiddink & $1,2,3$ & $\begin{array}{l}\text { Office manager } \\
\text { and controller } \\
\text { institute }\end{array}$ & $\begin{array}{l}\text { September } 2006 \\
\text { and June } 2012\end{array}$ \\
\hline 3 & Jos de Smit & 1 & $\begin{array}{l}\text { Member executive } \\
\text { board institute }\end{array}$ & July 2012 \\
\hline 4 & Henk Zijm & 2 & $\begin{array}{l}\text { Scientific director } \\
\text { institute }\end{array}$ & June 2012 \\
\hline 5 & Iddo Bante & 2,3 & Manager institute & July 2012 \\
\hline 6 & Carla Verwijs & 1 & PhD student & July 2012 \\
\hline 7 & Jan van der Veen & 1 & PhD student & July 2012 \\
\hline 8 & Rene Bakker & 1 & $\begin{array}{l}\text { Faculty council } \\
\text { Informatics }\end{array}$ & July 2012 \\
\hline 9 & $\begin{array}{l}\text { Marten van } \\
\text { Sinderen }\end{array}$ & $1,2,3$ & $\begin{array}{l}\text { Research group } \\
\text { TIOS, member } \\
\text { executive team } \\
\text { institute, SRO } \\
\text { leader }\end{array}$ & July 2012 \\
\hline 10 & Henk Alblas & 1,2 & $\begin{array}{l}\text { Chairman TIOS } \\
\text { research group, } \\
\text { programme } \\
\text { director Telematics } \\
\text { master programme }\end{array}$ & July 2012 \\
\hline 11 & Henk de Poot & $1,2,3$ & $\begin{array}{l}\text { Core member TRC } \\
\text { and TI, partner in } \\
\text { CTIT programmes }\end{array}$ & July 2012 \\
\hline 12 & Pim Fij & $1,2,3$ & $\begin{array}{l}\text { Manager Faculty } \\
\text { Informatics, ad } \\
\text { interim manager } \\
\text { institute }\end{array}$ & June 2013 \\
\hline
\end{tabular}

Table 5. Interviewees CTIT

\subsection{Episode 1 (1992 - 1998)}

\subsubsection{Brief historical overview of this episode}

There was a pre-history in which the promise of "telematics", a fusion of parts of electrical systems engineering and informatics, attracted senior scientists to form an informal network in the University of Twente which was turned into a formal interfaculty group Tele-Informatics and Open Systems (TIOS). It was on this group that the University could draw to develop a bid for a

Distributed academic leadership in emergent research organisations

5. CTIT 
national Telematics Research Centre (TRC). From 1991 when the bid was awarded, TIOS provided core members of a Gideon's band, setting out on a journey in new territory, to explore and organise research and innovation in a new field under the banner of "telematics". They had a strong vision, mainly fuelled by their contacts with international (European, but also American) industrial telecom partners. Institutionally, the journey included two paths, one building up TRC, the other building CTIT.

In terms of organisational change, the first episode of CTIT starts in 1992, but the groundwork was laid earlier, with TIOS and the work on the bid for TRC. The Board of the University supported the endeavour right from the start. It was a heady time, not just because of winning the bid for TRC. There was the dream of Twente as a two-core university for technical and social sciences, where research groups from both cores of the University would work together, here in opening up a new research field telematics (with groups from educational science involved). Another dream, of relevance to the Twente region, was visible in the collaboration with regional authorities in TRC, but also when main telecom partners opened R\&D labs and offices near the UT campus (particularly Ericsson, CMG, Lucent, KPN Research).

There were also setbacks, in particular when the Faculty of Informatics was confronted a strong drop in student numbers, with the financial problems that go with it. It was a nationwide development, but it hit the Faculty severely. The ensuing tensions fuelled debates about the profile of the faculty: technology and applications, or informatics and science?

In this context, CTIT's mission was to serve and stimulate the co-operation between research groups of seven faculties, Informatics, Electrical Engineering and Applied Mathematics being the core in terms of number of researchers.

All in all, the challenges and successes at a European research level, and the tensions at the University of Twente, resulted in a turbulent first phase of CTIT's development. It is important to trace this is some detail because of the interactions between organisational change and emerging leadership. Ending when the first five-year mandate ran out, by the year 1998, there were also first signs of limitations of the path and thus a need for re-orientation.

Distributed academic leadership in emergent research organisations

5. CTIT 


\subsubsection{Analysis of leadership practices}

\subsubsection{1 a strategic research programme focused on industrial partners}

Formally, the activity started in January 1992, when after ample deliberation between the Deans of the Faculties of Informatics and of Electrical Engineering, two professors from the interfaculty TIOS department ${ }^{48}$ were invited to prepare a proposal for the CTIT research institute. That there would be such an institute was a foregone matter, because it was part of the bid for the national Telematics Research Centre to have a twinning institute within the University of Twente. The content of the bid was drawn up by the various partners (see Section 6.2.1), but it reflected ideas and initiatives that have been circulating for some years, and had already led to the establishment of the interfaculty department TIOS. Indicative is how the bid book was written and submitted to the Dutch Ministry of Economic Affairs in a very short time, in a couple of months.

The two TIOS professors accepted then assignment for an "information" phase: to conduct a broad consultation among a range of departments covering all faculties of UT, to draw up the outline of a research programme, and to advise on the organisation form of the institute to be established.

Within five months' time they managed to fulfil this assignment and present a report to the Board and the Deans. A sense of urgency was voiced continuously because of the link with TRC: a successful take-off of the new national research institute required a swift start of the UT institute. This feeling of urgency also had to do with the fact that at the time, mid 1992, almost a year after the University of Twente had won the bid for the national institute, the new national institute went through rough times in finding a scientific director, and competing universities from the bidding phase, as well as (and in particular) the chairman of the institute's Board appointed by the Ministry of Education and Sciences, were voicing concerns that the choice for "Twente" might not have been the correct one, and that a start in "Delft", linked to Delft University of Technology, might after all offer better perspectives. It is not clear whether this sense of urgency was helpful to close the ranks and create a broad support for the CTIT initiative, but it was definitely important for the Board of the University of Twente. The national

\footnotetext{
${ }^{48}$ It concerned professors Ignas Niemegeers and Chris Vissers, who jointly had developed the TIOS group, the first mentioned primarily representing the Faculty Electrical Engineering, the second the Faculty of Informatics.
}

Distributed academic leadership in emergent research organisations

5. CTIT 
institute TRC and the establishment of CTIT has been positioned by the Board as being of strategic importance for the university at large. Thus, the deans saw this as an opportunity to negotiate with the Board about strategic priorities in budget allocation. So, in their consultation rounds the two professors had to take complex negotiation processes in different arenas into account.

Meanwhile, the Faculty of Informatics was struggling with decreasing student enrolment. The Faculty Board was convinced that this was not a temporary dip, but a more structural tendency. They were preparing far-going interventions in the study programme, and immediate consequences for the size of several departments. The situation was exacerbated by the fact that the Faculty in particular, and the domain of information science and informatics in general, were only recently established, and there was uncertainty regarding the financial perspectives for funding from industry and research funding agencies. In these circumstances, adopting and supporting a new interfaculty institute was not welcomed (by the Faculty board, and by the Faculty council). The concern was that, once decisions on budget cuts had to be taken, departments that did not belong to the core of the CTIT, would be hit. This would reinforce the tendency to go for existing strength, as the departments that appeared to be central in the CTIT initiative, were also the departments with the strongest own income, and with the most extended relationships with industry. This could have blocked the preparation for CTIT, and the two professors in their consultation rounds were not able to get to an agreement. It took several interventions (about finance and about other challenges that Faculties were struggling with) from the Board of the University to get CTIT accepted and its strategic planning to move to a next stage.

Eventually, the two professors succeeded in bringing together a varied group of stakeholders that shared the common vision that was presented in an initial research programme. It concerned companies in the telecom sector and UT research groups that were keen on research cooperation in ICT related innovations in their own scientific domains. A particular cooperating group that substantial in size, compared to the TIOS group, came from the Faculty of Education; this group was also keen on cooperation because of a shared vision about multidisciplinary research and an engineering and design approach of ICT innovations.

Distributed academic leadership in emergent research organisations 5. CTIT 
The preliminary research programme that was drawn up had an innovation oriented focus, as was to be expected from the link with TIOS and the necessity of twinning with TRC. Relevance to industry was seen to imply multidisciplinary co-operation, within the UT and with industrial partners.

In contrast to articulation of research interests as a basis for a research programme, a vision was voiced and communicated. By nature "top down", also because of the active role of the Board of the University, as it was perceived at the time. An interviewee, a key player promoting CTIT at the time, used a metaphor: they were like architects systematically drawing up a visionary and solid business building, but the building did not necessarily attract more people that wanted to dwell in it.

There was distributed leadership, in the sense that the vision was carried forward and communicated by a limited but varied group of senior academics from departments in Mathematics, Educational Science, Electrical Engineering and Informatics, strongly supported by the Central Board, with the interfaculty department TIOS as a motor. This also created separation between the visionaries and others. Senior academics from other departments, in particular in the envisaged administering Faculty of Informatics, were not interested in taking up leadership roles in the formation of CTIT at the time.

Based on the draft report of the "informateurs", in November 1992, the Board of the University convened the Deans of the seven Faculties concerned. After ample ${ }^{49}$ deliberation it was agreed to enter a next phase, that of the "formation" of the institute. One of the two professors who had conducted the information phase was invited to conduct the formation phase, implying that he would get appointed as scientific director of CTIT if he did a good job. The deliberation had reflected the concerns among the Deans: they were not willing to give too strong a mandate to a research institute, and did not like the possibility of having a scientific director who would also have a key role in the new partnering national institute TRC. They also made clear that CTIT should not be a candidate for the national support scheme of so called graduate research

\footnotetext{
${ }^{49}$ The terminology of "informateur" and "formateur" is used in the Netherlands to indicate the two steps in the preparation of a new government (that is, a new Cabinet of Ministers), with the "formateur" often being the presumed Prime Minister. Its explicit use here carried the message that the "formateur" might be the scientific director, and definitely that he would be responsible for creating a program for the new institute.
}

Distributed academic leadership in emergent research organisations

5. CTIT 
schools. ${ }^{50}$ When the TRC board appointed the envisaged director of CTIT as scientific director of TRC, the immediate response of the Board of the University was to appoint the other professor who had conducted the information phase, to finalise the formation phase. Within two months' time he delivered the formation report. The report covered negotiation talks with thirteen departments in seven faculties. Six faculties, all except Business Administration, committed to the CTIT programme, which added up to a research workforce of sixty-five fte's, currently organised in twenty-five research projects. On January 211993 the Dean of Informatics presented the report to his colleague Deans, inviting them to accept the conclusion. The Board of the University had to consult the university council, which had some major concerns (March 1993). The Council agreed with the strategic importance of the Institute for the UT, but wanted to see a coherent research programme before a final approval could be given.

In response, the new "formateur", supported by a few senior academics defined (within six months' time) an innovation-oriented core project for CTIT, on Computer-Supported Collaborative Work. It was a converging project, because the theme enabled a large range of departments to join the project. The negotiations for a multi-annual research programme and this plan for a core converging project, were successful in the sense that the Board of the University and the University Council agreed, on November 30 1993,to the start of the CTIT, and allocated a multi-annual grant to develop core projects.

On January $25^{\text {th }}, 1994$, CTIT was officially launched. A steering and management structure was put in place early in 1994. A general board was installed, comprising senior foreign researchers, including a professor from Germany as chair. The executive board comprised the scientific director and two professors one from the Faculty of Informatics (Peter Apers) and one from the Faculty of Mathematics (Jos de Smit) (the latter also represented the non-technical departments). A manager was appointed assisted by project management staff. A professor from Educational Science was invited to guide the CTIT PhD programme. A senior academic from Informatics led the core project CSCW.

\footnotetext{
${ }^{50}$ While graduate training was a component of these graduate research schools, the national scheme other main aim was to structure the research landscape in terms of these "schools". This created a competition for who would be able to get in, and thus have an assured position in the research landscape. The Deans did not want another competitor.
}

Distributed academic leadership in emergent research organisations

5. CTIT 
As the projects to be done in CTIT depended on contributions from existing departments, in particular also from the Faculty of Informatics, the budget cuts faced by this Faculty were immediately relevant for the leadership of CTIT. The Faculty decided to focus on the disciplinary departments, while CTIT envisaged new combinations and multidisciplinary research areas. This difference in strategy added to the tensions that already existed between CTIT and the Faculty of Informatics.

The partnering with TRC, a key argument to establish CTIT, could profit from the shared background of key leading academics in these organisations. In the first few years, however, the actual effect of having the University's research workforce contribute to TRC, was not very visible, compared with the initial high expectations and the substantial financial support provided by the regional authorities. Thus, when in 1995, the Ministry of Economic Affairs launched the national scheme of Leading Technology Institutes, consortia of leading companies and excellent research groups/organisations which would accelerate innovation, it was not automatic that CTIT would be the main envisaged consortium partner at the academic side. It did engage in the bid development, but a range of firms and universities were involved, and the process was managed by a consulting firm. As a Leading Technology Institute, the new TRC should be truly national, it was felt. (See Chapter 6 for the details of the bidding process and its outcome.) For CTIT's academic leaders it was a new playing field with unknown rules of negotiation. Then, when the new TRC, now named Telematics Institute (TI), had been granted the status of a "leading technological institute" , CTIT had to co-operate and compete with other TI partners from universities and industry to get access to the innovation funds that the Ministry made available to the TI consortium. Actually, they were quite successful due to the research capacity and organisational force that CTIT had developed by then. In general, CTIT would have to think of itself as an entity independent of what used to be a twinning relationship with TRC, but still take into account its links with the overall development of TI.

There were further internal and external incentives for strategic reflection and choices about an eventual new research programme. Since CTIT was an interfaculty research institute in the sense of the Dutch Higher Education Law, they had to prepare an institute's plan, including a strategic research program, to be agreed upon by the participating faculties, and confirmed by

Distributed academic leadership in emergent research organisations

5. CTIT 
the Board of the University. Given the increasing importance of multi-annual commitments with industry and research funding agencies, definitely so in the case of CTIT, an institute would have to start preparing a new five-year research programme two years ahead of the formal end of its mandate, in this case the beginning of 1999. As was stated in the year report 1996, Internally, there had been a certain consolidation, through learning by doing, and in building trust among a core group of academic leaders from different scientific disciplines. As the Annual Report for 1996 notes, building on this, it was considered timely to take a next step.

As in the early 1990s, CTIT wanted to develop a vision to support a mission-driven research programme. As a first step, the scientific director took the initiative in March 1996, supported by the Central Board, to present a vision document to the University Council, "Telematica aan de UT".

This almost backfired. The Deans of the Faculties of Electrical Engineering and Informatics perceived this initiative as a provocation. In the strongest possible tone they wrote to CTIT, the Board of the University and the University Council that this initiative, as well as the content of the vision document, was out of order. They argued that CTIT at this stage had to conduct research as agreed in the current five-year mandate. New perspectives have to be negotiated according to regular consultative procedures. They also took issue with the relative autonomy from the Faculties that CTIT claimed, and with the influence that CTIT aspired to have on educational programmes -- a no go area. Informally, it was clear that the Board of the University and the University Council were favourable to CTIT's ambitions. To handle the impasse (in typically Dutch way), the University Council refrained from a formal reaction on the vision document, but agrees on substantial funding (1 million guilders annually for five years), because of the strategic importance of CTIT for the University.

Following the formal steps, CTIT's scientific director pursued his consultations among the groups and among external stakeholders and produced a research programme in 1997. After ample consideration CTIT's Board agreed with the programme. When CTIT approached the administratively responsible Faculty of Informatics, asking them to consult the other participating Faculties and the Board of the University, it quickly became clear that there is little support for CTITs' vision and programme among the senior academics in the Faculty of Informatics who are not participating in the core of CTIT. It also becomes clear that the Board of

Distributed academic leadership in emergent research organisations

5. CTIT 
the University supports CTIT. Smaller and larger conflicts culminated. In September 1998, in the Dean of the Faculty of Informatics offering, in an open letter to the Board of the University, his resignation as Dean. His argument was that, as the Board of the University had declared that in matters of strategic importance to the University, it will give priority to spearhead research institutes like CTIT, he can no longer fulfil his responsibilities as Dean.

There were also substantial issues about the scientific domain. In June 1999, four Faculty of Informatics professors sent an open letter to CTIT to voice their doubts about the "scientific vision" of CTIT. In their opinion, "telematics" no longer needed dedicated research institutes; it had become integrated in on-going research. The other argument was that the scientific basis was too weak, too much attention was paid to systems and technology research. Clearly, the expansive visions of CTIT had stretched the limits of what a Faculty of Informatics considered to be appropriate. Something had to give, and the transitional year (to be described in the next episode) was meant to explore and negotiate this.

\subsubsection{Convergent research projects}

Right from the start, development of converging research projects was a core feature of CTIT'S leadership activities. There was continuity with CTIT's founding department TIOS, which had a portfolio of projects with industrial partners, and international projects in the framework of EU programmes. Project-based work belonged to the repertoire of TIOS' academic leaders, and they were good at it. Thus, project development became a focus activity of the senior academics of CTIT in the starting phase of the institute.

Project-based work was not just a way of organising research, it was also seen as allowing, and thus stimulating, academics from different disciplines to enter into multi-disciplinary collaborations. The latter was promoted by the academic leaders in the start-up phase of CTIT, who held management positions in CTIT. It was strongly supported by the Board of the University, and the various University councils saw the creation of multidisciplinary projects as a key landmark of the development of CTIT the institute ${ }^{51}$.. Doubts were voiced, however, by the central advisory committee for research (CCR), of which all vice-deans for research were

\footnotetext{
${ }^{51}$ This opinion of the University Council was based on the "two kernel strategy" of UT and on the positive appreciation of the so-called OSF policy programme: an annual grant that was allocated to a multi-annual programme based group of departments, preferably representing the two cores of the University
}

Distributed academic leadership in emergent research organisations

5. CTIT 
members. They were concerned that project definitions articulated from a top-down strategic perspective would actually be able to bring different disciplines together, and preferred a bottom-up approach in which departments would play a role. CTIT's academic leaders were convinced that a theme and project driven approach was necessary for change in research approach. In the starting document for CTIT, it was phrased as an additional approach. CTIT should not duplicate the disciplinary nature of research groups, but work with themes and projects, as necessary to carry forward innovative research ventures.

CTIT counted twenty-six on-going projects in its starting package, but the next step was generating new projects. As framed in CTIT's starting document, an additional approach was necessary, now to be materialised in new projects. How to do this became a hotspot of discussion. Project generation, from formulation to mobilizing funding, required a lot of effort from senior academics in the departments. CTIT's core academic leaders, the scientific director and manager in particular, were active themselves, and thus got an image of being project generators. Due to the nature of the CTIT projects, it was not easy to get access to primarily discipline oriented funding agencies, in particular the Dutch NWO-Foundation, a lot of effort had to be spend that eventually succeeded at the STW Foundation. The most favourable opportunities were found in the new national programmes that were initiated by TRC/TI and proposals that were submitted to the EU in cooperation with European industrial partners.

In a few years' time, a range of externally funded projects resulted, differently appreciated by research groups and their leaders. Important for those academic leaders, primarily in the core of CTIT's programme, were the financial returns in terms of externally funded projects that otherwise would not have been granted due to its multidisciplinary character. These results were promising. Related to the successful development of externally funded projects, the visibility of CTIT as a unified entity got a boost. The results were appreciated in a less favourable perspective, in particular in those research groups that were only for a minor part participating in CTIT. In their opinion, other ways of funding, especially projects funded by the Dutch research council, were of higher importance in terms of reputation. These kinds of projects were not the prime focus of CTIT.

Distributed academic leadership in emergent research organisations 5. CTIT 
As a result of CTIT's core research programme, two kinds of bridging projects materialised.

In terms of inter-departmental collaboration, there were shared PhD projects, building on existing relations between departments, also across Faculties, particularly Mathematics and Electrical Engineering. The projects were also spaces, with a certain flexibility, where senior academics involved in the PhD project would meet and get to know each other. Such spaces were also an opportunity to create new inter-departmental interactions, at least on the small scale of a PhD project. PhD projects between departments from the science faculties and the Faculty of Educational Sciences, were interesting in this respect, but also challenges.

Inter-departmental collaborations were at the core of the programmatic approach, more or less new at the time. In the starting-up document for CTIT, two overarching thematic programmes were mentioned: CSCW and "Optical functions in multiwavelength data exchange networks". When the Board of the University asked the University Council to approve the formal start of the institute in 1994, it proposed to allocate a start-up budget for theme of Computer Supported Co-operative Work (CSCW), a two-core programme. ${ }^{52}$ The University Council recognized the strategic importance of the theme, and approved the start-up funding.

The budget was used to open four PhD positions, under supervision of Sjef Moonen, a professor on Tele-learning from Educational Science. While all four PhD projects were duly finished, there was little direct impact on further convergence between departments. There were related programmatic activities, though. In 1996, the so-called IDYLLE project was formulated and submitted to the central research stimulation fund (OSF) of the University. Based on an assessment of proposals by an independent advisory group, the project was awarded the multiannual research grant. Probably more important in terms of visibility was the range of projects on tele-education, initiated in the framework of CTIT, by professors Betty Collis and Sjef Moonen from the Faculty of Educational Science, jointly with professors from Informatics. Tele-education was a swiftly growing area of research and development and application work. The faculty of Educational Science itself became a test lab, resulting in the TeleTop course management system that in later years was developed in quite a number of other universities and networked international companies, such as Shell that later on established a chair on Tele-learning with professor Collis. The overall promise was recognized at the university level, when the leading

\footnotetext{
${ }^{52}$ At the time, UT's strategy was emphasizing multidisciplinary relations between the two cores, of engineering sciences and social sciences.
}

Distributed academic leadership in emergent research organisations

5. CTIT 
professor Betty Collis, was invited to present her vision at Dies Natalis (the University's anniversary) in 1997. From within CTIT, there was recognition when Sjef Moonen, the supervising professor from Educational Science, became a member of the CTIT programme management as of 1998.

Another development added to the programme-based approach. In 1996, the so-called recognized spearhead institutes of the University, CTIT being one of the first of them, got multiannual core funding, of $1 \mathrm{M}$ guilders per year, was allocated to the research institute rather than the administratively responsible Faculty. This was a break with the formal procedures, and argued for by the Board of the University, supported by the University Council, as necessary to allow the recognized spearhead institutes to implement their strategic role in the University's profile.

in the case of CTIT to materialise the strategic vision on telematics, by bundling current research and raising external funding for multidisciplinary research projects.

Most of the core funding was spent on postdocs and PhD positions often linked to the TIOS department. Other co-operating departments in CTIT were not amused, and after some time it turned out that the intended bridging with research groups that were not engaged yet and the planned impact on new projects that would attract and embrace current research threatened to fail. The core funding was also used to provide matching budget to acquire funding amounting to $1.2 \mathrm{M}$ guilders annually from the Telematics Institute $(\mathrm{TI})$. The multidisciplinary projects submitted by CTIT to TI were oriented to the goals of $\mathrm{TI}$ and did not fit in the work of many departments that were involved in CTIT.

Within a few months' time, CTIT managed to allocate the UT grant and the project funds from TI. Three senior academics were given assignments as programme leaders. Their task was to manage programmes as coherent part of the CTIT research programme and to assist in further developing the overall programme by seeking additional external funding. In this frame of strategic programming in interaction with further programme development and managed, a common task for them was to get projects, once funded, actually started. This particular task was necessary to assure that multi-disciplinary projects would not get delayed at the pre-start, due to negotiations between departments about the joint supervision of a PhD.

Distributed academic leadership in emergent research organisations

5. CTIT 
Their way of working was to be a bridge with specific departments, to stand with one leg in a department, and the other leg in CTIT's overall research programme leadership. The research groups, however, saw them as CTIT managers, not representing their group's research interest, but working on an agenda that had been decided elsewhere. That impression was partly correct, in so far as the programme leaders were mainly busy with project development, acquiring funding and start-up of projects.

In the next few years, many project proposals were developed and submitted to the Dutch research funding agency NWO, EU Framework Programmes, and industrial partners. These were all multidisciplinary projects, and reflected a vision of what CTIT could and should do. In hindsight, actors find that strategic goals were realised. Getting these projects executed was the major struggle. The main envisaged new practice at the time was a range of co-operative projects between research groups, explicitly labelled as "hinge projects". In order to create good practices as a strong position and showcase for new project acquisition, CTIT's academic leaders asked for and got substantial financial support from the University Board for three hinge projects: User interface for a multimedia database (Faculties of Informatics and of Philosophy of Science \& Technology), Desktop tele-learning environments (Faculties of Informatics, Electrical Engineering and Educational Science), Evaluation of performance and quality of service (Faculties of Mathematics, Informatics and Electrical Engineering). These funds were used to finance $\mathrm{PhD}$ en post-doc projects on multidisciplinary topics across departments from different faculties.

With these projects, CTIT got visibility on a European level, in particular among industrial partners in the telecommunication sector. In terms of participation, these projects were taken forward by about half of the senior academics involved in CTIT.

It was a deliberate, strategic decision of CTIT to spend time on development of a master degree programme. In their strategic vision, as expressed in the document that was, via the UT Board, presented at the University Council, CTIT stated that development of human resource in telematics was of the highest priority. Their main concern was to recruit excellent PhD's. what they saw was that in order to recruit high potentials internationally for $\mathrm{PhD}$ positions, research masters were needed to select and prepare PhD's.

Distributed academic leadership in emergent research organisations 5. CTIT 
Other research institutes at UT at the time participated in modules or tracks of master and PhD programmes, CTIT took the initiative as they were anxious to make a quick start with the new programmes.

\subsubsection{A business model for networked cooperation}

Right from the start of CTIT, its founders had envisaged a specific business model, ${ }^{53}$ a model that was different from university practice at the time (explicitly in the 1993 starting-up document, section 1.4). The overall aim was to be a "business unit" that would generate and support multidisciplinary research. In the dynamic interaction with the national institute TRC, CTIT should be complementary, with a broader spectrum of expertise and a more fundamental scientific approach. CTIT claimed an autonomous position from the start. When CTIT started in 1994, core of the project portfolio came from the interdepartmental TIOS group with $50 \%$ of CTIT's turnover. CTIT's business manager was paid for $50 \%$ by the TIOS group, and $50 \%$ by CTIT. The dominance of TIOS in CTIT was an important motor for the development and growth of CTIT's project portfolio and its business model in terms of approach, financial means, and administrative set up. But a more balanced growth, engaging departments that felt less connected to the overarching mission of CTIT, did not occur in this starting phase.

In 1996 CTIT was recognized as one of the spearhead institutes of the University, which went with substantial core funding (1 million guilders annually). It also allowed CTIT to autonomously submit project proposals to external funders and to administer research budgets, an important chance for CTIT to pursue its efforts to develop a specific business model.

The spearhead institute was a new instrument for the University of Twente, and thus also for the academic leaders in CTIT. The actual responses within CTIT varied. For the academic leaders coming from the interdepartmental TIOS group, from Mathematics and from Educational Science, it created opportunities. The pivotal leader was the CTIT business manager who at the time was almost full time dedicated to development and administrative support of European projects. The advantage for the participating research groups was that they could learn and save time; European projects and projects with industry posted new requirements that required specialised knowledge and project management and accounting skills that CTIT now organised.

\footnotetext{
${ }^{53}$ Par. 1.4 of the start-up document (1993)
}

Distributed academic leadership in emergent research organisations 5. CTIT 
Professors and senior academics at Faculties of Informatics and of Electrical Engineering, preferred the usual way of project development and administration via their own department and administering faculty, a common practice that had evolved for PhD projects funded by the Dutch research council.

CTIT was able to get a range of projects externally funded. The strategic funding awarded by the Board of the University was used to match EU-project and projects co-financed by the national programmes of the Telematica Instituut got granted, jointly with CTIT and others. From 1995 to 1998, there was growth of the project portfolio, almost doubling each year. Working on developing these projects was not just a matter of trying to acquire funding. There was learning involved, also about interactions and research approaches. The projects were spaces for learning. Their success confirmed the quality of the approach, but may have also confirmed the particular path that the CTIT's core leaders had been following, backgrounding alternatives. An innovative business model, aligned to EU and private sector partners, as envisaged at the start in 1994, did not fully develop, however.

Recruitment of excellent PhD's was, as in other science and engineering domains, a vulnerable aspect of CTIT's business model development and its growth ambitions. For CTIT the particular issue was, that candidates were hard to find, as that the cooperating faculties were facing diminishing enrolment, and CTIT had to compete in the shrinking pond of graduates with companies that were offering well paid positions. In the vision document of CTIT's scientific director that was presented in 1996 to the Central Board and the University Council, CTIT stated that it would take the initiative to start a PhD programme in telematics and, where necessary, a master programme. Aiming at master programmes that would attract young academics that, while preparing their master degree, would prepare their PhD project. CTIT, that is, CTIT's core leaders, tended to see itself as relatively autonomous, not just because of their new core funding, but also because of its guiding vision. So it seemed natural to them to take the lead in launching (in 1996/1997) a Dutch master programme in Telematics, as well as an international master programme based in the University of Twente. To speed up preparation of this new programme CTIT, supported by the Central Board of UT, hired a senior executive from Dutch KPN (Telecom) to conduct a "green field study" for the masters programme.

Distributed academic leadership in emergent research organisations 5. CTIT 
The cooperating faculties did reject this initiative, in particular the Faculties of Electrical Engineering and of Informatics were clear in their response: education was not a research institute's responsibility. Another argument was that the intended master and PhD programmes in Telematics would have an overlap with their current and planned master and PhD programmes, so would draw students away from their programmes. Several departments that co-operated in CTIT were participating or leading in new master programmes ${ }^{54}$. This was in particular the case in the faculty of Informatics, where two new mainly additional programmes were launched. One in "Bedrijfsinformatiekunde" (BIK), the other in telematics led by the TIOS department. The Dutch telematics master programmes was also launched in an international fashion. CTIT continued its efforts for PhD recruitment, the ideas of CTIT's scientific director to organise it as an American style graduate programme were not taken over. In 1997 CTIT established in conjunction with the cooperation faculties the PhD programme that was, as off 1998, accredited by the Royal Academy of Sciences as a research school (the Telematics Graduate School).

So, in negotiation with the cooperating faculties CTIT worked in four years' time since its establishment in early 1994 towards a new business model that would serve further growth of the interfaculty research programme. The initiatives taken and the struggles and negotiations that occurred took mainly place within the University, between CTIT, its Board and academic leaders, and the Central Board and the deans. These initiatives taken and the response from faculties was mainly vision and mission driven, what was lacking at the time, was articulation or pressure from external partners. New research institutes often could make use of new strategic national programmes as a stepping-stone to explore new directions in research. This was not the case, CTIT lived in a scattered research landscape. Research groups that participated in CTIT were each cooperating with a variety of industrial partners and were attracting funding form different programmes from the Dutch research council. The dedicated project development and acquisition of EU funds by CTIT's core academic leaders added to agenda setting by those research groups within CTIT that participated in it, only limited for the overall business model

\footnotetext{
${ }^{54}$ As of the mid-nineties, a strategic initiative taken by the Central Board in cooperation with the deans, to develop some selective new master programmes. These were interfaculty programmes that were given some financial support to develop, and also to develop additional research capacity that would eventually merge with existing research groups into interfaculty groups.
}

Distributed academic leadership in emergent research organisations 5. CTIT 
development of CTIT. CTIT's academic leaders were aware of this; they expected a high structuring impact on the business and research landscape from the new national Telematica Instituut ( $\mathrm{TI}$ ), that was accredited and got core funding from the Ministry of Economic Affairs as of 1997. TI was established as a national consortium of companies, universities and other knowledge institutions. CTIT expected that TI as a public-private consortium would articulate needs from business, develop a national research agenda, and articulate priorities towards the participating universities.

The establishment of TI was favourable for the further development of CTIT's business model. Profiting from the project development capacity that had been developed, during the starting phase of TI, CTIT was successful in acquiring project funding via TI. After this starting phase, TI systematically aimed at the creation of a constellation of programme based senior academic project leaders, this approach did not lead to a similar or competitive response from CTIT.

There were legitimate expectations about more autonomy because of the University's policy of "kanteling", that is, giving more responsibilities to research institutes compared with the traditional exclusive responsibility of Faculties. In 1996, once CTIT got the status of a spearhead research institute, acknowledged by the University council, CTIT's academic leaders were assured by the Board of the University, that in a few years' time CTIT would get an autonomous status, as part of the strategic policy of "kanteling" which should result in a new UT-wide governance structure, a balanced model of "schools and institutes". This perspective gave CTIT's core academic leaders and its Board a focus for the development of an innovative business model. In particular the chairman of CTIT's board, a professor who himself headed a relatively autonomous research institute in Germany, was in favour of a high amount of autonomy for CTIT, and was arranging for meetings to promote this towards the Board of the University and the Deans.

The new chairman to the Board of the University, Frans van Vught, who added this responsibility to that of the rector, made the "kanteling" to one of his prime policy issues. So, at CTIT's Board and with the core academic leaders new hope arose that the promised autonomy would be at hand. However, the Deans resisted strongly, and Chairman Van Vught had to give in, to be able to continue with another strategic policy, to have mergers to reduce the number of faculties. The "kanteling" was once again postponed, to the distress of CTIT's core leaders.

Distributed academic leadership in emergent research organisations 5. CTIT 
One could say that the original thrust of CTIT had been important, and had created successes in external visibility and funding, but had also run against limits, and perhaps exhausted its resources to overcome them. Without the autonomy that was envisaged in the "kanteling", initiatives that stretched present structures and traditions had a hard time, whether these were a new master programme, or new approaches to project development and links to external actors. Internally, there were differences between visions, ambitions and perceptions about the envisaged development of CTIT as an organisation, with the core leaders (and the roots of CTIT in TIOS) having positions and perspectives contrasting with other leaders involved in CTIT (and with Deans and other senior academics in participating Faculties). As became clear in 1998, in the preparations for the new five-year mandate, CTIT as an organisation did not have procedures and common practices to handle conflicts in strategic deliberation and decisionmaking. CTIT was like an open forum, which might, but need not be conducive to learning. Several academic leaders involved in CTIT had problems because they were wearing different hats in the colliding processes and stakeholder perspectives.

All this came to a head in the preparation for the next five-year mandate in 1998, and extending into 1999. There had been an evaluation, conducted by an external panel of senior academics, which offered an overall positive assessment. ${ }^{55}$ There was a draft research plan for the next five years. These failed in creating common ground, however, among academic leaders in mainly important Faculties of Electrical Engineering and Informatics. In fact, an open letter to CTIT's board was written by four professors of Informatics, some of them involved in CTIT, declaringthat the next five-year plan to start in 1999 should be rejected. To overcome the impasse, CTIT's Board intervened and asked for a new plan. They invited a consulting firm to coach CTIT's core leading academic group in a process of planning and organisation design for such a new plan. This resulted in a report (October 1999) titled "CTIT, fit for the future", ${ }^{56}$ but this did not resolve the differences in opinion. Soon after, it so happened that two of the academic leaders, who had been co-founders of CTIT, accepted positions outside the University (see further Section 5.3.1). Clearly, the first period in the life of CTIT was concluding. Thus, the first episode ends in 1998, with a transitional year 1999.

\footnotetext{
${ }^{55}$ It did identify insufficient coherence of interactions between academic leaders in CTIT, notwithstanding broad support for CTIT's mission and its efforts and achievements so far.

${ }^{56}$ Rapport Twijnstra Gudde dd oktober 1999: "CTIT, klaar voor de toekomst".
}

Distributed academic leadership in emergent research organisations

5. CTIT 


\subsection{Episode 2 (1999 - 2002)}

\subsubsection{Brief historical overview of this episode}

In 1999, CTIT entered its second episode. That year was a transitional year: one can see it as the final year of the first episode in which the preparations for the next five-year mandate (which had run into trouble) were concluded; or as the first year of the next episode in which CTIT embarked on other ways of research programming, and a business model aligned to the cooperating faculties was explored. When the new five-year programme was accepted by the seven Faculties involved in CTIT in July 2000, the transformations were already well on their way. When this episode ended, in 2002, there was some stabilisation, and the advent of a new director created further direction, exploiting the new arrangements. In a sense, the whole of the second episode was a transitional period.

Part of the transition was that in 2000, the scientific director (Ignas Niemegeers) and CTIT's manager (Jeroen van de Lagemaat) were succeeded by Henk Zijm and Iddo Bante, respectively. There were some changes in the research policy context at the University, and there was the burst of the internet bubble in 2000, resulting in a crisis in the IT sector and for CTIT, a shift in research themes.

Whereas CTIT's core academic leaders had followed an entrepreneurial route, where project development was the key to create a coherent research programme with a mission-driven perspective, the new core group academic leaders chose a thematic approach, with themes agreed with the Deans and Heads of Departments. CTIT's internal institutionalised gatherings (e.g. the annual research days) that had not been convened on a regular basis, were revitalised. Three loosely coupled categories of academic leaders were so far active in the framework of CTIT. The academic leaders that were active in the core of the institute, working closely together on activity basis, voicing a consistent vision on CTIT's development.

- The executive board comprised five persons: senior academics from Electrical Engineering, Informatics and Mathematics, the scientific director and the manager.

- The members of the CTIT Board, in particular the chair person.

- Academics performing leadership roles, belonging to the TIOS department and/or being paid by project funds that were managed by CTIT.

Distributed academic leadership in emergent research organisations 5. CTIT 
Senior academics from the four social science Faculties showing a low level of interaction and joint leadership activities. An exception were Betty Collis and Sjef Moonen, professors from the Faculty of Education Science. In terms of research manpower a minority, but voicing a consistent and at the time triggering innovation perspective, in particular articulated in the OSF programme IDYLLE.

Senior academics from Electrical Engineering and Informatics, comprising almost 50\% of CTIT's research capacity, among them the senior researchers who also were the deans of these Faculties. Often having a critical stand towards the vision and activities of CTIT core academic leaders, because they have a different and sometimes opposed perspective on the way ahead to be taken by CTIT.

\subsubsection{Analysis of leadership practices}

\subsubsection{A strategic research programme}

As was noted already, the scientific director had submitted a research programme for the next five years, agreed by the CTIT Board, and supported by the Board of the University. The Deans of the Faculties involved, however, in particular of Informatics and Electrical Engineering, had severe doubts and reservations. In order to overcome this impasse, the CTIT board invited a senior academic, Henk Zijm, a professor in the fields of mathematics, logistics, and production management, with experience in Philips Company, to assist CTIT's scientific director to prepare a new research programme proposal for submission. It took about 6 months to consult various academic leaders and the deans and present a new programme. During that period, in April 2000, the scientific director stepped down (he had accepted an invitation to develop a new chair in the Technical University of Delft). His colleague Henk Zijm was invited to take over his position as scientific director of CTIT, as he agreed to do.

The new scientific director had approached the research programme from a different perspective, in an effort to overcome impasses by re-framing dialogues about research programming and steering, from vision and projects towards themes and strategic research orientations. Application areas would be important, in line with an overall shift in the wider landscape of informatics research towards application-oriented approach, in particular concerning complex systems e.g. in healthcare, and themes important to business like e- 
Commerce, e-Services and Logistics. The autonomous steering mandate of CTIT was no longer a prime issue of discussion with the Central Board of the University and the Deans.

This approach was well received among the Deans. It had become clear to key actors involved, that the differences in perspective on CTIT had to be bridged so as to revitalise the by now widely accepted strategic mission of CTIT. The acceptance of CTIT's mission grew within the Faculty Informatics, it was voiced that it was time to review the scientific and technological perspectives of telematics as a special domain. There were developments in the national academic community, openings for research on applications starting to occur. In his negotiations for the new five year programme, the new scientific director engaged a major part of the research groups from Informatics. There were also developments in de business world, new themes as e-commerce came up, themes that engaged new business partners in academic research.

Helpful in this respect was the announcement of the national Telematics Institute that it might leave the UT campus and settle somewhere else in The Netherlands. It made CTIT's academic leaders reflect on the need to keep their prominent position in the TI research and innovation consortium. They closed ranks, as it were, and agreed on multi-annual programmatic commitments with a focus on applications of ICT.

In July 2000, the new five-year programme was agreed upon by the seven Deans involved. The thematic basis of the programme had broadened. While the draft programme of 1998 presented three thematic areas, the present agreed programme offered a wider spectrum, of six themes. It was visualised as a diamond, a coherence of four ICT systems research areas and six ICT application areas. This diagram became almost a logo (Fig. 5).

Distributed academic leadership in emergent research organisations 5. CTIT 


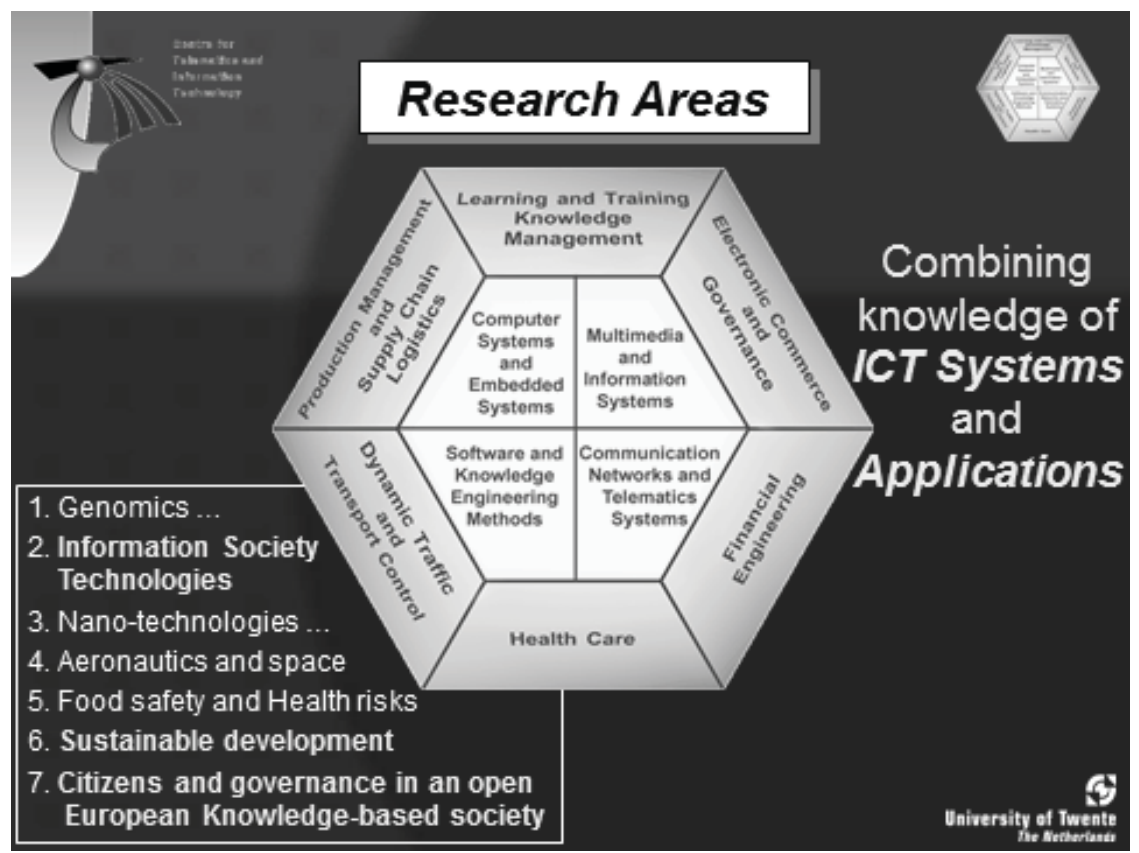

Figure 5. CTIT's constellation of research and application areas (Annual Report, 2000).

Concurrently, the chairman of the Board, a reputed international researcher and head of a research institute in Germany, was succeeded by a senior executive from industry, the CEO of the Dutch IBM subsidiary. The scientific advisory board saw a shift in members from exclusively academic institutions to include experts from industry.

The new scientific director was accepted as a change agent to introduce and promote the new, more application theme oriented, approach to research programming. He was supported by a new institute manager who came from another interdepartmental research institute in the University of Twente, the Institute for Biomedical Engineering. In a sense, space was created for CTIT's academic leaders to develop new leadership practices. CTIT got further institutionalised and anchored in the overall UT structures. In particular, the Deans of the involved faculties now had an ex officio place in the Board of CTIT. And the scientific advisory board was revitalised, with a broad representation of senior academics from participating departments being invited, structured according to the new programme, with six members for the application domains and four members for systems research.

All this gave a new sense of direction to CTIT. But it came at a time, as interviewees observed in retrospect, that the overall enthusiasm had passed its peak. Studying informatics and working towards careers in internet-related business were no longer hot among young people. Partly because of the bursting of the internet bubble, the dream of a "Silicon Valley at the Dinkel" had

Distributed academic leadership in emergent research organisations

5. CTIT 
disappeared, with companies like Ericson, Lucent and CMG had leaving the region, and Dutch KPN downsizing its research department. One could also see this as a new sense of realism, reflected in the move towards application areas. One interviewee observed how in 1992 telematics was a promising niche area taken up enthusiastically in TIOS and CTIT, but by 2000 telematics was broadly recognized as important, but not a mission in its own right anymore Thus, the transitional character of this episode does not derive from a new strong vision replacing an old one, but from an attempt to come to terms with the new situation in the informatics landscape.

\subsubsection{Convergent research themes}

In line with the overall re-orientation of CTIT's research programming, the new core academic leaders (the scientific director, individual board members, the institute manager, the programme leaders) worked on an improved links between on-going research projects in departments and multidisciplinary, more or less application oriented, research projects set up within CTIT. The role of the three programme leaders appointed in 1998, funded by the spearhead budget for a period of five years, would be pivotal. They had been appointed as bridging agents between the research groups and the overall CTIT programme. In practice, they had mainly been working on project development and execution at the level of CTIT, and accordingly, were perceived by the research groups as part of the CTIT core group and its mission. The new core leaders made efforts to stimulate that the programme leaders would indeed be accepted as leaders in their groups as well as on the research institute level. As in the first episode the focus was on projects as a carrier for co-operation between groups, but now they took the research interests of groups into account as a starting point.

What then intervened, in 2001, was a new research policy scheme from the Board of the University, going for programmatic financing of research, channelling the funding through the recognized research institutes (five at the time). As a consequence, if academic staff wanted to have research activities, they had to be part of one of the interfaculty research institutes. This new policy confronted all research institutes with a challenge, whether and on what conditions to accept the academic staff wanting to join them, so as not to dilute their status as being excellent in research. So far, growth of the institutes had been a "natural" development, through attracting academic staff to join, and employing researchers through external funding.

Distributed academic leadership in emergent research organisations 5. CTIT 
With the possible new influx of researchers with their own research interests, it was not clear how these could be integrated into the life of the institute. In actual fact, the new policy scheme was refracted by these difficulties and only partially implemented.

For CTIT, it was an incentive to fully adopt, and adapt, the Strategic Research Orientation (SRO) model that had been developed by the MESA+ institute, and had been pushed by the Board of the University. All research themes and projects were organised in six SROs, and newly participating academic staff had to adapt their research so as to fit into one or another SRO. Each of the SROs should comprise systems research as well as research on applications (cf. Figure 12). Programme leaders, who used to have a broad assignment, would now focus on one or another SRO.

\subsubsection{A business model}

The shift, broadening scope and focus, initiated in this episode, had its implications for CTIT's business model and related governance issues. A key step was the change in status and role of the programme leaders. Their position had been introduced in 1996, when the then scientific director used some of the spearhead institute funding to have three senior academics seconded to him for programme development, offering them adequate remuneration. In 1998, their number was expanded to five; they formed a separate group working to implement the vision for a strong CTIT which should not depend on slow bottom-up changes in the departments, particularly the departments in the Faculties of Informatics and Electrical Engineering. They were directly accountable towards the scientific director, and thus outside the regular work organisation where heads of department would be responsible for all academic staff in their department. In the director's vision, if CTIT was to be a centre of excellence and partner for industry, then key staff like the programme leaders should be treated as would happen in business, and with remuneration sufficient to avoid their being tempted by employers in high tech industry hunting for high potentials. The research groups into which the programme leaders were formally located were of course not happy about having a person in such an exceptional position. In 2000, the new scientific director was adamant this should change, and was able to rearrange their positions. While keeping a role in the central activities of CTIT (like leading an SRO), they were now located in a department and formally accountable to the Head of Department. The new set-up implied that departments would be more closely involved in the

Distributed academic leadership in emergent research organisations

5. CTIT 
overall workings of CTIT. A similar move was visible when the scientific director recommenced meetings of the heads of department involved in CTIT.

CTIT's business model changed also because the new strategic program organised in SROs allowed exploitation of opportunities to acquire external programmatic funding. The main driver had been external funding from and co-operation with European industry, but new possibilities were emerging. Building on its past work and performance CTIT could get a central position in execution of the national Gigaport programme, coordinated by the Telematica Instituut. Exploiting its new SRO structure, CTIT started to acquire funding from the governmental BSIK (earlier called ICES KIS) funding program that was opened at the time. While developing cooperating programmes with industrial partners in this new national programme, CTIT's academic leaders, including the new academic leaders that joined when their groups engaged in the new research themes, could explore and learn ways to extend the (business) 'relevance' activities in domains such as logistics and ehealth.

An internal challenge to the business model was the advent of new research groups, not because they wanted to contribute to CTIT's strategic programme, but because of the new policy of the Board of the University that all research (apart from the teaching-related research) had to be part of an accredited research institute, CTIT being one of them. While the actual implementation of the policy was not as strict as originally announced (there was learning), it did imply that the ranks of CTIT, and thus its formal budget, were swelled by groups whose contribution was "in kind", the money value of the research they were doing already. That part of CTIT's budget (sometimes called the "federal part" as in the earlier interfaculty institutes) could not be mobilized for strategic purposes of CTIT. The prospect of acquiring external programme funding was seen as the way forward for CTIT.

\subsection{Episode 3 (2003 - 2006)}

\subsubsection{Brief historical overview of this episode}

The transitions set into motion from 2000 onwards were stabilizing in new approaches and leadership arrangements. It is somewhat arbitrary when the stabilization is to be considered advanced sufficiently to speak of a new episode. There were no changes in context that would be markers for a new episode. There was an internal change, the departure of the scientific

Distributed academic leadership in emergent research organisations

5. CTIT 
director, and the advent of his successor who could exploit what had been achieved already in terms of approaches and leadership arrangements.

CTIT was one of the accredited, strategically important spearhead institutes of the University of Twente, and the realisation of its second five year's mandate was well underway. CTIT further broadened its research focus, shifting away from systems research towards application areas. Newly important was a focus on ICT in practice, no longer restricted to professional organised settings like companies or hospitals, but also taking into account the perspective of the individual user in his environments.

As noted already, CTIT with its new approach could profit from the Dutch government launching large-scale programmes that fitted well with the multidisciplinary and programmatic approach of CTIT. Jointly with the national Telematics Institute, a number of programmes were acquired. While major private firms in ICT had left the Twente region (or even completely stopped operations), the regional dimension was now kept alive by CTIT spinning out small high tech companies, up till about 20 firms by the year 2005.

A major change, and as noted, a reason to start the new episode in 2003 rather than later, was the stepping down of CTIT's scientific director by the end of 2002. He was appointed Dean of the new Faculty of EWI, a merger of the Faculties of Electrical Engineering, Mathematics, and Informatics - the three key Faculties participating in CTIT. Peter Apers, at the time Member of the Board of the University, responsible for research policy, and a former Dean of the Faculty of Informatics, was willing to take over as scientific director of CTIT. In his Annual Report over the year 2003, reflecting on the previous ten years' development of CTIT (in which he had been variously involved), said that CTIT was now embracing new opportunities, "harvesting" from the long term efforts that were made up till then.

In this episode, multi-annual thematic programmes, covering excellence as well as relevance, became the main site of leadership arrangements, inside the University, and externally, as interface to national and international programmes. This is another reason to start this new episode here and, as will become clear in the next subsections, to end it around 2006; CTIT entered a new phase of expansion and differentiation, distributed leadership stabilised around strategic programming and continued project and business development. In the words of the

Distributed academic leadership in emergent research organisations

5. CTIT 
scientific director (in 2005), CTIT had become a "network institute", flagging how it now functioned in these wider arenas.

\subsubsection{Analysis of leadership practices}

\subsubsection{Programmes entering wider arenas}

In this episode, the focus of academic leaders was increasingly externally oriented. No longer were the internal boundary struggles between CTIT and departments predominant. Attention could now be paid to research programmes on a national and international scale; to capture opportunities required a broad effort, which stimulated internal co-operation structured in the six SROs, and learning, capitalising on the first experiences that ware gathered with multidisciplinary approaches in previous years.

The challenge continued to be the multidisciplinary nature. CTIT had been heading for multidisciplinary projects, often projects that created hinges with disciplinary research in the departments. Since funding for basic ICT research was not growing, it was not easy for the departments involved, in particular those in the Faculty of Informatics, to add such projects to their existing research portfolio. While the departments remained important, already because CTIT researchers would be located in them, the main road would be through multi-annual programming of research, using the six SROs that had been defined already. They were a profiling instrument to acquire external funding, and were quite successful in the national Bsik programme (CTIT involved in nine programmes) and the EU FP6 programme (CTIT in 25 EU projects).

CTIT's scientific director presented his perspective on this situation in his Dies Natalis lecture in December 2003. In his view, CTIT was well positioned in the various road maps that had been published at national and European levels. ${ }^{57}$ Thus, in principle, a promising future for CTIT; a "fertile tree" had been created, and fruits could be reaped. But in practice the health of the heart of the "tree" was in danger. He was voicing the strong concerns of CTIT's academic leaders who had increasing difficulties in matching externally funded projects with basic, long term funding from the University.

\footnotetext{
57 "Samen, strategischer, sterker" ICT Taskforce, 2001; “Innoveren door ICT" (Visie ICT-Forum, 2003); reports of ISTAG (EU IST Advisory Group), WWRF (Wireless World Research Forum) and ITEA (EU Eureka programme).
}

Distributed academic leadership in emergent research organisations

5. CTIT 
Part of a solution to the basic funding problem, and a new departure point for joint international profiling, was found in a closer cooperation and task division with the other two Technical Universities. After years of preparation and negotiation, led by the Central Boards of the Technical Universities, as of 2006 a strategic alliance was concluded between the Technical Universities, comprising task division and priority setting in education, research and valorisation. In the frame of this strategic 3TU Alliance, that formally started in 2007 as a Federation in legal terms, a subsidy of 50 million euros from Dutch government could be used to organise five centres of excellence. CTIT took a leading role in the establishment of the Netherlands Institute for ICT Research (NIRICT).

All in all, a stabilised pattern of leadership arrangements in research programming was visible. Leadership roles became institutionalised as management responsibilities. For example, as of 2005 , SRO leaders were ex officio member of the management team. With the participation in the national and international research funding arenas, there was further learning about the necessary leadership activities.

\subsubsection{2 convergent research themes (SROs)}

CTIT's core academic leaders no longer acted as initiators of projects that would create protected spaces in which researchers could explore and innovate. In general, the core leaders now expected the research groups to stimulate new research by creating spaces for it. They had promoted SROs as a platform for co-operation, internally by having at least two, and later five, research groups involved, and externally by inviting partners from telecom industry, or from the health care sector. Another co-operation was stimulation of collaboration from information sciences (and electrical engineering) and humanities and social sciences. CTIT's core leaders continued to emphasize the role of the SROs, but retreated somewhat and relied on distributed leadership carried by seniors in the departments. By 2005, the six SROs covered a stabilised set of themes that linked to the national ICT research agenda as agreed in the NIRICT consortium and to application oriented thematic programmes in eHealth and eProductivity with European partners.

Thus, a pattern of stabilised spaces resulted showing a size and internal diversity that would run as self-supporting programme units for at least five years, sometimes longer.

\section{Distributed academic leadership in emergent research organisations}

5. CTIT 


\subsubsection{A stabilised business model}

There was little need to create a new business model. CTIT embodied the ICT knowledge cluster of the University of Twente. It covered the full ICT research capacity of the faculties concerned. (By the time, all research groups concerned were organised, after a university wide merger of faculties, in three rather than seven faculties.) The size and span of control in terms of finance and personnel was adapted to the possibilities that the University offered. CTIT's leaders deliberately kept away from career development and other human resource affairs in their planning and operations. This had to be taken care of by the Faculties. Actually, this became a general requirement for the accredited institutes when at the end of this third episode, the Board of the University decided on "terugkanteling", giving primary responsibility to the Faculties rather than the Institutes.

Externally, as was envisaged by CTIT's leaders in the early 2000s, there was enhanced participation and an increasingly leading role in national research and innovation programmes. An example was CTIT's leading role in the development of the NIRICT consortium: a strategic coalition between the three Technical Universities of Delft, Eindhoven and Twente in the area of ICT.

While overall arrangements, including the business model, had stabilized, there were still challenges for CTIT and its leaders, about governance and associated leadership issues. The number of projects and programmes had grown considerably. There were projects funded by the Dutch research funding agency NWO, by the European Commission (about thirty projects over the period) and national projects (about nine, funded by the BSIK programme).

As the activities of CTIT expanded, so did the number of academic leaders. By the year 2005 CTIT had six SROs, each including five research groups, and thus at least thirty academics conducting leadership roles. In addition, some ten senior academics had roles in the central scientific and business management and the Board of CTIT.

At the end of this episode, when stabilisation appeared to be assured, one of the key-actors at the time characterized the arrangements as a "light weight constellation that perfectly suits the challenge of supporting and where needed steering a diversity of self-steering clusters of groups, in fact operating as a well organised "bazaar" of research groups. ${ }^{58}$ " The idea of

\footnotetext{
${ }^{58}$ Prof. Fred van Houten, Faculty of Engineering Technology
}

Distributed academic leadership in emergent research organisations 5. CTIT 
distributed academic leadership now comes back, in the form of a distributed "bazaar" of research groups.

\subsection{Concluding observations}

It is on an upwards curve that I leave CTIT. It was an established spearhead institute in the international research profiling strategy of the University of Twente. A centre of excellence that increasingly also became a centre of relevance, visible as an international innovation research centre and linked to spin-out companies and industrial projects.

Transformations that took place over the last twenty five years in the research domains telecommunication, informatics and connected areas in mathematics, business administration, public administration and educational science, were reflected in the development of CTIT's research programme, most recently the move from systems research towards human centred IT and services. CTIT is no longer an acronym standing for "Centre of Telematics and Information Technology", but brand name in its own right. Its size and the variety of disciplines including strong groups from social sciences, help this Centre of Excellence \& Relevance to attract new themes like eHealth, cybersafety, smart cities, that rank high in the new strategy of the University of Twente, sometimes indicated by the slogan High Tech, Human Touch.

Instrumental to these on-going developments were the strategic research orientations (SROs) ${ }^{59}$ and later, the strategic themes agreed in the Dutch NIRICT network of which CTIT was cofounder and CTIT's scientific director the chairman. Substantial groups of researchers were working on them, and they constituted learning environments for academic leadership. Senior researchers recognized their importance of this learning, and engaged in strategic management and development of new approaches to further enhance the cohesion in CTIT's research work in interaction as well as improved positioning in national and European networks.

CTIT's pathway had its specificities, including the major changes during what I called the transitional episode. It bears interesting features relevant for analysis of development of other such research organisations, as will be discussed in the cross-case analysis in chapter 7 .

\footnotetext{
${ }^{59}$ The SRO approach was evaluated in 2007, and again in 2012, and assessed positively.
}

Distributed academic leadership in emergent research organisations

5. CTIT 


\begin{tabular}{|c|c|c|c|}
\hline & Episode 1 & Episode 2 & Episode 3 \\
\hline $\begin{array}{l}\text { Distributed leadership } \\
\text { constellations }\end{array}$ & Top down orchestrated & Top down orchestrated & $\begin{array}{l}\text { Orchestrated } \\
\text { differentiated } \\
\text { constellations }\end{array}$ \\
\hline Spaces & $\begin{array}{l}\text { an intra-organisational } \\
\text { learning space, } \\
\text { comprising loosely } \\
\text { coupled protected } \\
\text { activity spaces } \\
\text { protected spaces } \\
\text { comprising fusing } \\
\text { existing areas }\end{array}$ & $\begin{array}{l}\text { Emerging leadership } \\
\text { learning space around } \\
\text { one protected activity } \\
\text { space } \\
\text { orientation space for } \\
\text { research leaders that } \\
\text { are positioning in the } \\
\text { institute }\end{array}$ & $\begin{array}{l}\text { a leadership learning } \\
\text { space around an } \\
\text { orchestrated set of } \\
\text { protected spaces } \\
\text { protected spaces } \\
\text { comprising fusing } \\
\text { existing areas }\end{array}$ \\
\hline $\begin{array}{l}\text { Sites of change and } \\
\text { leadership }\end{array}$ & $\begin{array}{l}\text { Primarily selective } \\
\text { converging project } \\
\text { development and } \\
\text { strategic programming, } \\
\text { and selective business } \\
\text { model development. }\end{array}$ & $\begin{array}{l}\text { Primarily strategic } \\
\text { programming and } \\
\text { converging projects. }\end{array}$ & $\begin{array}{l}\text { Primarily strategic } \\
\text { programming and } \\
\text { converging projects. }\end{array}$ \\
\hline
\end{tabular}

Table 6. Summary of CTIT's development over time (according to the conceptual model)

\section{Overall organisational changes}

CTIT was the first research institute at the University of Twente that aimed to bring a broad spectrum of research groups (eventually from seven Faculties) together under one banner. This invited major organisational change. The immediate challenge was that these groups, having different practices and subcultures, had to evolve into a more or less coherent community of researchers, with research themes that were boundary spanning. The change path that was eventually followed built on two core groups: the interfaculty TIOS group (Electrical Engineering and Informatics) and a cluster of groups in the Faculty of Educational Science\& Technology (Educational instrumentation, Tele-learning, Networked learning), both with strong visions about directions to go. Rather than relying on endogenous developments in the participating Faculties, ${ }^{60}$ these groups developed a separate layer of activities, in cooperation with companies and EU partners, which constituted the bulk, or at least the most visible bulk of CTIT's activities in the first episode. The vision-driven development was supported, since CTIT's preparation as

\footnotetext{
${ }^{60}$ The Faculties were reluctant to join because the two CTIT core research groups did not, at the time, hold a prominent position in the strategy of the administratively responsible Faculty of Informatics. And the Faculties had their own problems in the organisation of education and research, particularly because of the shrinking student enrolment.
}

Distributed academic leadership in emergent research organisations

5. CTIT 
of 1992 and its formal start in 1994, by the Central Board of the University, promoting CTIT internally and externally, and in 1996 awarding special funding to CTIT as the first spearhead research institute in the then evolving institutional research strategy.

At an early stage, and pushed by the TIOS group, a business-like approach of research project organisation became the norm, aligning to the operational standards of international telecom companies that TIOS, now CTIT, cooperated with, up to strict delivery schedules. This strict quality assurance approach was loosened somewhat once CTIT took more research groups on board and welcomed companies from other sectors. Still, project and program-based working continued to be a strength of CTIT when it geared to national and European programmes. It was a legacy of TIOS, one could say. ${ }^{61}$

Research programming was mission and vision driven, so orchestrated but with a lot of liberty for senior academic researchers. During the starting years, when CTIT was twinning partner of TRC, which was completely mission driven, this appeared to be appropriate, and conducive to success. But it was difficult to embed in the Faculties. Eventually, the separate layer of activities did not disappear, but became part of the move to stronger links to the Faculties, in particular, as of 2000, with the research policy of the Faculty of Informatics. The new research programme, the basis for the second five year mandate, reflected this, connecting application-oriented research with fundamental research. Almost the full research capacity of the Faculty of Informatics now joined CTIT.

The new change path, embedded in the Faculties but not depending on them because of the participation in national and international programmes, was shaped in the transitional period of the second episode. There were also continuities, as in the relevance ambition, but with a twist. The strong visions were now replaced by interactions in various application areas. This was not just a matter of new leaders coming in with a different perspective. It also reflected overall changes in the ICT landscape.

\section{Distributed leadership activities and spaces}

\footnotetext{
${ }^{61}$ This feature of the life of CTIT in the first episode remained implicit in my reconstruction in section 5.2.2.
}

Distributed academic leadership in emergent research organisations

5. CTIT 
In the first episode, distributed leadership activities were linked to strategic programming and primarily informal and explorative entrepreneurial. Learning, related to visions, occurred in the two spaces that were at the core of CTIT's then strategy: around the TIOS research group and around the e-learning cluster from the Faculty of Educational Science. Entrepreneurial It was ambidextrous leadership, working towards creation of new research areas, and fusing them with existing areas in programmes with strategically chosen external, often industrial partners. Important activities were strategic negotiations with the Deans and Central Board of the University, and strategic positioning of "Telematics" as a theme in national and international networks.

With the transition in the second episode (1999-2002) the focus continued to be on fusion of research areas, and joining forces with external strategic partners, but now themes were structured in terms of six strategic areas, the Strategic Research Orientations. Leadership activity patterns continued to be explorative entrepreneurial and informal, but becoming increasingly formal because of the reference to the six strategic areas and their programme leaders. They became increasingly contextually ambidextrous when seeking for strategic partners in application areas.

In the third episode (2003-2006), alignment with national programmes and strategic alliances in particular with the new NIRICT consortium were important. While leadership activity patterns were still mainly informal, with the growing number of research management positions in projects and programmes, formal leadership and the accompanying learning in these spaces was emerging. Similarly, while explorative entrepreneurial leadership was important in the continued search for new application areas, exploitative entrepreneurship was visible as well, one indication being the high tech start-ups spinning out from CTIT. With all strategic areas focusing on excellence as well as on relevance, leadership was contextually ambidextrous with growing structural ambidexterity when specialised business development positions were created.

The trade-offs between the different aspects of distributed leadership appeared to stabilize, and innovative business model development was implied in the reference to CTIT becoming a 'network institute'.

Distributed academic leadership in emergent research organisations

5. CTIT 


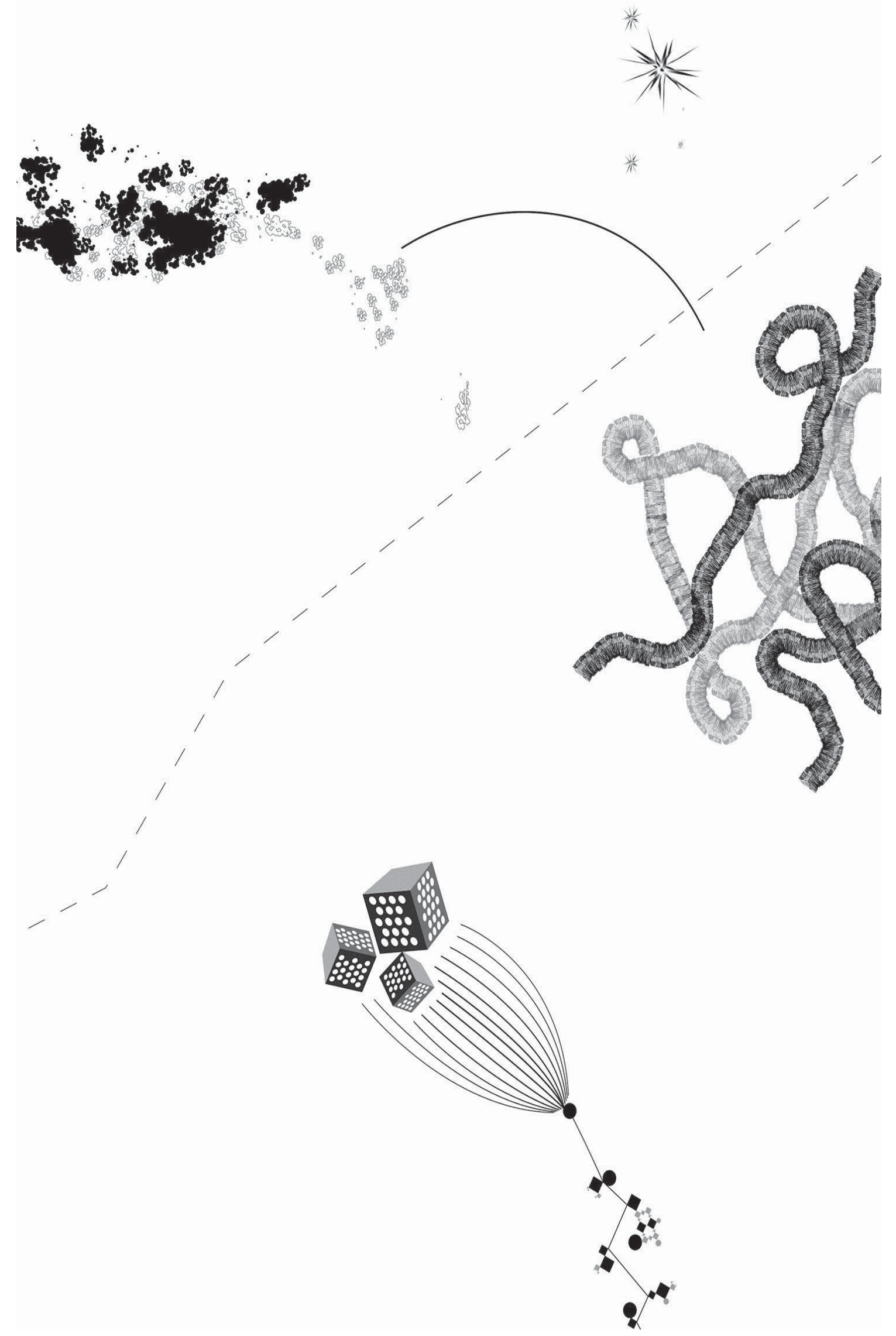




\section{6. the Telematica Instituut}

\section{Contents}

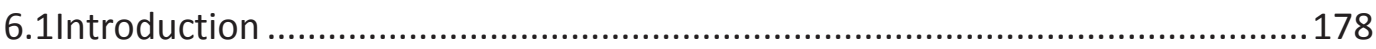

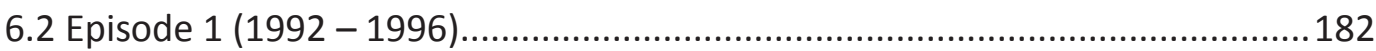

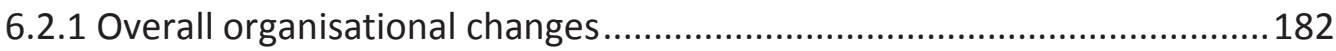

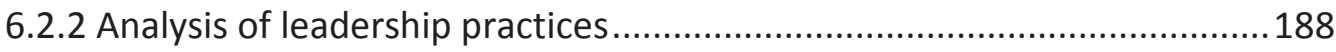

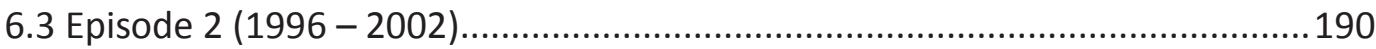

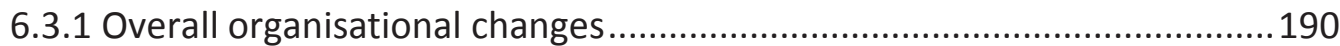

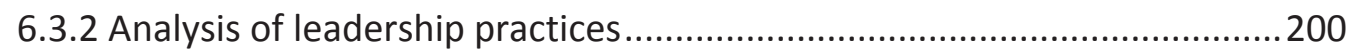

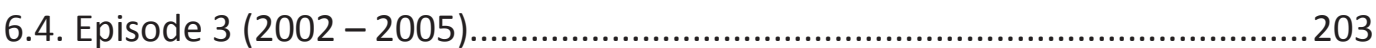

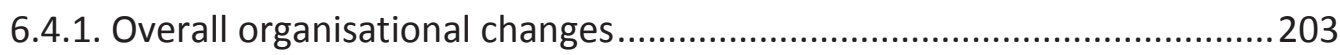

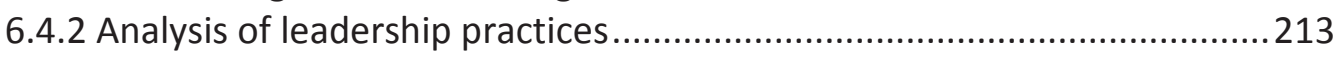

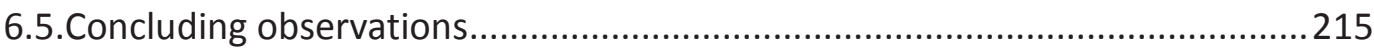




\subsection{Introduction}

This case study introduces the reader to what at the time, in the early nineties, was a new phenomenon in the Dutch research and innovation landscape: a research institute with an explicit nationwide mission, launched from scratch. Beside the scientific director and his core administrative staff, all academic core staff had to be recruited, and no existing academic groups or industrial teams moved as a team to Telematics Research Center (TRC). The context of TRC and later Telematica Instituut (TI) was highly volatile. The research fields IT and ICT were areas that at the time showed strong, primarily internationally driven, competition. Furthermore, the Dutch research and innovation landscape in IT and ICT was scattered: many university groups from a range of disciplines were involved but not connected. Industrial groups were mainly subsidiaries of international companies. SMEs were not linked to university research, although later on, after 2000, started to engage in innovation programmes together with university departments.

As noted already in Chapter 5, in 1991, a unique experiment had been launched by a coalition of the Dutch Government (represented by the Departments of Education and Science, and of Economic Affairs), Dutch KPN, Philips and IBM. In close co-operation with the Dutch universities, the University of Twente in particular: the Telematics Research Centre (TRC) was launched as a foundation under Dutch law. The main mission of TRC was to establish pre-competitive research programmes, joint ventures of industrial and public sector partners, working on "breakthrough technologies".

In 1996 TRC entered a new stage in its lifecycle becoming an LTI, "Leading Technological Institute", still, a public-private pre-competitive research institute, but with a different statute. Four such LTIs were established, jointly announced by the Ministers of Education and Science, and Economic Affairs, in the framework of the policy "Kennis in Beweging". This policy was launched in 1996 in order to "strengthen the innovation potential and competitive position of Dutch Industry". In other words, LTIs should help in bridging the gap between the research in the public knowledge infrastructure and the knowledge needs of industry. One of the strategic areas selected by government was telematics: accelerating innovative ICT applications to boost Dutch business and increase social wellbeing. TRC was invited to submit a proposal for the new LTI scheme, jointly with a public-private consortium of universities and companies. The bid was successful and the Telematica Instituut could be started up. A period of swift growth followed,

Distributed academic leadership in emergent research organisations

6. Telematica Instituut 
creating lots of openings for researchers to develop leadership and create new ways of working. After this period, by 2000, together with partners in and outside the TI-consortium, broader multi-annual national and international programmes were initiated in response to national and European research and innovation funding schemes. Once again leadership, this time distributed between different members in the TI consortium, was challenged; in particular, as a new kind of companies had to be pulled on board: no longer were telecom companies at the core of research projects, but ICT and internet services companies.

Clearly, TRC/TI is a good site to study the main research question of this thesis: "What are evolving distributed academic leadership arrangements in research organisations in transformation?" It contrasts with the first two cases, as it was not immersed in university structures with their specific opportunities and constraints.

\section{The structure of the chapter}

The presentation follows the underlying structure of analysis (see chapter 3, Research Design), where the history is divided into episodes. The description of events is based on the understanding of patterns in distributed leadership activities.

The first episode covers the years 1992-1996, the start and build-up of the Telematics Research Centre. It ends at the moment that the Ministry of Economic Affairs launched the new "leading technological institutes" policy, and the Centre shifted gears to work on the bid for the new policy.

The second episode covers the years 1996 - 2001, the formation and start of the Telematica Instituut as a new kind of research and innovation entity. When the internet bubble burst, $\mathrm{TI}$ had to shift its focus. It was a time of broadening the scope, and loosening its relationships with the University of Twente.

The third episode covers the years $2002-2005$, with the organisational development of $\mathrm{TI}$ into a fully operational innovation expertise centre, well positioned in the national innovation landscape. This episode sees growth and new challenges as companies from other sectors than ICT became involved in the TI consortium. Another challenge was that universities became competitors in the sense that they also embarked on multi-annual programme co-operation with companies, often the same as TI worked with. In addition universities had easy access to EU networks and programmes, and some, like the CTIT research institute that was started at the

Distributed academic leadership in emergent research organisations

6. Telematica Instituut 
University of Twente parallel to the TRC, now was a leading party in University-wide programmes for business start-ups.

Within each episode, three key activities are taken up in an integrated way for further discussion in the final subsection and in Ch. 7 (Analysis). Different from the other two case studies, these key activities are not presented in separate subsections; as will become clear from the text, at TRC and TI the key activities occurred in a much more centrally orchestrated way. There is still distributed leadership, but it is orchestrated distributed leadership.

A final introductory remark concerns the organisational structures of TRC and TI. In a formal sense, TRC and TI had a board, a scientific director and a business director, a management team. Around these formal positions and bodies, within $\mathrm{TI}$ and the TI-consortium different informal bodies and leadership activities evolved in episodes 2 and 3 of this case. I will use the names of the formal positions and bodies when appropriate, but also use my terminology by speaking of "scientific management" if it concerns the scientific director and his advisory team of senior researchers, and of "research leaders" if it concerns leadership activities of the group of eventually about 30 researchers who developed leadership activities, often connected to their tasks as project leader, project supervisor or business developer. Most of these research leaders are employees of what was called TI's central organisation, TI-CO. This central organisation comprised researchers (about 70), scientific management and project control and support staff. Regarding the formal structures, when I speak of the "TI consortium" it concerns the universities, other knowledge institutions and companies that were member of the consortium.

Distributed academic leadership in emergent research organisations

6. Telematica Instituut 


\section{An overview of the history}

Episode 1 (1992-1996)

\begin{tabular}{|l|l|}
\hline 1992 & Official start of the Telematics Research Centre \\
\hline 1994 & $\begin{array}{l}\text { Official start of the CTIT research institute, started at the } \\
\text { University of Twente as a parallel initiative to TRC }\end{array}$ \\
\hline 1996 & $\begin{array}{l}\text { Preparation of the tender for the LTI, formation of the public- } \\
\text { private LTI consortium (comprising } 20 \text { parties: universities, TNO } \\
\text { and companies) }\end{array}$ \\
\hline
\end{tabular}

Episode 2 (1996-2002)

\begin{tabular}{|l|l|}
\hline $1996 / 1997$ & $\begin{array}{l}\text { Telematica Instituut launched as Leading Technological } \\
\text { Institute". (CTIT acknowledged as UT's first "spearhead institute) }\end{array}$ \\
\hline 1998 & $\begin{array}{l}\text { TI embarks on a range of nationally funded strategic } \\
\text { programmes }\end{array}$ \\
\hline 2000 & Internet bubble bursts \\
\hline 2001 & $\begin{array}{l}\text { Shift in companies participating in the TI consortium, new } \\
\text { companies, not restricted to the telecom sector, get on board } \\
\text { (banks, internet services etc.) }\end{array}$ \\
\hline
\end{tabular}

Episode 3 (2002-2006)

\begin{tabular}{|l|l|}
\hline 2002 & $\begin{array}{l}\text { TI receives positive evaluations of its approach and succeeds in } \\
\text { expanding and broadening its portfolio of programmes }\end{array}$ \\
\hline 2005 & TI fully geared to national programmes. \\
\hline
\end{tabular}

Table 7. An overview of the history of TRC and Telematica Instituut

\section{Sources}

Data sources for the reconstruction and analysis of TI's development are threefold. The author of this thesis was an observing participant in different parts of the life of TRC and TI; this included access to internal, often informal documents of TRC and TI. Second, in 2006 and 2012, six key actors were interviewed and invited to reflect on specific events and on patterns of

Distributed academic leadership in emergent research organisations

6. Telematica Instituut 
leadership activities at the time. Once the author was allowed to devote time to prepare his PhD casus on TI before leaving his position in 2006, he got engaged in a number of spontaneous reflective talks that were very valuable, but could not be recorded nor registered in a structured way $^{62}$.Third, publicly available documents about TI were collected and analysed.

\section{$\underline{\text { Interviewees }}$}

\begin{tabular}{|l|l|l|l|l|}
\hline & Name & Episode & Position at the time & Date interview \\
\hline 1 & $\begin{array}{l}\text { Hermen van der } \\
\text { Lugt }\end{array}$ & $1,2,3$ & $\begin{array}{l}\text { Manager business } \\
\text { development, } \\
\text { business director }\end{array}$ & September 2006 \\
\hline 2 & Janine Swaak & 2,3 & $\begin{array}{l}\text { Senior researcher, } \\
\text { expertgroupleader }\end{array}$ & August 2006 \\
\hline 3 & Henk de Poot & $1,2,3$ & $\begin{array}{l}\text { Researcher } \\
\text { August 2006, July } \\
2012\end{array}$ \\
\hline 4 & Henk Eertink & $1,2,3$ & $\begin{array}{l}\text { Senior researcher, } \\
\text { expertgroupleader }\end{array}$ & September 2006 \\
\hline 5 & Marcel Bijlsma & 2,3 & $\begin{array}{l}\text { Senior researcher, } \\
\text { human resource } \\
\text { manager }\end{array}$ & September2006 \\
\hline 6 & Rene Bakker & 2 & Senior researcher & July 2012 \\
\hline
\end{tabular}

Table 8. Interviewees TRC and Telematica Instituut

\subsection{Episode 1 (1992 - 1996)}

\subsubsection{Overall organisational changes}

It is March 1991, the breaking news in the University of Twente's weekly is that UT has won a bid, beating heavy competition from seven other regional coalitions ${ }^{63}$ : Twente has been chosen as the location for the new Telematics Research Center (TRC). This would have a major impact on UT's research policy setting. It was also a truly "undutch" event: the world famous Poldermodel would have implied deliberating for about a decade; instead an expert committee had been given the mandate to decide. This "Oele-Biesheuvel Committee" (Biesheuvel being a

\footnotetext{
${ }^{62}$ As these talks were not recorded, there are no data that can be shared. The insights from these reflective talks were used for the interpretive case writing.

${ }^{63}$ 'regional coalitions' comprised alliances of cities, provinces and universities, due to the criteria of the tender that addressed not only a strong science and technology knowledge capacity, but required also innovation fund commitment and an offer for supply of high rank work places for researchers. Besides the coalitions around the three technical universities of Delft, Eindhoven and Twente, coalitions led by the city of The Hague and by the Open University were bidding as well.
}

Distributed academic leadership in emergent research organisations

6. Telematica Instituut 
former Dutch PM, and Oele being a former Commissioner to the Queen) succeeded in finalizing the decision within six months' time. Such rapid decision-making was in particular very unusual for the Dutch university system. Also, there was a balanced argumentation for the decision: scientific excellence as well as the political dimension, especially the potential of an alliance between regional partners. The government, represented by the Ministries of Education and of Economic Affairs, could thus respond to the challenge that had been posed by three Dutch companies who were at the time major players in the international telecommunication arena: Philips, IBM (its Dutch branch) and PTT Telecom (predecessor of KPN Telecom). While they were to some extent competitors, they had joined forces to convince the government that a national initiative was needed in order to boost the Netherland's international position. Once the government had taken over the Oele-Biesheuvel Committee decision, these three companies, jointly with the two Ministries, became founding fathers of the TRC.

Expectations from the founding fathers were high. The University of Twente had given a strong commitment to make TRC a successful endeavour, and was now confronted with a major challenge: winning the bid was a success, but little time was given to celebrate. UT had committed itself to contribute academic manpower to the TRC capitalised to a million guilders annually. UT had to bring in expertise to get this new breed of research institute off the ground. A challenge that fitted the so-called "entrepreneurial university" as promoted by its rectors at the time, and already embodied in some research groups and institutes.

Almost two years later, TRC was in operation. A major issue was the appointment of the scientific director; in contrast to the swift decision-making about the location, the choice of the scientific and business leadership took a while. The appointment procedure included invitations to foreign applicants. The final choice was for Chris Vissers, a reputed academic and professor at the University of Twente, who was also an insider in the Dutch business network. Then, the core scientific staff was swiftly appointed.

In the meantime, as the appointment of the scientific director took more time than expected, the founding parties (the two Ministries, IBM, Philips and PTT) made sure that basic operations were not threatened by the on-going uncertainty about who was going to lead the endeavour: they appointed an interim business director, assisted by the quartermaster team that comprised experts seconded from the founding parties. Two years of so-called quartermaster activities

Distributed academic leadership in emergent research organisations

6. Telematica Instituut 
which included finding a suitable location near the university even if legally not attached to it; and the financial arrangements which had to deal with complex legal issues in a context where public and private partners joined forces but were concerned to secure their own interests as well. The quartermaster team could not build on good practice elsewhere. The Dutch academic research institutions landscape comprised of some - mainly discipline oriented - universitybased institutes and a league of internationally oriented big institutes connected to NWO, KNAW and companies as Philips (NatLab) and Shell.

The resulting "TRC in operation" was a research institute, an autonomous foundation under Dutch lab; in practice, a business-oriented community of some 40 senior researchers and administrative staff, geared towards the needs of the industrial founding fathers and an additional portfolio of research issues that were proposed by the Ministry of Economic Affairs and the regional and local governments.

The material and financial basis of the TRC was of a peculiar nature, compared to research institutes within the Dutch university system. The main drivers were the industrial companies who had co-founded TRC and donated the initial grant, supplemented by subsidies from the Ministries of Education \& Science and of Economic Affairs. Although the partners were in agreement when founding TRC, it was still a challenge for the TRC scientific management to get the operation going, as the industrial partners were major competitors. In a formal sense TRC was embedded and steered by their industrial partners, but interviewees report that in fact these partners did not intervene. TRC scientific management and researchers felt free to act and choose subjects and define projects, and could do so because they had the authority spend the starting grant of the founding parties as it saw fit, within the overall framework as agreed with the founders. There was additional funding for further projects, to establish co-operations not driven by financial needs, but important to create visibility in the market for strategic research .

In 1993, the first operational year, the operational and administrative organisation, the organisation and execution of research projects, had to start from scratch. It was here that the TRC scientific management took a deliberate decision; they decided to give space to their researchers to develop a learning by doing, bottom up approach, but, strictly limited. The space to experiment and learn with new ways of working was framed in a business wise project organisation; that way they imposed a specific organisational identity and related internal

Distributed academic leadership in emergent research organisations

6. Telematica Instituut 
culture. The first experiences led to their decision in 1994 to establish a project based organisation of a specific nature. Based on the good experiences of the scientific director and the business manager earlier with European Union rules for project organisation and with IBM's research project approach, a set of "working practices" were adopted and implemented strictly as an integral quality management approach. The resulting mode of operation and organisational culture was familiar to the companies that TRC was co-operating with, but very different from usual practices in Dutch universities in the early nineties.

A main concern for TRC scientific management at the time was the creation and subsequent availability of a test lab that would meet the requirements of the different stakeholders.TRC scientific management saw it as a core activity to have a lab that would support pre-competitive research and would serve the kind of application-oriented projects that TRC was looking for. Their decision was based on keen opportunity spotting: at the time the Dutch private and public knowledge infrastructure lacked a substantial lab facility on telematics.

At the time, also in the Netherlands, policy discussions occurred about the organisation and financial set up of large scale or distributed interconnected lab facilities. Universities were keen to meet high lab requirements to be able to join in international co-operation; at the same time the required budget caused concern about the sustainability of labs and technical support staff. At the University of Twente academics were exploring the feasibility of labs that would serve researchers from different academic backgrounds, meanwhile creating a natural meeting place $^{64}$. A flexible working place where a (foreign visiting) researcher would dwell for some time, meeting colleagues that he would not have met otherwise. These explorations were not limited to publicly funded research institutes. At the time, a major player like Philips considered to move its main research labs to fast growing and/or cheap labour regions outside The Netherlands.

The TRC lab had to serve two specific purposes. As TRC's mission was to conduct precompetitive research, a lab environment was needed that would meet the requirements of a scientific lab as well as of a TNO or an industrial R\&D lab, i.e. severe Intellectual Property Right (IPR) security regulations for researchers. A regular university lab organisation would, at the

\footnotetext{
${ }^{64}$ At the time, partially triggered by national funding schemes, in Twente initiatives were taken for labs on neuroscience, materials engineering and molecular science.
}

Distributed academic leadership in emergent research organisations

6. Telematica Instituut 
time, not be able to guarantee IPR security standards as imposed by competing industrial partners that nevertheless want to work in the same lab environment. It was also not a feasible option that one of the industrial partners in the TRC alliance would organise a lab for "common use".

Against the backdrop of its financial basis and result oriented organisational culture, TRC developed a specific personnel policy.

TRC scientific management did not have to work with existing staff, so had the opportunity to choose scientific staff freely. Financial resources were basically guaranteed by the founding fathers. No restrictions were imposed on the scientific management by the founding partners or by a specific law, as would be the case for a university institute that had to comply to the Higher Education Act. As TRC started from scratch, TRC scientific management did not have to cope with a personnel legacy, existing checks and balances among researchers, no sharing of power with adjacent research groups, as would have been the case at a university. This opportunity posed of course a challenge as well. TRC had to meet expectations that were high, pressure was heavy to get to usable research results. Buying in successful existing groups from universities and companies would have allowed short term results, but this was not an option in view of TRC's mission to strengthen the overall knowledge base among the founding partners by adding to existing workforce, not by transferring 'winners' from one place to another within the TRC partner network. Also, due to the nature of the decision making process and the choice for a location near the University of Twente, other universities who had not won the bid were reluctant, TRC had to deal with tense relationships with some other Dutch universities for quite some time. Cherry picking excellent researcher groups from these universities would not have helped to create sustainable co-operative networks with these universities.

Once appointed, TRC scientific staff did not have to deal with limitations that their research partners in universities or industry were confronted with. Different from university practice, they felt no pressure from teaching obligations. Compared to their colleagues in industry, they were not limited to stick to specific technological solutions. A senior researcher who joined TRC in this period has good memories: "it was a great time, we were rapidly growing. No worrying strategic debates, just go for the challenges posed". The resulting freedom created, according to interviewees, the basis for a new breed of researchers: those researchers that wanted to be challenged, not only by complex questions of a fundamental nature, but also to be challenged to

Distributed academic leadership in emergent research organisations

6. Telematica Instituut 
come up with answers and "solutions" of an applied generic nature, new perspectives that might contribute to "market breakthroughs". At the time, creation of breakthroughs on a more systemic level were talk of the town in IT. TRC scientific management, and in particular its scientific director who had been active on a European level in standardisation committees, was convinced that TRC should create substantial innovation that would help industry to bring technologies on the market that would lead to systemic breakthroughs in for instance ICT supported trade and services.

TRC scientific management selected primarily postdocs who could be immediately engaged in industry oriented projects. Different from university research institutes - where PhD students were the main workforce - at TRC the main workforce consisted of postdocs, led by senior researchers with a career background in industry. These postdocs were young and prepared to work in multidisciplinary teams, representing a variety of scientific disciplines, not solely in informatics or telecommunication, but also mathematics, psychology, sociology and business administration.

The senior researchers were primarily occupied within strategic planning and project development with industry, once TRC scientific management started to expand towards a broader core research staff that got the opportunity to embark on new initiatives. Except for the close links to co-founder University of Twente, there was few co-operation between TRC and universities. New scientific staff that joined the TRC drove the growth of project portfolios and, framed by TRC's application research oriented policy, came up with new business-oriented research proposals.

The growth resulted primarily in expertise and skills that were of high value in research on applications and in innovation management, performance and career development in strict academic terms came second. The scientific director held the sole senior scientific position, linked to a professorship that comprised PhD projects in a university ${ }^{65}$.

Academic career development and leadership of academic research projects was not challenged by the way TRC was organised at the time; TRC scientific management took care of negotiations with universities and industry, most TRC researchers were not engaged in negotiations, nor did hold part-time positions in universities that could have given them recognition and academic reputation. This reinforced TRC's policy to develop its own quality standards and seek for

\footnotetext{
${ }^{65}$ As of 1995, the scientific director became the overall director of TRC; beyond his responsibility for strategy and scientific quality, he was now also accountable for the financial status of the institute.
}

Distributed academic leadership in emergent research organisations

6. Telematica Instituut 
adherence to international standards and benchmarks, as TRC was heading to belong to a new league of international research institutes.

Due to a liberalization of the European market and an enhancing consumer market orientation, service companies had to refocus, putting the client central, creating the necessity to re-align their business processes. This was seen as an opportunity by some senior researchers and by the scientific director. Jointly with partners in the banking and insurance branch they identified the need for business process re-engineering. TRC developed leadership in this area, setting the research agenda, involving a range of technology suppliers and customers in a multi-annual research programme. For quite some time, from 1994 to 1999, almost half of the academic staff could devote time to this area. This programme became a financial backbone, and a matching fund for co-operation in EU programmes.

In 1995, the context altered at the moment that the Ministry of Economic Affairs invited TRC to prepare a tender to acquire the so-called LTI-status.

\subsubsection{Analysis of leadership practices}

In this episode, 1992 - 1996, the leadership approach and practice was by and large orchestrated by the founding academic, later on scientific director, and the Board of TRC (an autonomous legal entity: foundation under Dutch law). TRC started from scratch; the founding director, being an internationally reputed professor, had the mandate from his board to set up "his own" institute. He saw openings in the scientific and industrial fields of telecommunication and IT and, as an information architect, he constructed a robust and scalable organisational setup.

The formal task of the founding scientific director was of a managerial nature, i.e. primarily to control quality and financial performance; however, he went beyond this formal assignment, he performed as an informal, boundary spanning, leader. He deliberately invited senior researchers and post docs in his staff who were willing to co-operate with industrial partners, and he stimulated leadership and mentoring in order to stimulate the development of a co-operative organisational culture and identity.

In shaping the governance structure, the Board of the TRC Foundation had an influential role. As founding and hosting university, the University of Twente took a somewhat distantiated position. They were fully aware that, in particular in the start-up phase, the scientific director

Distributed academic leadership in emergent research organisations

6. Telematica Instituut 
and the other board members should play the balancing act between the founding parties. Eventually it turned out that from the private partners, IBM was the most influential; IBM and UT jointly formed a quartermaster team and IBM later on seconded a financial manager. Moreover, the scientific director applied project management practices that he had picked up earlier in his co-operation with foreign IBM research groups. The chairman of the board, Van Spiegel, played an influential role. He had just retired from a leading position at the Ministry of Education \& Science; he took responsibility for the national positioning of TRC, to make sure that TRC would not only focus on co-operation between UT and companies, but would engage research groups in other universities that had competed for TRC as well, among them Delft, Eindhoven and Groningen.

Over time, some fifteen, primarily senior, researchers formed a coherent identity. On an informal basis they developed TRC's leadership practice, strongly influenced by the scientific director. He was the sole institutional manager, bearing a management responsibility, reporting to the board. The other seniors had no institutionalised management position, they acted on an informal basis.

TRC's scientific director imposed a model of strict project management, combined with a great liberty for senior researchers to set their own research priorities. This leadership approach was not felt to be restrictive; it served as a common learning environment for a young team of researchers having quite different backgrounds. Furthermore, this model of project management served to implement a result oriented and business like organisational culture. The senior researchers learned by doing how to act in different arenas: on the one hand the academic world, on the other hand the business world, with each arena bringing along its own rule systems that they had to cope with. In this way, TRC's director was consciously creating an "ambidextrous" research organisation. While recruiting additional research staff, TRC's academic leaders took the opportunity to choose academics who were keen to work outside academia or industrial lab settings. TRC researchers had a great freedom, not being bothered by teaching obligations or company policy duties. This way, TRC was what I have called a leadership learning space comprising explorative and exploitative research, by organising training on the job learning spaces for a new breed of researchers.

Distributed academic leadership in emergent research organisations

6. Telematica Instituut 
TRC's scientific director created a programme basis in co-operation with a dedicated team of senior researchers. It marked a step in the organisational development of TRC, in particular in the distributed leadership of research and innovation: shaping a pathway of multi-annual and multi-partner programmes, of loosely coupled self-steering "protected spaces" that together formed a leadership learning space.

\subsection{Episode $2(1996-2002)$}

\subsubsection{Overall organisational changes}

In 1995, there was a major change in the policy context for TRC. No longer, was TRC the lonely cowboy in the Dutch knowledge landscape. The Dutch government, in the person of its dynamic Minister of Economic Affairs Hans Wijers, introduced a new feature: the TTI, "Technologisch Top Instituut, Leading Technological Institute, LTI. LTIs were public-private consortia, embarking on strategic research and joint innovation-oriented projects. The LTI-programme would select a small range of institutes for core funding, based on business plans submitted by consortia of companies and universities ${ }^{66}$.

TRC had good prospects to acquire the status of an accredited LTI. They were invited by the Ministry to submit a proposal. To TRC it was clear that this was a once in a lifetime chance: if, for whatever reason, they would not succeed in bringing a consortium of companies and universities together for a submission to the LTI programme, the Ministry would have to stop the core funding of TRC.

Meanwhile, TRC had to cope with a short-term challenge. TRC scientific management and academic staff were now confronted with the burden of an extra workload. They had to combine on-going business with the very labour intensive process of business plan writing and consultation of partners in industry and knowledge institutes. This was time consuming, as many of these partners were new to TRC and to each other. At the same time, daily business had to go on. This was not only a matter of going concern, TRC scientific management was anxious to keep good academic staff on board and to continue recruitment. In an increasingly competitive market, companies were hunting for bright people. TRC scientific management got more

\footnotetext{
${ }^{66}$ The LTI-programme, aimed at acceleration of innovations in market oriented consortia of companies and universities, had a twofold purpose: to accredit a selected set of institutes and to support them with core funding. The funding depended on the number of companies and their financial commitment.
}

Distributed academic leadership in emergent research organisations

6. Telematica Instituut 
cautious to share strategic information with their university and business partners, at the same time they had to invite more partners on board and get their support for their research programme.

TRC's scientific management response to this challenge was twofold. First, the major effort of compiling the bid for the LTI tender and negotiating with many new business partners, was conducted by a dedicated team, directly steered by the scientific director. Second, based on the way that TRC had been drawing up programmes so far in a systematic way (reflecting their way of working as architects of information systems), TRC was seeking support for their research themes at management levels of universities and companies, translating this support into the research programme and business plan for the LTI. TRC's scientific management took the proven practice of a programme-based organisation as its organisational design. The orchestrated and systematic negotiations with universities and companies gave leadership at TRC a boost. Orchestrated by TRC's scientific director, Chris Vissers, distributed leadership evolved among those researchers that were involved in the negotiations with companies and universities. A steep learning curve for most of them, who had up till then done the usual handwork of research proposal writing and leadership of projects. Now, they had to negotiate in direct contact with envisaged members of the consortium. These members were very different in their academic background, covering areas from applied mathematics to economy. While negotiating, TRC's researchers had to develop and articulate their vision, and do this in an concerted way, in order to build a coherent overall research programme.

The process of distributed leadership development continued once the TI consortium was formally established. As the LTI research programme and business plan was finalised, leadership evolved within the TI consortium, a process in which managers and researchers from IBM and the University of Twente (its research institute CTIT) played prominent roles. When the bid was successful and the TI consortium got the LTI-status, a larger number of TI's scientific staff were invited to sit in workgroups to elaborate on the original bid and convert it into more detailed business plans. The planning practice that TRC had previously developed, now was an operation on a much larger scale: where TRC had mainly dealt with three founding companies and two ministries, from now on a range of TI-consortium members were on board in each of the programme oriented planning work groups. The broader participation of up to ten of TI's senior research staff resulted - according to interviewees - in an "unplanned but effective impulse for the learning organisation, a wider range of academics learned how to write business plans, a

Distributed academic leadership in emergent research organisations

6. Telematica Instituut 
skill that showed to be effective once we had to submit proposals for the new national ICES-KIS programme" (this occurred a few years later).

The up-scaling of TRC's programming practice up to a feasible programming practice for the $\mathrm{TI}$ consortium confronted TI's scientific management with particular challenges.

First there were the new requirements set by the consortium of companies that had committed to the LTI-bid. Whereas TRC scientific management were used to negotiations that were primarily restricted to the founding firms and ministries, now they had to cope with a consortium of about ten companies. The bilateral agreements with each the industrial partners had to be developed into workable joint research projects. Joint research projects had to meet requirements of the strict monitoring system that the Ministry of Economic Affairs imposed on all LTIs. LTIs had to report annually according to a fixed set of indicators that were (scientific) output and (business) result oriented.

Second, TI scientific management was under pressure by a wider range of universities and institutes, and in a way that they were not used to. Whereas TRC had mainly dealt with the University of Twente, there were now nine universities and research institutes committed to the LTI-bid, including CWI and TNO and the university related SURF Foundation ${ }^{67}$. These new partners wanted TI scientific management to allocate budgets to them. While finalising the research programme and business plan as part of the bid, they had been given financial guarantees that they could submit proposals in specific areas according to a certain budget volume. The participating universities were pressing TI by submitting many research proposals. The two challenges caused a crisis that Tl's scientific management was struggling with; in particular the different dynamics set by the business community (expecting TI to assist them in articulating their business requirements and convert these in research projects) and the universities (not interested in business requirements, nor awaiting $\mathrm{TI}$ to investigate these, but submitting proposals based on their own research interests). Interviewees, actors at the time, report in hindsight that the existing internal procedures for budget allocation and leadership of members of the scientific management were not yet sufficiently developed to deal with the requirements from companies and pressure from universities. Universities submitted proposals that they could hardly influence or refuse. In effect, the universities dominated TI's research agenda for some time. Tl's scientific management had to allocate budgets as the overall

\footnotetext{
${ }^{67}$ SURF Foundation, the IT organisation of the Dutch universities, was at the time forerunner in broadband research.
}

Distributed academic leadership in emergent research organisations

6. Telematica Instituut 
pressure was high to get to tangible results; not allocating budgets was at the time a signal that private firms research needs were not as acute as had been pictured in the bidding for the LTI. It is here that $\mathrm{Tl}^{\prime} \mathrm{s}$ scientific management started to think about further organisational adaptations that would take time to become effective and did not overcome the short term, but were a way out for Tl's scientific management to avoid a next crisis and loosing steering power to universities.

The struggles with the first rounds of project appraisal and budget allocation enhanced the feeling in TI, in particular with those researchers who came from TRC, that university consortium members were not their best friends. It was felt that these universities were not supporting TI's mission towards the business community, but primarily their own research interests. The scientific management's response was to stop an initiative that had been undertaken by some $\mathrm{TI}$ senior researchers; in the mandate that they had to develop new programmes, they worked enthusiastically on a virtual organisation that would comprise networks of research groups in companies and universities, in a similar way that the other three LTIs developed at the time. This initiative was not continued, and the focus of Tl's scientific management shifted further towards co-operation with companies.

The focus on cooperation with companies gradually became a deliberate choice, that is, Tl's scientific management decided to deviate from the virtual organisation approach as followed by the other three LTIs, and to develop a central organisation. Their reasoning was that Tl's mission and consortium context was different from other LTIs, which were light weight interfacing organisations between companies and universities. Such an interface would not be sufficient given the, as they saw it at the time, volatile IT context. A strong, more or less autonomous, organisation was needed; an organisation that could take innovation leadership in creating and leading temporary alliances of competing companies, and that could assist end users (in the case of software innovation often SMEs or business departments of large organisations) in articulating their requirements. Several implications occurred for the way that TI programmed its research portfolio. Given the business oriented nature of TI's projects, these often did not fit with the disciplinary organisation of university departments, even if some university research institutes in the TI-consortium were evolving towards multidisciplinary portfolio programmes. Some interviewees still see it as a wise decision that TI defined its own research portfolio, directed at the demands of the envisaged market, instead of the 'old order' of the university

Distributed academic leadership in emergent research organisations

6. Telematica Instituut 
departments. Other interviewees voice a different opinion: although the overall broad strategy was of a planned nature, the development of new programmes and business lines was primarily an initiative of one or more groups of academic leaders, connected to their work as programme leaders and senior researchers at TI-CO. Results of this ad hoc approach were then translated into 'strategy'. All in all, what we see is a turbulent period with a lot of bottom up distributed leadership initiatives that, orchestrated by and in discussion with the scientific management more or less collectively reflect and learn, adding up to an emergent strategy that would include further organisational change.

These further organisational changes included a range of interventions by TI's scientific management. First, there was top down delegation of leadership and a few management positions, and training on the job of research leadership. Second, there was the establishment of additional governance structures within the TI consortium that would give companies a stronger position in decision making.

The scientific director started to delegate responsibilities and extended the internal management structure. Being director of a foundation under Dutch law, he could do so swiftly. Of course he had to negotiate with his Board, but in creating new management positions, he did not have to deal with Faculty deans or university personnel affairs departments as his colleagues at a university research institute had to do. In two years' time he installed a management team, a so-called project review team, a resource manager, an expertise development manager and a business development manager. His main concern was to secure an orchestrated growth of TI$\mathrm{CO}$, to keep the management structure lean and mean, and to sustain an organisational development approach that followed the dynamics of programmes and projects. Interviewees thought this was, what they perceived from their own experience or were told by colleagues, good practices that were developed in the previous episode, the development of TRC into a programme based organisation. Basically, at the operational level the interplay between scientific management and scientific staff was that Tl's scientific management put in place rigorous guidelines and strict quality control procedures, but left a lot of freedom for researchers to develop their own working procedures. Their individual space to develop and experiment was framed in individual annual plans in which performance indicators were agreed, including scientific productivity and accountability for on-going projects. In this practice of top

Distributed academic leadership in emergent research organisations

6. Telematica Instituut 
down orchestration, the process of delegation and creation of specialised positions stimulated organisational learning and leadership, be it in an orchestrated framework.

An important place for organisational learning was the so-called Project Review Team; a newly installed body, chaired by the scientific director, that had to deal with the more tactical decisions. This was an immediate response to the lessons learnt from TI's first year. TI needed a sound internal procedure in order to assess proposals from companies and from universities. The Review Team ("PR"), chaired by the scientific director, met every other week to decide on new projects and to monitor the development of on-going projects. The PR comprised senior academics from $\mathrm{TI}-\mathrm{CO}$, chosen and appointed by the scientific director, based on his appraisal of the research leadership that they had shown so far. This new organisational entity broadened the formal decision making and leadership of research, fuelling discussions on priority setting within TI-CO.

Organisational learning and research leadership development was, as had been the case in the previous (TRC) period, framed in a rather formal and result-oriented approach, combined with a learning by doing practice with active peer to peer feedback and coaching by seniors. The scientific management's approach continued to be developing standards for quality control and developing leadership competences that would suit Tl's particular innovation mission. They consciously introduced a 'role organisation' that embraced all scientific staff of TI-CO. Instead of appointing scientists to a certain management position with the necessary competencies and skills, each staff member got an assignment, a role in the overall project organisation. Implying that senior scientists got a lot of responsibility within the frame of an assignment or project, but low or no decision making power to change that frame. Interviewees tell that this caused a lot of debate within TI-CO between those who felt that TI-CO should emphasize the professional autonomy of the individual researcher and those that preferred rationalisation resulting in a clear allocation of responsibilities. The scientific director decided to further develop $\mathrm{Tl}$ as a role organisation and including further strengthening of the professional autonomy. An important implication of this approach was that a key player in the daily operations of $\mathrm{Tl}$, the project manager, had a role, not a management position. This low formal management responsibility stimulated research leadership; it triggered researchers who were appointed as project leaders to develop, often learning by doing and coached-on-the-job by their senior people managers,

Distributed academic leadership in emergent research organisations

6. Telematica Instituut 
activities and skills to lead thematic communities within the TI consortium of project groups of researchers. They had to deal with different contextual backgrounds, working with researchers for companies and universities, so, their ambidextrous capabilities were challenged.

This pushing through of distributed leadership at project level was not without problems. Most prominent were conflicts of interest and competition between project leaders to get and to keep the best researchers on board. This was linked to the dynamic situation, where most projects would not employ researchers full time. Another tension was between the operational level of project leaders who were optimising their man power resources, resulting in a somewhat scattered pattern of participation in projects, and the tactical interest of TI-CO to develop the expertise of their researchers, requiring a certain continuity in participation.

In response, it was decided to create a linking pin between operational and tactical level, the new role of 'resource manager' was created; a part-time role for a TI-CO senior researcher. The decision to put this new management position in place was consciously taken by the scientific management, after long deliberations. They were cautious to create too much bureaucracy that would hinder self-steering of researchers; the basic assumption continued to be that individual researchers were to decide on their participation in new projects. This self-steering model conflicted too often with the business model of $\mathrm{TI}$ and the pressure from $\mathrm{Tl}$ 's consortium members to have swift procedures for budget and resource allocation. As interviewees report, one of the leading researchers who took the lead for business development as a primus inter pares among his colleagues, pushed the creation of the management position for resource management through, convincing the scientific management that "the wild west resourcing of projects" had to come to an end.

Complementary to the activities that were aiming at a strengthened development of the TI central organisation (TI-CO), TI's scientific management established additional governance structures within the $\mathrm{TI}$ consortium that would give companies a stronger position in decision making. This further organisational development of the TI consortium was embedded in the implementation of an integral strategic planning approach for the consortium research programme. Tl's scientific management introduced a strategic planning cycle consisting of annual business plans and multi-annual research plans. In this planning cycle, the members in the TI-consortium had a key role, because they had to approve the plans. Senior experts and managers from the participating companies and universities were assembled in a formalised

Distributed academic leadership in emergent research organisations

6. Telematica Instituut 
body known as the "Raad van Deelnemers" (Council of Participants) that met on a regular basis with the scientific management and the Board of $\mathrm{TI}$.

For leadership practices within the TI consortium, the strict implementation of the annual planning cycle had diverse implications, limitations and opportunities as well. Depending on the organisational culture of the participating companies or universities, individual members in the "Raad van Deelnemers", being managers or senior experts, would coordinate their research priorities with their researchers who were participating in TI programmes or projects. They could not do so in detail, as the annual plans that the scientific director presented in the "Raad van Deelnemers" were not systematically prepared and discussed in programme and project committee meetings. This was not so much on purpose, just driven by practical circumstances. It was too much of a workload for Tl's central organisation to coordinate this, and anyway, programmes and projects had very different internal dynamics, implying that in a lot of cases project participants, that is, researchers, were not motivated to spend time on discussions that concerned the overall strategy of the TI consortium.

Further opportunities for boundary spanning leadership by managers and senior researchers from TI consortium members arose once Tl's research leaders started to anticipate on future business opportunities by developing focus areas. In developing these areas, workshops and planning sessions were organised that were interesting for researchers and for decision makers of companies and universities as well.

The implementation of these governance structures on the consortium level also caused controversies. Some interviewees told about the convenient distance between the daily operations of research and the strategy level; they were satisfied with the setting that TI-CO was the initiator of research priorities and programmes, so that TI-CO could guarantee that requirements of companies and related deliverables would be realised in due time, not being hindered by complex decision making procedures in strategic advisory bodies such as the "Raad van Deelnemers". Others criticize that is was not smart to keep the decision makers assembled in the "Raad van Deelnemers" too much at a distance while their staff, the researchers from companies and universities, were fully participating in the TI consortium projects; they saw that chances were missed to engage senior decision makers in early adoption of prospects and prototypes, that way lowering the chance for successful implementation of deliverables in the operations of a participating company.

Distributed academic leadership in emergent research organisations

6. Telematica Instituut 
The TI consortium lived through its first, turbulent years and evolved to a programme based organisation, organised in a consortium of with about 25 participants (universities, other knowledge institutes, and companies). At the time, around 1999, $\mathrm{Tl}^{\prime} \mathrm{s}$ academic leaders were struggling to keep companies on board, and to keep their managers as well as the researchers at operational levels satisfied. This was not always an easy job as interviewees recall: "at some moment, putting all our effort in keeping the top managers in companies on board and at the same time getting to agreement with project developers, we lost touch with the R\&D managers who were acting at a tactical level, a level that our organisation was not sufficiently matching with." This self-critical observation relates to the situation described before in the starting years of the TI consortium, that TI's scientific management kept the R\&D managers from companies, and professors from universities at a distance from strategic decisions (influence was kept limited to CEO's financial commitment for TI's multi-annual programme) and the daily operations. Now, the scientific management recognized this gap and allowed some researchers to develop specific activities to engage companies in a more structured and pro-active way in project development; an activity that was from then on called 'business development' and was primarily taken forward by a senior scientist who was a few years later (2003) appointed as manager business development at TI-CO.

In material and financial terms the $\mathrm{TI}$ consortium as a whole and the central organisation $\mathrm{TI}-\mathrm{CO}$ went through a period of swift growth. Because of the availability of the LTI-funding and a few major multi-annual programmes that were financed from national innovation schemes, the scientific management had the chance to employ new research staff. Interviewees tell that this opportunity was used to attract new senior staff that would promote new envisaged research lines. That way, the explorative entrepreneurial approach that had been developed in previous years, continued. Framed in the overall mission and strategy individuals saw opportunities. Even a major feature of $\mathrm{TI}$ consortium as the 'public-private programme consortium' was initiated bottom up, not based on thorough policy discussions, but developed in practice.

By and large, since its start in 1996, TI developed within three years' time from a programme based organisation into a consortium with a range of projects and an extended network of participating companies and universities. TI's scientific management was preparing for a new growth step in terms of turnover, anticipating future challenges and new requirements for a LTI

Distributed academic leadership in emergent research organisations

6. Telematica Instituut 
as they perceived them. But then the context changed, in 1999 the internet bubble busted. As a result of collapse (primarily on the stock exchange) of a range of internet services oriented companies (and also the expected major problems with the technical consequences of the switch to the year number 2000), major technological ICT players in the Netherlands went through severe restructuring and shake out. In a year's time three main stakeholders in TI had to leave the consortium: Ericsson closed down all its R\&D operations in the Netherlands, Lucent downsized its operations, and KPN Research went through a buyout, resulting in a take-over by TNO.

TI managed to conduct a 'knowledge shift' as one interviewee labelled it: within two years' time TI's scientific management succeeded in engaging a range of new companies. While losing the main technology providers, the Tl-consortium was joined by media companies, banks and insurance companies and public transport companies (e.g. Prorail). The main response of the scientific management was to aim at acquiring more multi-annual research programmes. Also, programme and project managers strived to make better use of programmes in the sense that in priority setting for human resourcing of on-going programmes, a higher priority was given to researchers from TI-CO instead of experts from companies or scientists from participating universities.

In hindsight, $\mathrm{Tl}-\mathrm{CO}$ 's scientific managers at the time reflect in satisfaction on their response to this high impact event. Other interviewees tell that the main response to the bursting-of-thebubble, engaging new participating companies in the TI programmes, came from senior scientists who had been around for a longer time, not holding a management position, in particular those that were in closer contact with participating companies.

The 'bursting of the bubble' did cause anxiety among TI-CO's scientific staff. They were relatively young people who had little experience with worsening labour market conditions and were not experienced in competing for a job. Interviewees tell that individual responses varied and included people leaving for a more stable position.

The 'bursting of the internet bubble', and TI's scientific management's and other academic leader at TI-CO's response to it, coincided with the five years' evaluation of the LTIs in 2001. At its conception, the Minister of Economic Affairs had imposed a strict annual planning and reporting system on the LTIs, and had invited STW to monitor and from time to time evaluate the development of the four LTIs. A main outcome for TI was that TI-CO should improve its

Distributed academic leadership in emergent research organisations

6. Telematica Instituut 
research programming and in particular should allow companies a more prominent role in the strategic research programming process. Interviewees tell that this new requirement was not so much a result of dissatisfaction among participating companies, but primarily a new requirement put by new companies that joined the Tl-consortium after the bursting of the internet bubble. In response to this review outcome, the Ministry of Economic Affairs now allowed TI to include 'in kind' research participation of companies in its annual research income. This had a major impact on the actual leadership of $\mathrm{TI}$, as TI-CO was no longer driven towards the universities in order to match the funding but could also invite a company to step in a project on a matching basis. In response, TI-CO scientific management drew up a budget allocation system in which part of the annual budget that was made available by the Ministry would be allocated on an annual basis jointly by representatives from TI-CO and the companies and universities concerned.

The implementation of this new financial allocation model caused some debate in TI-CO. Some interviewees tell how frustrating it felt that other, less formalized, research project leadership practices were eliminated in favour of this new model. They would have preferred to continue developing research leadership practices that in their opinion served well the practice of coleadership, primarily focused at boundary spanning between the interests of companies, universities and TI-CO.

All in all, Tl's leading academics dealt with the bursting of the internet bubble and TI's first full evaluation and entered the second millennium with a broadened consortium of companies and universities. TI as a consortium had reached a rather balanced growth by attracting new companies and Tl's central organisation anticipated further growth, supported by a renewed financial commitment of the Ministry of Economic Affairs that included new openings for participation with companies. In the aftermath of the 2001 evaluation and the new perspectives that turned out favourably for TI, TI's research leaders were prepared for a next step in the overall positioning and development of the TI consortium, with a further shift towards new participating companies in a broader spectrum of service innovation.

\subsubsection{Analysis of leadership practices}

In the initial stage of $\mathrm{TI}$, the leadership model as developed by TRC could not just continue. TI, different from TRC, was no longer a limited consortium of three companies and a university,

Distributed academic leadership in emergent research organisations

6. Telematica Instituut 
supported by two Ministries. TI was committed to eight universities and more than ten companies. In order to meet expectations from the business partners to swiftly convert the $\mathrm{TI}$ bid into a work programme and projects, the scientific director delegated management responsibilities and broadened leadership. Whereas only five of the fifteen seniors had been involved in the bid writing, he engaged a larger number of researchers in elaborating the overall program into project plans. It concerned mainly senior researchers that had been working with him at TRC, who in their way of working and cooperation were at the time seen as the informal network of leading academics.

The orchestration of distributed leadership within in the TI consortium got tested when several initiatives were undertaken that were not initiated by TI's scientific management. Some universities in the consortium were claiming substantial project funds from the newly established LTI programme funding, supplied by the Ministry of Economic Affairs. Promoted by some companies that were members of the TI consortium, a major initiative in the $\mathrm{TI}$ consortium was initiated by experts from outside $\mathrm{TI}-\mathrm{CO}$, and a reputed consulting firm was hired to assist in writing a multi-annual programme plan.

The TI-CO scientific management and informal leadership network, struggled with these initiatives. They wanted to be in control, but that part of its distributed leadership had not been developed yet, decision procedures were not fit to this scale of budget allocation. They were also struggling to take the lead in developing new initiatives that could convince academic researchers at universities. The response of Tl's scientific management was, different from the other LTIs, not to extend the network to include senior academics from participating universities, or to second researchers to universities. They deliberately headed for strengthening of their own position in decision making about the allocation of LTI-funding. The decision making and project and programme monitoring control and monitoring capacity was extended by the scientific management. In an administrative sense, creating an project and financial control unit and connected procedures. And also in the sense of project management and connected research leadership in developing projects. Selected researchers were trained on the job to become project managers and leaders. This way, the from then on called 'central organisation' developed, abbreviated TI-CO. The scientific management strived to have all projects and programmes led by a TI-CO researcher.

Distributed academic leadership in emergent research organisations 
A further response of TI's scientific management was to focus even stronger on co-operation with business partners. In their way of working, the business and result oriented way of project development and execution, the way that $\mathrm{TI}-\mathrm{CO}$ presented its position and propositions, $\mathrm{TI}-\mathrm{CO}$ 's research leaders developed professional identities, this way recognisable for business partners as, in my terminology, ambidextrous and entrepreneurial leaders. The scientific director pursued his dominating role as a boundary spanning leader, by orchestrating the diversity of projects and programmes. Based on good practices developed at TRC, he imposed strict quality control procedures combined with a lot of freedom for researchers to develop their own way of working. Breaking with the originally bottom up project organisation, a resource manager was appointed so as to optimise the overall human resourcing in projects. These measures were promoted by some of TI-CO's research leaders, they convinced the director that this new management position was necessary, as they felt that TI was at risk of putting too much effort in business demands and related project results at the cost of individual academic career development of its researchers.

In shaping focal research areas in co-operation with business partners, individual scientific $\mathrm{TI}-\mathrm{CO}$ seniors took freedom to act and further develop their research leadership towards the business partners. They had to cope with a new level of complexity, due do the larger number of companies involved compared to previous years. Not only the number of companies, but also the different organisational levels of companies that had to be kept engaged, were a new challenge. In due course, this led to the emergence of a new professional role in the leadership network, the role of business developer.

At the end of the second episode, TI-CO's research leaders faced a rapidly changing context: especially by the bursting of the internet bubble, but also by the conclusions of the evaluation commissioned by the Ministry of Economic Affairs. In response, more or less concerted actions resulted in strong responses in terms of new multi-annual programmes, new participating companies, as well as extended business development leadership.

The business development leadership was extended as the senior researchers who were acting on a role basis as business developers, were brought together in an institutionalised group, chaired by a business development manager. The main activities of the these business developers was to conduct relations management, and to consult the companies that participated in the TI consortium or on an ad hoc basis in projects, assisting and advising them how to articulate their business oriented requirements, how to translate these in interests for

Distributed academic leadership in emergent research organisations

6. Telematica Instituut 
specific research themes and requirements for research project configurations. The latter task regarded the specific character of TI projects: temporary consortia where companies shared their interests and requirements and invited researchers from $\mathrm{TI}-\mathrm{CO}$, universities and knowledge institutes such as TNO or CWI. This process of project development, and supervisory work during project execution, became the backbone of Tl's approach and a characteristic of TI-CO's research leadership of innovation consortia.

\subsection{Episode $3(2002-2005)$}

\subsubsection{Overall organisational changes}

During the third episode of this case study, the TI-CO's research leaders further developed its operations and got increasingly entangled in a complex setting of sectoral and political dynamics. TI played an active role in the implementation of the governmental innovation policy framework, ranging from the programme management and research leadership of national programmes on mobile communication, ICT in Health up to creation of project consortia in collaboration with governmental departments or provincial/local public authorities. The role of governmental bodies varied from funder to launching customer for new products and services.

A salient feature compared to previous episodes is that in this period TI linked up with a high variety of project partners outside the TI-consortium. So, the scope of distributed leadership got extended, no longer focused exclusively on companies that were member of the consortium; as now also companies, among them SMEs, would participate in a programme, on a temporary basis, complexity and span of control expanded for TI-CO's research leaders.

In the public domain, cooperation broadened to include more universities, and also semigovernmental organisations (e.g. ProRail, the Dutch railways) and Universities of Applied Science (Hogescholen).

The co-operation with private sector partners also broadened, by 2005 some fifteen companies. Main players in the ICT and telecom sectors continued to participate in the TI-consortium. Due to their (international) market position and R\&D expertise, they played an important role in the long term strategic planning of the consortium and in the annual cycles of project formation and execution. In addition, an increasing number and variety of companies - among them banks,

Distributed academic leadership in emergent research organisations

6. Telematica Instituut 
insurance companies and service oriented SMEs - participated in ad-hoc project consortia. By 2005 TI managed about 60 projects annually.

Based on the positive outcome of the 2001 evaluation conducted by STW, TI could work with an annual budget from the Ministry of Economic Affairs that was guaranteed for a period of four years. Connected to this commitment from government, the participating companies and universities committed themselves to multi-annual contributions in kind and in cash. The multiannual research programmes funded by national innovation programmes, at the time, the so called BSIK programme, were an important part of the financial basis in this period. As was the case in previous years, TI created opportunities by bidding for joint research subsidies in the frame of national innovation programmes; once these subsidies were granted, TI took the lead in converting them into multi-party projects that $\mathrm{TI}-\mathrm{CO}$ research leaders would conduct leading roles in. These national innovation programmes gave the TI-consortium status and financial continuity. In terms of distributed leadership, TI-CO used it to strengthen its own leadership capacity, in business development with companies and in project execution. Universities did not develop leadership within the TI consortium, by the time they had the networks and capacity to develop their own consortia with European research partners and in some cases with companies. For the short term operational development of the TI-consortium this was not a problem, but the distributed leadership anticipation within the TI-consortium for the longer term strategic research development of the consortium and for its impact on university research programmes was not triggered.

In this context TI's scientific management developed its organisational and leadership structures to address the new scale, scope and orientation.

As of 2002, daily operations was the exclusive responsibility of the scientific, by then, general director $^{68}$, and the approximately twenty programme and project managers that reported to him. The director was accountable to a Board of Trustees that was appointed by the consortium

\footnotetext{
68 In 2001, there had been an initiative to support the scientific director by an institute's manager with a strong political network; eventually it was decided by Tl's board not to pursue this initiative and to extend the responsibility of the scientific director by appointing him as general director.
}

Distributed academic leadership in emergent research organisations

6. Telematica Instituut 
members $^{69}$. He delegated the execution of this daily operations responsibility to an operational management team, chaired by a new position, the manager operations. This operational management team, acting as a collegial team of controller, resource manager and manager operations, continuously monitored the integral TI project portfolio. This construction guaranteed a maximum flexibility towards the volatile IT market and connected research projects; it enabled TI to adapt to the sudden changes in human resource requirements of multiparty innovation projects that could not be executed as blue print projects.

The strategic and tactical planning capacity was extended in terms of number of consortium members and in terms of involvement. A practice that had been initiated around specific themes in previous years, now got formalised in order to engage consortium members in the annual planning cycle; as of $2004 \mathrm{TI}-\mathrm{CO}$ organised so-called 'expertise communities' comprising professors, R\&D directors and senior staff of universities and companies within the TIconsortium. These communities were being regularly consulted about new themes or a further elaboration of focal areas, in intensive workshops and mini-conferences, organised twice or three times a year, and led by senior researchers from TI-CO. A complementary development in the overall governance structure of the $\mathrm{TI}$ consortium, was the extension with a new advisory body, called Programmaraad (Programme Council), that was consulted pro-actively on chances and intentions for new research topics. Up till then, TI-CO had taken this role and had submitted elaborated proposals for mid-term and annual priority setting to the annual meeting of the Raad van Deelnemers (Council of Participants).

A key change was the establishment of expertise groups within $\mathrm{Tl}-\mathrm{CO}$, the appointment of expertise group leaders, and the appointment of a broader circle of 'people managers'. By 2004, building on the expertise communities that had developed on an informal basis as from 2001, it was formally decided to have 'expertise groups' within TI-CO, led by formally appointed expertise group leaders. The scientific management appointed six expertise group leaders from the TI-CO researchers. These expertise group leaders were explicitly pushed by the scientific director to develop and position themselves in terms of research leadership. Internally, in leading groups of researchers that might change on an annual basis based on individual

\footnotetext{
${ }^{69}$ At the retirement of the scientific director in 2005, it was decided to separate responsibilities for overall strategy and for scientific management and to appoint two seniors on these positions, one from the business community and one from within $\mathrm{TI}-\mathrm{CO}$.
}

Distributed academic leadership in emergent research organisations

6. Telematica Instituut 
performance and market needs. And externally, in creating and leading expertise communities that would engage companies and universities alike in planning and strategy development of TI. In order to stimulate internal cooperation and to coordinate the expertise development policy, the scientific director established regular meetings with the expertise group leaders on an individual basis and as a group.

The scientific management invited a broader group then before, about fifteen senior researchers, to act as 'people manager', who would take specific responsibility for the expertise development of about six researchers each. An important part of their work was, to appraise the annual plans and performance of researchers, resulting in an advice to the scientific director to raise (or not) a researchers salary, which gave the people managers a lot of influence and the informal status of research leader.

A change in organisation and a push for distributed leadership that was taken after ample deliberation. Arguments varied; some senior researchers who had served the scientific management on a task or role basis were no longer satisfied with this, were asking for a more structural position. A main argument was that expertise groups and a more intensive coaching by people managers was necessary to stimulate the further development of research leadership, in order to accommodate the co-operation with universities. This decision marked a break in the project and business oriented tradition of TRC and subsequently TI-CO. So far, TI had been structured in two organisational levels: scientific management and researchers. As described before, researchers took up or were given 'roles' but with limited decision power. Each researcher had been accountable for his overall performance towards the scientific director who had delegated this task to a few senior scientists appointed as 'people manager'.

In the new situation, a researcher would report to an expertise group leader about his scientific planning and output, and to a people manager about his overall career planning and performance. Until then, the scientific director had not taken up expertise development in a programmatic way, nor had he delegated responsibility for expertise development to a proactive assignment or position; he had attracted a professor from the TUD on a part time basis to monitor expertise development affairs.

The push for distributed leadership continued to be framed in a strict overall strategic research planning approach, the multi-annual strategic research programme, that was renewed each year in a structured annual decision making cycle. The scientific management continued to work with

Distributed academic leadership in emergent research organisations

6. Telematica Instituut 
multi-annual plans that were primarily fuelled by the professional vision of senior researchers from TI-CO.

As interviewees mention, this interactive configuration was crucial in order to adapt to the highly dynamic and short life cycle innovation environment that TI had to deal with. Unlike the other LTIs, TI dealt with research \& innovation projects that had a short life cycle, on average 1.5 years instead of four to five years as is usual in universities. Also, TI was engaged in variety of sectors with different dynamics ranging from healthcare, banking and finance up to chemical process industry.

This approach was not without problems. Once again, in particular universities who were used to governance and leadership structures linked to multi-annual research programmes, were having problems to properly engage in a broad spectrum of short life cycle projects. TI scientific management's response to this tension was for TI to invest heavily in communication and trust creation among consortium partners. Primarily newly engaged companies were requesting enhanced influence in the yearly allocation of research budgets. The scientific management's response was to introduce a new model of budget allocation that would allow project consortia comprising $\mathrm{TI}-\mathrm{CO}$, companies and universities to decide jointly on dedicated research budgets. This new model got under pressure, once the business development activities reached a higher level of activity. A relatively fixed allocation of budgets was not compatible with the dynamics of business development, and business developers requested more flexibility. Given the limited budgets, they continued to work within the frame of allocated budgets, seeking flexibility in their mutual cooperation and sharing of budgets. The point of trust was made and allowed participating companies and universities in the TI consortium to take a more prominent role in the development of new projects, that way giving an impulse to distributed leadership in project conception and development. A development that caused trust related controversies in the TI consortium, was the growth of the central research organisation, $\mathrm{TI}-\mathrm{CO}$. The size of this central organisation was time and again an issue for debate in the TI consortium, in particular as the other three LTIs, strictly governed by consortia of branch specific companies and universities, were not following that path. ${ }^{70}$ The issue of the size of Tl's central organisation was at the time

\footnotetext{
${ }^{70}$ As I have noted before, the other three LTIs employed a small dedicated scientific and managerial staff and a pool of research trainees. They were a virtual organisation, a smart brokerage organisation that mediated between universities and companies, but did not engage itself in research nor in innovation project execution.
}

Distributed academic leadership in emergent research organisations

6. Telematica Instituut 
raised by participating universities, that were developing their own programme and project management structures in ICT research, and therefore no longer saw the added value of TI-CO. TI-CO's scientific management did not change its approach regarding the position and size of the central organisation that, in their opinion, was required to have a substantial size in order to be effective. In their communications towards participating universities and companies they tried to explain that the growth of TI-CO was not due to a growth ambition as such, but was necessary to support the growth of the overall research portfolio of the TI consortium. In their opinion, two characteristic, even somewhat unique, supporting expertise's were supplied by TI$\mathrm{CO}$ that could not be organised by a single university of company in the TI consortium. First, the constitution of the research and development staff that was solution oriented (mainly working in business requirement driven projects), multi-disciplinary (ranging from mathematics, informatics, economy to psychology), flexible (following the quickly changing human resource developments of business driven research project) and substantial in size and expertise (matching the variety in requirements from business). Second, the test lab and software engineering group for prototyping. In their opinion, no single research lab in the private sector or in a university could meet requirements to support nationwide public-private research programmes in ICT. Prototyping was in their opinion vital for the research on application that the TI consortium conducted. A dedicated group of software engineers were seen as crucial for swift development mock ups, demos and test settings. Interviewees witness that it was productive to have these engineers work shoulder to shoulder with the researchers, creating a two-way transfer of knowledge. Not just the researcher telling the engineer what he should build and test, but also the engineer keen to apply generic applications in a variety of contexts advising the researcher. In order to make sure that this mutual benefit would be optimised, the engineering group was led by a senior researcher who had also the responsibility for their expertise development.

TI's scientific management signalled to the consortium members that they did not aim at a central research staff of hundreds of researchers, including a large number of PhDs as a university would do. Nor did it employ a large number of software engineers, as a software house would do. By 2005 TI-CO's research staff comprised approximately seventy full time equivalents; a third of the total manpower of the TI-consortium, counting in total some 200 full time equivalents researchers and developers from universities and companies being engaged in projects.

Distributed academic leadership in emergent research organisations

6. Telematica Instituut 
The universities were not convinced, they saw it as a deliberate choice of Tl's scientific management to support new projects and programmes by extending the central organisation, instead of establishing networked programme support units at participating universities.

Controversies continued between participating universities and $\mathrm{Tl}^{\prime} \mathrm{s}$ scientific management, coming to a new climax at the end of this third episode, and TI-CO's continued its orientation towards companies. An important factor in the controversies was, that universities were taking the route towards the EU that TI as a consortium could not follow. Due to the fact that the European Commission saw an LTI, receiving its core funding from the Ministry of Economic Affairs, as a private sector subsidy, the TI consortium was not allowed to use the core funding as matching budget for EU projects. This implication of Brussels' regulations struck the $\mathrm{TI}$ consortium heavier than the other LTIs, because of the substantial central organisation. TI-CO was losing money on each EU project that was subsidised, and participating universities and companies were not willing to compensate this. So, the TI consortium could only selectively participate in EU projects. In effect, TI-CO continued to seek cooperation with European industry for strategic reasons, where subsidies were not the prime carrier, but TI-CO was not able to support universities, TNO, CWI and other members in the consortium in the development of this international path.

Against that backdrop, the national innovation policy framework and the development of programmes in it, became all the more important for $\mathrm{TI}$. TI increasingly got engaged in government initiated debates around the issue of the (Dutch) knowledge society. By 2004, TI's scientific management started to promote their analysis of the so-called "knowledge paradox" or "innovation paradox". Their message was that more or even higher quality research does not automatically result in innovative solutions. In their opinion, innovation asked for pro-active creation of business cases jointly with companies.

They were struggling to get this message supported, they were balancing between their own conviction and vision on the one hand and their commitment towards the participating universities on the other. They had no means to influence the policy of the participating universities, not on a Board level to influence strategic decisions of universities, nor on a tactical level that would have been necessary to convince groups of academic researchers to follow the path as TI was developing in conjunction with groups of companies. Support from the Ministry of Economic Affairs was limited by the fact that science policy and the main stream of research

Distributed academic leadership in emergent research organisations

6. Telematica Instituut 
funding came from the Ministry of Science \& Education, the Ministry of Economic Affairs was very explicit in their approach, they refrained from structure transformation discussions, theirs was to give impulses and, in this case, to support LTIs on a contract basis, connected to temporary programmes, not on a structural basis.

Tl's scientific managements' response was to enhance its efforts to engage companies and to bundle needs among competing firms for research. A path, aiming at a company sponsored business model, that was not without problems.

Companies that $\mathrm{TI}-\mathrm{CO}$ dealt with were limited where it came to effective co-operation. $\mathrm{TI}$ brought together a wide variety of companies. Most of them, in particular those that did not run an R\&D department, did not know how to deal with research and were not able to articulate their problems in terms of scientific questions. Furthermore, TI suffered from the fact that at the time in the Dutch research and innovation landscape ICT as a focal area was still not a policy issue that companies were building alliances for; TI's situation differed in that sense from the other three LTIs that were operating in rather structured interest groups in chemistry, food and new materials.

The enhanced focus on further development of a company sponsored business model gave space to the intensification of business development activities in the TI consortium and directed at none member companies that were willing to cooperate on a project basis, among others high tech SME's. This approach, enthusiastically picked up by TI-CO's business developers, caused further organisational changes within TI-CO, with implications for the overall organisation of the TI consortium.

First, the position of the business developers within TI-CO and within the $\mathrm{TI}$ research projects and programmes changed. Since 2002, TI-CO had been investing in a dedicated group of business developers, comprising six senior researchers stemming from TI-CO and two researchers with an extensive marketing experience that were later on recruited. Whereas until then business development activities had been performed by researchers on an ad hoc and part time basis, as an additional element of their role now it became a part of TI-CO's policy and formal organisation. The dedicated group developed their own procedures and ways of working. One element new to $\mathrm{TI}-\mathrm{CO}$ was how travelling and visiting envisaged customers became the rule, and being in the office an added duty, as the business developers saw it. Tl's researchers

Distributed academic leadership in emergent research organisations

6. Telematica Instituut 
and research project leaders got increasingly concerned about this development, they were anxious that the business developers might lose touch with the practice of research projects and would become a Fremdkörper inside TI-CO. Now, by 2004, a new model was introduced by TI's scientific management: the business developers should not only develop a project proposal, but also supervise the subsequent project execution. In practice this amounted to their chairing a supervisory team, comprising representatives of companies and universities involved. The business developers were now playing a crucial role that exceeded the mere project development, including strategic marketing and gradually building the new company sponsored business model. In practice, it often occurred that in addition to chairing the supervisory teams, they had to gain, and where necessary, during project execution re-contract the expectations and interests of all parties concerned. Tl's scientific management saw that this supervisory model was crucial in order to organise innovation projects that were to meet the - often dynamic and shifting - demands of companies and public institutions that TI was dealing with. In practice, the supervisory model served as a marketing opportunity for TI-CO and companies, in identifying early signals of new upcoming expectations and demands with customers. By implication, it helped to free the operational project managers from too much turbulence in terms of shifting demands and requirements, they could focus on achieving the results and deliverables as agreed.

Second, the overall process of business requirement identification, proposal writing, organisation and funding, project execution and supervision, and evaluation, was re-aligned.

A business manager was added to Tl's scientific management and an expert was to implement a systematic project appraisal procedure, a stepwise procedural approach, which fitted well with the pervasive quality and control culture, as part of the overall TI consortium annual planning cycle, that the scientific management so far had been implementing. The expert was, assisted by the financial controller of $\mathrm{TI}-\mathrm{CO}$, for some time the prime promoter of this new working procedure; meeting resistance from researchers who felt that this procedure did not fit with their way of working, and that the co-operation with universities or companies would be more difficult if an internal TI-CO procedure would dominate the development of a project. After about a year of initial experience gathering with this new procedure, at the occurrence that the business manager left for a position outside TI, in 2003 the scientific director appointed a manager strategy and operations, from outside, who took the initiative to extend this procedure

Distributed academic leadership in emergent research organisations

6. Telematica Instituut 
to the full life cycle of projects and started to implement it throughout the entire project portfolio.

These two developments had an impact on the business model of $\mathrm{TI}$, including the development and execution of projects and the daily operations of the business development group. The scientific director and the financial controller started to meet frequently with the business development group. There was pressure for better financial results, but also an invitation to contribute to the annual planning and multi-annual research programming process, especially in setting up consultation meetings with companies and universities who were represented in the Council of Participants. By 2004, the business development group had become an institutionalised part of TI-CO and the TI consortium, covering a substantial part of its de facto business oriented steering and supervisory leadership of programmes and projects.

The enhanced company oriented business model and the growth of Tl's project portfolio posed extra heavy requirements on the agility of TI's researchers, in particular on the research leadership of TI-CO's researchers and business developers.

In this period all $\mathrm{TI}-\mathrm{CO}$ researchers were fully engaged in projects; their performance was monitored and subject to management by the Resource Manager and the Manager Operations. ${ }^{71}$ There was particular emphasis on quick starting of projects. As TI projects were mainly driven by research needs from business, TI scientific management felt that a swift start of projects was vital. Not only to get to quick results, but also to create trust and co-operation among the project partners. There was variety: some project consortia comprised competing firms, others covered participants from an entire service industry chain: producers, suppliers and buyers. But always, TI-CO's research leaders strived to have a project resourced and up and running within three months. This implied a high demand on the flexibility of TI-CO scientific staff. In order to meet the varying demands of business partners, TI-CO further developed an operational organisation that was project based, fit for quick starting, transparent and accountable.

A side effect was that the working relationship with cooperating universities was again under pressure. Often universities were not able to engage quickly enough in a project, simply because

\footnotetext{
${ }^{71}$ The same goes for the TI-CO support and management staff: approximately twenty fulltime equivalents experts covering fields varying from project administration, project management, dissemination of project results up to literature and other electronic search support. They worked in direct contact with the project managers devoting about sixty percent of their time directly to projects.
}

Distributed academic leadership in emergent research organisations

6. Telematica Instituut 
their resourcing life cycle, in particular attracting new PhDs or postdocs for a project, was longer. Therefore, $\mathrm{TI}-\mathrm{CO}$, when developing new research programmes, continued to be reluctant in relying on universities, that way giving priority to their own TI-CO researchers. Senior academic staff from universities did engage in a scattered way, spending time on specific parts of projects, less on distributed leadership of interconnected projects.

By 2005 , in the participating business community, TI-CO's way of programme and project steering was acknowledged. At the time, in the TI-consortium a variety in modes of operation was in development, representing a business model that suited the interests and requirements of the cooperating companies:

- Competing companies co-operating in the development of future standards;

- Suppliers of complementary products and services coordinating their strategies and products/services, in order to create effective business models;

- Suppliers and users in a vertical chain optimising their operations in order to raise the overall efficiency and to develop and exploit new market opportunities;

- Technology suppliers and users meeting in order to raise the mutual awareness of user demands and technological constraints and opportunities, in doing so creating opportunities for new products and services.

The maturity and effectiveness of $\mathrm{TI}$ leadership of research programmes in consortia of companies and universities was recognized in 2005 by the positive evaluation by an international consulting group, commissioned by the Ministry of Economic Affairs to evaluate all four LTIs (Van der Veen et al., 2005). The evaluation also included some critical remarks. The overall leadership of research programming was mainly business oriented. Although TI-CO's cooperation with universities had intensified, the about sixty projects concerned a scattered pattern of projects with only a minor participation of senior university staff. Senior researchers from universities were not participating in the leadership of TI research programmes on a senior academic level. Conversely, TI's influence on the planning and leadership of research in the participating universities, in particular on the programming of research, was limited, according to the evaluators.

\subsubsection{Analysis of leadership practices}

Distributed academic leadership in emergent research organisations

6. Telematica Instituut 
In the third episode (2002-2005), the overall leadership constellation of TI was extended; a broader (multi-sectoral) scope and stronger participation of companies. Although a broader participation of universities was also realised, because of funding through the BSIK programme, the engagement of universities in the leadership of TI did not increase.

As was already apparent in the second episode, Tl's overall research planning changed. This had to do with the growing number of companies involved, mainly companies that did not participate in the $\mathrm{TI}$ consortium. They joined only through multi-annual participation in a research programme. They expected useful outcomes, and did not commit themselves to the overall consortium. The challenge for the research leaders of TI-CO: senior project managers, business developers, programme managers and the management team, was to keep a balance between the need for midterm strategic management of $\mathrm{TI}-\mathrm{CO}$ and the $\mathrm{TI}$ consortium on the one hand and the practice of the somewhat independent multi annual programme consortia on the other where TI was just serving as a holding company.

In 2002 the scientific director appointed a team of business developers headed by a business development manager. Most of these researchers or professionals acted before in TI-CO as business development leaders on a role basis, some were recruited from business partners. This intervention in 2002 had an impact on the overall leadership of TI-CO. Since 2003 gradually the decision making about project development and execution got systematised and structured in an integral control cycle. The business development group became an institutionalised part of TI-CO playing a dominant role in the research programming.

Another impulse for strengthening of leadership was given in 2004: TI-CO's scientific management was extended in a formal sense once six expertise group leaders were being appointed. The expertise group leaders got a formalised management responsibility for the development of coherent research programmes, and for the expertise development of the researchers that fell under their responsibility, and for the relationship management with research organisations in the TI consortium. This decision by the scientific director was seen as a break in the egalitarian tradition of TRC which continued into TI-CO. All six were selected from an informal group of some fifteen 'people managers' who had acted on a role basis without formal management responsibilities; as these people managers appraised the result oriented planning and annual performance of individual researchers, directly coupled to their career development, they were seen as the informal research leadership. This informal research

Distributed academic leadership in emergent research organisations

6. Telematica Instituut 
steering core of about fifteen seniors was from then off concentrated around the six expertise group leaders.

Finally, the scientific management extended and structured the role organisation of $\mathrm{TI}-\mathrm{CO}$. They appointed a supervisor to each project from the business developers and expertise group leaders. The project supervisor had to take care of the leadership of multi-partner projects, balancing the different interests of the public and private - sometimes competing - partners involved.

By the end of this episode, TI-CO's research leaders steered and guided a flexible research work force that was fully oriented towards research questions from private sector partners. TI-CO was a fully fletched role organisation, every single researcher and support staff member had a role in the overall project organisation.

This organisational achievement in terms of distributed leadership in the context of a highly complex pattern of programmes and projects was positively assessed in 2005 in an evaluation of the four LTIs, commissioned by the Ministry of Economic Affairs (Van der Veen et al., Technopolis, 2005).

\subsection{Concluding observations}

Here, in the midst of Tl's ongoing change and strategic struggles, just entering a new phase in its development, my story ends. The Telematica Instituut lived on, be it in a context that changed fundamentally, challenging TI's research leaders and managers to adopt a completely new image. As the Ministry of Economic Affairs stopped its basic funding for $\mathrm{Tl}$ as a Leading Technological Institute (LTI) in 2009, TI moved away from its acknowledged status of 'institute' and continued as a science based consulting firm, from now on named "NOVAY". In this period of transition, one other option, a merger with Dutch TNO, was explored. The negotiations took years, to eventually conclude, by 2012 , that an alliance or merger was not feasible.

And so the TRC/TI path came to an end in 2014. The immediate reason was that NOVAY had eventually not found funders that were participating in programmatic funding, neither knowledge institutions (universities, CWI or TNO), nor companies. In a broader context, the overall landscape had become competitive in a way that NOVAY could not meet. The research and innovation landscape in which TRC and TI had earlier taken initiatives and assumed a path-

Distributed academic leadership in emergent research organisations

6. Telematica Instituut 
creating role, had become completely international. Whereas TRC started as a limited alliance between three Dutch international firms (IBM's subsidiary in the Netherlands, Dutch KPN Telecom and Philips) and the Ministries of Economic Affairs and Education\& Sciences, then (as TI) embarked on the open innovation field of temporary limited alliances between sometimes competing companies and universities, now a volatile open world market of research and innovation initiatives was setting the pace. Dutch parties could only take a recognized position in this open innovation by joining forces. The nationwide NIRICT initiative, led by CTIT's scientific director Peter Apers, was adopted as a strategic priority area by the three Technical Universities, and is a prominent example of an attempt to address these new challenges. ${ }^{72}$

Although TI's successor NOVAY went bankrupt in 2014, the capacity that was built up continued: there were offsprings that lived on. For example BizzDesign, a company that started as an offspring from TRC in the mid-nineties, and by now belongs to the Dutch top-ten fast growing high tech firms, picked up many 'two handed' researchers, with an excellent research track record and a feeling for business case creation, over time and after the bankruptcy of NOVAY. BizzDesign is now a core knowledge partner in the international knowledge and business community ARCHIMATE that was once started by researchers from the TI consortium.

The case study was done to describe the development of a Centre of Excellence and Relevance, a member of a new species in the landscape of science and innovation. It does have specific features, reinforced when the Telematics Research Centre, converted in 1996 into a "Leading Technology Institute", the Telematica Instituut. It remained strongly oriented at business firms, even it was also linked to universities. After the earlier focus on IT firms, TRC's founding fathers, it later on co-operated with a wider spectrum of companies, from sectors as different as chemistry and health care. Tl's pathway is additionally specific compared with the two other cases studied because of its legal status outside the university system. It might be seen as an extreme case, but since it is not clear yet what the range of variety of this "species" CER is, one should not assume that it is extreme. Its specificities make it interesting to explore the range of variety. In chapter 7 I will come back to the pathways visible in the three cases.

\section{Overall organisational changes in TRC and TI}

\footnotetext{
${ }^{72}$ There, one sees an entity of substantial size (600+ researchers) that holds a solid and leading position as a node in international networks (an ambidextrous organisation that spans the contrasting dynamics of excellence and relevance in a productive way).
}

Distributed academic leadership in emergent research organisations

6. Telematica Instituut 
TRC and later on TI started more or less from scratch and were therefore sites of organisational experimentation. There was learning by doing, but also some strong convictions, leading to orchestrated distributed leadership.

TRC and TI had an independent status in legal terms and, by and large, in financial terms. They were administered as foundations under Dutch law, formally led by a director and a board. Its financial independence was guaranteed by core funding for more than fifteen years (1991 2008) by the Ministry of Economic Affairs. For fifteen years, 1991 - 2005, Chris Vissers was the scientific director. A core group of researchers travelled with Vissers through the stages of TRC's and TI's development.

Over time the independence got tangled up in a network of dependencies, connected to cooperative alliances and programmatic collaborations. Once TRC transformed into TI, a consortium of companies and universities was formed with a formalised structure; representatives from companies were holding decision seats in overall strategic and tactical bodies and meetings, especially decision making bodies that met periodically to decide on the annual plans and broad strategic research plans. Most programmes and project were led and administered by what was called TI's central organisation, TI-CO. This central organisation comprised researchers (about 70), scientific management and project control and support staff. At the operational level, Tl's scientific management kept control in several ways. Administrative project management was supported and controlled by the non-academic staff of TI-CO. Projects had to meet quality and performance criteria and follow procedures that were set by the scientific management. furthermore, TRC and TI deliberately did not seek joint appointments with universities.

TRC's plus TI's life shows three stages, described as separate episodes. TRC started off in 1991 as a limited alliance between three Dutch 'internationals' (Philips, IBM's subsidiary in the Netherlands, and Dutch KPN Telecom) and the Ministries of Economic Affairs and Science \& Education. Within a few years' time, about 30 young academics (post docs) had been appointed, under the scientific director and a few senior academics. IBM seconded a business manager. The work organisation was modelled on European projects and IBM.

TRC's transformation, as of 1996, into the Telematica Instituut, accredited as a Leading Technology Institute. TI found its way in the open innovation landscape, creating temporary limited alliances between sometimes competing companies and universities. It had another

Distributed academic leadership in emergent research organisations

6. Telematica Instituut 
organisational set-up and work organisation than TRC. TI was a consortium of companies and universities, supported and coordinated by what was called TI-CO, the central organisation of about eventually 100 employees: project leaders, project supervisors, project administrators, researchers and software engineers, and business developers. This central organisation comprised about $50 \%$ of the academic capacity that was involved in the $\mathrm{TI}$ consortium research portfolio of $140 \mathrm{fte}$. The development of this central organisation was a deliberate choice of Tl's scientific management, carried forward by TI-CO's research leaders, as opposed to the other three LTIs that organised as a 'virtual organisation'. They were convinced that knowledge based, ambidextrous leadership was required to organise effective innovation oriented research projects and programmes. Furthermore they were convinced that, as such an approach was new to companies and universities, it could only be made effective when orchestrated and where possible, controlled. Structures and procedures were put in place: a Management team, a project appraisal committee (called ProjectReview), and later on s Operation Management team (planning and controlling the resourcing of projects), project supervisors that managed the expectations and requirements of project participants, the integral project quality control cycle. As of 2002, once the $\mathrm{TI}$ consortium opened to new companies, $\mathrm{TI}$ became an important knowledge partner in public-private consortia, in a volatile world market of research and innovation initiatives. The number and variety of programmes and projects increased, a substantial part was led by partners in the TI consortium, so distributed academic leadership got more dispersed within the consortium. In terms of the concepts of the framework in chapter 2 structural ambidexterity was visible in how specialised leadership tasks evolved, researchers got assigned to a specific assignment in exploration and organisation of new focal areas or in business development and research on exploitation.

It is against the backdrop of these overall organisational changes, that distributed leadership arrangements and learning spaces evolved.

\begin{tabular}{|l|l|l|l|}
\hline & Episode 1 & Episode 2 & Episode 3 \\
\hline $\begin{array}{l}\text { Distributed leadership } \\
\text { constellations }\end{array}$ & Top down delegated & Top down orchestrated & $\begin{array}{l}\text { Top down orchestrated } \\
\text { differentiated } \\
\text { constellations }\end{array}$ \\
\hline
\end{tabular}

Distributed academic leadership in emergent research organisations

6. Telematica Instituut 


\begin{tabular}{|l|l|l|l|}
\hline Spaces & $\begin{array}{l}\text { Leadership learning space } \\
\text { around one protected } \\
\text { space }\end{array}$ & $\begin{array}{l}\text { an inter-organisational } \\
\text { learning space, } \\
\text { comprising loosely } \\
\text { coupled protected } \\
\text { spaces } \\
\text { protected spaces fusing } \\
\text { existing areas }\end{array}$ & $\begin{array}{l}\text { An inter-organisational } \\
\text { learning space around } \\
\text { orchestrated protected } \\
\text { spaces }\end{array}$ \\
$\begin{array}{l}\text { Somprising new areas } \\
\text { leadership }\end{array}$ & $\begin{array}{l}\text { Strategic programming and } \\
\text { converging projects } \\
\text { coupled. }\end{array}$ & $\begin{array}{l}\text { Combined strategic } \\
\text { programming, } \\
\text { converging projects and } \\
\text { business model } \\
\text { development }\end{array}$ & $\begin{array}{l}\text { Focus towards } \\
\text { innovative business } \\
\text { model development. }\end{array}$ \\
\hline
\end{tabular}

Table 9. Summary of Tl's development over time (according to the conceptual model)

\section{Distributed leadership activity patterns and arrangements}

In the first episode, leadership activities were primarily top down framed and initiated. As it started from scratch, orchestrated leadership activities were focused at human resourcing, attracting and selection of researchers, and the formation of projects and teams. In the years thereafter, gradually, pushed by high ambitions and expectations, the focus of leadership activities shifted towards enhancing TRC's productivity, i.e. the delivery of high qualitative and, for industrial partners relevant, project results. In terms of the conceptual framework, what we see is mainly formal leadership, leadership activities connected to academics who were holding management positions. Ambidexterity of leadership was for that reason mainly structured ambidexterity linked to designed, specialised, tasks and positions. There were contextual ambidextrous leadership activities as well, as the main focus of strategy and project development was with industrial partners. TRC as a whole was explorative entrepreneurial in the sense that TRC as such, in its legal status and its operations, was a leadership entity beyond existing rules and regulations in universities. Within this framework, there was ample room for additional entrepreneurial leadership initiatives, the focus was to realise the overall entrepreneurial ambition.

In 1996,onceTRC had won the bid and got the opportunity to establish the Telematica Instituut, a new start had to be made. TI's leaders had to combine efforts and span different interests, this time comprising a broader scope of partners from industry and universities. Building on the experience that had been gathered in TRC, the focus of leadership activities shifted towards ambidexterity: creating and leading productive relations between development of innovative approaches and securing productivity.

Distributed academic leadership in emergent research organisations

6. Telematica Instituut 
At the end of the second episode, a balanced leadership activity pattern had been achieved that was sustained during the third episode. There were leadership activities in quality control, productivity, professionalization and an emphasis towards a search for innovative work forms. In the second and third episode top down orchestrated informal leadership. Most researchers who developed leadership activities did this in connection with their tasks as project leaders, only about ten people held a formal management position in the TI-CO structure. Contextual ambidextrous leadership activities flourished, in particular in multi-party programmes in which research leaders, in their roles as project supervisors or project leaders, had to find and maintain productive balance between commercial partners and university groups. Entrepreneurial leadership was primarily explorative in episode 2, as TI's research leaders were embarking on a range of new areas and were stretching rules and regulations in order to enable open innovation programme consortia to be effective. In the third episode exploitative entrepreneurship became the stronger focus, as it became clear that results of TI's research did not commercialise as expected, and TI's research leaders felt that a next step in the valorisation process had to be orchestrated by TI as well.

\section{Sites of organisational change and leadership}

Stabilisation of patterns and arrangements of distributed leadership occurred ${ }^{73}$. In the first episode, two interconnected sites of change evolved, pushed by TRC scientific management. Converging project development came first, resulting in a coherent package of projects based on negotiations between the scientific management together with supporting staff that started the centre and the founding parties (three companies and two ministries). Leadership activities were connected with and followed up by strategic programming activities. TRC's academic leaders worked hard to create visibility for the emerging field of telematics, and for the development of the business model of their institute.

The second episode, leadership activities for preparing and establishing the LTI Telematica Instituut, saw a break with the previous episode in legal terms. The two interconnected sites of change continued to occur. TRC scientific management and other academic staff stayed on

\footnotetext{
${ }^{73}$ As stated in the introduction of this case study, for the description of what happened at TRC and TI, a somewhat different structure of presentation was used compared to the other two cases. The reason being that the key activities of leadership and connected sites of change were in the case of TRC/TI more integrated than in the other cases. In this Section, this argument returns and is illustrated by the more or less top down orchestrated distributed leadership constellations that occurred in the successive episodes.
}

Distributed academic leadership in emergent research organisations

6. Telematica Instituut 
board and took their practices in strategic research programming and project development as a starting point for the development of TI practices, an approach that was appreciated by new partners in the TI-consortium of companies and universities. These leadership activities had a much larger scale and saw a higher complexity than in the previous episode. Due to the scale and the diversity of interests of companies and universities, once a large number of multiannual and multi-partner programmes got off the ground, different change modes occurred. Strategic research programming and project development were still interconnected, but were less generic, more articulated towards different branches and themes. This became visible in the research work, taking place in programmes and projects with their own dynamics, and also in the overall structure of TI. The so-called ' $\mathrm{TI}-\mathrm{CO}^{\prime}$ ', the central organisation of about 70 researchers and 20 project support staff within a loosely coupled network of thematic groups adding up to about 140 fte's academic researchers in the TI-consortium. Increasingly in the about 60 projects and programmes annually research leaders were seconded by participating companies or universities; causing new learning spaces, as these distributed leaders had to deal with contrasting interests within these projects and programmes. The new business model development was a challenge as well for this emerging distributed leadership constellation. TICO was bound to regulations of the Ministry of Economic Affairs that often collided with regulations from universities, implying that $\mathrm{TI}$ could not realise planned growth steps; for example, it was not possible for TI to engage in EU-projects, while these increasingly became a main funding source for universities.

In the third episode, all three sites of change occurred with a continued distributed leadership orchestration between strategic programming and project development, now connected with business model development. Tl's research leaders focused on company sponsored programmes geared to national programmes for the continuity of the $\mathrm{TI}$ central organisation, as the competition from universities and TNO grew.

\section{Trajectories of spaces}

Within the distributed leadership activities and arrangements there are learning spaces, which contribute to further development of the research organisation. I speak of trajectories of spaces to indicate that there was a certain continuity in occurrence of spaces in the successive episodes.

Distributed academic leadership in emergent research organisations

6. Telematica Instituut 
In the first episode, about three protected spaces developed around sets of projects within TRC. Projects that were explicitly positioned as 'pre-competitive', allowing researchers from companies, TRC and universities to work in an environment that was, at least for the period agreed upon, protected from competitive pressures, embedded in strict intellectual property right agreements. The protected spaces comprised new research areas in telecommunication and informatics, i.e. telematics and could develop in a stable environment of stakeholders of the founding organisations that were now the co-operating parties. The learning environment comprised almost exclusively TRC researchers, most prominently that researchers who were challenged to develop leadership activities in the protected space in which telematics road mapping and vision studies were conducted.

The three protected spaces continued in the second episode, and new spaces occurred linked to new programmes that were developed in the starting phase of the new LTI Telematica Instituut (TI). Within a few years' time, $\mathrm{TI}$ had established a set of multi-annual programmes that each offered protected spaces for leadership activities. As was the case in TRC projects, in TI projects and programmes companies were keen on strict intellectual property agreements. Due to Tl's mission to connect ambitions from industry with expertise from universities, most spaces consisted of combinations or mergers of existing research projects of private sector partners and universities. Bringing together existing practices implied that Tl's research leaders were boundary spanning the contrasting rules, regulations and procedures; this was a source for double loop learning as they to reflect, collectively, on the new problems and opportunities that occurred in order to find organisational solutions and to develop a recognisable identity for the new species LTI that could at the time only rely on political support from the Ministry of Economic and high expectations from industry, but only modest enthusiasm from universities. As a result of the growth in number of programmes a loosely coupled structure of programme based protected spaces evolved. Tl's researchers got increasingly involved in leading roles in multi-annual programmes, facing the full complexity of not only developing these and acquiring funding, but also implementing and materialising these in terms of scientific output as well as results that were relevant for companies involved. Reflection and learning was stimulated by the ambidexterity of these leadership practices. The learning spaces that occurred were half-open, that is, they were open to the international scientific and technologic world but framed in agreed, temporary, shared interests. The leadership learning spaces were part of a broader international development in user centred design and new forms of software development and

Distributed academic leadership in emergent research organisations

6. Telematica Instituut 
testing, but in their specific thematic domains at the time added to path creation in the Dutch landscape.

The development of multi-annual programmes continued in the third episode, although the orientation changed. Due to withdrawal of IT private sector partners and a growing contribution from partners from other sectors, in particular health, financial and public services, protected activity spaces materialised increasingly in application and business modelling of new technologies. A leadership learning space evolved that was driven by top down orchestrated leadership activities; development of leadership competences of research leaders became part of human resource policy embedded in a new structure of about twenty researchers who got a designated task in human resource management (they had to appraise annual plans and performance of researchers), of which six eventually got a management position as expert group leaders. The protected spaces were primarily single loop learning spaces aimed at scientific and applicable results; research leadership was distributed over researchers who were responsible for work packages, for software development and testing, for project leadership and for supervisorship. The leadership learning space was closed, as it comprised mainly research leaders from the central TI organisation, who were anxious to strengthen their expertise. Nevertheless, eventually the leaning space got under pressure to open, as the embedded protected spaces were increasingly part of evolving paths in national and company sponsored programmes. TRC/TI had come a long way since it start from scratch in 1991, by developing a path that was characterised by mission driven research work, aiming at the requirements of private firms and at breakthrough themes in the national research and innovation agenda. A path that could develop profiting from major changes in the context, implying that new companies and knowledge institutions joined the TI consortium. TI continued to seize opportunities and learn and anticipate where possible. The collective learning capacity was primarily orchestrated and got under pressure, once result oriented (single loop) learning prevailed due to Tl's strengthened orientation towards company sponsored programmes, evolving in a science based consulting approach that saw many advantages for the private sector partners, but limited the possibilities for TI's research leaders to collectively reflect and learn and anticipate on new openings in the science and innovation landscape.

Distributed academic leadership in emergent research organisations 


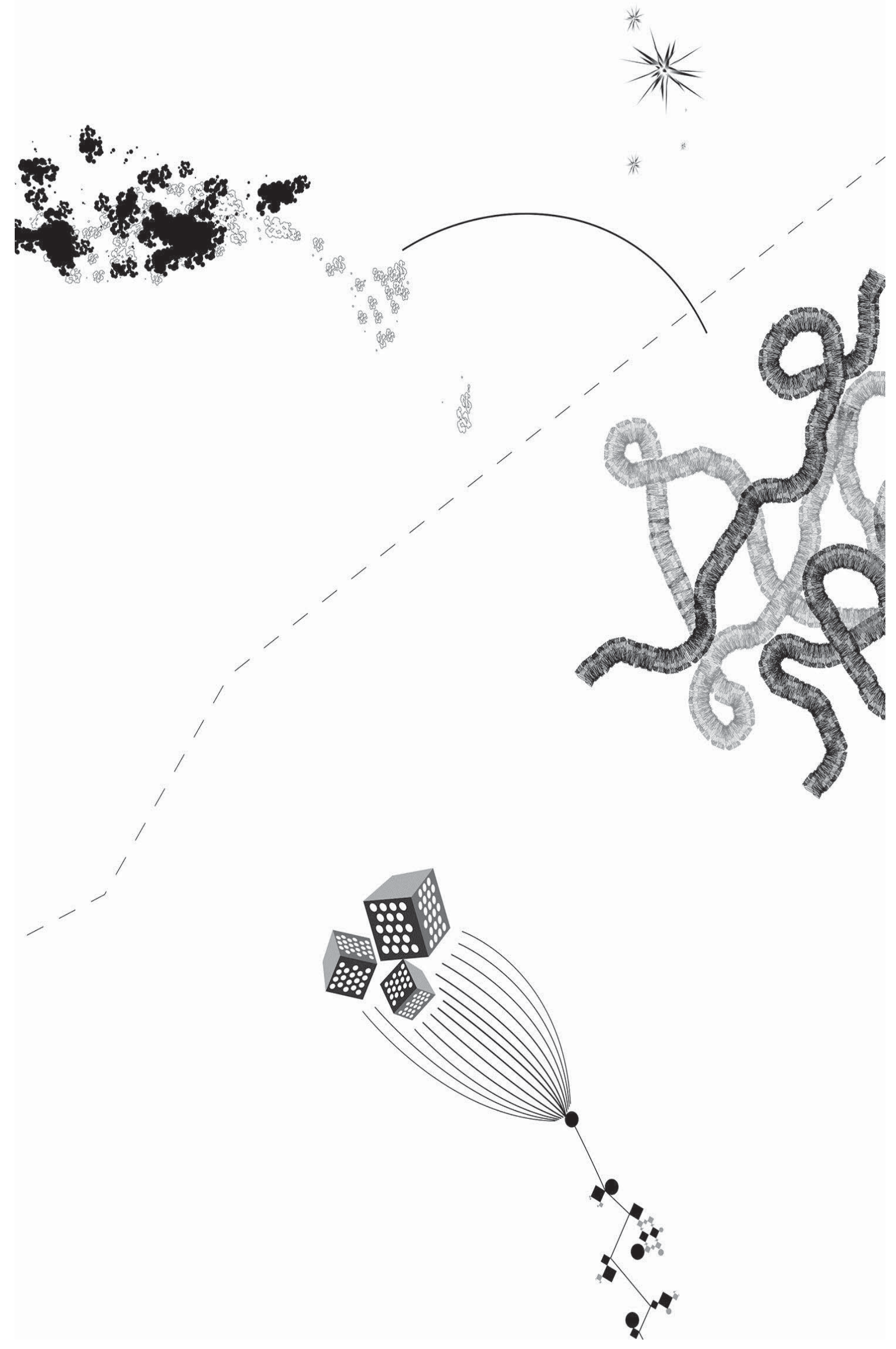




\section{Analysis and findings}

\section{Contents}

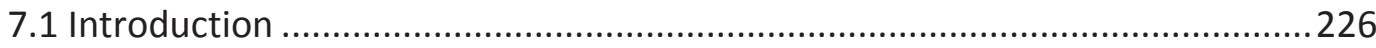

7.2 Organisational change in emergent research organisations in context..........227

7.2.1. Dynamics of organisational change in the context of a CER ...................2227

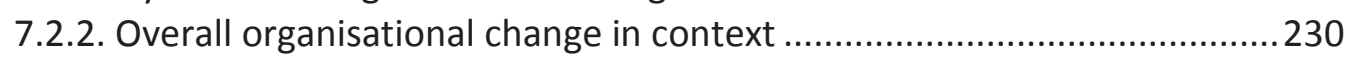

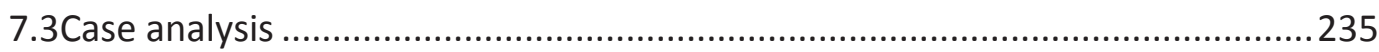

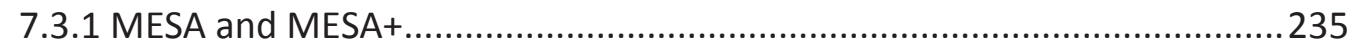

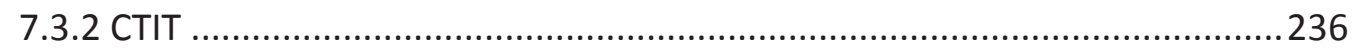

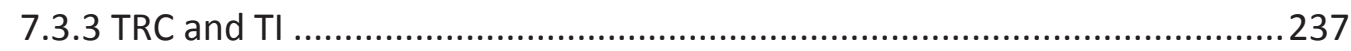

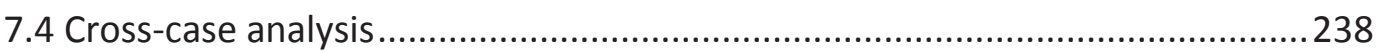

7.4.1 Trajectories of distributed leadership constellations ................................238

7.4.2 Variety of spaces in transformation pathways ......................................241

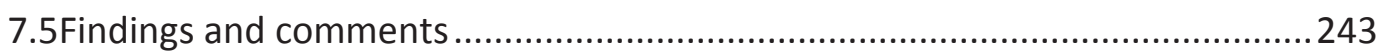




\subsection{Introduction}

We can now take a step back from the details of the cases. The histories are important, but they were selective histories, focussing on the aspects important for my theme. Writing a full history, would easily fill a PhD thesis, for each of the cases. There were also glimpses of the history of this entrepreneurial university, and how it tried to arrange to be innovative, internally and in its contexts. The focus on organisational change in interaction with distributed leadership and learning that characterised how I looked at the cases, could also be applied to the evolution of the university.

All three cases show distributed leadership endeavours, of academics who jointly developed leadership constellations when exploring new ways of working beyond existing procedures and structures. They offer a mixed picture of distributed leadership constellations in which individual academic leadership also plays a role, as visionary leadership or managerial. Looking across the cases, we might find patterns, and that is what this chapter aims to do. Overall conclusions regarding my main research questions will be presented in the final chapter (Ch. 8), followed by some broader reflections.

My cross-case analysis draws on the conceptual framework and analytical models that were developed in chapter 2, Conceptual Framework, and Chapter 3, Research Design. They are summarised visually here.

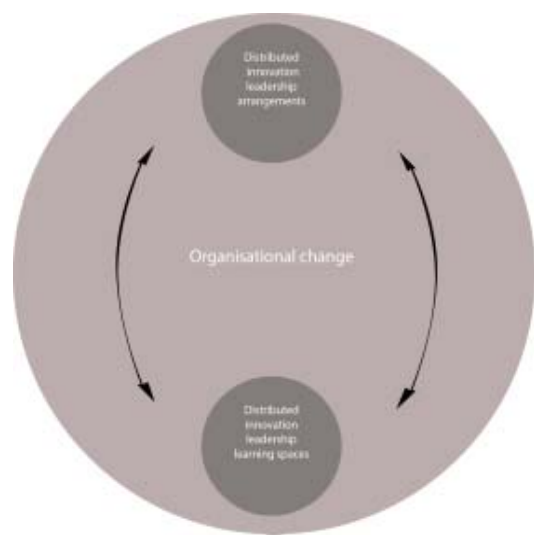

Fig. 1: Basic conceptual model

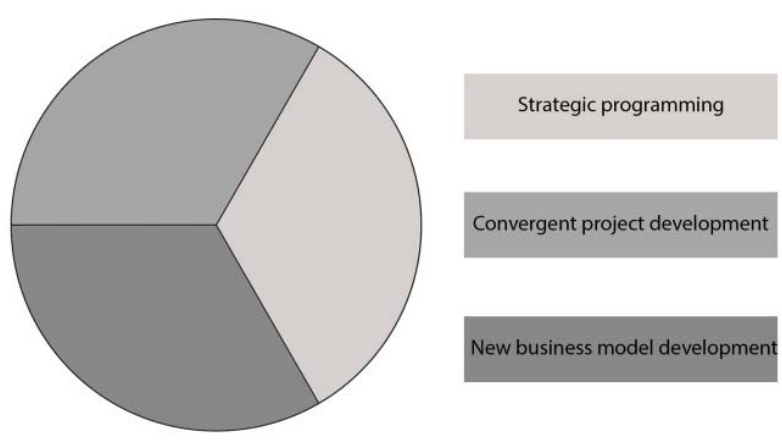

fig. 1.a Sites of organisational change and leadership

Distributed academic leadership in emergent research organisations 7. Analysis and findings 


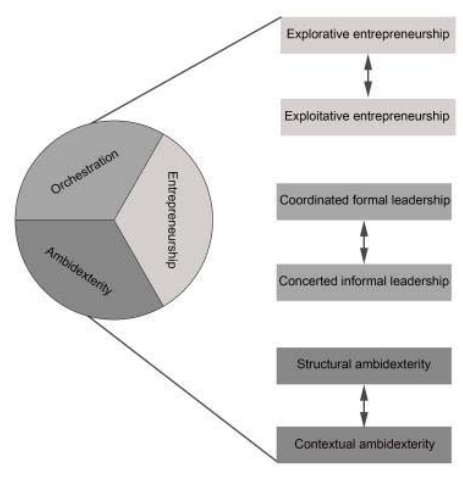

Fig. 1.b: Conceptual model distributed leadership

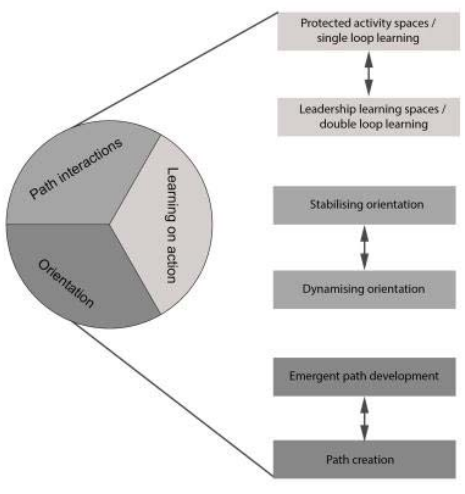

Fig. 1.c: Conceptual model spaces

I will start with characterising overall organisational changes (in 7.2), and then zoom in on the cases and cross-case analysis (in sections 7.3 and 7.4). I think there is a general pattern in the evolution over time, and come back to this when I discuss some key findings in 7.5.

\subsection{Organisational change in emergent research organisations in context}

\subsubsection{Dynamics of organisational change in the context of a CER}

The longitudinal analysis of organisational change processes in the three cases, allows preliminary conclusions, for example about where in the context of an emerging CER do change processes concentrate, which key sites of distributed leadership and change occur, and what can be said about the development of business models in spite of their differences.

Key sites of change where distributed leadership activities occur were located, in the model developed in Ch. 3, in four process layers (see Figure below). In the case studies one can trace how stabilisation occurs in these processes.

Two levels are in the formal organisational setting of a CER: the operational processes in and between research groups that participate in the CER, and the strategic processes in and between Faculties that participate in the CER and the Board of the University (in so far as Board

Distributed academic leadership in emergent research organisations 7. Analysis and findings 
members played roles in the distributed leadership of the CER, as has been the case with CTIT and MESA/MESA+). The two other levels are organised by distributed leadership in the CER, and in that sense informal. It concerns the leadership activities of theme leaders, programme leaders and business developers who are active on an operational level but also inform leadership processes linked to the strategic development of the CER (and are informed by them). This is where the key activities of distributed leadership in interaction with organisational change concentrate. It is as it were an intermediate layer in the organisation of an evolving CER, where distributed leadership lives and learning occurs. Similar phenomena have been noted in the literature on learning organisations in general.

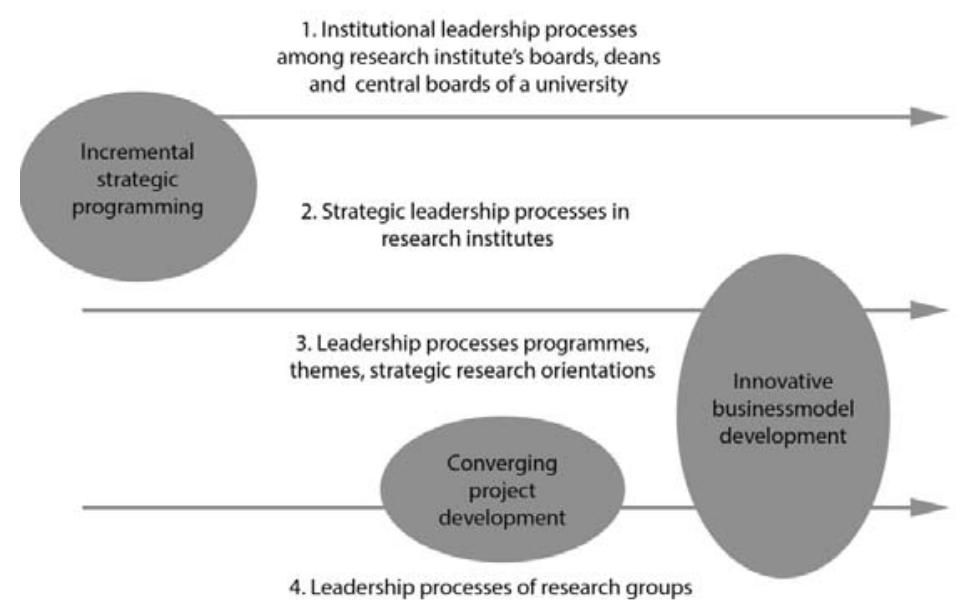

Fig. 5 Leadership key activities layered processes model

The notion of boundary spanning, generally important as a feature of distributed leadership, can be applied to the function of the intermediate layer as interacting between the two formal process levels, strategic and operational. Such boundary spanning leadership activities may lead to identification of new ways of working and possible structures which can stabilize and sometimes be formalised, and thus constitute organisational change in the CER and its interaction with contexts.

The cases show that eventual organisational change and its stabilisation is located differently in each of the CERs. Examples are the development of business plans and strategic research orientations in MESA+, the development of a strategic research programme in cooperation with

Distributed academic leadership in emergent research organisations

7. Analysis and findings 
Faculties in CTIT, the development of multi-annual research and valorisation programmes in TI and MESA+.

The development of new business models differs across the cases, and was shaped by internal drivers and changes in the context of the CERs. The latter will be visible in the next subsection, the former is briefly discussed below.

TI was the most prominent case of developing new business models. Core funding was a key element, for example the core funding supplied by the Ministry of Economic Affairs to $\mathrm{TI}$ as a Leading Technological Institute. It offered flexibility, and possibility of longer-term investments. The actual use that the Tl's distributed leadership made of its core funding also derived from the challenge of the contrasting dynamics in the $\mathrm{TI}$ consortium between participating universities and the Tl-central organisation (CO). There were different attempts, but no business model was developed that was mutually beneficial, and stabilized as such. One net effect was that TI's central organisation's research leaders eventually focused on research project development and business development with companies.

MESA+ had been quite ambitious in exploring the possibility of a joint research and innovation development fund, supported by capital investment groups, but eventually remained a university-based research organisation, with some core funding depending on the vagaries of the university's internal budget allocation policies. Internal opportunities were creation of a joint lab facility that became a driver for further and enhanced cooperation in particular after the1999 fusion of MESA with the Centre for Materials Research CMO. The step-up to the development of a major research lab facility was envisaged, and was eventually realized through a national research programme on nanotechnology, which had separate funding for a distributed NanoLab, located in Twente, Delft and Groningen, the main partners in the national programme. The business model of MESA+ now also contained the running of the Twente NanoLab one component being payments from users of the facilities (including the members of MESA+). While being complex business, the latter stabilized the business model, and MESA+ continued to be university-based, but in its size and organisation geared to national and international programmes.

CTIT started with an interest in links with companies, but when it was the first institute within the UT system that got the status of a spearhead institute, there was structural link with UT strategy, including some core funding. CTIT's leadership initiatives to align the business model to

Distributed academic leadership in emergent research organisations 
private sector funding stayed limited to profiting from EU funded research programmes in which companies participated as well, and to CTIT being a prominent member in the TI consortium. CTIT's business model eventually became integrated in the organisational models of the cooperating Faculties, and then became closely linked to the national ICT research programme NIRICT.

A final reflection on overall patterns regards the combination (including tensions and trade-offs) of excellence and relevance, dynamic because of informal entrepreneurial leadership, partially and temporary stabilising due to boundary spanning ambidextrous leadership constellations. CTIT, and particularly MESA+, developed relevance building on excellence. Considered as a Centre of Excellence and Relevance, one can say that TI developed some excellence building on relevance. One could speculate that this is not just historically contingent, but an indication that research institutes in the age of strategic science gravitate to develop into members of the new species of Centres of Excellence and Relevance.

\subsubsection{Overall organisational change in context}

Context was visible in the discussion in the preceding sub-section. The focus was on collectives of academic leadership seizing opportunities and openings occurring in changing contexts. In this sub-section I start from the changing contexts, and inquire into impacts on the three institutes.

First there is the immediate context of the University of Twente. MESA and CTIT can be seen as internal corporate ventures seizing the opportunities offered by the University of Twente, flagged as an entrepreneurial university since the mid-eighties. Entrepreneurialism was also an opening for groups of academics who wanted to seek new ways, for example when the UT was willing, as one of the first in the Dutch university system, to give groups of academics a financial and programmatic mandate for a period of five years. TRC profited by and large from the same conditions: UT researchers, in an orchestrated joint bidding with the City of Enschede and Region of Twente, won the call for tenders organised by Dutch government, its founding scientific director had also a position as professor at UT, and UT gave firm facilitating and programmatic support to get TRC off the ground.

Distributed academic leadership in emergent research organisations

7. Analysis and findings 
This local context was rather stable for years, until the end of the 1990s, and the two research institutes had the time to organise themselves. The Faculties were not always keen to support them, for example when the institutes wanted to have new professorial chairs (in the new domains that they developed), which were the Faculties' prerogative. Interestingly, individual members of the Board of the University, and central university staff actively participated in the development of the institute. ${ }^{74}$ had a particular role in the development of the CERs. One could say that they, for some time, were part of the distributed leadership network of a research organisation. Some were at the time seen as proponents of, what Clark (2003) called "the bureaucracy of change".

What did happen, as of about 1998, was that more research organisations like MESA and CTIT, officially recognized by the Board as strategically relevant for the UT, were set up, some like BMTI (BioMedical Technology Institute) building on existing initiatives from groups of senior researchers, others (Institute of Governance Studies, Institute of Behavioural Research) projected from above and linked to the mergers and reshuffling of Faculties that occurred at the time. The policy vision was to realize a so-called Schools and Institutes structure for the University, with appreciable autonomy for the accredited research institutes. One root of this vision was the notion, entertained from at least the mid 1990s, that the interfaculty research institutes, which were the governance framework from the Higher Education law used for CTIT and MESA and a few other research organisations in the University, could be "toppled" (in Dutch: kanteling) so that the institute would be the boss rather than the Faculties. While the "toppling" could not be pushed through against the resistance of the Faculties, the School and Institutes structure, where research would be governed somewhat independently from teaching, was realized to some extent. There was the probably ill-advised policy, introduced in 2001, of assuring the research component of the academic staff only when they would be a member of one of the accredited research institutes of the University. There was an influx of new members, more so in CTIT than in MESA+, and in some of the other accredited research institutes, a problem with eligibility if a proposed new member did not meet the quality or strategic criteria or strategic priorities set by the institute. There was also, as of 2002, a newly established University Management Team (UMT), comprising the Central Board, the Deans (of

\footnotetext{
${ }^{74}$ These were successive Presidents, Rectors, Vice-Presidents (the Board member who was responsible for financial affairs during the 1990s), and a few members of the central staff who were occasionally seconded at these research organisations.
}

Distributed academic leadership in emergent research organisations 7. Analysis and findings 
the by then five Faculties) and the Scientific Directors of the (by then six) recognized institutes. For the Central Board, this was a way to broaden its governance arrangements, and create a location for discussing strategic issues. For the newly involved Scientific Directors, it was an opportunity to have their say and push their interests - and perhaps be disappointed if they did not get enough of a hearing. One issue was the New Public Management inspired research management initiatives from the Board, which were seen as too bureaucratic, and thus constraining rather than enabling strategic choices that might be necessary. A background issue was their relative independence of University support, given their external partners and funders, in terms of financial resources as well as reputation, while the University depended on them for its profiling. The possibility of breaking out of the university, and becoming a fully independent research organisation was seriously discussed inside the group of academic leaders, and scientific directors (especially of MESA+) were willing to do some soft-blackmailing. They were listened to, but nothing came of it.

There were changes in the national context that had a more or less pronounced impact on the development of each of the CERs. TRC/TI was an example of a CER that saw clear impact of changing contexts. Conceiving TRC was a political action, a decision by the Dutch government in cooperation with a coalition of Netherlands based international companies. It was a first-time public-private impulse of this size in the Dutch research and innovation landscape. TI was oriented to national research programmes and the innovation programme led by the Ministry of Economic Affairs; once these innovation funding programmes diminished, $\mathrm{Tl}$ had a hard time in finding alternative core funding. The private sector context of TI saw major shifts (e.g. the burst of the internet bubble in 2000, resulting in IT and telecom companies leaving the TI consortium). CTIT and MESA/MESA+ developed in a rather stable national context; there were changes, but not radical or sudden. Important changes for CTIT were developments in the direction and organisation in the scientific domain of Informatics where by 2000 research on application was becoming accepted. Also the establishment, profiting from strategic deliberations between the three Technical Universities in which CTIT's scientific director had a prominent role, of the national ITC research programme NIRICT. After the period of this case study, CTIT continued its European path, seizing opportunities in EU framework programmes, profiting from its past performance, size and node position in international networks.

Distributed academic leadership in emergent research organisations 7. Analysis and findings 
MESA/MESA + was strongly embedded in national innovation policy frameworks, partly because they helped create them, as in the case of the R\&D programme NanoNed. This is an example of the importantcontinuing promotional work that MESAt's scientific and commercial directors were doing. Earlier changes for MESA were the reluctance of the Dutch government (around 1988) to continue its support for micro-electronics research, the strategic decision of the Dutch government not to support the joint national initiative of the three Technical Universities, submitted in 1996, for the development of a joint research and laboratory infrastructure in micro-systems, and of course the merger with the CMO institute for materials science research, which was an internal Twente discussion but changed (expanded) the links with international scientific domains. Soon after, the labels nano science and nano technology research for the whole of MESA+, following international trends, particularly in North America.

Of course, this brief analysis of the changing context cannot cover everything of importance for the CERs as presented in the cases. A final point to make is about the changing combination of excellence and relevance since the early 1990s. Relevance had become an obvious consideration, also when excellence was promoted. It was becoming a conditio sine qua non to survive in the research and innovation landscape of the 2000s. This had implications for the institutional division of labour, up to possible competition. Interesting is how the Dutch national applied research organisation TNO, with a history dating back to the 1930s, had been taking up newly emerging sciences and technologies, and then cover similar ground as the Centres of Excellence and Relevance that I have been discussing. In the case of TI, itself strongly oriented to relevance, there had actually been negotiations, when the core funding of the Ministry of Economic Affairs ended, about a merger with TNO. For MESA+, TNO was one of the partners in the NanoNed R\&D consortium with only minor overlap in topics and approaches. But if TNO had chosen to embrace nanotechnology, that would have had an impact on the strategic choices MESA+ would be making. One could even envisage situations in which a Centre of Excellence and Relevance would build on the TNO infrastructure. Excellence would still be an integral part, not just as an objective in its own right, and as a way to better achieve relevance, but also, as the cases have shown, to structure the use of core funding. The notion of 'exploration' that I have been using (together with its contrast, 'exploitation') indicates such use, and can actually be used to make a general point about Centres of Excellence and Relevance. Such Centres need

Distributed academic leadership in emergent research organisations 7. Analysis and findings 
to have (and cherish) spaces for exploration, and thus, if there is no formal core funding, create a structural equivalent.

Distributed academic leadership in emergent research organisations

7. Analysis and findings 


\subsection{Case analysis}

In each of the cases, one sees co-evolution of organisational change and spaces of distributed leadership activity. This had different shapes in the episodes that were discussed in detail in the empirical chapters. In the concluding observations in each of these chapters an overview was presented already. Here, I offer brief summaries to prepare for the cross-case analysis in Section 7.4 .

\subsubsection{MESA and MESA+}

How did the co-evolution work out over time? The first episode, covering eight years, can be characterised as searching for ways to go and ways to organise oneself. Key sites of changes and leadership were loosely coupled. Strategic programming, creating visibility and reputation for the new field of micro-systems research, came first. Some themes were selected carefully, in intensive consultation with research leaders, and their feasibility was evaluated in trying by doing. Protected spaces occurred around two selected themes, mainly to fuse existing strengths in research. Distributed leadership constellations were bottom up and mainly informal, comprising explorative entrepreneurship as internal and external boundaries were explored and where feasible, crossed.

In the second episode the interactions between strategic programming and converging project development accelerated, partly because of the so-called spearhead grant from the Board of the University. Over time, risk taking research was promoted, in particular once the Strategic Research Orientations got off the ground in full strength. There was intensive exploration of an innovative business model that would open new relations with industry and new resources, in national programmes, and in a dedicated research fund. A distributed leadership constellation stabilised with top-down orchestration by the new scientific director; ambidextrous distributed leadership activity became visible as the portfolio of projects with industry expanded.

In the third episode strategic programming continued to be an important site of change and leadership, with an enhanced focus on national programmes in which MESA+ played key roles. The eventual business model was less innovative than aimed for, but still allowed for a coherent configuration of strategic thematic programmes, embedding loosely coupled interorganisational (inter)national research programmes and connected learning spaces for academic leadership. Explorative and exploitative entrepreneurship occurred as new ways were sought in

Distributed academic leadership in emergent research organisations 7. Analysis and findings 
national and international programmes, including valorisation projects in dedicated consortia with companies. Top down orchestration of the distributed leadership constellation continued; moving to a differentiated, structural ambidextrous approach following the widening scope of projects, becoming visible in a more structured task division and specialisation for valorisation.

\subsubsection{CTIT}

Although there was a fundamental turn in the second episode, there was also continuity in learning and building on achievements. There were struggles, but about directions to go, not whether to have CTIT at all In the first episode, covering six years, converging project development came first, quickly followed and supported by strategic programming, creating visibility and reputation for a new, emerging field of telematics, later on joined by the emerging field of distance learning and IT. For some time, efforts were made to develop a business model that in terms of flexibility of approach, work processes and career perspective would align with companies in the telematics sector. The distributed leadership constellation was top-down orchestrated, vision and mission driven, becoming visible in an explorative entrepreneurial approach that explicitly aimed at fundamental changes in the organisation of research. This was happening in a research organisation embedded in a university, which created tensions, in particular with the Deans of the immediately involved Faculties, while the Board of the University was often supportive. In the strategic programming necessary to renew the mandate of CTIT as an interfaculty research institutes, these tensions came to a head. Its partial resolution, in the second episode, was a radical turn in the focus of leadership practice: to give up on full autonomy, and align strategic programming and project development to the strategy and procedures of the cooperating Faculties, in particular to the Faculty of Informatics. Protected spaces were now top-down orchestrated around six strategic themes. This structured change pattern and the spaces involved continued into episode 3 and stabilised, once these six Strategic Research Orientations got momentum and a leadership learning space evolved around these SROs. Strategic programming was the prime site of change, and the locus of leadership with an enhanced focus on national programmes and business model development. The distributed leadership constellation was top-down orchestrated working in a business model coupled to internal University strategy and processes (for example, human resource management and financial matters being covered by the faculties concerned) and to a stable configuration of strategic thematic programmes on a national level, later on in the NIRICT

Distributed academic leadership in emergent research organisations

7. Analysis and findings 
consortium, and as one of UT's spearhead institutes in European networks. Ambidextrous leadership occurred when innovative business modelling took place outside CTIT's organisation, in the growing number of start-up ICT SMEs.

\subsubsection{TRC and TI}

TRC and TI show continuity in distributed leadership and organisational change. The organisational set up changed in 1996/1997 when TRC transformed into a Leading Technology Institute, arranged in the TI consortium. Around 2000 there was a major shift in participating companies. But the mission-driven approach characterises all three episodes.

In the first episode, when TRC became established, converging project development was the main site of organisational change and entrepreneurial leadership, quickly followed and supported by strategic programming, creating visibility and reputation. TRC became a solid group, a top down leadership constellation in which the scientific director delegated openings for leadership, and focusing on a set of central research themes. It completely opened up and changed itself after 1997, once it became one of the four Leading Technological Institutes.

The leadership activities at TI were of a much greater scale and complexity than in the first episode, as many companies and universities now joined the TI consortium. Strategic programming in interaction with project development continued to be the main site of change and leadership. Tl's ambidextrous distributed leadership got tested once a variety of multiannual and multi-partner programmes got off the ground. These implied protected spaces with their own dynamics, because they were in different sectors, varying from financial services up to health or chemical industry. The distributed leadership constellation was top-down orchestrated by an expanding group of academic leaders, with the scientific and by then general director at the core.

In the third episode, focus of leadership activities was on the continuity of $\mathrm{Tl}$, as competition increased, from universities and from TNO, and TI's business model gradually got oriented to national programmes. TI as a consortium covered some 60 projects, counting more than 200 academics of which 80 (and 20 project management support staff) were employed by the central TI institute. The distributed leadership constellation expanded with the growing number of projects, and an evolving contextual ambidexterity as business development required more attention and specialised expertise from TI's academic leaders.

Distributed academic leadership in emergent research organisations 7. Analysis and findings 
As an acknowledged open innovation research centre, TI was challenged to keep its strong position, which was an incentive for further development of organisation and leadership approaches.

\subsection{Cross-case analysis}

In a first step, a shared or backbone pattern of development over time is distilled out of the case analyses, while relevant variety is discussed. To bring out the backbone pattern, I will focus on 'primary' leadership constellations, that is, what the distributed leadership is explicitly focusing on. Other leadership practices and constellations can play a role, but in the background.

In a second step, I will consider spaces and learning. Not to find a shared pattern, but to show their importance, and their variety, across the cases.

\subsubsection{Trajectories of distributed leadership constellations}

While attempting to identify an overall or backbone pattern, in this section I will keep close to what was actually happening in the episodes. This will provide the basis for a more ambitious attempt at identifying a pattern that may be typical for the development of Centres of Excellence and Relevance. I will do so in the concluding section of this chapter, and will then speak of phases in the development, to distinguish them from the empirically (historically) defined episodes.

In the Table below, I indicate the primary leadership constellations in all episodes in all cases, and have a bottom line suggesting what would be the overall primary constellation, across the variety visible in the cases.

Distributed academic leadership in emergent research organisations 


\begin{tabular}{|l|l|l|l|}
\hline & Episode 1 & Episode 2 & Episode 3 \\
\hline MESA & Emergent, bottom up & $\begin{array}{l}\text { Top down } \\
\text { orchestrated }\end{array}$ & $\begin{array}{l}\text { Orchestrated } \\
\text { differentiated } \\
\text { constellations }\end{array}$ \\
\hline CTIT & $\begin{array}{l}\text { Top down } \\
\text { orchestrated }\end{array}$ & $\begin{array}{l}\text { Top down } \\
\text { orchestrated }\end{array}$ & $\begin{array}{l}\text { Orchestrated } \\
\text { differentiated } \\
\text { constellations }\end{array}$ \\
\hline TI & Top down delegated & $\begin{array}{l}\text { Top down } \\
\text { orchestrated }\end{array}$ & $\begin{array}{l}\text { Top down } \\
\text { orchestrated } \\
\text { differentiated } \\
\text { constellations }\end{array}$ \\
\hline $\begin{array}{l}\text { Overall Primary } \\
\text { leadership } \\
\text { constellation }\end{array}$ & $\begin{array}{l}\text { Exploration and } \\
\text { variety }\end{array}$ & $\begin{array}{l}\text { Top down } \\
\text { orchestrated }\end{array}$ & $\begin{array}{l}\text { Orchestrated } \\
\text { differentiated }\end{array}$ \\
\hline
\end{tabular}

Table 10. Distributed leadership constellations

In the first episode, the start-up and first articulation of work and structures, the evolving primary leadership constellation is oriented towards exploration, including encouragement of bottom-up variety. But there will always be elements of 'top down orchestration' in conjunction with entrepreneurial leadership practices. This can be related to a vision, but there is also a functional argument: the distributed leadership has to remain interactive, rather than fragmenting into separate groups and their interests. We do see a shift towards entrepreneurial leadership, crossing internal and external boundaries. One can understand this as an effect of articulation of leadership identities, in interaction with emerging strategic research programming. In general, collective learning about identities contributes to strategic thinking and work on programming, and vice versa. Thus, such articulation goes together with increasing coherence of distributed leadership.

Distributed academic leadership in emergent research organisations 7. Analysis and findings 
Differences between the research institutes are visible in the nature and extent of conjoint leadership. MESA+ and TI had extensive distributed leadership activities, in the case of $\mathrm{TI}$ also including experts from industrial firms in the TI consortium, and in the case of MESA+ including academic leaders on all process levels. In CTIT, distributed leadership was in practice (not necessarily in intent) limited to a small group of academics setting up the new institute.

In the second episode, top down orchestration becomes the primary constellation. Academic leaders concern themselves with questions of implementation and achieving results. Does the organisation deliver research activities that make a difference, that respond to innovative challenges of societal relevance and scientific excellence? Are there multi-annual programmes that promise new approaches and new areas? The ambidextrous leadership practice becomes dominant during this episode, addressing the interactions between exploration and exploitation. In general, stabilisation of constellations and leadership practices occurs, and towards the end of this episode, there may be attempts to capture the learning that occurred in more formal roles and structures.

In the third episode there is more variety. New structural and organisational processes and entities occur, and can be accommodated because of the earlier, partial stabilisation. Ambidextrous leadership activities balancing competing values of exploration and exploitation remain important. The variety can be an effect of expansion that is occurring, but also be pursued actively as leadership looks for new challenges when the limitations of what is possible in present structures comes into sight. The new activities, in their contexts, will have their own thrusts and leadership constellations, but the net effect is that a more or less top-down orchestrated "ecosystem" of distributed leadership constellations evolves. For example, in all three cases, there is a shift in focus of leadership activities towards new business model development, geared to national programmes.

Of course, there were differences between the cases in how the general pattern of development that was just sketched was actually filled in. MESA+ and TI walked a more or less planned route of ambidextrous leadership covering several process levels, and with a keen interest to be productive in conjunction with development of innovative ways of working. CTIT, at first,

Distributed academic leadership in emergent research organisations 7. Analysis and findings 
focused on scientific vision development and strategic programming in order to materialise a new interdisciplinary field.

The co-evolution of organisational change and distributed leadership can (and will, eventually) lead to closure and some stabilisation. The closure and lock-in, of an overall trajectory or a particular arrangement, can come too early and/or reduce the capacity to respond to changes in context. The risk that this will happen is diminished by continued entrepreneurial and ambidextrous leadership activities. Formulated in this way, these are normative points. Their force can be recognised by actors, and they can be taken up in their debates and influence choices. Empirically, one could say that both MESA+ and CTIT, each in their own way, have kept openings and avoided strong lock-ins. For TI, there might have been some lock-in, in spite of its encouragement of entrepreneurial and ambidextrous leadership activities. We can't say much about how this would have worked out because TI stopped, and its successor NOVAY eventually wasn't able to survive on the market of strategic ICT research and development.

\subsubsection{Variety of spaces in transformation pathways}

While looking from some more distance at the development of spaces over time in the three cases, the importance of spaces in emergent research organisations is clear. Looking at the variety of spaces (as summarised in the table below) the question returns what we can learn from this. My conceptualisation of leadership learning spaces and their characteristics, in an attempt to better understand the occurrence and working of spaces in emergent research organisations, might add, even if it is little, to further discussions on spaces and learning, as I will discuss briefly across the cases.

Distributed academic leadership in emergent research organisations 


\begin{tabular}{|c|c|c|c|}
\hline & Episode 1 & Episode 2 & Episode 3 \\
\hline MESA & $\begin{array}{l}\text { Emerging leadership } \\
\text { learning space around one } \\
\text { protected activity space } \\
\text { fusing existing areas }\end{array}$ & $\begin{array}{l}\text { Leadership learning space } \\
\text { around an orchestrated set of } \\
\text { protected activity spaces } \\
\text { Protected activity spaces } \\
\text { comprising new areas }\end{array}$ & $\begin{array}{l}\text { an inter-organisational } \\
\text { leadership learning } \\
\text { space, comprising } \\
\text { loosely coupled } \\
\text { protected activity } \\
\text { spaces. } \\
\text { protected spaces } \\
\text { comprise fusing existing } \\
\text { areas }\end{array}$ \\
\hline CTIT & $\begin{array}{l}\text { an intra-organisational } \\
\text { learning space, comprising } \\
\text { loosely coupled protected } \\
\text { activity spaces } \\
\text { protected spaces } \\
\text { comprising fusing existing } \\
\text { areas }\end{array}$ & $\begin{array}{l}\text { Emerging leadership learning } \\
\text { space around one protected } \\
\text { activity space } \\
\text { orientation space for research } \\
\text { leaders that are positioning in } \\
\text { the institute }\end{array}$ & $\begin{array}{l}\text { a leadership learning } \\
\text { space around an } \\
\text { orchestrated set of } \\
\text { protected spaces } \\
\text { protected spaces } \\
\text { comprising fusing } \\
\text { existing areas }\end{array}$ \\
\hline TI & $\begin{array}{l}\text { Leadership learning space } \\
\text { around one protected } \\
\text { space } \\
\text { protected spaces } \\
\text { comprising new areas }\end{array}$ & $\begin{array}{l}\text { an inter-organisational } \\
\text { learning space, comprising } \\
\text { loosely coupled protected } \\
\text { spaces } \\
\text { protected spaces fusing } \\
\text { existing areas }\end{array}$ & $\begin{array}{l}\text { An inter-organisational } \\
\text { learning space around } \\
\text { orchestrated protected } \\
\text { spaces } \\
\text { protected spaces fusing } \\
\text { existing areas }\end{array}$ \\
\hline
\end{tabular}

Table 11. Spaces in transformation pathways

'Protected spaces' are important for the dynamics of organisational change and transformation in general (cf. Section 2.3) and occur in all three cases in stabilising distributed leadership activity, becoming visible in thematic research programmes. Here, some freedom was found to experiment and learn while fusing existing research domains or exploring new domains. At MESA and CTIT, research organisations that needed time to emerge and organise themselves from within the university structure, spaces first focused at bringing together ongoing research while spaces around new research areas occurred from the second episode onward. TRC/TI was a protected space in its own right from the beginning.

Distributed academic leadership in emergent research organisations 7. Analysis and findings 
Leadership learning spaces are more specific in their occurrence in the cases. A distinctive characteristic of a distributed leadership learning space (cf. Section 2.4, my conceptual model) is double loop learning while academic leaders are collectively reflecting, and sometimes anticipating, in action. There were examples of leadership learning spaces in the cases, where leadership activities crossed boundaries.

$\mathrm{TRC} / \mathrm{TI}$ developed the most pronounced learning space, right from the start working towards a body of experts that crossed boundaries of private sector and academia, showing in entrepreneurial and ambidextrous distributed leadership. MESA/MESA+ primarily focused selectively on professional space for some selected ambidextrous academic leaders who would be able to develop and manage multi-annual and multi-stakeholder programmes. Small in number of academic leaders but substantial in size and complexity of programmes, CTIT walked a different path where the learning space comprised the distributed leadership of strategic research theme development.

The interlink between protected activity spaces and leadership learning spaces seem to be a general pattern in the cases. Be it de facto, as a learning space could not survive without thriving activity space that offers sufficient protection to experiment, or, from time to time, as a metacognitive understanding among academic leaders while strategic programming. In the final episodes spaces seem to offer less room (as there was perhaps less need) for experimenting at the overall organisational level; protected spaces had become business as usual in differentiated programmes of a substantial size.

\subsection{Findings and comments}

There are two sorts of findings: about distributed leadership practices and their value, and about transformational pathways of Centres of Excellence and Relevance. I will offer comments on the former, and draw out a general pattern for the latter.

While I have emphasized the importance of distributed leadership to understand what is actually happening, the case studies can be read as showing a mixed picture. Not a return of the classical, hierarchical model, but the occasional importance of individual academic leadership, be it visionary or managerial. A clear example is the leadership practice of the scientific directors. They are the main spokesmen on behalf of the research institute, publicly and in

Distributed academic leadership in emergent research organisations 7. Analysis and findings 
overarching formalised structures, be it the university management structure or, as in the case of $\mathrm{TI}$, towards the Board of Trustees. Thus, in a formal sense, the steering of the institute depended on a single leader, with a management mandate from the Board of the University for a limited period of time, five years, possibly prolonged. At TRC/TI, the scientific director was appointed by the Board of Trustees. (He actually stayed in office for more than fifteen years, covering the life of TRC and the subsequent Telematica Instituut.) The cases show that actual leadership did not solely rely on the steering capacity of a single leader (or the combination of the scientific director and the business manager). Leadership was distributed over senior scientific staff, from fifteen to thirty academics, who were learning by doing about leadership and about joint anticipation and response to challenges posed by internal organisational changes or changes in the (inter)national context. As I noted already, collective learning about their new identities contributed to strategic thinking and work on programming, and vice versa. In this emerging distributed leadership, orchestrated leadership activities and specific constellations occur. Constellations of distributed leadership can be more collegial or more topdown orchestrated, but the key point is to replace the notion of steering, with its connotation of an actor doing the steering, with the notion of orchestration as a process which shapes what is going on and can have different inputs.

A clear example of this perspective is how strategic programming is a de facto dominant feature of distributed leadership and prominent mode of organisational change. The anticipatory and pro-active character is clearly visible, and in processes at different levels. (Of course being anticipatory is an important aspect of leadership, anyhow.) It is striking how the pro-active stance of emergent strategic programming, combined with internal (ambidextrous) and external (entrepreneurial) leadership activities has become an obvious part of the identity of academic distributed leadership.

In this notion of orchestration distributed leadership lives (cf. Section 7.2.1) in the, as it were, intermediate layer of an evolving Centre of Excellence and Relevance interacting between the formal process levels (strategic and operational) in a university system. Orchestration and boundary spanning leadership activities stabilise in new ways of working that sometimes are formalised, and thus constitute organisational change in the CER and its interaction with contexts.

Distributed academic leadership in emergent research organisations 7. Analysis and findings 
All these interaction processes and their partial stabilisations actually add up to a pattern. In Section 7.4 I already outlined a backbone pattern, visible in the mapping of the leadership arrangements and activities over the three empirical episodes. With the benefit of the general considerations about distributed leadership I just offered, I can now make a next step and reformulate this pattern as a succession of phases, which need not exactly coincide with the discussion of the episodes in Section 7.4. The identification of the pattern is not just an empirical generalisation, but also depends on plausibility arguments.

First, there is the start-up of the new institute, as a Centre of Excellence and Relevance, and the experimenting with leadership activities and arrangements. The pressure to produce can be strong, as with TRC/TI, but even then, learning spaces are important. In a second phase, where strategic programming and project development interact, and ambidextrous leadership activities sustain the work of the Centre, there is growth and stabilisation. In a third phase, paths have been stabilised, and profiting from the achievements of the path, the Centre can address new challenges and differentiation occurs.

Phrasing it this way, it can be recognised as the general sociological pattern of emergence, institutionalisation and differentiation. The specificities derive from the particular institution, a new species of research organisations which have to invent themselves.

Over time, they create and reproduce patterns of distributed academic leadership which allow them to be productive, also in addressing new challenges. What we also see, is the tension between their growth (and the development of innovative business models) and the structures within which they grew up. An example is how MESAt's leaders did not get (eventually, in the third episode) the strategic, human resource and financial instruments from the Deans and Board of the University that they had looked for (and which had been envisaged by rectorates already in the mid-nineties). Another example is how CTIT's academic leaders, when confronted with the limits posed by the university system by 1998, chose to accept these constraints, aligning their human resource and financial planning with the Deans, and focused instead on the development of a networked institute as a node in international networks. The case of $\mathrm{Tl}$ is an example of a business model that, while acknowledged as open and innovative compared with other research organisations, definitely when compared to the other three accredited Leading Technological Institutes, came under pressure once the core funding from government ended

Distributed academic leadership in emergent research organisations 7. Analysis and findings 
and competition with other research organisations, also CTIT at the University of Twente, which went in the same direction of multi-annual strategic research and innovation programmes, became more difficult.

If I am correct in positioning this phase model for Centres of Excellence and Relevance, it raises further questions about future developments. For example, will differentiation continue and lead to specialisation (in terms of competencies, networks and business models) and thus fragmentation, and perhaps a break-up of a Centre? This is speculation, of course, but in the concluding chapter, I will have occasion to come back to such questions.

Distributed academic leadership in emergent research organisations

7. Analysis and findings 


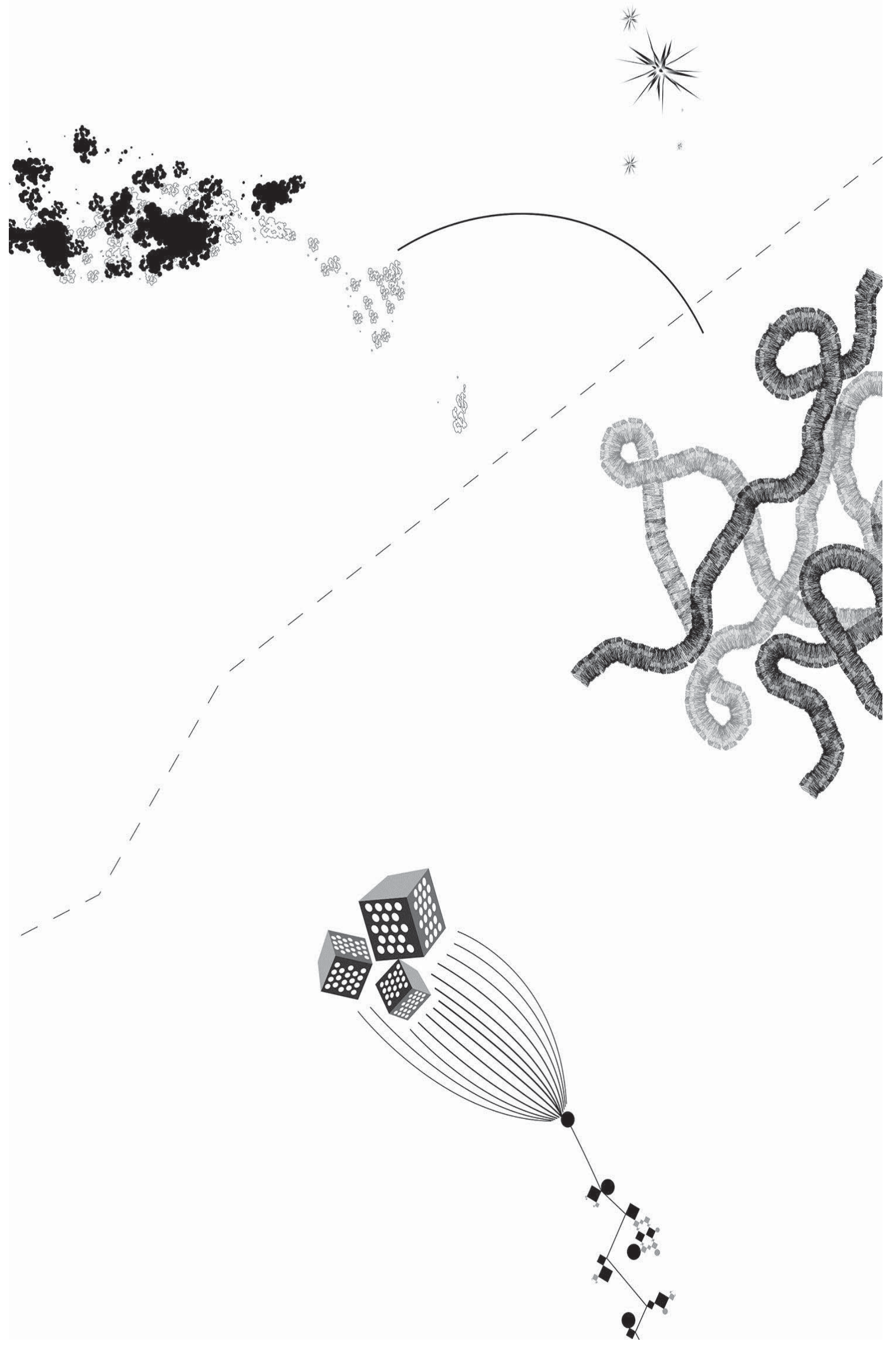




\section{Conclusions}

\section{Contents}

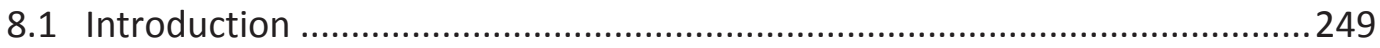

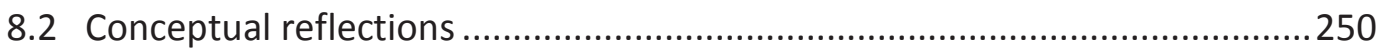

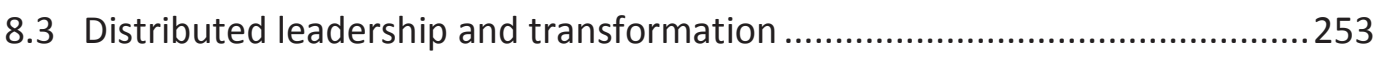

8.4 Perspectives on spaces and distributed leadership .....................................256

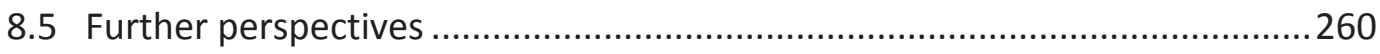




\subsection{Introduction}

After the long journey of working on this thesis, "seven (and more) years to Tibet" that allowed me, off and on over a period of almost ten years, to travel over high plains with beautiful views, now is the time to conclude. The purpose was not to draw strong conclusions, but to explore an open field of research, on distributed academic leadership in research organisations. Thus, it is "in conclusion" that I reflect on the empirical work and literature study that I conducted, and articulate insights achieved, topics for further research, and recommendations for those academics who embark on leadership tasks in emergent research organisations. My eventual conceptual model can be read as an attempt to bridge some higher peaks in sociology and management studies; however far I have come in this attempt, my findings along the way are definitely interesting for further empirical research and for practical use. My case studies of centres of excellence and relevance in changing contexts were very rich empirically, but not all of my data and insights could be presented.

What kept me on track during my journey was my fascination with the vicissitudes of distributed academic leadership in emergent research organisations. Understanding co-evolving distributed academic leadership arrangements and organisational change, the learning that occurs in various spaces, and the overall pathways that become visible - those were the questions which I addressed. The entrance point in exploring these questions is the transformation paths that occurred in, or linked to, the University of Twente in the $1990 \mathrm{~s}$ and the early $2000 \mathrm{~s}^{75}$. The University as a whole was transforming itself, and this was part of the context of three research institutes, the MESA+ institute for nanotechnology, the Telematica Instituut for telematics applications (outside the university structure), and the CTIT institute for information science and information technology. All three faced opportunities and challenges, and to understand how these were addressed and what the outcomes were, one has to study the practice of academics taking up leadership and governance tasks in these research institutes. They offered spaces where distributed academic leadership played out. These institutes were also sites where on-going worldwide changes in research and innovation were visible, particularly because they were set up as centres of excellence and relevance, and developed their activities in this context.

\footnotetext{
${ }^{75}$ Transformations continue, but the paths have stabilized to some extent - until they open up again, which may actually be an issue now (see Section 8.5).
}

Distributed academic leadership in emergent research organisations

8. Conclusions 
The theme of this thesis, distributed academic leadership in emergent research organisations, is definitely important for research organisation facing open-ended challenges. But the questions are not just instrumental, indicating ways for such organisations to do well. I am finding out basic points about research organisations and leadership (and perhaps about organisations in general), viz. that formal structures and arrangements are at best part of the answer (and sometimes part of the problem), while distributed leadership co-evolving with organisational change is the basic process. Of course, there may be stabilisation and formalisation, and this may function more or less well. But even then, distributed leadership is there, and has to be recognised as also a resource for collective anticipation and learning, particularly when contexts change and the situation opens up.

Clearly, there is a need to overcome "heroic stories" of individual leadership as these are insufficient to understand the complexity of contemporary research organisations. There is also a need, however, to overcome simplistic expectations about networked, self-governing, possibly inter-organisational teams, and to avoid projecting ideologies of academic autonomy or democracy within organisations on the notion of distributed leadership. The road I have taken is to first try to understand distributed leadership better, at least for emergent research organisations.

In this concluding chapter I will start by looking back on my approach and conceptual framework, before going forward and outline the broader findings.

\subsection{Conceptual reflections}

My overall research approach stands in the tradition of contextual theories (Cohen, March \& Olsen, 1972; Quinn \& Rohrbaugh, 1983; Pettigrew, 1990), and relatedly, processual approaches, as hinted at by Bolden et al. (2008) and as strongly advised by Pettigrew (1990). The approach included participating, observing, and also reflecting, in retrospect, with actors who played a role at the time in retrospect. The eventual systematic data collection was informed by an elaborated conceptual model which built on literature, as well as the overall process perspective.

A distinctive feature of the conceptual model is that distributed leadership is not approached as a matter of personal style or effectiveness, but as a process of interactions between academic

Distributed academic leadership in emergent research organisations

8. Conclusions 
leaders, and resulting in stabilising of processes, routines, temporary structures and leadership arrangements.

Another feature is its focus on the dynamic context of academic research (nowadays including valorisation). Empirically, this is the domain of academic work at Dutch universities that allows academics to explore new ways of working, innovative and entrepreneurial approaches. The emerging Centres of Excellence and Relevance that have been studied are approached as part of processes, not as fixed structures and organisations.

A third particular feature of the conceptual model is that it includes a focus on transformation, specifically on pathways that shape, and are shaped by, distributed leadership, and introduces the notion of spaces in which distributed academic leadership can invent or re-invent itself and be productive. This notion was developed with the help of somewhat disparate literature, and turned out to be important to understand the co-evolution of distributed leadership and organisational change. This is further discussed in a separate section, Section 8.4.

Distributed leadership is becoming popular. In their critical appraisal prepared for the Leadership Foundation, Bolden et al. (2008) state that, in response to the growing pressure on academic leaders in the UK Higher Education system, "distributed leadership" threatens to become a normative and rhetorical notion, mobilising opposition to managerialism. This thesis is not an attempt to oppose "new public management" in the Dutch Higher Education system. It presents empirical evidence and theoretical reflections and develops a conceptual model which overcomes the old dichotomy between "management" and "leadership". Moreover, as the conceptual model specifies particular features of distributed academic leadership in organisational transformation, it helps organisation researchers and academic leaders to avoid being stuck in rhetorics ${ }^{76}$.

Given these features, the conceptual model has been developed in three related directions. First, it addresses the tensions and the attempts at balancing between what I called "contrasting dynamics" of organisational change in context. This notion is inspired by what Quinn \& Rohrbaugh (1983) called "competing values" that academic leaders live with, and a contrasting

\footnotetext{
${ }^{76}$ In a recent review of academic leadership literature for the British Leadership Foundation (Lumby, 2012) the same thrust is visible. In contrast to them, I am not limiting myself to interactions within the organisation. The organisations are in transformation, and leaders cross boundaries in their entrepreneurial activities.
}

Distributed academic leadership in emergent research organisations

8. Conclusions 
dynamics diagram, building on a diagram from Cameron et al. (2006) was created that could be helpful to map leadership activities in the cases (see Chapter 3). A key point is that, in contrast to most of the literature on leadership tasks and styles (excepting perhaps Cameron et al. 2006), the focus is not on characteristics of individuals but on activities. One implication is that one can trace changes over time in what is prominent in a group of academic leaders not as an effect of changing demography, but as a result of learning in a changing context.

The focus on activities allows further development of the notion of distributed leadership, particularly in relation to organisational change. This second direction of development of the model considered continuous interaction between formal and informal leadership activities, and distinguished different levels and their interactions. In Section 7.2, this part of the model was used to trace the dynamics of leadership and organisational change in the three cases. The interaction perspective is also visible in the challenge of balancing internal and external developments, a challenge that is highlighted by the increasingly important entrepreneurial activities. ${ }^{77}$ This happens through what the model calls contextual ambidextrous leadership, balancing contrasts in tasks and values through leadership activities, and not necessarily by creating structures and new boundaries, which would be structural ambidexterity.

The third direction of development of the model is to be more specific about the process approach, with its focus on organisational change processes and the patterns that emerge and sometimes stabilize. One element, implicit in the discussion of interactions between informal and formal, is how patterns in informal leadership can stabilize and lead to formalisation, highlighting good practices. It is an open question what sort of patterns will become visible, but for research organisations there are definitely three key sites of change and leadership: strategic programming, project development and business models. One can use a functional argument to argue that this is what research organisations in the present research and innovation landscape have to do, but the main point is they evolved together with distributed leadership arrangements. This opens the possibility that there might be particular and recurrent pathways in the co-evolution. This is actually the case, I can now claim, with the benefit of the cross-case analysis in Chapter 7.

\footnotetext{
${ }^{77}$ Explorative entrepreneurial leadership as the continuous search for opportunities beyond internal and external boundaries, that might include exploitative entrepreneurship, that is, the actual leadership engagement in exploitation of research results, as it shows in many forms of start-ups.
}

Distributed academic leadership in emergent research organisations 


\subsection{Distributed leadership and transformation}

The process approach, and the possibility of there being patterns that stabilise, and recurrent pathways, is a plausible general perspective. In this section, I will put it to a test by arguing that there are indeed such pathways. This was already intimated in the final section of Chapter 7.I claim, first, that there is a general trajectory of co-evolving sites of change and distributed leadership arrangements. Thus, I jump from three cases with their specificities to a generally occurring trajectory. Second, I reintroduce specificities, but in relation to the contexts of the cases, arguing that there are at least three ways (pathways) that Centres of Excellence and Relevance can develop in the present research and innovation landscape. Each of my cases exemplifies such a pathway.

In the first phase of the trajectory, the primary leadership arrangement is "strategic programming" in conjunction with "concerted leadership" practices. Identity building by individual leaders contributes to strategy articulation and programming, and vice versa. "Entrepreneurial leadership", the crossing internal and external boundaries, is important.

In a second phase, "converging project development" becomes the primary arrangement and mode of change. By then, it is crucial for academic leaders to deliver research activities that make a difference, in terms of societal relevance and scientific excellence. "Ambidextrous leadership" practices become predominant: in order to be effective, the interactions between exploration and exploitation need to be intensified.

The third phase is different in kind. A path is stabilized towards the end of the second phase, and arrangements and leadership activities can build on this to address specific challenges. One or another leadership arrangement may then be foregrounded, depending on how the challenge is perceived. New structural and organisational processes and entities occur that can sustain for some time, supported by "ambidextrous leadership" and "entrepreneurial leadership" activities. One new challenge could be that the limitations of being embedded in the university system come in sight, and new directions are sought, including "innovative business model development".

One can speculate about what might happen next. One is that the differentiation occurring in the third phase continues and leads to fragmentation and perhaps some splitting up. Whether this happens will also depend how much coherence has been built over time, in terms of

Distributed academic leadership in emergent research organisations

8. Conclusions 
identities, shared resources (like laboratory infrastructure) and the nature of the business model. the new phase of the centre of excellence and relevance might then be one of independence of the structures they grew up in, and in a sense, being able to stipulate their future. Rip (2011)called this possibility one where centres of excellence and relevance were bursting the seams of the modern research university.

As I noted already (in Section 7.5), the three-phase model reflects the general pattern of institutionalization of what starts out as new and uncertain. One might ask whether there are specifics patterns for research organisations. That may well be, but one then has to take the evolving research landscapes into account (compare Chapter 2). There are methodological issues here, starting with the claim that the present research and innovation landscape, given its nature and dynamics, affords certain avenues of development, which I provisionally label as strategic science, open innovation, mode-2 science (see Chapter 2). A concrete case, depending on its situation, can reflect, more or less, one of the three avenues of development. The second claim is that the three cases that I studied are instances of these avenues of development, so that they can be used to find out about the nature of of these avenues. Actually, my empirical claim is that it so happened that each of the three avenues is illustrated by one of the cases. Of course, the result of this exercise will be preliminary. Further work is necessary, on separating the specificities of the three institutes from the general pattern for each of the avenues, by including other cases, also in other countries than the Netherlands. The phenomenon of centres of excellence and relevance, a changing research and innovation landscape, is international (Gray and Boardman, 2010). A final consideration is that the pathways of the institutes are transformational in the sense that the institutes following them break new ground and stretch rules developed under earlier research regimes and their divisions of labour. On the one hand, they have to do so to adequately address the ongoing changes in the overall research landscape. On the other hand, their activities and their effects will contribute to changes, and in particular directions. The whole constellation of pathways, avenues and landscapes is dynamic.

\section{The strategic science pathway}

A number of elements and features of the MESA+ path can be identified as characteristic for a strategic science pathway. For more than ten years, the MESA+ institute, preceded by the

Distributed academic leadership in emergent research organisations 
institutes MESA and CMO has been the motor and model for innovation of research organisation at the University of Twente. During its starting years, 1989 till 1999, it stretched the research organisation regime of the University. MESA stimulated Deans and successive Boards of the University to develop new management rules and regulations and incentives. In its second phase, the configuration of thematic Strategic Research Orientations was defined and tested by MESA and later on adopted by other institutes, thus stretching the research management and research policy approach of UT. Throughout the development of the institute, in particular in the third episode starting in 2002, the ecology of related spin-off firms and other research and innovation partners became increasingly important. Such links, typical for strategic science, continued in the national level NanoNed R\&D programme, the set-up of which was heavily influenced by the MESA+ experience. Programmatic multi-partner approaches including fundamental research as well as high-tech SMEs, allowed this centre of excellence and relevance to emerge and flourish. Thus, there are good reasons to characterize the MESA+ path as a strategic science pathway. Conversely, we can take the features of the MESA+ path typical for a strategic science pathway, at least as a hypothesis for further research.

\section{The open innovation pathway}

The Telematica Instituut ( $\mathrm{TI}$ ), preceded by the Telematics Research Centre (TRC), has been a model of open innovation for many companies and universities. Since its model and governance structure were unprecedented in the Netherlands, it explicitly stretched the rules, bridging between research management cultures of universities and companies. In the second episode, when it became embedded in the new national innovation policy scheme of "Leading Technological Institutes", TI stretched this scheme in an ambidextrous move: where the others consciously limited themselves to a virtual network organisation, TI shaped, in a number of steps, a core body of academic researchers that were also trained as business developers and project leaders. In the third episode, TI became a programme creator at national level, projecting its best practices in open innovation on multi-partner research and innovation programmes, and in doing so, stretching the existing practices of one to one co-operation between companies and a university department towards consortia of (otherwise competing) companies and academic research groups, a marked feature of open innovation.

\section{The Mode-2 science pathway}

Distributed academic leadership in emergent research organisations 
The CTIT institute's mission, founded in 1994 complementary to the establishment of the TRC, was to bundle the efforts of research groups of seven Faculties, in response to challenges that asked for multi-disciplinary research, one key feature of Mode 2 science. It had roots an earlier collaboration between, researchers from areas like electrical engineering, information science and mathematics and broadened its scope further by including business administration, public administration, educational science. In the first episode, this is visible in the development of strategic programmes between research groups, in particular around key themes bridging telecommunication, information technology and educational science. At the time, the emerging field of "telematics and IT" was very promising. Indicative were the establishment, at the Twente science park, of R\&D labs by Ericsson, Lucent and KPN. In the second episode, CTIT continued to define itself as mission driven, including a strengthened focus on application areas as e-commerce and tele-learning - definitely research in the context of application, as Mode 2 science authors formulate it. In the third episode, CTIT in interaction with the firms it collaborated with, adopted the Strategic Research Orientations approach, linking the themes with national research and innovation programmes. In this national framework, CTIT created space for evolving new fields of research on the edge of IT, for instance overlapping with medical technology and science.

\subsection{Perspectives on spaces and distributed leadership}

Spaces, opening up (and also closing down) and/or created intentionally, are a general phenomenon, and an integral element of transformational processes. The concept is not primarily about physical space, it can be social or institutional space; actually, physical/material and social/institutional occur together (Rip \& Joly, 2012). In Chapter 2, I zoomed in on two kinds of spaces, protected activity spaces and so-called "learning space" because the latter phrase captures the nature of that space. In Chapter 2, the concept of "leadership learning space", encompassing elements from Argyris \& Schön (1996), Whitchurch (2008), and Rip \& Joly (2012), was characterized as "a space allowing for experimental role development", and thus linked to the key point that distributed leadership activities and roles are not given beforehand, but are tried out and articulated while reflecting in and on action. This requires a certain freedom, in the sense of protection against traditional structures, and a willingness to explore and stretch existing roles.

Distributed academic leadership in emergent research organisations 
The characterization, in Chapter 2, of protected spaces are spaces that allow for experimenting with new ways of organisation", has to be modified slightly in the light of what I encountered in the cases. The emphasis in the original characterization was on the function of the protected spaces, but in the instances of protected spaces in the cases, in particular the multi-party, multiannual research programmes the point is also that such a space is needed to do research and to experiment with ways to be productive (cf. also Rip and Schot, 2002, for a similar perspective, for technology development and innovation).

It is clear that protected spaces allow some learning about roles, so they are, to some extent, also learning spaces. Conversely, learning spaces as such will also enable learning within the protected spaces that are around. Sometimes, a learning space is made possible by, and builds upon, protected spaces that are oriented towards production, but allow experimenting and learning.

Spaces are open to the things they let happen within them, but they do structure the possibilities. One example is how protection, ensuring the continued non-interference, comes with requirements, including making sure that the overall legitimation of having such a protected space is met. So spaces are a form of meta-governance, the governance of governance.

In my perspective on distributed academic leadership, and as is visible in the cases, spaces emerge in and through the interactions between academic leaders, as well as through their intentional creation. This is informed by, often implicit, collective reflection. The structures that result have formal and informal components, and the whole process is definitely nonhierarchical. It is task oriented, and that is why the mapping of leadership roles with the help of the "contrasting dynamics" diagram (see Chapter 3) was important to capture the nature of the ongoing interactions.

In passing, I note that in all three case studies the initial agreement on themes and an outline of a research programme was not the end of interactions. The academics involved continued together, as it were a fellowship of travellers on an open-ended journey. Academic leaders may have started their interactions as ad hoc allies, but gradually became a "Schicksalsgemeinschaft", which implied an own social space. There was an element of identity building (for example, "We are from MESA+"), but also a focus on tasks - joint research work,

Distributed academic leadership in emergent research organisations 
planning and execution, acquiring funding, seeking new joint ventures - that had to address the changing research landscape. Thus, while there was institution building, the story is not just one of institution building, as institutional theories would have it. Nor is it about growth as such, in terms of scope and power. The meta-governance is a pattern of structuring but also dissolving spaces linked with distributed leadership arrangements. While centres of excellence and relevance can have hierarchical elements in their governance (up to reporting and quality assurance measures), their key feature, related to their survival in the world of strategic science, is the meta-governance pattern I just outlined. In a sense, such centres are learning spaces themselves.

What are the conditions for a productive learning space, for centres of excellence and relevance, and perhaps more generally? There must be a sense of opportunity, of shared challenges in the evolving research landscape, and of a "Schicksalgemeinschaft" in addition to the heterogeneous interests and struggles that will always be present. This is visible in all three cases. There must also be temporary, but multi-annual, protected spaces for explorative research and development, possibly in close interaction with exploitation, and interacting with the strategic process layer in these centres. This was very visible in all three cases. Thirdly, the dual character of transformational processes should be recognized. On the one hand, experience will accumulate, paths will emerge that can be built upon. This is the core of the three-phase model outlined in Section 8.3. On the other hand, one should not become prisoner of this learning by experience and interaction. There might be changes in the links between research groups and the wider world, and the wider world may be changing. This should lead to further experimenting rather than attempts to apply the existing leadership patterns and arrangements to the new situation. Entrepreneurial and ambidextrous activities are therefore important for leadership learning spaces because they can link to openings in the changing context.

Building on these general considerations, I can look again at the three sites where distributed leadership practices evolve. Strategic programming, converging project development, and innovative business model development were used as lenses to look at the cases, and then used in Chapter 7 to analyse overall dynamics. I can now consider how they can be done well, in terms of the learning that can and should occur. Of course, there are guidelines and handbooks.

Distributed academic leadership in emergent research organisations 
My point here is to draw lessons from what happened in the cases when viewed from my perspective on the role of distributed leadership.

Key features for the strategic programming arrangement include the importance of incremental and tentative planning, in the sense that a long term vision is being combined with adaptability to events and external changes, whether in line with the present vision or not. Relatedly, strategic planning has to be pro-active, informed by the evolving agendas of stakeholders in the science and innovation landscape, and occasionally trying to influence these agendas. Then, there is the importance of conjoining processes at different organisational levels via an informal network of distributed leadership. And the mutual translations between process levels, for example leadership translating on-going results from converging projects into strategy articulation, and strategic marketing of the organisation.

Converging innovative projects should stimulate multi-disciplinary co-operation, and engage different processual levels of a research organisation. There are overall requirements to be inviting and relevant for stakeholders in the science and innovation landscape; and to combine, in a productive way, academic excellence, organisational performance, social relevance. Protected spaces play an important role.

The quest for an innovative business model that can evolve in relation to changing circumstances can build on aspects of leadership that I have highlighted. Leadership is entrepreneurial in the sense that leaders continuously stretch the boundaries of the internal organisation and the science and innovation landscape. And ambidextrous, in the sense that leaders in an informal collective continuously create productive bonds between innovative and productive activities.

On this basis I can also add to the discussion of the phase model as involving an overall pattern of distributed leadership constellations, spaces and organisational change.

In the first phase, distributed leadership is loosely coupled, often having two or more core groups of 'promotors of innovation', which in the second phase stabilises in a top-down orchestrated leadership constellation, and in the third phase evolves into a pattern of collegial orchestration and, once differentiation occurs, new cores of distributed leaders, not limited to the own organisation but linked into inter-organisational networks. Strategic programming is the prominent mode of organisational change in the first phase, taken forward bycore groups of

Distributed academic leadership in emergent research organisations

8. Conclusions 
promoters. This constitutes a leadership learning space including reflection on their actions in emerging protected activity spaces. In the second phase strategic programming continues in an orchestrated leadership learning space that links the stabilising strategy to converging project development and creation of elements of a new business model. In the third phase the leadership learning space expands following the differentiation of protected activity spaces that can become mainstream. Coherence is possible through ambidextrous distributed leadership and broad and orchestrated strategic programming. Or core groups emerge of newly evolving distributed leadership constellations that develop their own path.

It is possible to go further and consider, not just a fourth phase in the evolution of a Centre of Excellence and Research, but a new kind of leadership learning spaces. Their experience with handling relevance can be used to contribute to overall societal agenda building with regard to Grand Challenges as these are pushed by the European Commission. Kuhlmann and Rip (2014) argued for such a broader approach, and Centres of Excellence and Relevance could play a strong role in it. It would help them to develop beyond the immediate goals of (one way) commercial valorisation, and create rich leadership learning spaces where academic leaders jointly with leaders in stakeholder groups, inquire and reflect-and-learn-on-the-job, with a view to create scientific and social value.

\subsection{Further perspectives}

In this final section, I will draw out further perspectives, starting with discussing further research, as usual in the academic tradition, and particularly in the concluding part of a PhD thesis. This will focus on distributed leadership linked to organisational change. But I will then broaden out by considering the role of Centres of Excellence and Relevance in the evolving research and innovation landscapes, still with organisational change and distributed leadership in the back of my mind. I can only discuss a few issues, to show the importance of this broader approach.

\section{Distributed leadership}

The emphasis on distributed leadership, interactions and tasks has been important to grasp the dynamics of developments in my cases. It did background questions of competences. There is quite some literature on this topic, including the later work of Cameron \& Quinn and others, whose competing values model I adopted to analyse patterns in distributed leadership. In my 
cases another feature is visible: the openings that occurred in the early nineties because of macro developments and the University of Twente's policy response, were seized by senior academics with particular competences enabling them to develop entrepreneurial leadership activities. They were around their fifties and identified with the approach and spirit of the University of Twente, a new style campus university that saw itself as an experiment. It came natural to the senior academics to be actively involved in the set-up and development of the centres of excellence and relevance. Thus, there was a generational effect in the pathways I reconstructed. This may not be the case, or not so emphatically, for centres in and around other universities. But they will be historically situated, also in terms of available competences. The distributed leadership may have other shapes, but the overall patterns remain the same.

This brief discussion shows interesting topics for further research on distributed leadership and emergent organisations. Further research can also be identified by considering relevant ongoing studies, and what they imply for further elaboration of my distributed academic leadership approach.

Defining the 'proper' constellations for distributed leadership, for its orchestrated development, is an interesting issue for further research. To overcome the romantic assumptions around the self-steering of loosely coupled temporary groups of professionals, an almost iconic belief of policy makers at the moment, we need to understand what new ways can be followed to develop dynamic and effective constellations. Based on my cases, there may be solutions in boundary spanning activities, in stabilising sites of change that can be orchestrated by distributed leadership. A complementary approach might focus at new competencies that are required to make distributed leadership constellations viable. Dijkstra has started a research programme on "personal leadership and innovation" among professionals, based on the approach he presented in his book on dispersed leadership, chosen as management book of the year 2012 (Dijkstra \& Feld, 2012). (Interestingly, he includes research on competences of students in his longitudinal study.) Similar research can be pursued on competences of individual academic leaders in the context of distributed leadership in emergent organisations. The Rathenau Institute's science system analysis division has been paying attention to dynamics of academic leadership in research groups (Van der Weijden, Verbree, Braam \& Van den Besselaar, 2009). Their focus is on researchers with a formalised management role and on

Distributed academic leadership in emergent research organisations 
network management, particularly in medical and pharmaceutical sciences (cf. also Verbree 2011a \& 2011b). One can locate these studies as looking at the more stabilized phase of the distributed academic leadership model (as outlined in Section 8.2 towards the end). Still, one can use these studies to raise questions about possible differences between sectors of science. In my case studies I did not find big differences between materials science, micro-systems and nanotechnology on the one hand (MESA+) and ICT and telematics on the other hand (CTIT, $T R C / T I)$. One can look at other sectors; agriculture would be interesting because of the transformations with respect to the earlier tradition of research and development.

The research programme of the Open University, headed by Kessels, on distributed leadership and professional spaces, focusing on leadership in primary and secondary education establishments, promises to be interesting because of the overlap in approach (Kessels, 2012). It will help us to see what might be specific to higher education and research in the analysis I offered in this thesis.

Finally, the approach I developed in this thesis appears to overlap with work in management studies and in science and technology studies.

One shared topic is the inherent duality of an organisation in a transformational context, and dynamic professional spaces that require balancing leadership (Fisscher et al., 2004). Another topic links up with ambidextrous leadership activities and "layered processual organisational innovation" (Fisscher, Nederweert et al., 2004). Rip (2012), in his essay on layers in the context of innovation journeys, introduces the aspect anticipatory coordination. He does not refer to distributed leadership, but does discuss open-ended approaches that may stabilize, as when he discusses how the future environment "is unknown but deemed to become more manageable thanks to forward looking co-ordination" (Rip, 2012, p. 164). Thus, I should, in my approach, explicitly add a forward-looking leadership activity pattern, not focusing on control, but focusing on collective forward steering and anticipation. Rip adds a further important point about agency: "when patterns and their shaping of innovation practices are emphasized, there is the question how much scope there still is for agency. (...) The modest version is that innovators can recognize patterns and take them into account so as to become more successful (...). In the case of anticipation, there is a dialectical relationship between projections of the future which must be sufficiently solid to base action on, and the possibility to choose actions that go against these projections." (ibidem, p. 166)

Distributed academic leadership in emergent research organisations 


\section{Research landscape changes and distributed leadership}

A background topic, but important, and not just as a historical question, is to reconstruct the dynamics of the emergence of Centres of Excellence and Relevance since the 1980s, driven by landscape changes and the responses to them, but then becoming occasions in their own right for further landscape changes. This should not be limited to the entities that are called 'Centre' or 'Institute'; there are other forms of combining excellence and relevance in an organisation. ${ }^{78}$ Such a reconstruction can now build on the historical reconstruction done for this PhD thesis. And it would allow a better diagnosis of the dynamics of the present situation.

While centres of excellence and relevance tend to have a strong international orientation, there are also local and regional links. The latter can be part of the mission of a research university, as was the case for the University of Twente. When founded in 1963, it was given the mission to act as a motor for innovation of the region. The University of Twente started to present itself as an entrepreneurial university in the late 1980s. Its particular efforts and achievements have since been noted by international forums (OECD, European Rectors Conference, European Consortium of Innovative Universities) and international researchers (Clark, 1998; Schutte \& Van der Sijde, 2000; Rip, 2002; Benneworth, Charles \& Madanipour, 2010).

What is happening now is a renewed interest in regional innovation systems, also internationally as when EU policy frameworks emphasize "smart regions". Regional innovation systems see themselves as competing internationally, and centres for excellence and relevance play an important role there, particularly when emerging technologies are concerned. Thus, relevance gets an international orientation as well. "Think global, act local" gets a new meaning.

Networking and public-private collaborations are important, and this will extend distributed academic leadership. Ambidextrous leadership activities were already covering public-private interactions, and further balancing becomes important: directly, between regional stakeholders and leadership domains, and indirectly, between the regional relevance and international competition as well as strategic science. In practice, as the case of MESA+ shows already, there

\footnotetext{
${ }^{78}$ An interesting, because unexpected example would be some of the institutes of the German Fraunhofer Gesellschaft in the 1990s (Kuhlmann et al. "Erfolgsfaktoren der wirtschaftsnahen Forschung", 1995, ch. 4. And Trischler \& Vom Bruch. Forschung für den Markt: Geschichte der Fraunhofer-Gesellschaft,1999).
}

Distributed academic leadership in emergent research organisations 
can be a division of labour within a centre, with some academic leaders focusing on research excellence, and others on regional and international relevance.

Thinking globally and acting locally implies further interest in valorisation of research and scholarship. This is a general trend, and while there are institutional arrangements like university transfer offices, the actual and somewhat productive practices are distributed valorisation. These are additional challenges for distributed academic leadership.

Compared to the strategic and thematic approach of "grand challenges", which mobilize new activities and arrangements in the European Union and internationally, the Dutch national science and innovation landscape seems to become less challenging. The amount of funding is not increasing, programmatic approaches are losing force being replaced by mixed arrangements that require industrial investments, or by generic tax measures that do not aim at specific innovation areas. Nevertheless, expectations and opportunities are high. Dutch research organisations belong to the top leagues, Dutch public opinion expects an active stand of academics in the solution of societal problems.

In many countries, "valorisation", the creation of social and economic value of research, has become an important issue. There appears to be a "valorisation paradox" however: in spite of the promises and expectations, value creation has not been very successful. Maybe we are looking in the wrong direction, wanting packaged impacts and explicit, formalised valorisation. Instead, we can consider "distributed valorisation" organised in inter-organisational learning spaces: thematic learning communities, each working in dynamic protected spaces that focus on topical issues, intertwined via distributed leadership networks with a public-private character. ${ }^{79}$ The new learning spaces can be used by academic leaders (as well as private organisation leaders, for that matter) to experiment, learn and further transform their ways of working. The challenge of further diversification in interaction with social actors will require institutional and career transformations as well, especially for the mobile workforce of postdocs and other nontenured research staff which bears the brunt of actual work on the new themes and their valorisation.

What this last discussion shows is not only that distributed academic leadership is important (and thus worthy of further attention and study), but also that it is embedded in institutions and

\footnotetext{
${ }^{79}$ This is also the thrust of Kuhlmann and Rip's (2014) argument that we noted already about how to address Grand Challenges. As they comment, there is overlap with the new interest in so-called tentative governance (Kuhlmann, $\mathrm{S}$., Stegmaier, P., Konrad, K., Dorbeck-Jung, B., 2012).
}

Distributed academic leadership in emergent research organisations 
part of broader developments and changes which have to be taken into account. It is a matter of opening of new perspectives. Academic leadership is called for nowadays, also to engage societal stakeholders, and to show (not just claim) to wider audience how scientific work can have an immediate value, and a long term value in adding to sustainable innovation systems (Lundval, 2007; Dutch Scientific Council for Government Policy, 2014).This not just a matter of leadership activities, but also of evolving identities. Generally, there is a renewed appreciation of professionalism and professional communities, for example in advice and other interactions with policy, and in a perspective of international cooperation (Sennet, 2012). ${ }^{80}$ The new academic leadership will take part in this general movement.

\section{Coda}

Academics who take up leadership in a context of change face opportunities and hurdles, struggles and challenges. They are 'knowledgeable agents' but also 'responsible agents'. In the cases presented in this thesis, academic researchers, individuals who have to perform and live up to many high expectations, found ways to cooperate and co-create their futures. This will continue, and needs to continue. Learning, increasingly embedded in wider societal developments, are important to explore openings, to craft joint opportunities, to experiment, and while jointly reflecting in action, bringing forward the best that academic professionals can offer. The present thesis contributes to this reflection. The understanding of the processes of coevolving organisational change and distributed leadership is important to overcome a too exclusive focus on immediate and short-term problems. This understanding builds on what I have learned from how the academic leaders in the cases were learning about it, through experience and reflection. I was privileged to be a participant observer in these processes.

\footnotetext{
${ }^{80}$ In addition, professionalism is becoming "porous (cf. new modes of knowledge production)", includes a variety of actors, all 'knowledgeable agents' but with different knowledges. The prefix "academic" in academic leadership will be less exclusive in character.
}

Distributed academic leadership in emergent research organisations 


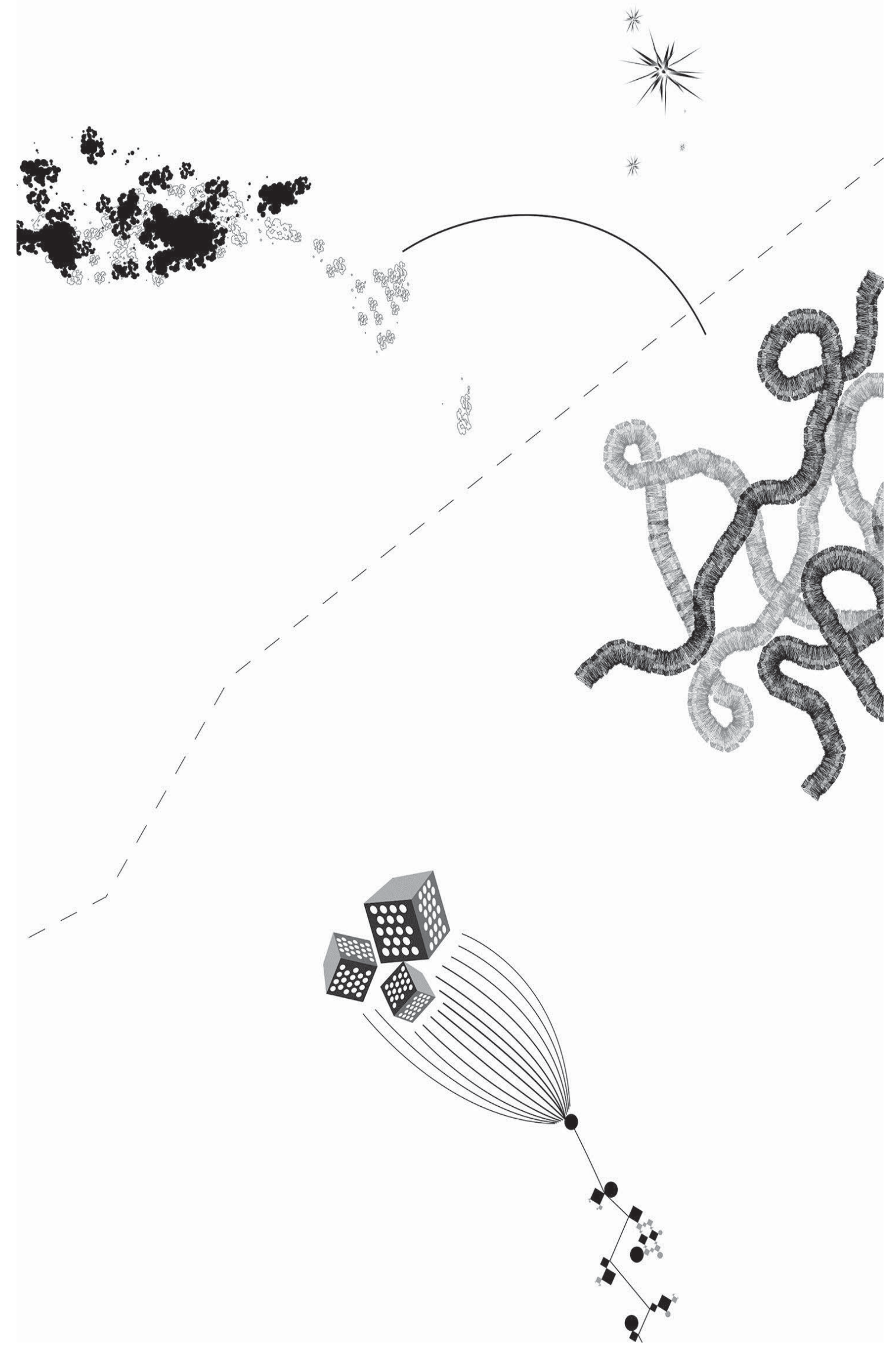




\section{Samenvatting}

Academisch leiderschap, in dit proefschrift met betrekking tot wetenschappelijk onderzoek en de organisatie daarvan, speelt zich af in een onderzoeklandschap dat voortdurend in beweging is. Beleidsinterventies spelen een rol, maar minstens zo belangrijk zijn algemene lange-termijn ontwikkelingen die tot transformaties in het onderzoek en innovatielandschap leiden. Onderzoeksorganisaties zoals universiteiten reageren en kunnen proactief zijn waardoor bepaalde ontwikkelingen zoals bijvoorbeeld globalisering versterkt worden. Onderzoeksorganisaties zijn zelf in transformatie, en doorlopen wat ik zal noemen transformatie-paden.

Academisch leiderschap ontwikkelt zich in de praktijk en wordt beïnvloed door de overall transformaties, terwijl leidinggevende academici zelf mede vorm geven aan transformatiepaden. Academici streven naar strategisch inzicht in nationale en internationale netwerken waarin in toenemende mate maatschappelijke partners een rol spelen. Zij overwegen welke richtingen in te slaan, en nemen actief deel in coalities en arrangementen die zelf in de praktijk van leiderschap evolueren. Leiderschapspraktijken en organisatieverandering beïnvloeden elkaar wederzijds.

In dit proefschrift staat het gedistribueerde karakter van leiderschapspraktijken centraal: verdeeld over academici en verspreid in de tijd en over sociale ruimtes. De aandacht is dus niet gericht op individuele kenmerken bevorderlijk voor leiderschap, maar op leiderschapactiviteitenpatronen waarin meerdere academici een rol spelen en welke zich ontwikkelen in interactie met organisatieverandering en organisatieleren. Er zijn pogingen de complexiteit van de transformaties te reduceren zonder deze te ontkennen, onder andere door de ambiguïteiten van transformatie te adresseren. Dit is een ingang om belangrijke kenmerken van leiderschapactiviteitenpatronen te identificeren.

De complexiteit van de transformaties is zichtbaar in het Europese hoger onderwijs landschap en universiteiten "in transitie" sinds de jaren zestig, o.a. door grotere autonomie (in het Nederlandse hoger onderwijs systeem) en differentiatie. Tegelijkertijd zijn er transformationele ontwikkelingen in wetenschapsdomeinen, met name emergente gebieden als nanotechnologie, IT en open systemen, bio-science en biotechnologie, welke leiden tot multidisciplinaire 'fusie' gebieden van onderzoek en innovatie. In tandem ontstond een nieuw soort researchorganisatie,

Distributed academic leadership in emergent research organisations Samenvatting 
binnen of buiten universiteiten, die excellentie en relevantie van onderzoek combineert - als het ware een nieuwe species in het onderzoeksecosysteem. In dit soort nieuwe researchorganisaties zijn bestaande formele leiderschapspatronen onvoldoende en worden de uitdagingen opgepakt door gedistribueerd academisch leiderschap. Het zijn plekken waar evoluerend academisch leiderschap bestudeerd kan worden.

De Universiteit Twente is een goede locatie voor dergelijke studies. In de jaren tachtig werd deze universiteit internationaal bekend als een "ondernemende" en "innovatieve" universiteit, een koploper van de "ondernemende universiteiten" in Europa (Clark, 1998). In de periode van midden-jaren tachtig en midden-jaren tweeduizend, vond een aantal initiatieven plaats zowel in de organisatorische vernieuwing van onderwijs, onderzoek en innovatie, als in de bottom-up ontwikkeling van informele netwerken van gedistribueerd academisch leiderschap. Dit was niet uniek voor Twente, maar wel expliciet gethematiseerd, zodat de locatie een goede basis vormt voor de studie van gedistribueerd academisch leiderschap in emergente onderzoeksorganisaties.

Dit proefschrift is een lange-termijn studie (vijftien jaar, circa 1990-2005) in de recente geschiedenis van transformaties in het onderzoekslandschap, op basis van drie casestudies van emergente research-organisaties op de terreinen van nanotechnologie, ICT en Open Systemen, gerelateerd aan de Universiteit Twente. De casestudies zijn gebaseerd op interviews met actoren, archiefonderzoek in de betrokken onderzoekinstituten en de Universiteit Twente, en eigen observaties als een waarnemende deelnemer in research-organisaties in de afgelopen dertig jaar. Naast mijn onmiddellijke taken als staflid in de universiteiten van Twente en Dortmund, in het Telematica Instituut en als secretaris van het European Consortium of Innovative Universities (ECIU) dacht ik na over wat er gebeurde en probeerde patronen te begrijpen.

In de eerste drie hoofdstukken van het proefschrift worden context en thematiek geïntroduceerd, een conceptueel model ontwikkeld voor organisatieverandering, gedistribueerd academisch leiderschap en lerende organisaties, en verder geoperationaliseerd in het hoofdstuk

Distributed academic leadership in emergent research organisations Samenvatting 
over de onderzoeksopzet. Het conceptuele model kent een drietal onderscheidende kenmerken:

- organisatieverandering wordt benaderd als een proces van "contrasterende dynamieken";

- de focus ligt niet bij competenties van leiders, maar bij leiderschapsactiviteiten die in de praktijk ontstaan, de gedistribueerde leiderschapspraktijk;

- in de langjarige patroonanalyse van gedistribueerde leiderschapspraktijken staan organisatieleerprocessen centraal.

De verzameling van empirische gegevens heeft een focus op informele, ondernemende en ambidextere leiderschap-constellaties in emergente researchorganisaties. Hoofdstukken 4, 5 en 6 presenteren de drie case studies van onderzoekinstituten: het MESA+ Instituut voor Nanotechnologie (oorspronkelijk MESA, gericht op microsysteemtechnologie), CTIT, Centrum voor Telematica en Informatietechnologie, beide in de Universiteit Twente, en TI, Telematica Instituut, oorspronkelijk TRC, Telematics Research Centre, met een sterke band met de Universiteit Twente.

Elk case hoofdstuk begint met de specifieke context van de casus en de details van gegevensverzameling. Elke casus is ingedeeld in drie episodes die de samenhangende ontwikkelingen in een bepaalde periode presenteren. De geschiedenis van de organisatorische ontwikkelingen en leidersschapspraktijken is op zich interessant, en levert de opmaat tot analyse. Leiderschapsarrangementen worden getraceerd voor strategische programmering van onderzoek, in interactie met ontwikkeling van convergerende projecten (die verbindende thema's concretiseren in onderzoekprojecten) en ontwikkeling van nieuwe business modellen (waarin condities voor werkorganisatie, financiering en loopbaanontwikkeling worden ontwikkeld die zich niet houden aan wat binnen het universitaire bestel gebruikelijk is). In de slotparagraaf van elk case hoofdstuk wordt kort geschetst hoe de ontwikkeling van het onderzoeksinstituut verder verliep, waarna een eerste analyse van de casus gegeven wordt, als voorbereiding op de overall analyse in hoofdstuk 7.

Distributed academic leadership in emergent research organisations Samenvatting 
In hoofdstuk 7 wordt eerst een overzicht gegeven van de cases op basis van de sleutel-termen in het conceptuele model. Daardoor wordt duidelijk dat er bepaalde patronen zijn die in hoofdstuk 8 verder besproken worden in de vorm van algemene bevindingen en conclusies.

Ten eerste dat er een nieuwe proceslaag van gedistribueerde academische leiderschapsactiviteiten ontstaat in de universitaire organisatie: in een intermediaire laag tussen onderzoekinstituten, faculteiten en het centrale bestuur, concretiserend in tijdelijke leiderschapsarrangementen, al dan niet gekoppeld aan tijdelijke formele management posities en rollen.

Ten tweede is duidelijk dat gedistribueerde leiderschapsactiviteiten tot op zekere hoogte georkestreerd worden. Dat gebeurt nadrukkelijk en top down in het Telematica Instituut. Er is ook gedelegeerde orkestratie, vanuit enkele senior academici, veelal met een formele managementspositie. Dat is met name zichtbaar in CTIT. Horizontale, collegiale orkestratie is zichtbaar in de eerste fase van CTIT, en in MESA+.

Ten derde lijkt er een patroon in de lerende organisatie-ontwikkeling te zijn waarin specifieke gedistribueerde leiderschapspraktijken evolueren en institutionalisering optreedt. Er zijn drie fasen te onderscheiden die in de case studies elk drie tot vijf jaren besloegen.

- Een eerste fase waarin ondernemende leiderschapspraktijken centraal staan, waarin geëxperimenteerd wordt met nieuwe organisatievormen en werkwijzen. Leidinggevende academici wordt de - beperkte - vrijheid gegund en/of verwerven deze om te kunnen experimenteren, als het ware in beschermde sociale ruimtes. In deze fase ontstaan met name constellaties van bottom-up gedistribueerde leiderschapspraktijken.

- Een tweede fase waarin veranderingsprocessen stabiliseren. Bij deze stabilisatie spelen constellaties van top down georkestreerde leiderschapspraktijken een rol en worden verbindingen gelegd, eerder gekarakteriseerd als ambidextere leiderschapsactiviteiten die exploratie en exploitatie in balans brengen door nieuwe werkpraktijken te ontwikkelen. Leidinggevenden kunnen gezamenlijk reflecteren en anticiperen (double-loop learning).

- Een derde fase bouwt voort op min of meer gestabiliseerde praktijken en arrangementen door specifieke ontwikkelingen passend bij nieuwe situaties en domeinen, hetgeen sociologisch gezien een differentiatie-proces is.

De drie fasen zijn in elk van de casussen zichtbaar. Verschillen in de situationele ontwikkeling zijn te karakteriseren als strategic science (MESA+), open innovation (Telematica Instituut), en

Distributed academic leadership in emergent research organisations Samenvatting 
mode-2 knowledge production (CTIT). In het slothoofdstuk werp ik de vraag op of er sprake is van een zekere mate van herhaling van deze fasen of veeleer van een nieuw patroon in de context van nieuwe business modellen. Spanningen tussen de voortdurende groei en diversificatie van emergente research organisaties en het universitair systeem waarin ze functioneren, beperkt een verdere groei van nieuwe modellen of stimuleert leidinggevende academici om organisatie overstijgende initiatieven te ontwikkelen, die kunnen leiden tot specialisatie en differentiatie en daarmee het in toenemende mate "poreuze universitair systeem" transformeren.

De dynamiek van stabilisatie, opening en differentiatie/fragmentatie wordt gedreven door de gedistribueerde besturing en het grenzenwerk in informele, ondernemende en ambidextere leiderschapsactiviteiten. Belangrijk is de co-evolutie van arrangementen en leiderschap-leren door reflectie en anticipatie in tijdelijke collectieve sociale ruimtes, veelal praktijk- en thema gebonden, zoals min of meer gestructureerde gemeenschappen rond de besturing van een meerjarig multi-partner research programma, dynamische entiteiten die veelal ontstaan als bondgenootschappen en gaandeweg evolueren naar "Schicksalgemeinschaften".

Leidinggevende academici slagen er kennelijk in om samen te werken en gezamenlijk toekomsten te creëren, terwijl ze moeten voldoen aan hoge individuele prestatie-eisen en verwachtingen. Het begrijpen van de processen van co-evolutie van organisatieverandering en gedistribueerde leiderschapspraktijken is belangrijk om een exclusieve focus op onmiddellijke en korte termijn problemen te overstijgen. Hierdoor wordt een zekere mate van meta-besturing mogelijk waarin tijdelijke constellaties van gedistribueerd professioneel leiderschap centraal staan.

Distributed academic leadership in emergent research organisations Samenvatting 


\section{By way of acknowledgement}

As an observing participant among academics who were, in the nineties, shaping their own worlds of working I was inspired to set out on a journey of my own. This 'Seven years to Tibet' became a longer journey. It took me past many beautiful views and had me face many up-hill struggles. I was fortunate to encounter other travellers, not least my supervisors. Also, an upslope forces a traveller to slow his pace, allowing him to think and reflect, and occasionally rest and look back to see patterns.

"Gauß kam auf den Zufall zu sprechen, den Feind allen Wissens, den er immer habe besiegen wollen. Aus der Nähe betrachtet, sehe man hinter jedem Ereignis die unendliche Feinheit des Kausalgewebes. Trete man weit genug zurück, offenbarten sich die großen Muster. Freiheit und Zufall seien eine Frage der mittleren Entfernung, eine Sache des Abstands..."

Daniel Kehlmann, Die Vermessung der Welt: Interpretation

A balance evolved: on the one hand, travelling with the actors on their own journeys as academics performing leadership roles in transformational situations, and observing from closeby. On the other hand, reflecting and, as a distantiated analyst, linking my findings with theoretical concepts to enhance their scope. My many talks with foreign colleagues in particular at the time that I worked among friends at the University of Dortmund and in universities in South-Africa, deepened my reflections -- "eine Sache des Abstands".

Many of the academic leaders with whom I interacted continue their journeys, and new generations of academics have entered into leadership practices in contexts in transformation. They may see the immediate obstacles and struggles, and perhaps appreciate the organisational learning that occurs and the structuring in distributed leadership processes. Thus, reading my book, academics can find theoretical and practical insights offered from the vantage point of my own practical and analytical journey. A resting place as it were, where they can appreciate their own leadership journey, before they continue on their way.

Distributed academic leadership in emergent research organisations By way of acknowledgement 
During my journey of more than ten years, as an observing participant and as an analyst, I was fortunate to meet many people that were prepared to share their insights and their experiences. I thank them all, and I mention in particular my colleagues and former colleagues at the University of Twente, the University of Dortmund, the Telematica Instituut, and the BMC Group.

I owe many thanks to my supervisors Arie Rip, Olaf Fisscher and, at a later stage, Stefan Kuhlmann for their excellent guidance as advisors on my journey; an example of excellent distributed academic co-operation.

This is also the place to thank in particular the colleagues from the STePS department for their companionship, even during weekends and holidays; a familiar, welcoming and stimulating place for the last ten years. A space of personal growth and transformation which actually started more than thirty years ago, as my first job at the University of Twente was located in FWT, the group that preceded STePS, together with the Technology Development Group.

I also deeply appreciate, but in another 'chapter of life', friends and of course my family without whom this endeavour would have been less colourful.

"A book should be an axe to chop open the frozen sea inside us." J.M. Coetzee, Summertime

Writing a book about changes, and in doing so, being part of them, is a balancing act in itself. It forces the author to fix the changes in text on paper, imprisoning them, while the aim is to "chop open" what perhaps seems frozen. I see change, development, and struggle, everywhere. A book, and definitely a dissertation, can only partially represent the fluidity of reality, its multidimensionality and the flexibility of living that I strive to understand and explore. It is perhaps different when writing a dissertation in your late twenties: on the threshold of new challenges and perspectives, and as an entrance ticket to a new academic identity. For me, working on the dissertation research and writing this book gave me a lot of joy, an incentive to study and read.

Distributed academic leadership in emergent research organisations By way of acknowledgement 
But it was a challenge too, to create "an axe", as Coetzee has it, now to open my observations of academic life that are stored in my "frozen sea" of memories and notes that condensed while, as a searcher, I was travelling in parallel spaces of work, intellectual interests, and spiritual drivers. Writing this book suits my personal journey as a sharer, a networker, practising knowledge and power sharing in order to support learning and create niches that help innovative leaders in opening up social systems and accelerate learning, so as to improve quality of life.

"Per aspera ad astra"

(on difficult trails towards the stars)

My professional and personal journeys do not end here. But the book creates a resting point from which I can look back and appreciate what has happened. I hope that others find some inspiration in this book before they move on.

Distributed academic leadership in emergent research organisations

By way of acknowledgement 


\section{References}

Adviesraad voor het Wetenschaps- en Technologiebeleid (2010). Kennis plaatsen. Onderzoeksinstituten in een veranderende omgeving. Rijswijk: Quantes.

Ancona, D., Malone, T.W., Orlikowski, W.J. \& Senge, P.M (2007). In praise of the incomplete leader. Harvard Business Review, 85(2), 92-100.

Argyris, C. \& Schön, D. (1996). Organisational learning II: Theory, method and practice. Reading, MA: Addison-Wesley, XXIX.

Arnold, E., Deuten, J. \& Van Giessel, J. (2004). An International Review of Competence Centre Programmes. Amsterdam: Technopolis Group.

Benneworth, P. S., Charles, D. R. and Madanipour, A. (2010) Building Localized Interactions Between Universities and Cities Through University Spatial Development. European Planning Studies, 18, 1611-29.

Bennet, N., Wise, C., Woods, P.A. \& Harvey, J.A. (2003). Distributed leadership: A Review of Literature. National College for School Leadership. The Open University. Retrieved from http://oro.open.ac.uk/8534/

Benz, A. (2007). Governance in connected arenas - Political science analysis of coordination and control in complex rule systems. In D. Jansen (Ed.) New forms of governance in research organisations. From disciplinary theories towards interfaces and integration (pp. 1-22). Heidelberg, Germany: Springer.

Birkinshaw, J. \& Gibson, C. (2004). Building Ambidexterity Into an Organisation. MIT Sloan Management Review, 45(4), 47-55.

Blank, S. (2013). Why the lean start-up changes everything. Harvard Business Review, May 2013, p. 3-9.

Blaschke, S., Frost, J. \& Hattke, F. (2014). Towards a Micro-Foundation of Leadership, Governance, and Management in Universities. Higher Education.

Boal, K. \& Hooijberg, R. (2000). Strategic leadership research: moving on. Leadership Quarterly, 11(4), 515-549.

Boer de, H., Huisman, J., Klemperer, A., Meulen van der, B., Neave, G., Theisens, H., Wende van der, M. (2002). Academia in the 21st century: an analysis of trends and perspectives in higher education and research. (AWT-Achtergrondstudie 28). The Hague: Adviesraad voor het Wetenschaps- en Technologiebeleid. ISBN 9789077005125

Distributed academic leadership in emergent research organisations References 
Boonstra, J.J. (2000). Lopen over water. Over dynamiek van organiseren, vernieuwen en leren. Inaugurele rede uitgesproken bij het aanvaarden van het ambt bijzonder hoogleraar (10 februari 2000). Amsterdam: Universiteit van Amsterdam, Vossiuspers AUP.

Bolden, R., Petrov, G. \& Gosling, J. (2008). Developing Collective Leadership in Higher Education: Final Report. London: Leadership Foundation for Higher Education.

Bradshaw, P. \& Fredette, C. (2009). Academic Governance of Universities. Journal of Management Inquiry, 18(2), 123-133.

Bryman, A. (2008). Effective leadership in higher education: a literature review. Studies in Higher Education, 32(6), 693-710. DOI: 10.1080/03075070701685114

Burgelman, R. (1983). A process model of internal corporate venturing in the diversified major firm. Administrative Science Quarterly, 28(2), 223-244.

Burgelman, R. \& Grove, A. (1996). Strategic dissonance. California Management Review, 38(2), 8-29.

Burnes, B. (2009). Managing change: a strategic approach to organisational dynamics. FT Prentice Hall.

Cameron, K., Quinn, R. , DeGraff, J. \& Thakor, A. (2006). Competing values leadership: creating value in organisations. Edward Elgar Publishing.

Chesbrough, H.W. (2003). Open Innovation: the new imperative for creating and profiting of technology. Boston: Harvard Business School Press.

Clark, B.R. (1998). Creating Entrepreneurial Universities: Organisational Pathways of Transformation. Oxford: Pergamon.

Clark, B.R. (2001). The Entrepreneurial University: New Foundations for Collegiality, Autonomy, and Achievement. Higher Education Management, 13(2), 9-24.

Clark, B.R. (2003). Sustaining change in universities. Tertiary Education and Management, 9, 99116.

Cohen, M.D., March, J.G. \& Olsen, J.P. (1972). A garbage can model of organisational choice. Administrative Science Quarterly, 17(1), 1-25.

David, P.A. (2007). Path dependence. A foundational concept for historical social science. The journal of historical economics and econometric history, 1(2), 91-114.

De Weert, E. (2007). National perspectives: The Netherlands. In J. Forest \& P. Altbach (eds.), International Handbook of Higher Education (pp. 899-918). Dordrecht, The Netherlands: Springer.

Distributed academic leadership in emergent research organisations References 
Dijkstra, J. \& Feld, P-P. (2012). Gedeeld leiderschap. Veerkracht door nieuwe vormen van samenwerken, organiseren, leren en leiderschap. Assen: Van Gorcum.

Dinh, J.E., Lord, R., Garnder, W., Meuser, J., Liden, R.C. \& Hu, J. (2014). Leadership theory and research in the new millennium: Current theoretical trends and changing perspectives. The Leadership Quarterly, 25(1), 36-62.

Duncker. E. (1998). Multidisciplinary Research at the University of Twente. The Challenges of Heterogeneous Cooperation. Enschede: Twente University Press.

Dutch Scientific Council for Government Policy (2014). Naar een lerende economie. Investeren in het verdienvermogen van Nederland (WRR-rapport nr. 90). Amsterdam: University Press.

Enders, J. \& E. de Weert (2009). The Changing Face of Academic Life: Analytical and Comparative Perspectives. Palgrave Macmillan.

Etzkowitz, H. (2003). Research groups as 'quasi-firms': the invention of the entrepreneurial university. Research Policy, 32(1), 109-121.

Evans, L., Homer, M. \& Rayner, S. (2012). Academic leadership from professors in the UK universities: the perspective of 'the led'. Paper presented at the international conference Changing Conditions and Changing Approaches of Academic Work, Seminaris Hotel, Berlin, June 4-6th, 2012.

Ferrary, M. (2011). Specialized organisations and ambidextrous clusters in the open innovation paradigm. European Management Journal, 29(3), 181- 192.

Fichter, K. (2009). Innovation communities: the role of networks of promoters in Open Innovation. R\&D Management, 39(4).

Fisscher, O.A.M., Van Looy, B., De Weerd-Nederhof, P. \& Debackere, K. (2004). Organisatie van innovatie: een radicale, gelaagde procesbenadering. In P.C. de Weerd-Nederhof, B. Van Looy \& K. Visscher (Eds.) Innovatie(f) organiseren (pp. 121-142). Deventer: Kluwer.

Fogelberg, H. \& Lundqvist, M. (2012). Integration of academic and entrepreneurial roles: The case of nanotechnology research at Chalmers University of Technology. Science \& Public Policy, 40(1), 127,139.

Fullan, M. (2005). Professional Learning Communities Writ Large. In R. DuFour, R. Eaker (Eds.), On Common Ground: The Power of Professional Learning Communities (pp. 209-223). Bloomington, Indiana: National Education Service.

Garud R. \& Karnøe, P. (2004) "Distributed agency and interactive emergence". In S.W. Floyd, J. Roos, C.D. Jacobs \& F.W. Kellermanns (Eds.) Innovating Strategy Process (pp. 88-96). Hoboken, New Jersey: Blackwell Publishers.

Distributed academic leadership in emergent research organisations References 
Garud, R., Hardy, C. \& Maguire, S. (2007). Institutional Entrepreneurship as Embedded agency: An Introduction to the Special Issue. Organisation Studies, 28(7), 957-969.

Garud, R. \& Karnoe, P. (2001). Path dependence and creation. Lawrence Erlbaum Associates Publishers.

Gibbons, M., Limoges, C., Nowotny, H., Schwartzman, S., Scott, P. \& Trow, M. (1994). The New Production of Knowledge. The dynamics of science and research in contemporary societies. London: Sage.

Giddens, A. (1984). The constitution of society. Outline of the Theory of Structuration. Cambridge: Polity Press.

Grande, E, Jansen, D., Jarren, O., Rip, A., Schimank, U. \& Weingart, P. (2013). Neue governance der Wissenschaft. Reorganisation, externe Anforderungen, Medialisierung. Transcript Science Studies, 8 October 2013.

Gray, D., Boardman, C. \& Rivers, D. (2010). The new science and engineering management: cooperative research centres as intermediary organisations for government policies and industry strategies. In D. Gray, C. Boardman \& D. Rivers (eds.), Cooperative Research Centers (pp. 3-36). Heidelberg, Germany: Springer.

Gronn, P. (2002). Distributed leadership as a unit of analysis. The Leadership Quarterly, 13(4), 423-451. doi:10.1016/S1048-9843(02)00120-0

Gronn, P. (2010). Leadership: its genealogy, configuration and trajectory. Journal of Educational Administration and History, 42(4), 405-435. DOI: 10.1080/00220620.2010.492959

Hattke, F., Blaschke, S., \& Frost, J. (2014). Governance Logics in Universities - Organisational Change as Oscillating Conversations. In A. Pettigrew, E. Cornuel, \& U. Hommel (Eds.), The Institutional Development of Business Schools. Oxford: Oxford University Press.

Hauschildt, J. \& Kirchmann, E. (2001). Teamwork for innovation, the 'troika of promoters'. R\&D Management, 31(1), 41-50.

Hood, C. \& Peters, G. (2004). The middle aging of new public management: into the age of paradox? Journal of Public Administration Research and Theory, 14, 267-282.

Hoppe, R. (2002). Van flipperkast naar grensverkeer. Veranderde visies op de relatie tussen wetenschap en beleid (AWT-achtergrondstudie nr. 25). Den Haag: Adviesraad voor het Wetenschaps- en Technologiebeleid.

Hoppe, R. (2010). From 'knowledge use' towards 'boundary work'. Sketch of an emerging new agenda for inquiry into science-policy interaction. In R. in 't Veld (Ed.), Knowledge democracy: consequences for science, politics, and media (pp. 169-186). Heidelberg, Germany: Springer.

Distributed academic leadership in emergent research organisations References 
Horta, H., Huisman, J. \& Heitor, M. (2008). Does competitive research funding encourage diversity in higher education?. Science \& Public Policy, 35(3), 146-158. DOI:

10.3152/030234208X299044.

Jackson, D. (2003). Distributed leadership, the space between the pebbles in a jar. National College of School Leadership, Cranfield, UK.

Kellog, K.C., Orlikowski, J.W. \& Yates, J. (2006). Life in the trading zone: structuring coordination across boundaries in post bureaucratic organisations. Organisation Science, 17(1), 22-44.

Kessels, J.W.M. (2012). Leiderschapspraktijken in een professionele ruimte. Inaugurele rede uitgesproken bij het aanvaarden van het ambt hoogleraar (30 maart 2012). Open Universiteit: Heerlen.

Kets de Vries, M.F.R. (2001). The Leadership Mystique: A User's Manual for the Human Enterprise. London: Financial Times Prentice Hall.

Kohler-Koch, B. \& Edler, J. (1998). Ideendiskurs und Vergemeinschaftung: Erschließung transnationaler Räume durch europäisches Regieren. In B. Kohler-Koch (Ed.), Regieren in entgrenzten Räumen (pp. 167-206) Politische Vierteljahresschrift Sonderhefte (29). Springer VS Verlag für Sozialwissenschaften. doi:10.1007/978-3-663-01337-2_8

Konradt, U. (2011). The Dispersed Leadership Theory in Teams: Model and Empirical Evidence. Institute of Psychology (Working paper 2011:11). Kiel, Germany: Christian-AlbrechtsUniversity. Retrieved from http://www. http://www.unikiel.de/psychologie/AOM/index.php/reports.html.

Kuhlmann, S. \& Holland, D. (1995). Erfolgsfaktoren und Leistungskriterien für die wirtschaftsnahe Forschung. Heidelberg, Germany: Springer.

Kuhlmann, S. et al. (1999). Improving distributed intelligence in complex innovation systems. Final report of the Advanced Science \& Technology Policy Planning Network (ASTPP); a thematic network of the Targeted Socio-Economic Research Programme (TSER). Karlsruhe: Fraunhofer Institute Systems and Innovation Research.

Kuhlmann, S. (2007). Governance of Research - Nine Comments on Arthur Benz. In D. Jansen (Ed.) New forms of governance in research organisations. Disciplinary approaches, interfaces, and integration (pp. 23-26). Heidelberg, Germany: Springer.

Kuhlmann, S., Stegmaier, P., Konrad, K., Dorbeck-Jung, B. (2012). Tentative GovernanceConceptual Reflections and Impetus for Contributors to a planned Special Issue of Research Policy on "Getting hold of a moving target-the tentative governance of emerging science and technology".

Kuhlmann, S. \& Rip, A. (2014). The challenge of addressing Grand Challenges. Retrieved from the European Research and Innovation Area Board http://ec.europa.eu/research/innovationunion/pdf/expert-groups/The_challenge_of_addressing_Grand_Challenges.pdf

Distributed academic leadership in emergent research organisations References 
Leithwood, K., Jantzi, D., Earl, L., Watson, N., Levin, B. \& Fullan, M. (2004). Strategic leadership for large-scale reform: the case of England's national literacy and numeracy strategy. School Leadership \& Management, 24(1), 57-79. DOI: 10.1080/1363243042000172822

Leisyte, L. \& Enders, J. (2011). Understanding knowledge disclosure of life scientists: a question of contextual and organisational ambidexterity? Paper for the RESUP Conference, 27-29 January 2011.

Liyanaga, S. \& Mitchell, H. (1993). Organisational management of Australian Cooperative Centres. Technology Analysis \& Strategic Management, 5(1), 3-14.

Lumby, J. (2012). What do we know about leadership in higher education? (Review paper). London: Leadership Foundation for Higher Education.

Lundval, B.-Å. (2007). National innovation systems - Analytical concept and development tool. Industry and Innovation, 14(1), 95-119.

Meulen, B. van der \& Rip, A. (1994). Research institutes in transition. Delft: Eburon.

Middlehurst, R. (2004). Changing internal governance: A Discussion of leadership roles and management structures in UK universities. Higher Education Quarterly, 58(4), 258-279.

Müller-Böling, D. \& Fedrowitz, J. (1998). Leitungsstrukturen für autonome Hochschulen: Verantwortung - Rechenschaft - Entscheidungsfähigkeit. Gütersloh: Verl. Bertelsmann Stiftung.

Müller-Böling, D. (2000). Die entfesselte Hochschule. Gütersloh: Verl. Bertelsmann Stiftung.

Nonaka, I. \& Takeuchi, H. (1995). The knowledge creating company: how Japanese companies create the dynamics of innovation, New York: Oxford University Press.

Nooteboom, B. \& Stam, E. (2008). Micro-foundations for Innovation Policy. Amsterdam, The Hague: Amsterdam University Press, Dutch Scientific Council for Government Policy.

Nowotny, H., Scott, P. \& Gibbons, M. (2002). Re-Thinking Science. Knowledge and the Public in an Age of Uncertainty. Cambridge, United Kingdom: Polity Press.

Oborn, E., Barret, M. \& Dawson, S. (2013). Distributed Leadership in Policy Formulation: A Sociomaterial Perspective. Organisation Studies, 2013, 34, 145-167. DOI: $10.1177 / 0170840612473552$

O'Reilly, C.A. \& Tushman, M.L. (2004). The ambidextrous organisation. Harvard Business Review, 82(4), 74-81.

Parandian, A., Rip, A. \& Te Kulve, H. (2012). Dual dynamics of promises, and waiting games around emerging nanotechnologies. Technology Analysis \& Strategic Management, 24(6). $565-582$.

Distributed academic leadership in emergent research organisations References 
Pettigrew, A.M. (1990), Longitudinal Field Research on Change: Theory and Practise. Organisation Science, 1(3), 267-292.

Pettigrew, A.M., Massini, S., Numagami, T. (2000). Innovative Forms of Organising in Europe and Japan. European Management Journal, 18(3), 259-273.

Pettigrew, A. \& Whipp, (R.) (1991). Managing change for competitive success. Oxford: Blackwell Publishers.

Pettigrew, A. , Woodman, R., Cameron, K. (2001). Studying organisational change and development: challenges for future research. Academy of Management Journal, 44(4), 697-713.

Philpott, K., Dooley, L., O'Reilly, C., \& Lupton, G. (2011). The entrepreneurial university: Examining the underlying academic tensions. Technovation, 31(4), 161-170.

Provan, K.G. \& Kenis, P. (2007). Modes of Network Governance: Structure, Management, and Effectiveness. Journal of Public Administration Research and Theory, 18(2), 229-252.

Quinn, R.E. \& Rohrbaugh, J. (1983). A Spatial model of effectiveness criteria: towards a competing values approach to organisational analysis. Management Science, 29(3), 363377.

Reinhardt, W., Schmidt, B., Sloep, P. \& Drachsler, H. (2011). Knowledge Worker Roles and Actions: Results of Two Empirical Studies. Knowledge and Process Management, 18(3), 150-174. DOI: 10.1002/kpm.378.

Reinhoudt, D. (2007). Moleculaire engineering, synthese en analyse. Boekje bij het Afscheidscollege (13 september 2007). Enschede: University of Twente.

Rip, A. (2002). Regional Innovation Systems and the Advent of Strategic Science. Journal of Technology Transfer, 27, 123-131.

Rip, A. \& Schot, J.W. (2002). Identifying Loci for Influencing the Dynamics of Technological Development'. In K. Sørensen \& R. Williams (Eds.) Shaping Technology, Guiding Policy; Concepts, Spaces and Tools (pp. 158-176). Cheltenham, United Kingdom: Edward Elgar.

Rip, A. (2004). Strategic Research, Post-modern Universities and Research Training. Higher Education Policy, 17(2), 153-166. doi:10.1057/palgrave.hep.8300048

Rip, A., Joly, P., Callon, M. (2010). Reinventing Innovation. In M. Arentsen, W. Rossum \& B. Steenge (eds) Governance and Innovation (pp. 19-32). Cheltenham: Edward Elgar.

Rip, A. (2011). Protected spaces of science: their emergence and further evolution in a changing world. In M. Carrier \& A. Nordmann (Eds.) Science in the Context of Application:

Methodological Change, Conceptual Transformation, Cultural Reorientation (pp. 197-220). Dordrecht, Netherlands: Springer.

Distributed academic leadership in emergent research organisations

References 
Rip, A. (2012). The Context of Innovation Journeys. Creativity and Innovation Management, 21(2), 158-170. doi:10.1111/j.1467-8691.2012.00640.x

Rip, A. \& Joly, P. (2012). Emerging Spaces and Governance. A position paper for EU-SPRI. Retrieved from EU-SPRI website, http://www.euspriforum.eu/key missions/rip emerging spaces and governance.pdf

Rosing, K., Frese, M. \& Bausch, A. (2011). Explaining the heterogeneity of the leadershipinnovation relationship: Ambidextrous leadership. The Leadership Quarterly, 22, 956-974.

Rothaermel, F., Agung, D. \& Lin Jiang (2007). University entrepreneurship: a taxonomy of the literature. Industrial and corporate change, 16(4), 691-791.

Roussel, P., Saad, K. \& Erickson, T. (1991). Third Generation R\&D: managing the link to corporate strategy. Harvard Business School Press.

Schön, D. (1983). The reflective practitioner. How professionals think in action. Basic Books.

Senge, P.M. (1990). The Fifth Discipline: The art and practice of the learning organisation. New York: Currency Doubleday.

Sennet, R. (2012). Together: The Rituals, Pleasures And Politics Of Cooperation. New Haven: Yale University Press.

Schutte, F. \& Van der Sijde, P. (2000). The university and its region: examples of regional development from the European Consortium of Innovative Universities. Enschede: Twente University Press.

Shattock, M. (2005). European Universities for Entrepreneurship: Their Role in the Europe of Knowledge The Theoretical Context. Higher Education Management and Policy, 17(3), 1317.

Smits, R., KuhImann, S. \& Shapira, P. (2010). The Theory and Practice of Innovation Policy. An International Research Handbook. Cheltenham, United Kingdom and Northampton, MA: Edward Elgar.

Spillane, J., Halverson, R. \& Diamond, J.B. (2001). Investigating School Leadership Practice: A Distributed Perspective. Educational Researcher, 30(3), pp.23-28.

Spillane, J.P., Halverson, R., \& Diamond, J.B. (2004). Towards a theory of leadership practice: a distributed perspective. Journal of Curriculum Studies, 36(1), 3-34. doi:10.1080/0022027032000106726

Sporn, B. (2001). Building adaptive universities: emerging organisational forms based on experiences of European and US universities. Tertiary Education and Management, 7, 121134.

Distributed academic leadership in emergent research organisations 
Sporn, B. (2007). Governance and administration: organisational and structural trends. In J. Forest \& G. Altbach (eds) International Handbook of Higher Education (pp. 141-157). Heidelberg, Germany: Springer.

Sydow, J. Schreyögg, G. \& Koch, J. (2005). Organisational Paths: Path Dependency and Beyond. Paper presented at 21st EGOS Colloquium. Berlin: Free University of Berlin.

Tabatoni, P., Davies, J. \& Barblan, A. (2002). Strategic management and universities' institutional development. Genève: EUA.

Te Kulve, H. (2011). Anticipatory interventions and the co-evolution of nanotechnology and society (Doctoral dissertation). Retrieved from http://doc.utwente.nl/76955/

Tidd, J, J Blessant and K Pavitt (2001). Managing Innovation: Integrating Technological,Market and Organisational Change. Chichester: John Wiley \& Sons.

Trischler, H. \& Bruch, R. vom. (1999). Forschung für den Markt: Geschichte der FraunhoferGesellschaft. München: Beck.

Turpin, T, Garret-Jones, S. \& Woolley, R. (2011). Cross-sector research collaboration in Australia: the Cooperative Research Centres Program at the crossroads. Science and Public Policy, 38(2), 87-97. DOI: 10.3152/030234211X12924093660354.

Tushman, M., Anderson, P. \& O'Reilly, C. (1997). Managing Strategic Innovation and Change: A Collection of Readings. NY: Oxford University Press.

Van de Ven, A., H., Polley, D.E., Garud, R. \& Venkataraman, R. (1999). The Innovation Journey. New York \& Oxford: Oxford University Press.

Van der Veen, G., Arnold, E., Boekholt, P., Deuten, J., Van Giessel, J-F., De Heide, M. \& Vullings, W. (2005). Evaluation Leading Technological Institutes. Amsterdam: Technopolis Group. Appendix to Tweede Kamer der Staten-Generaal. Vaststelling van de begrotingsstaten van het Ministerie van Economische Zaken voor het jaar 2006, vergaderjaar 2005-2006, 30300 XIII nr. 66.

Van der Weijden, I., Verbree, M., Braam, R., Van den Besselaar, P. (2009). Management en prestaties van onderzoeksgroepen. Samenvatting van de bevindingen. Den Haag: Rathenau Instituut.

Van Helleputte, J. \& Reid, A. (2004). Tackling the paradox: can attaining global research excellence be compatible with local technology development? R\&D Management, 34(1), 33-44.

Van Looij, B., Ranga, M., Callaert, J. \& Debackere, K. (2004). Combining entrepreneurial and scientific performance in academia: towards a compounded and reciprocal Mattheweffect? Research Policy, 33(3), 425-441.

Distributed academic leadership in emergent research organisations References 
Verbree, M., Van der Weijden, I. \& Van den Besselaar, P. (2011a). Academic leadership of highperforming research groups (working paper 1103). Den Haag: Rathenau Instituut.

Verbree, M., Van der Weijden, I. \& Van den Besselaar, P. (2011b). Generation and life cycle effects on academic leadership (working paper 1101). Den Haag: Rathenau Instituut.

Weick, K. \& Quinn, R. (2004). Organisational Change and Development: Episodic and Continuous Changing. In J.J. Boonstra (Ed.) Dynamics of Organisational Change and Learning (pp. 177196). Chichester, United Kingdom: Wiley \& Sons.

Whitchurch, C. (2008). Professional Managers in UK higher Education: Preparing for Complex Futures. Final Report for the Leadership Foundation for Higher Education. London: Leadership Foundation for Higher Education.

Yates, J. (1997). Using Giddens' structuration theory to inform business history. Business and Economic History, 26(1), 159-182.

Yin, R.K. (2003). Case Study Research. Design and Methods. London: Sage.

Distributed academic leadership in emergent research organisations 